$\mathrm{DOE} / \mathrm{SF} / 15134--\mathrm{TI}$

DE86 009444
Received by CSTI

APR 221986

GEOTHERMAL RESOURCE EVALUATION of the YUMA AREA

FUNDED by USDOE contract \#DE-FGO3-84SF15134

DOE Program Manager:Mr. John Crawford

San Francisco Operations office 1333 Broadway

Oakland,CA 94612

By:Eugene W. Poluianov Ph.D

1329 E. Fremont

Tempe, Az . 85282

and:Frank $P$, Mancini Ph.D, PE, CEM Az. Solar Energy Commission

-.. Capitol Torer. Pm. 502 $1700 \mathrm{w}$. Washington Phoen IX, Az, 85007

Under the Direction of

James $F$. Warnock CEM,Executive Director

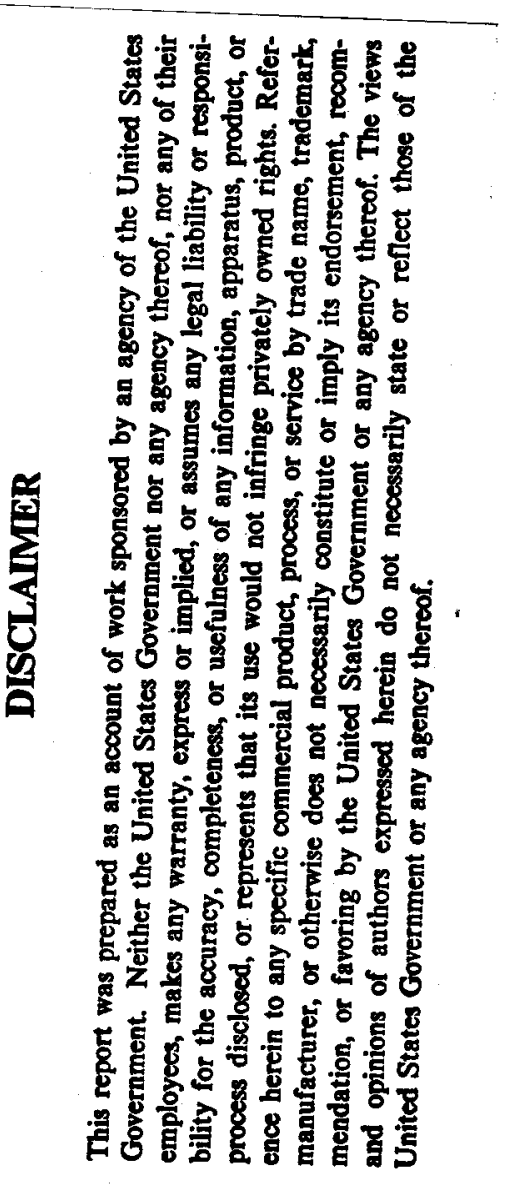

ARIZONA SOLAR ENERGY COMMISSION

CAPITOL TOWER,RM 502

1700 W. WASHINGTON

PHOENIX,AZ 85007

OOE $|\subseteq F|$

$15 \mid 34--71$

NOVEMBER 29,1985 


\section{DISCLAIMER}

This report was prepared as an account of work sponsored by an agency of the United States Government. Neither the United States Government nor any agency Thereof, nor any of their employees, makes any warranty, express or implied, or assumes any legal liability or responsibility for the accuracy, completeness, or usefulness of any information, apparatus, product, or process disclosed, or represents that its use would not infringe privately owned rights. Reference herein to any specific commercial product, process, or service by trade name, trademark, manufacturer, or otherwise does not necessarily constitute or imply its endorsement, recommendation, or favoring by the United States Government or any agency thereof. The views and opinions of authors expressed herein do not necessarily state or reflect those of the United States Government or any agency thereof. 


\section{DISCLAIMER}

Portions of this document may be illegible in electronic image products. Images are produced from the best available original document. 


\section{YUMA AREA GEOTHERMAL RESDURCE EVALUATION}

TABLE DF CONTENTS

\section{DESCRIFTION}

FAGE

Table of Contents

List of Figures

List of Digital Maps

List of Tables

$v i$ i

Prefatory Note

CHAFTEFS

I. Introduction

1. Furpose of This Feport

2. Why Investigate the Yuma Area?

3. The Froblem

II. Description of the Area

1. General Deseription

2. Climate and Availability of Water

3. Fopulation and Land Use

4. Geology: Surface Structure

5. Geology: Easin Description

6. Description of the Salton Trough Area

7. Geological History of the Area

III. Geothermal Analysis of the Area

1. Dverview

2. Digital Maps

3. Thermal Gradient Maps

4. Hot Impermeable Fiock Evaluations 40

5. Depth to Eedrock: and Isotherm Maps 


\section{YUMA AREA GEOTHERMAL RESOURCE EVALUATION}

\section{TAELE OF CONTENTS}

DESCFIIFTION

F'AGE

III. Geothermal Analysis of the Area (continued)

6. Depths to Various Units

7. Fecoverable Water and Water Temperature

8. Testing the Model

9. General Conclusions

IV. Selecting the Hottest Areas

1. Using All of the Evidence

2. The General Frocedure 68

3. Assigning Numerical Values

4. Classifying the Evidence

5. Mating the Maps and Conclusions for This Chapter 76

V. Economic and Institutional Factors

1. Overview of the Factors

2. Ecomomic Description of Yuma County

3. Demand Considerations

4. Costs and Rist:s of Geothermal Exploration and Analysis

5. Conclusions

VI. Conclusions and Recommendations

86

1. Remarks

2. The Eest Frospects

3. Fecommendations for Development.

4. Recommendations for Further Testing

5. Final Conclusions 


\section{YUMA AREA GEOTHERMAL RESOURCE EVALUATION \\ TAELE OF CONTENTS}

\section{DESCFIPTION}

F'AGE

NOTES, AFPENDICES AND EIEL IOGRAFHY

90

Notes

90

AFFENDICES

92

A. Fiadium Hot Springs, Geothermometry and the Fhysics of a Hot Spring

92

1. Fadium Hot Springs and Agua Caliente 92

2. Geothermometry

93

3. A Fhysical Model of a Hot Spring 95

4. Estimating the Gradient 97

E. The AHF Method 98

1. Introduction 98

2. Fating a Geologic System by AHF 99

3. A Specific Hierarchical Example 100

4. States of Fhysical Data 105

5. Example 110

C. Solar/Geothermal Hybrid System 113

1. Introduction 113

2. Examples 116

D. Costs of Geothermal Development 121

1. Exploration Costs 121

2. A Complete Estimate 126

E. Collected Data $\quad 129$

F. Full Scale Digital Maps 145

Eibliography 206 


\section{YUMA AREA GEOTHERMAL RESOURCE EVALUATION}

\section{LIST OF FIGURES}

DESCRIFTION

FAGE

1. Lower Colorado River Basin and the Area of Investigation ix from [olmsted, et al,1973]

2. Yuma County, old and New Obtained from the Map Foom, State of Arizona Archives.

3. Seismic Profile of the Yuma Area and Gila Trough

a. Seismic Profile

from [Eberly \& Stanley, 1978]

b. Gravity Modeled Depth to Eedrock Map with Frofile Location from [Eberly \& Stanley, 1978] Added from [Oppenheimer \& Sumner, 1980]

4. Gravity Frofiles from the Yuma Area

a. Frofile Showing the San Luis Basin

b. Profile of Fortuna Easin

from [0lmsted, et a1, 1973]

5. Hlock Diagram of Imperial Valley

from [Fuis, et al, 1982

6. Tectonic Map of Lute-Williams Air Force Fange from [Tucker, 1980]

7. Frincipal Faults of the Yuma Area

from [Mattick, et a 1, 1973]

8. Earthquake Epicenters of the Southwest from [Smith \& Eaton, 1978]

9. Cross Section of Gila Trough and Sedimentary Units of Arizona Easin and Fiange Frovince

a. Cross Section of Gila Trough

b. Sedimentary Units of Arizona kasin and Range from [Eberly \& Stanley, 1978]

10. Maps and Diagrams of the Salton Trough Area

a. Cross Section of the Mexicali Valley

Showing Units $A$ and $B$

from [Teilman \& Cordon, 1981]

b. Regional Geology of the Cerro Frieto Geothermal Field from [Fonseca, 1982]

c. Schematic of Flate Tectonic Movement from [Fuis,et al, 1982]. 


\section{YUMA AREA GEOTHERMAL RESDURCE EVALUATION}

\section{LIST DF FIGURES}

DESCFIFTION

FAGE

11. Eouguer Gravity Map of the Imperial Valley and Schematics of the Froposed Heat Source at Nuevo Leon

a. Bouguer Gravity Map of the Imperial Valley from [Fonseca, 1982]

b. Fielationship of Source to Extensional Faulting from [Goldstein, et a 1,1982$]$

c. Relationship of Source to Well Temperatures Near Source from [Goldstein, et al, 1982]

12. Contours drawn from Digital 'Hot' Map

13 Contours drawn from Digital 'Cool' Map 35

14 Seismic and Gravity Modeled Profiles of Depth to Eedrock: 51 Seismic Frofile from [Eberly \& Stanley, 1978]

Gravity Profile Calculated from

[Oppenheimer \& Sumner, 1980]

15 Hierarchy of Types and Subtypes of Data

16 Contour Map Fating the Geothermal Fotential of the Study Area Using the AHF Method

17 Hierarchy for Confidence in Data

18 Matrix for Types of Data

19 Matrix for Subtypes of Data 


\section{YUMA AREA GEOTHERMAL RESOURCE EVALUATION}

LIST DF DIGITAL MAPS

DESCFIFTION

FAGE

1. Basins of the Study Area $\quad$ ni

2. Fanges of the Study Area :i

3. Sumface Responsibility within the Study Area 10

4. Geology of the Study Area 12

5. Final Thermal Gradients 36

6. Surface Fumpage $\$ 8$

7. Thermal Gradients in Areas of Low Surface Fumpage 39

8. Depth to Eedrock: $\quad 41$

9. 50 Degree Isatherm 42

10. 80 Degree Isotherm

11. 125 Degree Isotherm 44

12. 150 Degree Isotherm 45

1.3.1. 170 Degree Isotherm 46

$\begin{array}{ll}\text { 13.2. } 190 \text { Degree Isotherm } & 47\end{array}$

14. Depth to the Top of the Eouse Formation 49

15. Depth to the Top of the Marine Wedge Formation 50

16. Depth to the Top of Unit I 53 


\section{YUMA AREA GEOTHERMAL RESOURCE EVALUATION}

\section{LIST DF DIGITAL MAPS}

DESCFIFTION

FAGE

17. USGS Ground Water Temperature Data 55

18. Thermal Well Temperature Data 50

19. Estimated Mean Unit II Temperatures 60

20. Difference Eetween Estimater Mean Unit II Temperatures and Temperatures from USGS Ground Water Data 61

21. Difference Eetween Estimated Mean Unit II Temperatures and Thermal Well Temperature Data 62

22. Estimated Unit II/Unit I Interface Temperatures

23. Difference Eetween Interface Estimates and USGS Ground Water Temperature Data

24. Difference Eetween Interface Estimates and Thermal Well Temperature Data

25. Estimated Hot Impermeable Fock Exploitation Costs in 1971 Dollars 


\section{YUMA AREA GEOTHERMAL RESDURCE EVALUATION \\ LIST OF TABLES}

DESCFIIFTION

FAGE

1. Codes for Final Thermal Gradient Map 37

2. Estimated Recoverable Water from Various Formations 54

3. Natural Fermeabilities of Geologic Materials 58

4. Fairwise Rating System for AHF Analysis 101

5. Definitions of Specific and Inferential Data 104

b. Definitions of Uncorrelated and Conjectural Data 105

7. Maximum Capital Investment for a Solar/Geothermal Unit at 28.5 MMETU Usage With Electricity the Only Alternative

8. Maximum Capital. Investment for a Solar/Geothermal Unit at 28,5 or 250 MMETU Usage With Electricity or Natural Gas as Alternatives

9. Fielative Costs per $5 q$. km. for geophysical exploration

10 Freprodiction Cost Estimates for One Froducible Hydrothermal Discovery (1979 Dollars) 
Figure 1

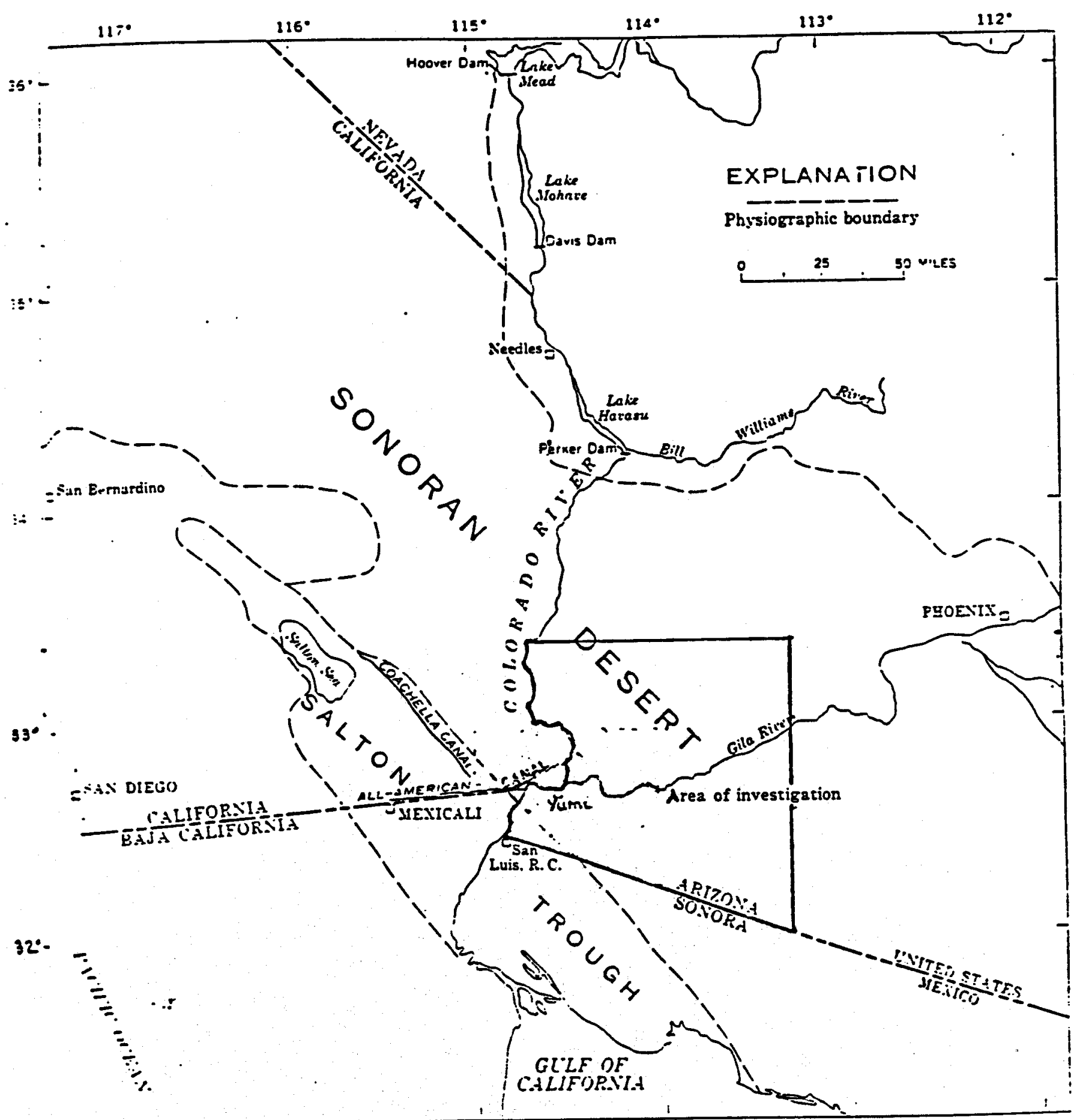

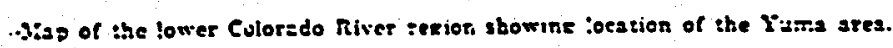


Figure 2

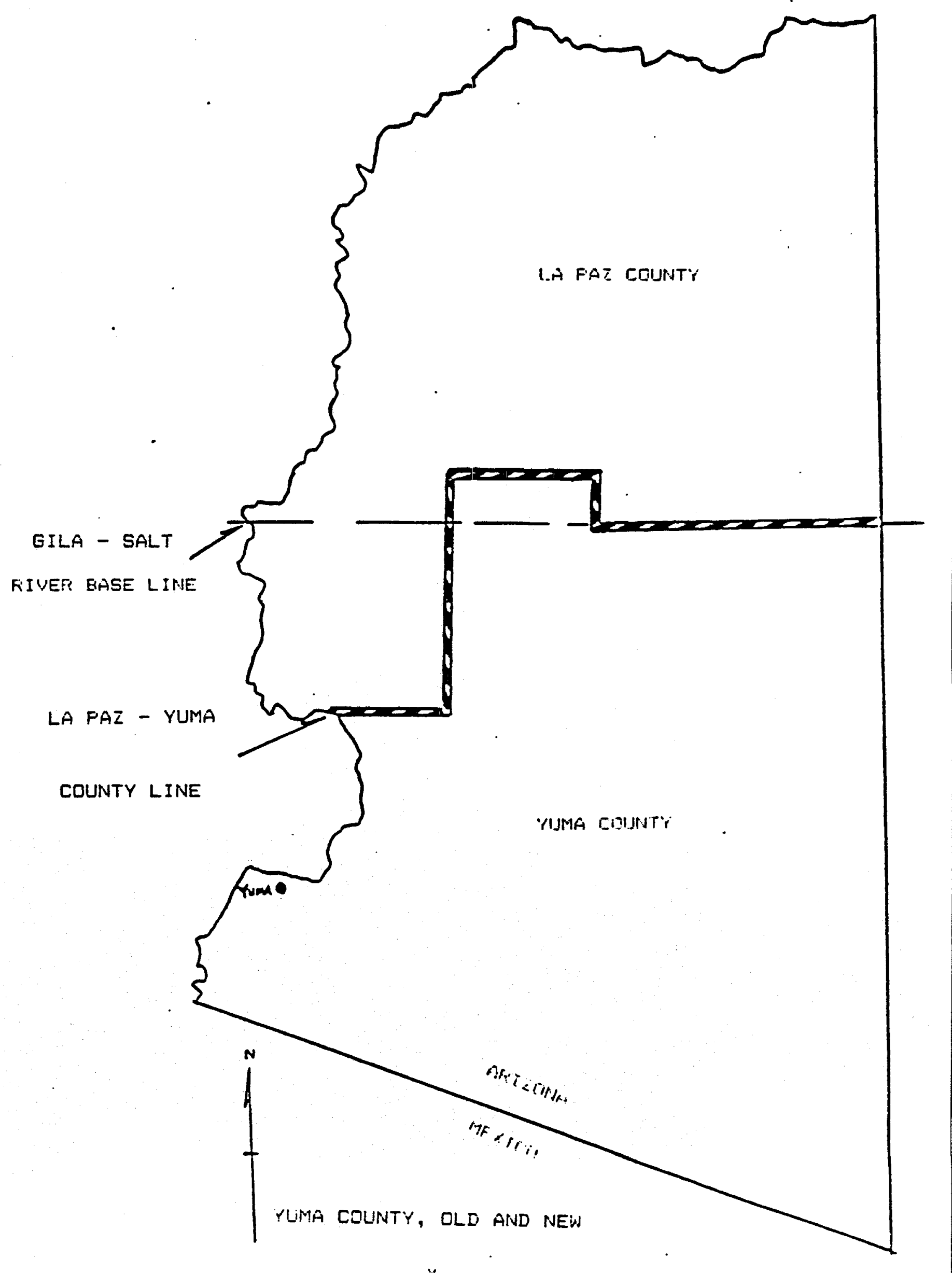




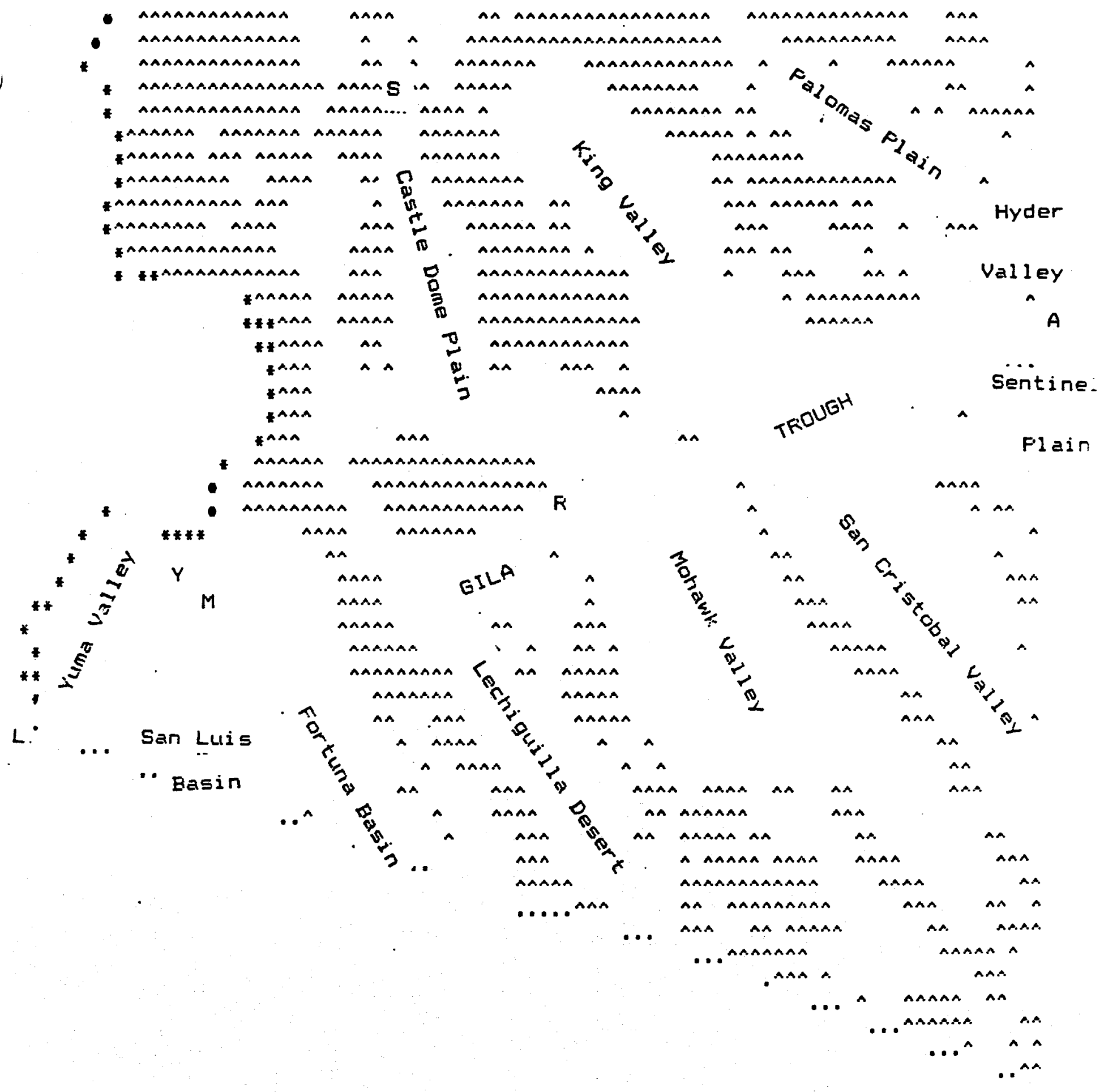

BASINS OF THE STUDY AREA

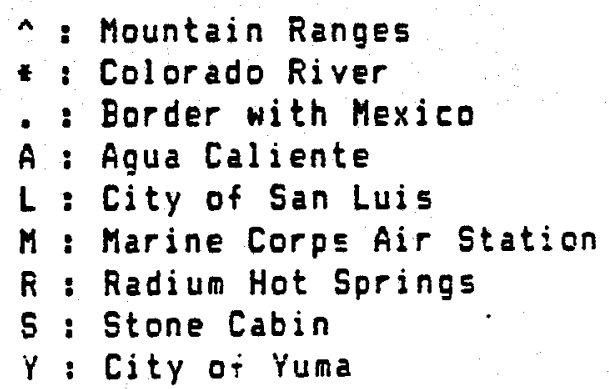




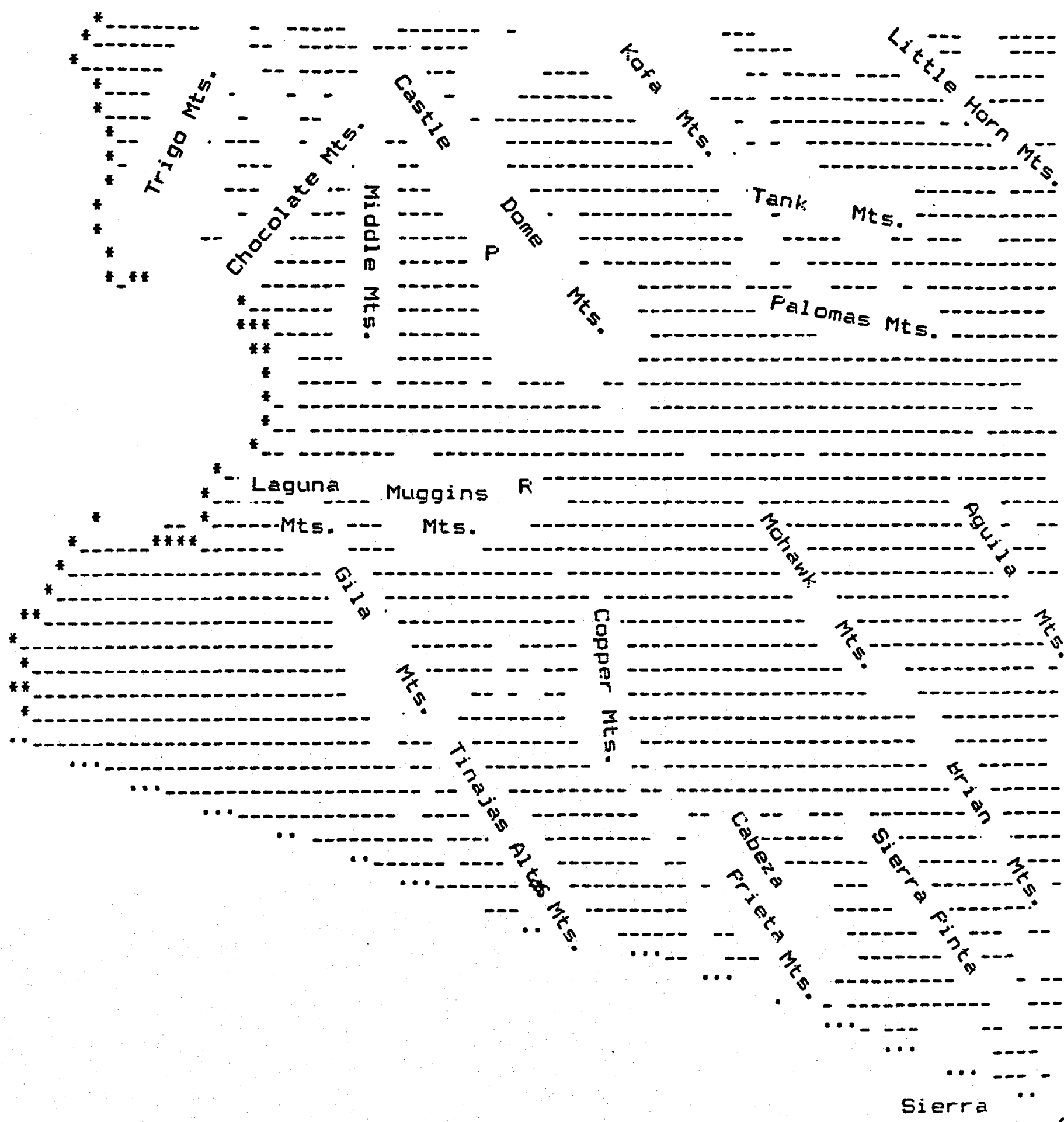

RANGES OF THE STUDY AREA

Finecate

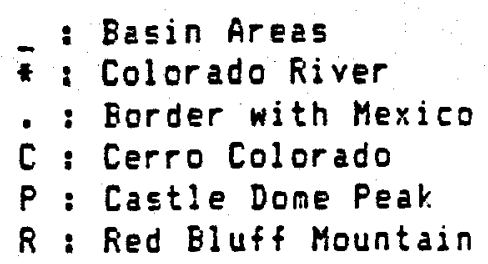




\section{GEOTHERMAL RESOURCE EVALUATIC:! NF THE YUMA AREA}

\section{PREFATDRY NOTE}

Explanatory notes are collected in the section termed 'Notes', following the main body of text and preceding the appendices. These notes are referred to by numbers in square brackets, [1], [2], [3], etc. Bibliographical references are in the following formats: e.g., [Aiken, 1976], [Eberly \& Stanley, 1978], [Goldstein, et al, 1982].

Digital maps are printed displays of maps stored as digital information on computer diskettes. Maps of the Yuma area are displayed in the main body of text in 'full scale' with a doubled symbol, (e.g., AA, \$f, etc.), representing one mile square. Maps of the entire study area (essentially Yuma County) are displayed with a single symbol representing 2 miles square. These quarter scale map displays therefore have discarded $50 \%$ of the stored information. Certain maps have therefore been reproduced at 'full scale' in Appendix $F$. 


\section{YUMA AREA GEOTHERMAL RESOURCE EVALUATION}

\section{INTRODUCTION}

1. Furpose of This Report.

This report is the culmination of a series of reports funded by the U. S. Department of Energy and administered by the Arizona Solar Energy Commission. Frevious reports had compiled and reported on the data which was relevant to the geothermal potential of the Yuma area, [1]. It is the purpose of this report. to use that, and additional information to evaluate that potential. In particular, as originally proposed, we shall be examining the Marine Corps Air Station and Yuma Froving Ground areas.

In the course of producing this report we performed an extensive literature survey - the results appear in the 1 ist of references; compiled ground water data for locations within present day Vuma County, in particular Castle Dome flain (in Yuma Froving Grounds), the Gila Easin and Palomas Flain; and compiled thermal spring and well data, with special attention to fiadium Hot Springs, and also thermal gradient and heat flow data. The locations mentioned above, and throughout this chapter, are shown in digital map numbers 1 and 2 .

Geothermometers, [2], were obtained for several locations, in particular Radium Hot Springs, and physical modelling was done for Fadium Hot Springs and Agua Caliente. The geothermometers and physical modelling are described in Appendix $A$. Heat $f$ low and thermal gradient data, given in Appendix $E$, was used to construct. the thermal gradient maps, [3], on which we have based certain conclusions of this report. We also found it necessary to develop special procedures to handle the diverse nature of geothermal information regarding the area. These procedures are discussed briefly in the text, in Chapter 4, and more fully in Appendix $B$. The economics of geothermal exploration and development are treated briefly in chapter 5, with Appendix C devoted to examining the economics of solar-geothermal hybrid systems utilizing low temperature geothermal brines.

The next chapter contains a brief description of the study area and the Salton Trough area. These are shown in figures 1 and 2 and digital maps 1 and 2 . The principal purpose of the chapter is to provide a prospective developer with basic geographical and geological information regarding the study area and to rough out the geophysics of geothermal resources in the Salton Trough area. The Salton Trough geothermal areas are taken as models for the convective systems which are most $1 \mathrm{ikely}$ to be found in the study area. The geological description also serves as the basis for the geological model of the area which we used in our analysis of the existence of geothermal resources in the study area. 


\section{YUMA AREA GEOTHERMAL RESOURCE EVALUATION}

We use the classification of Denton and Dunlop to distinguish four general types of geothermal systems: convective hydrothermal, geopressured, hot impermeable rock and magma, [4], [Denton \&. Dunlop, 1973]. We know of no evidence in the study area of a geopressured system or of a magma pool which is close to the surface. Thus we have eliminated these types of systems from further discussion. It served our purpose to classify the study area into hard rock and basin areas in order to distinguish potential sites for hot impermeable rock and convective hydrothermal systems. The available information allowed us to mal:e two kinds of estimates: the temperature gradient at a given location and the amount of recoverable water at different depths within a given basin. These estimates were definitely crude first approximations, but generally were sufficient for our purpose, which was to answer the following two questions:

1. Which hard rock areas are the most likely to have the high temperature gradients for economical hot impermeable rock: exploitation and development?

2. Which basin areas have the most favorable combination of sufficiently high temperatures and volumes of recoverable water at those temperatures?

Our first step in answering these questions was to subdivide the area according to water pumpage. This was based on the observation that areas of low pumpage correlated closely to hard rock or very shallow basin areas, which could be ruled out immediately as candidates for convective hydrothermal systems of any value. Our second step was to generate thermal gradient contour maps based on the available heat flow and thermal gradient data. We initially generated two thermal gradient contour maps - a 'hot' map and a 'cool' map, based on two different estimates of average thermal gradients in the principal Salton Trough geothermal areas. The wildly unrealistic hot map was used to eliminate areas from further discussion. The 'cool' map served as a lower bound, or minimum estimate. Ultimately, we produced a third thermal gradient map which reflected the thermal gradients we had the greatest confidence were correct. We based our final arguments on the results obtained with the 'hot' map and the final, corrected version.

The steps outlined above were sufficient to distinguish areas most suitable for hot impermeable rock exploration. In order to analyze basin areas we used depth to bedrock modeling from various sources. This, together with the 'hot map, successfully eliminated all but the Fortuna Easin from further consideration as potential sites for geothermal electric power production. 


\section{YUMA AREA GEOTHERMAL RESOURCE EVALUATION}

We next examined the possibility that the various data and information previously advanced in favor of the existence of a geothermal resource within the study area might point to areas of sufficient promise to warrant further exploration, in spite of the negative evidence which had been obtained. A brief discussion of the method is the subject of chapter 4, with a more complete discussion as the subject of Appendix $B$. The result was the generation of a 'preference' map, which was designed to use this more subjective information to locate possible additional areas suitable for further exploration. The map obtained was evidently sensitive to our conservatism in evaluating the available information, for it produced no surprises. The method used has some promise, but requires further development.

In chapter 5 we discuss the economics of geothermal exploration and exploitation. The discussion is primarily concerned with convective hydrothermal systems. This is necessary in order to complete the study of basin areas. Thus, in those areas not completely eliminated as containing potential high temperature reservoirs, the economic aspects of development require consideration. Also, there are a number of basins in areas of relatively high thermal gradients which could contain usable moderate or low temperature geothermal resources. We went a step further, and in Appendix c examined the economic viability of solar-geothermal hybrids, using low to moderate temperature geothermal resources.

In chapter 6 we give our conclusions and recommendations including our appraisal of the geothermal potential of this area. Eriefly we find that, al though the region contains several areas of interest, economic considerations do not favor geothermal development, at least at this time. Further geothermal exploration of this region is most likely to take place as a part of either experimental programs or in conjunction with exploration for other purposes.

\section{Why Investigate the Yuma Area?}

The ongoing exploration for and exploitation of geothermal energy in the Salton Trough area (figure 1), has been used to support suggestions (e.g., [Stone, 1981]), that the southwestern corner of Arizona, in particular the area which lies within the Salton Trough, has geothermal possibilities. A number of studies have resulted in findings which could be used to support this vi ew or which suggest that other areas of present day Yuma County might be favorable for geothermal development. These are as follows. 


\section{YUMA AREA GEOTHERMAL RESOURCE EVALUATION}

Two thermal springs, [5], - Agua Caliente, at 40 degrees Celsius, (104\%F), and Fadium Hot Springs at $600 \mathrm{C},(140 \circ \mathrm{F})$, flowed in the Gila Basin in the earlier part of this century. $A$ description and chemical analysis of Radium Hot Springs was given by Wilson in his geological description of what was then called southern Yuma County, [Wilson, 1933]. His description and chemical analysis of Radium Hot Springs is contained in Appendix $A$, as is the application of geothermometry to that data, and the physical modelling of both hot springs. See digital maps 1 and 2 for the locations mentioned here and below.

In his gathering, compiling, evaluation and mapping of aeromagnetic data for Arizona, Sauck pointed out that southwestern Arizona contains an area, nearly identical with the study area, of muted magnetic contrasts. He interpreted this data as the possible indication of shallow Curie depths for the region, [6], [Sauck, 1972]. This suggestion has since been disputed by $A$ iken and others, [Aiken, et al, 1980].

In the course of investigating the geahydrology of the Yuma area, olmsted, and others, noted certain warm water anomalies at shallow depths (less than 200 feet below the surface), [olmsted, et $a 1,1973 \mathrm{~J}$.

In an analysis of gravity data for Arizona, Aiken distinguished three areas in Arizona as having long-wavelength Houguer gravity values which were anomalously low. He interpreted this as evidence of unusually shallow crustal depth, [7]. In his words, "Areas with long-wavelength residual Eouguer gravity lows coincide with areas of high $F$ wave delays, low $F_{n}$ velocities, high heat flow, low crustal resistivity, a thick low velocity zone indicated by channel wave studies, and sometimes by subdued magnetic anomalies.", [Aiken, 1976]. All three of these areas contain extensive Quaternary (less than 2 million year old) volcanic fields, and two of these, the San Francisco volcanic field in the north and the sierra Pinacate field in the southwest, have been the scenes of historically recent volcanic eruptions: Sunset Crater in the north, (approximately 1065 A.D., [Chroriic, 1983]), and Cerro Colorado in the southwest, (probably at the end of the seventeenth century, [Shakel \& Harris, 1971]). The southwest low referred to by Aiken contains the Yuma area and Yuma County south of the Gila Basin.

There are a number of thermal wells, [5], in the area, particularly in the Hyder Valley and Falomas Plain. The Hyder Valley was the subject of a geothermal investigation by the Arizona Eureau of Mines and Mineral Technology. The report, [Jones \& Campbell, 1979], concluded that the area was promising for its low to moderate temperature (50 - 150 oc) geothermal prospects. 


\section{YUMA AREA GEOTHERMAL RESOURCE EVALUATION}

The north Castle Dome area was found by Gutmann to be of interest as a possible site for hot impermeable rock, [Gutmann, 1981 J, due to high temperature gradients in the area and a low Bouguer gravity anomaly, which he proposed as indicating a local high temperature intrusion of magmatic roct at a relatively shallow depth beneath the surface.

In a preliminary evaluation of the geothermal potential of the Yuma area, Stone referred to a number of the above points as supporting the geothermal potential of that area. However, she concluded that the only positive indication of a potential gecthermal resource in the Yuma Area was the abnormally high thermal gradients, [Stone, 1981 ].

3. The Froblem.

Although the points raised in the previous section are sufficient to excite some interest the study area, they are insufficiently precise, as stated, to provide a basis for an evaluation of the area. The reason is that there are several fundamental questions regarding geothermal resources which the above collection of information does not answer, and which the continuing collection of similar information is also unlikely to answer. These are as follows.

1. Which locations in the study area are the most litely prospects, at least for further exploration?

2. Will further testing, other than deep drilling, add appreciably to our capability of evaluating the geothermal potential of the area?

3. Based on current information, is there any location in the study area which can be recommended for geothermal development?

4. Is geothermal energy curreritly a practical energy alternative for Yuma County?

It is the purpose of this report to answer these questions. 
Seismic Profile of the Yuma Area \& Gila Trouah

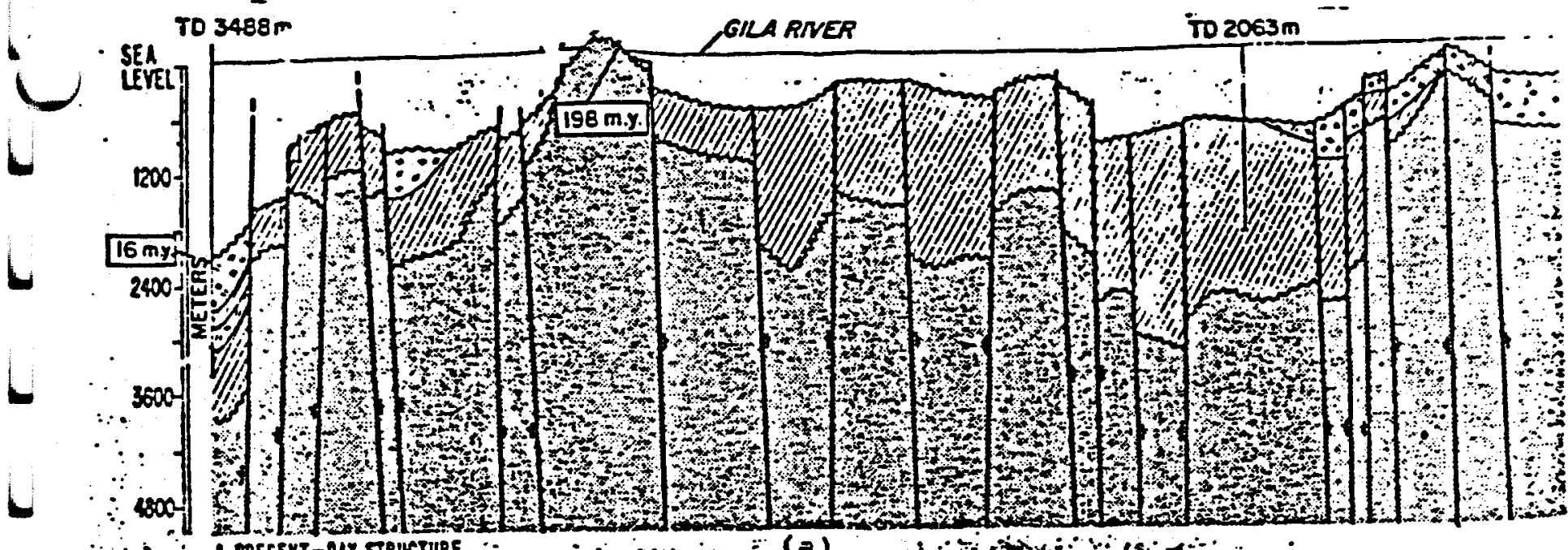

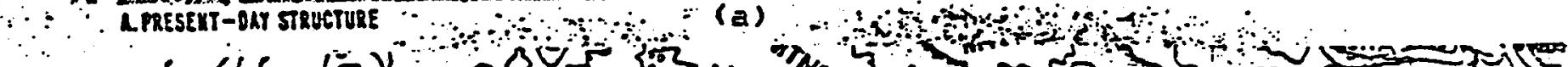
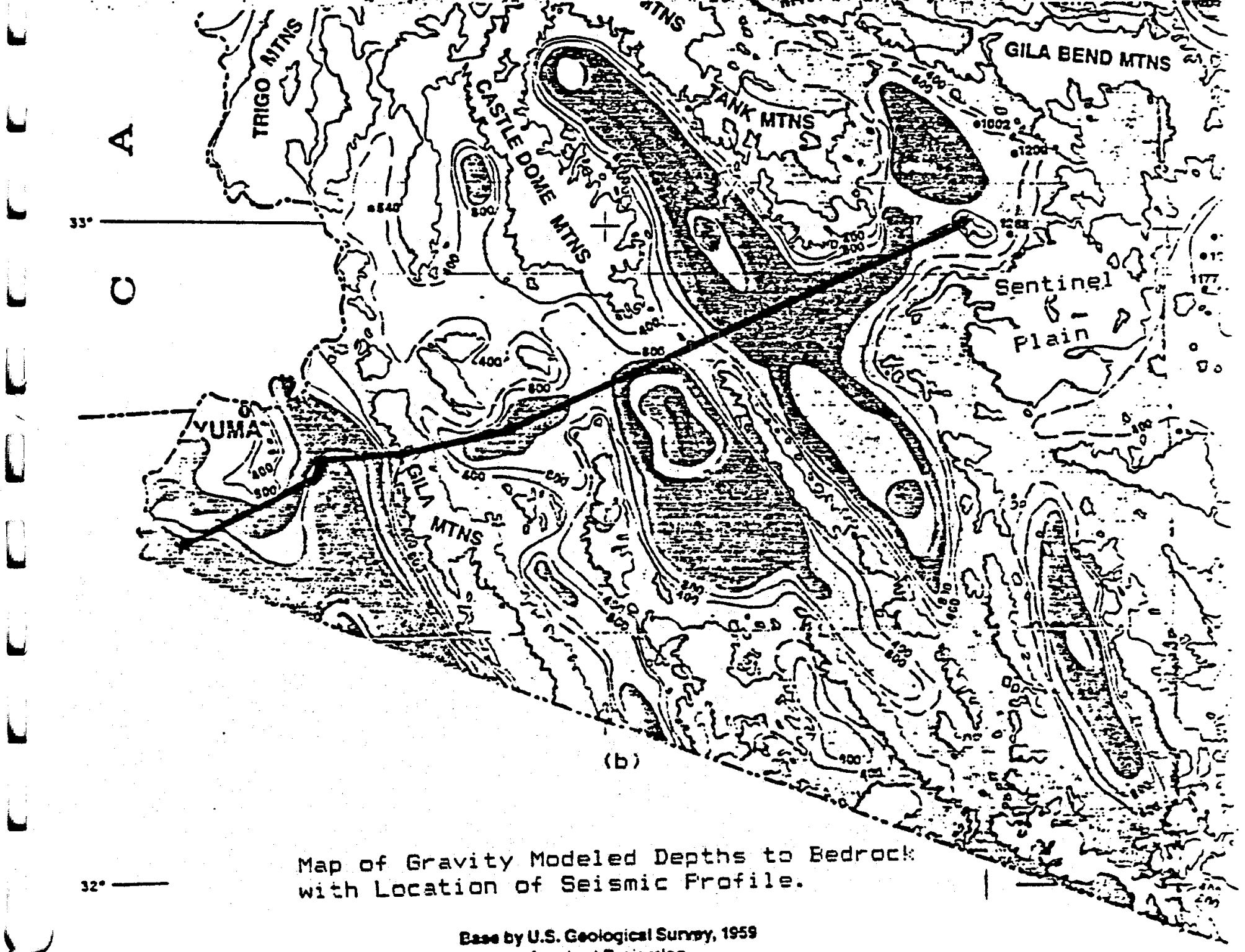

Bewe by U.S. Ceotogieal Sumby, 1958

Limbert Projection

Stuncard Paratbla 


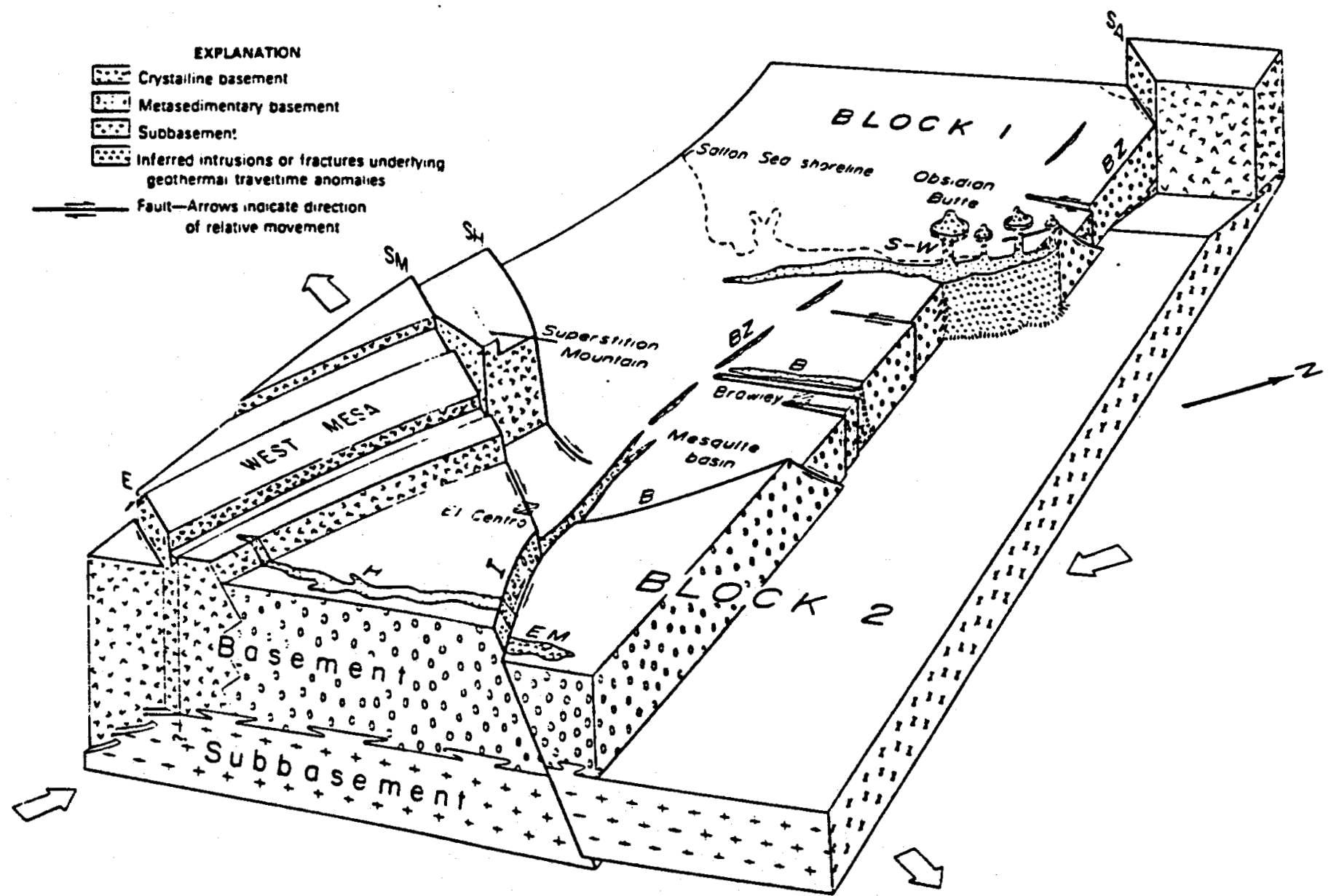

Fictre 3.-Schematic block diagram of Imperial Valley region. with sedimentar: rocks removed and basement cut iway along a line rouchly parallel to Brawley seismic zone. Grogruphic names are prniected downward onto basement for reference. Structures same ds in tigure 24: B. Brawley fault zone: BZ. Brawley seismic zone: $\mathrm{E}$ Elsinore fault: 1. Imperial fault: SA. San Andreass fault: SH. Superstuion Hills fault: SM. Superstition Mountain luult. Geothermal areas: B. Brawley: EMI. East Mesa: H. Heber: S. Salton Sea: W.
Westmorland. Shaded arrows indicate dominant tension and compression directions for recent geologic past. Blocks 1 and 2 are moving away from Brawley seismic zone. and inferted spreading center. in direction parallel to southern section of Imperial fault shown. Rhombochasms. or pullapart holes. are forming at Mesquite basin and Salton sink. which is presently occupied by Salton Sea. In addition. ductile thinning of both blocks may be occurring as they move away from Brawley seismic zone. 


\section{GEOTHERMAL RESOURCE EVALUATION OF THE YUMA AREA}

\section{DESCRIPTION OF THE AREA}

1. General Description.

The area of investigation is old Southern Yuma County: that part of Arizona which lies west of the Yuma County line and south of the Gila - Salt Fiver Baseline, as shown in figure 2. Physically it lies in the southern part of the Easin and Range Province of North America, thus, typically, it is characterized by nearly flat sedimentary basins intersected by narrow linear mountain ranges. In this part of the province the general elevation is low and contrasts between high and low elevations are not great. The City of Yuma has a mean elevation of 137 feet above sea level and the highest point in the study area is Castle Dome Peak at 3784 feet. The basins are frequently wide and deep. Thus, seismic testing, [Eberly \& Stanley, 1978], shows that bedrock: depths are as much as 3,200 meters $(10,500$ feet) below the surface in the Gila Trough, (figure 3(a)); gravity modeling, [Oppenheimer \& Sumner,1980], indicate depths of as much as 8 , dob feet, $(2.5$ kilometers), in the San Cristobal Valley, and 9,600 ft., $(3 \mathrm{~km}$.$) ,$ in the Mohawk and King Valleys, (figure $3(b)$ ): and geophysical testing by Matticl:, and others, has indicated depths of 13,000 ft., (4 km.), in the San Luis Basin and 16,000 ft., (5 km.), in the Fortuna Basin, [Mattick, et a 1, 1973], (figure 4). See digital map 1 for these locations. The Salton Trough, (figures 1 and 5), is deeper yet. Unmetamorphosed sediments fill the basin to a depth of approximately $5 \mathrm{~km}$. beneath the surface, with metamorphosed sediments expected to 1 ie from 5 to $6 \mathrm{~km}$. $(16,000$ to $20,000 \mathrm{ft}$. beneath the surface. Metamorphism is expected at temperatures above 300 degrees Celsius (approximately 5000F), [Fuis, et a 1 , 1982J. In Arizona, the plunge of bedrock depth to the deeper regions of the salton Trough begins at the southwestern tip of Arizona, where the San Andreas Fault - inactive in this area - is estimated to 1 ie, [Fonseca, 1982].

The basin surfaces are generalily of low elevation. Much of the Salton Trough is below sea level. The Yuma Valley ranges from 50 to 150 feet above sea level and the Yuma Mesa and Gila Easin range from 250 to 500 feet above sea level. The higher basin elevations reach 1500 feet above sea level in the piedmont areas.

The predominant orientation of the mountain ranges is from southeast to northwest. Exceptions are the Trigo, Chocolate, Middle, Copper, Granite and Aguila Mountains, which have a south to north trend, the roughly disk shaped volcanic shields of Sentinel Fiain and the Sierra Finacate, and the triangular anomaly of the Muggins Mountains, (digital map 2). 


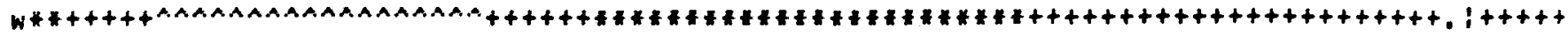

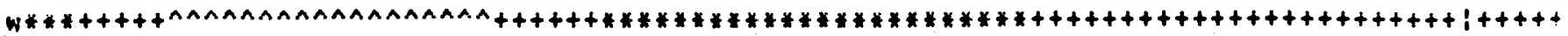

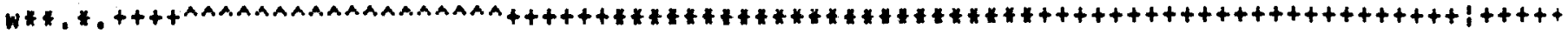

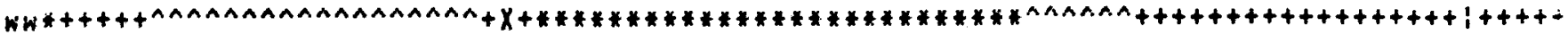

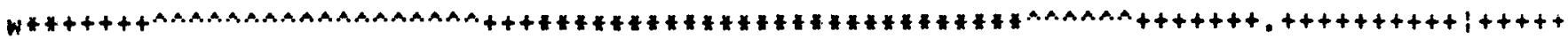

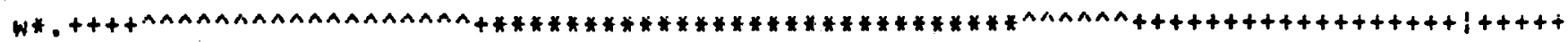

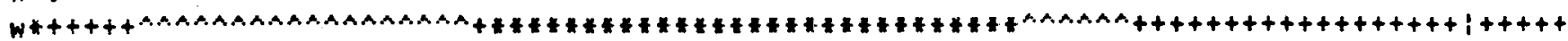

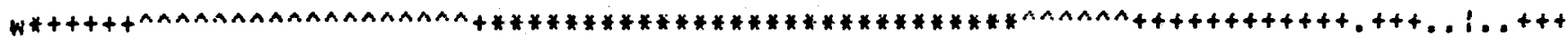

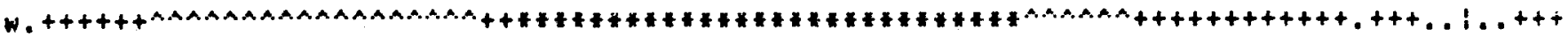

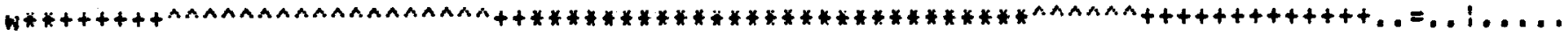

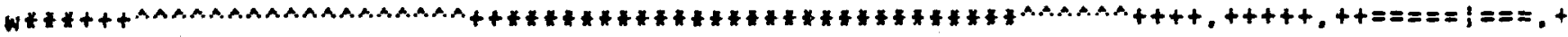

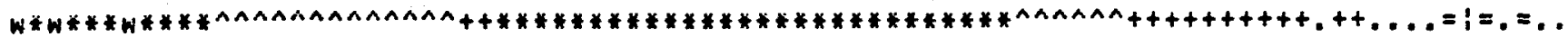

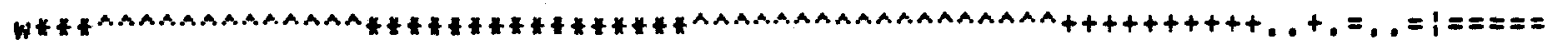

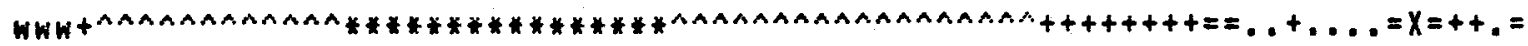

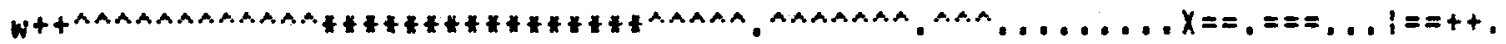

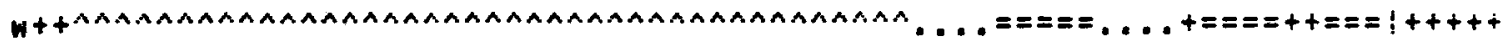

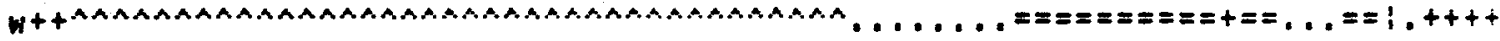

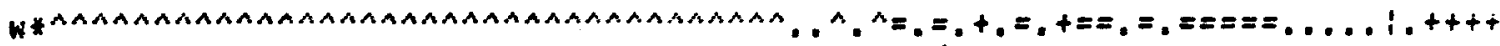

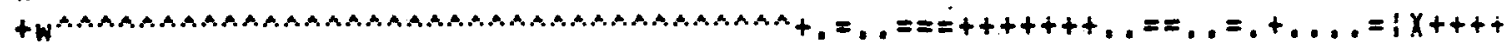

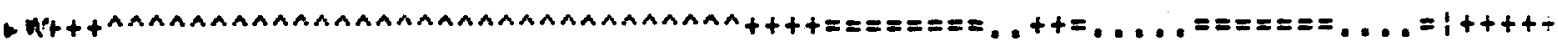

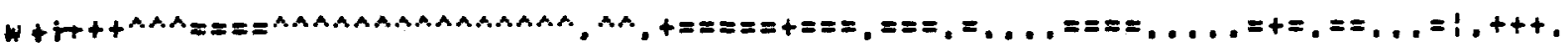
W. $R w==t+t=X++X+==\wedge \wedge \wedge \wedge \wedge \wedge \wedge \wedge \wedge \wedge \wedge t+==t+=X=========t==t+t===$

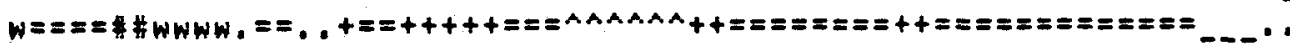

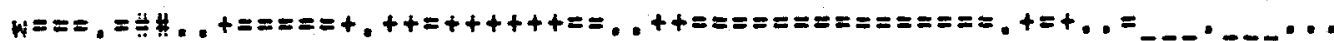

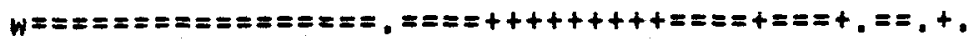

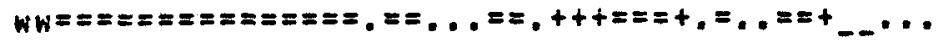
$W+.=\Sigma=\Sigma=++=\Sigma=\Sigma==$.

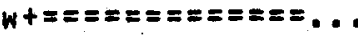
$w+=====+t+==\ldots$ $w t== \pm=t+t+\ldots .$.

$X+t+==t+t+t+t$ $t=t+t+t+$ $+++$ - -

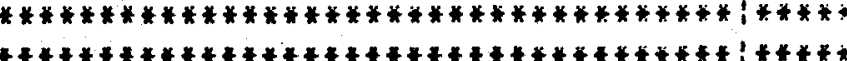

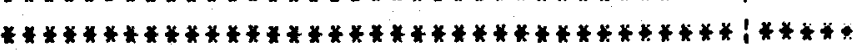

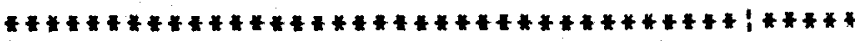

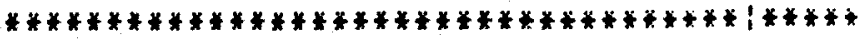

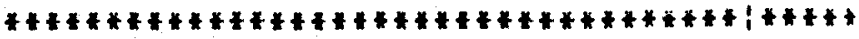

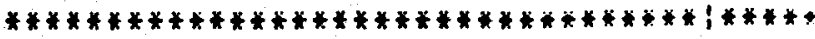

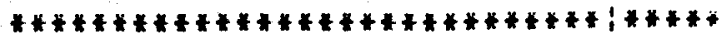

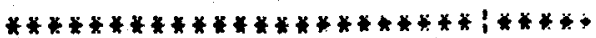

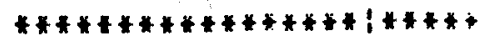
$*+* * * * * * * * * * * ; * X * * *$

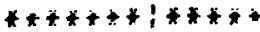
$* * * ! * * * *+$

Surface Menegenent Respensitiiity

W : Colorado River

* Wildife Refuge

=: Frivately Owned

: Luke-Williams Air force Range

$\mp$ : Bureau of Land Management
1 : Yuma County Line

$A$ : Yuna Test Station

$F$ : Indian Reservation

- : State Surface Trust 
$A: \triangle F A G E . D O C$

\title{
GEOTHERMAL RESOURCE EVALUATION DF THE YUMA AREA
}

\author{
2. Climate and availability of water.
}

Ecologically the area is part of the Sonoran Desert, home of the Saguaro Cactus. The average annual temperature is $21.50 \mathrm{C}$, (710F), dropping by arf:-inimately $10 \mathrm{C}$ for each $1,000 \mathrm{ft}$. of elevation. Feak temperatures may exceed $1200 \mathrm{~F}$, (500 C), at which times surface temperatures may approach 2000F, (930C), [Helms, 1983]. Daily and seasonal changes in air or surface temperatures. in any locale, have little effect below 50 meters beneath the surface. In crystalline rock, in the absence of free water, the temperature at this depth will be approximately equal to the average yearly temperature, increasing, in theory, at a constant rate with depth, the rate depending on the location and the type of rock. In actual testing, the rock: types vary widely through the length of a given borehole, with a concomitant variation in thermal conductivity, so the thermal gradient is taten as the average over the depth of the borehole. If water is present, in particular in wells (the most frequent source of subsurface temperature data), the temperature is affected by ground water movement and hydrothermal convection.

Rainfall is sparse in this area, averaging 3 inches per year at Vuma, $4 \mathrm{in.} / \mathrm{yr}$. at Farter, north of the study area, 5 at Gila Eend, to the east, and $q$ at the Organ Fipe National Monument. weather station, southeast of the study area, [Bulk, 1985]. There is, however, plentiful ground water in many of the basin areas, although it may be highly mineralized in some areas. Irrigation water from the Colorado fiver has actually contributed to the rise in the ground water level in the Yuma area, in particular, contributing to the flow of ground water from the Yuma area into the Mexicali Valley. In the Gila Basin it has been the practice to pump out the plentiful but saline ground water and replace it with water from the Colorado.

3. Fopulation and Land Use.

The population of present day Yuma County is 85,700. The major center of population in the county is Yuma, population 48,485 , through which all of the county's major routes pass. These are Interstate 8, U.S. 95 and the Southern Facific. The railway forks into two lines east of Wellton, (south of Fied Eluff Mountain). All of the settlements within the study area, except for Cibola and Martinez Lake, which are proximate to the Colorado, lie along these major routes.

The study area, shown in a Surface Responsibility Map digital map 3 , covers approximately 6,000 square miles, of which the $10 \%$ given over to private 1 and $u s e$, incorporated areas and Indian Reservation land is virtually confined to these traffic corridors within the Yuma Valley and Gila Easin. The only Indian Feservations are the Fort Yuma and Cocopah Indian Feservations, in the Yuma area. The remaining $90 \%$ of the land is the responsibility of the U.S. Army, (Yuma Froving Grounds); the U.S. Air Force, 


\section{Digital Map 4}

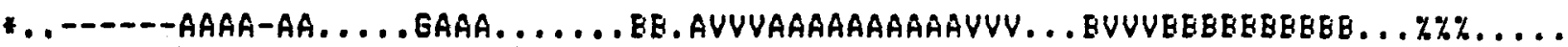

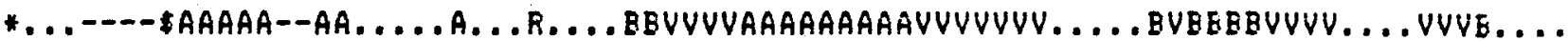

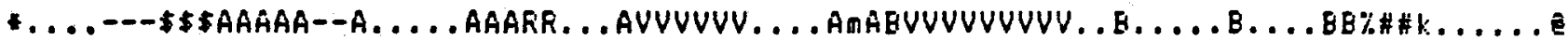

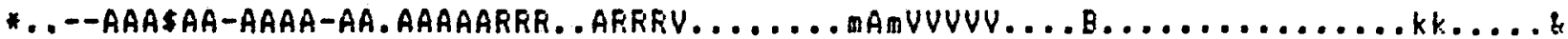

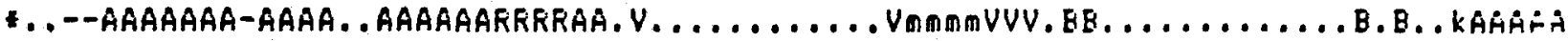

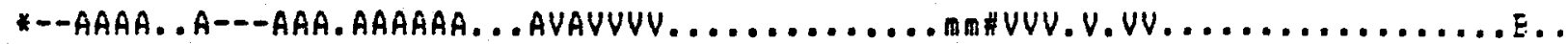

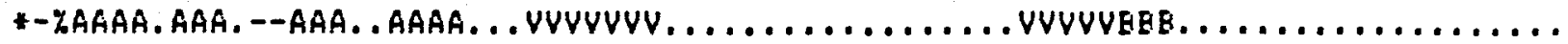

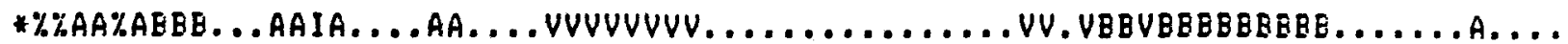

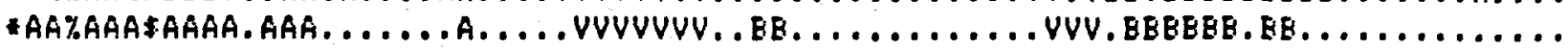

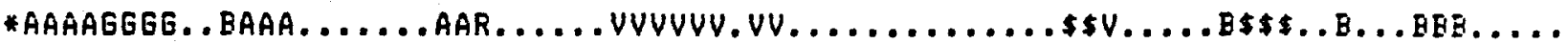

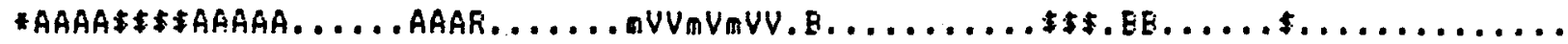

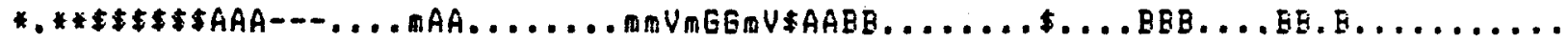

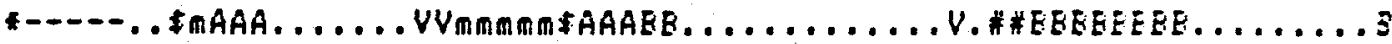

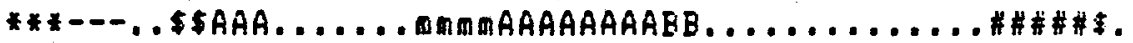

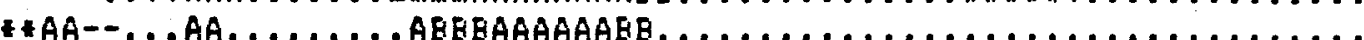

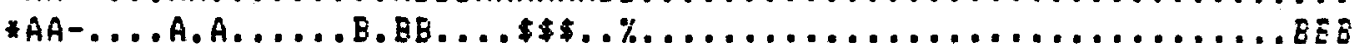

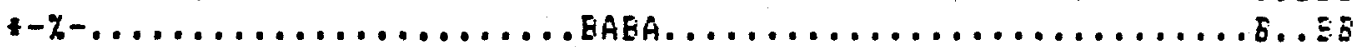

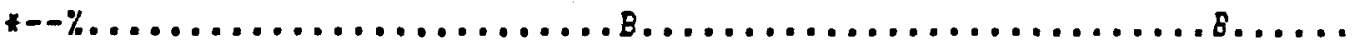
$+--\% \ldots \ldots \ldots \% \% \ldots \ldots \ldots \ldots \ldots \ldots \ldots \ldots 8 \ldots \ldots \ldots . \ldots \ldots \ldots \ldots$

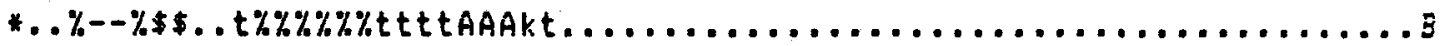

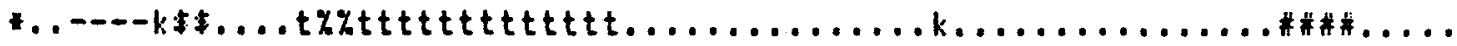

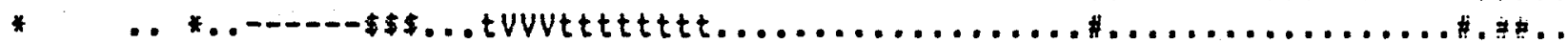

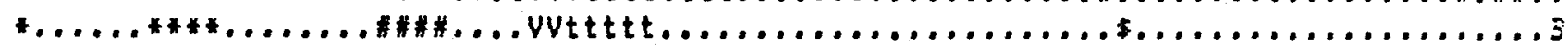

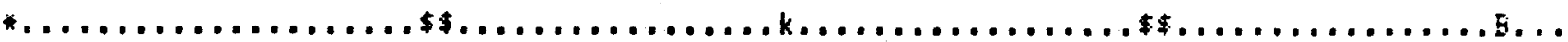

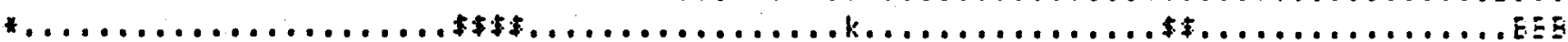

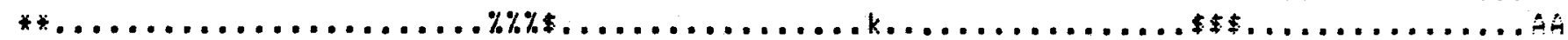

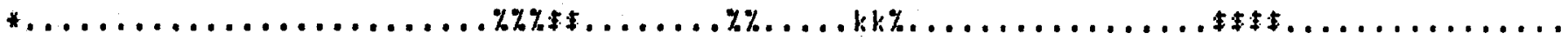
*.....................

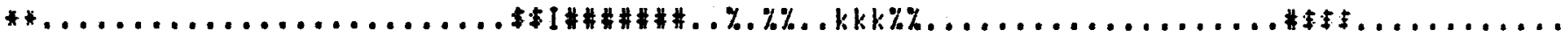

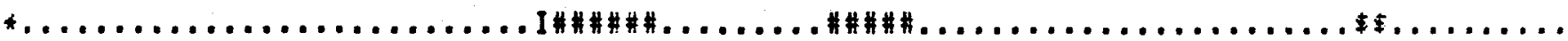

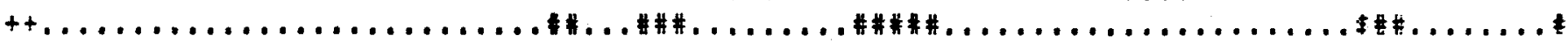
$+++\ldots \ldots \ldots \ldots \ldots \ldots \ldots \ldots \ldots \ldots \# \ldots \# \# \# \ldots \ldots \ldots \ldots \ldots \ldots \ldots \ldots \ldots \ldots \ldots \ldots \ldots \ldots \ldots \ldots \ldots \ldots \# \ldots \ldots \ldots$

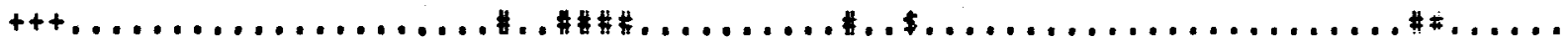
$+++\ldots \ldots \ldots \ldots \ldots \ldots \#, \ldots \ldots \ldots \#, \ldots \ldots \ldots \ldots \# \$ \$ \ldots \$ \$, \ldots \# \ldots \ldots \#, \ldots \ldots \ldots \# \# \ldots \ldots$

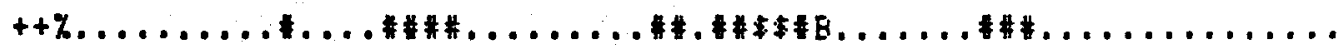

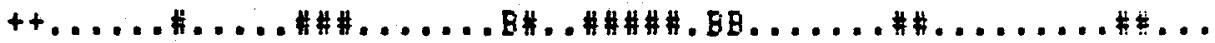

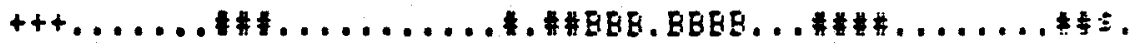

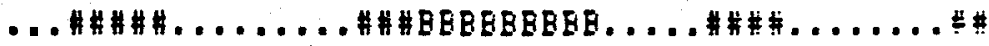
$+++++\# \# \ldots \ldots \ldots \# \ldots$. . BEBEE\%\% $\ldots \ldots \ldots \neq \ldots \ldots \neq \ldots$

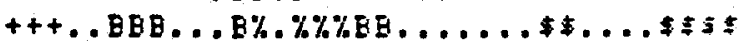
$+++\% \% \% \% \varepsilon E, \ldots \ldots \ldots \ldots \ldots \neq \$ \neq . \ldots$ $+\%, \%, \ldots \ldots \ldots \ldots \ldots \neq \neq \ldots$ $+++. \% \ldots B E B 85 \ldots \$ \ldots$ +++ SEEBBB...\% $+++E \ldots . . \%$ $++\because$

SURFACE GEDLDGY OF THE STUDY AREA

ERTER FEATURES: * : COlORadO RIVER EE: HEVITAEY FORMATIONS

- Ouaterrary Sediments

- : Guaternary-Tertiary Sediments

$t$ : Mid-Tertiary Deposits

$k$ : Miocene-Cretaceous Deposits

* : Mesozoir Formations

BCANITES

5: Tertiary Granite

* : Gunnery Range (Leramide) Granite

\# : Pre-Tertiary Granite

a: Fre-Cambrian Granite

VOLCANIC FORMATIONS

+ : Border with Mexico

B : Quaternary Basalts

B : Late-Tertiary Eseaits

I : Tertiary Intrusives

A : Mid-Tertiary Andesites

$V$ : Mid-Tertiary Andesites and Rhiciltes

R : Mid-Tertiary Fihyolites

METAMORPHIC ROCKS

*: Fre-Cambrian Schiet

* : Pre-Cambrian Schist, Recryetzl: $z z=$ in P!as

3 : Fre-Cambrian Eneiss, Reerystallized in Fias 


\section{GEOTHERMAL RESOURCE EVALUATION OF THE YUMA AREA}

(Luke-Williams Eombing and Artillery Range); set aside as National Wildlife Refuges, CCibola, Imperial, Kofa, Mittry Lake and Cabeza Prieta); or is unclaimed, the responsibility of the Bureau of Land Management or of the State of Arizona as State Surface Trust land. Land use percentages were calculated from a 1979 Bureau of Land Management map, [Bureau of Land Management, 1979]. Digital map 3 is based on this map.

\section{Geology: Surface structure.}

North of the Gila Basin the exposed outcrops of rock consist predominantly of extrusive igneous rock formations, primarily andesites and rhyolites, but also including outcrops of basalt, [B]. The Geologic Map of Arizona, [Wilson, et al, 1969] has the rhyolites in the neighborhood of Stone Cabin and all of the basalts as dating from the Quaternary period, (1ess than 2 million years before the present) and the andesites and remaining rhyolites as having a Cretaceous date of formation cover 65 m.Y.b.P.). More recent researchers, armed with the latest radioactive dating procedures, have cast new light on the subject.

Thus andesites and rhyolites in the fofa Mountains have been dated, [Shafiqullah, et al, 1980], from 23.6 to 18.3 m.y.b.p. Gutman dated volcanic flows in the Castle Dome Mountains from the same period, [Gutman, 1978]. Crowe dated volcanic rocks in the Chocolate Mountains of California from $31 . \theta+1-3.2$ to $22.7+1-$ 5.9 m.y.b.p., except for a basaltic formation dated as $13.1+1-$ 2.5 m.y.b.p., [Crowe, 1978]. Garner, and others, propose 29 to 21 million year old dates for the andesitic and rhyolitic flows in the Trigo Mountains and late Tertiary dates for the basalts found there, [Garner, et a 1,1978 ].

The general inference is that peak volcanism in the area, consisting of andesitic and rhyolitic flows, occurred between 29 and $21 \mathrm{~m}$. y.b.p., followed by a surge of basaltic volcanism which ceased before 8 m.y.b.p. On this basis, we have dated all of the more recent intrusives in the area as Tertiary on our digital geologic map (digital map 4).

This area north of the Gila Easin also has exposed stretches of metamorphic rocks - gneisses and schists, [9], of granites, and of sedimentary rocks of various ages and stages of hardening and densification. The largest sedimentary rock formation is the major portion of the Muggins Mountains, which is shown on the Geologic Map as late 01 igocene to mid Miocene (30 - $15 \mathrm{~m} . y \cdot b . p$.$) . Scattered$ outcrops of sedimentary formations, dated as mid-Miocene to later Cretaceous, (24 to 90 m.y.b:p.), appear within, and on both sides of the Gila Easin. The largest such formation is the northern Copper Mountains, with smaller outcrops appearing in the Laguna, Muggins and Mohawl Mountains, and at the northeastern edge of the Falomas flain, [Wilson, et al, 1969]. On digital map 4 we have labeled these outcrops as 'Miocene to Cretaceous' formations. 


\section{GEOTHERMAL RESOURCE EVALUATION OF THE YUMA AREA}

These are the only sedimentary strata of any magnitude exposed south of the Gila Easin. There are also large stretches of older sedimentary formations, metamorphosed in some places, to be found in the Middle, Castle Dome and Kofa mountains. The Geologic Map dates these as Jurassic to Triassic (13B - $240 \mathrm{~m} . \mathrm{y} \cdot \mathrm{b} . \mathrm{p}$.$) , and we$ refer to them on digital map 4 as Mesozaic.

South of the Gila Basin the exposed rock is predominantly metamorphic (gneisses and schists) or granite. There are no large stretches of exposed sedimentary strata other than the northern Copper Mountains and the northern tip of the Mohawl: Mountains. The principal volcanic outcrops within or close to the study area consist of Sentinel filain basalts; a basaltic table at the north end of the Aguila Mountains: the andesites and rhyolites which comprise the rest of the Aguila mountains: basalts at the north end of the Sierra Pinacate: the basalts of the Cabeza Frieta Mountains; and scattered Tertiary intrusive and extrusive formations in the Gila and Tinajas Altas Mountains.

The Sierra Finacate basaltic field, covering approximately 2,000 sq. $\mathrm{km} .,(750 \mathrm{sq}$. $\mathrm{mi}$.$) , is the most recent of these volcanic$ fields and has the greatest extent. Fotassium-Argon, (K-Ar), testing from two sites in Crater Elegante yielded respective dates of $0.465+1-0.065$ and $0.461+/-0.036$ m.y.b.p., [de Boer, 1979]. As mentioned earlier, the minimum date of formation of cerro Colorado has been established as 1100 A.D., with a probable date of last eruption in the late seventeenth century, [10], [Shakel \& Harris, 1971 J.

The Sentinal fiain basaltic shield is nearly as extensive as the Sierra Finacate, but is older. Shafiqullah, and others, refer to its age as between 4.2 to $1.3 \mathrm{~m} . y . b . p$. The basalts in the Aguila Mountains are referred to as $14 \mathrm{~m} . y . b . p .$, and the Cabeza Frieta basalts have been given 16-18 m.y.b.p. dates by the same authors, [Shafiqullah, et al, 1980].

The metamorphic rocks have been given 1.1 to 1.4 billion year old dates of formation, with occasional Mesozoic recrystallization dates. However, Shafiqullah, and others, have pointed out that the 1.4 b.y.b.p. dates are themselves from a period of recrystallization in this area.

The predominant type of granite south of the Gila River is described by Shafiqullah, and others:

"The largest exposed pluton of Laramide age in southwestern Arizona is a leucocratic two-mica granite batholith in the vuma Gunnery Range south of the Gila River., for which we propose the name Gunnery Fange batholith'. It crops up in mountain ranges within an oval shaped area of nearly 15,000 sq. km., which extends from the Tinajas Altas Mountains eastward to the Granite Mountains.", [Shafiqullah, et al, 1980]. 
$r e r c r c r c r c r$

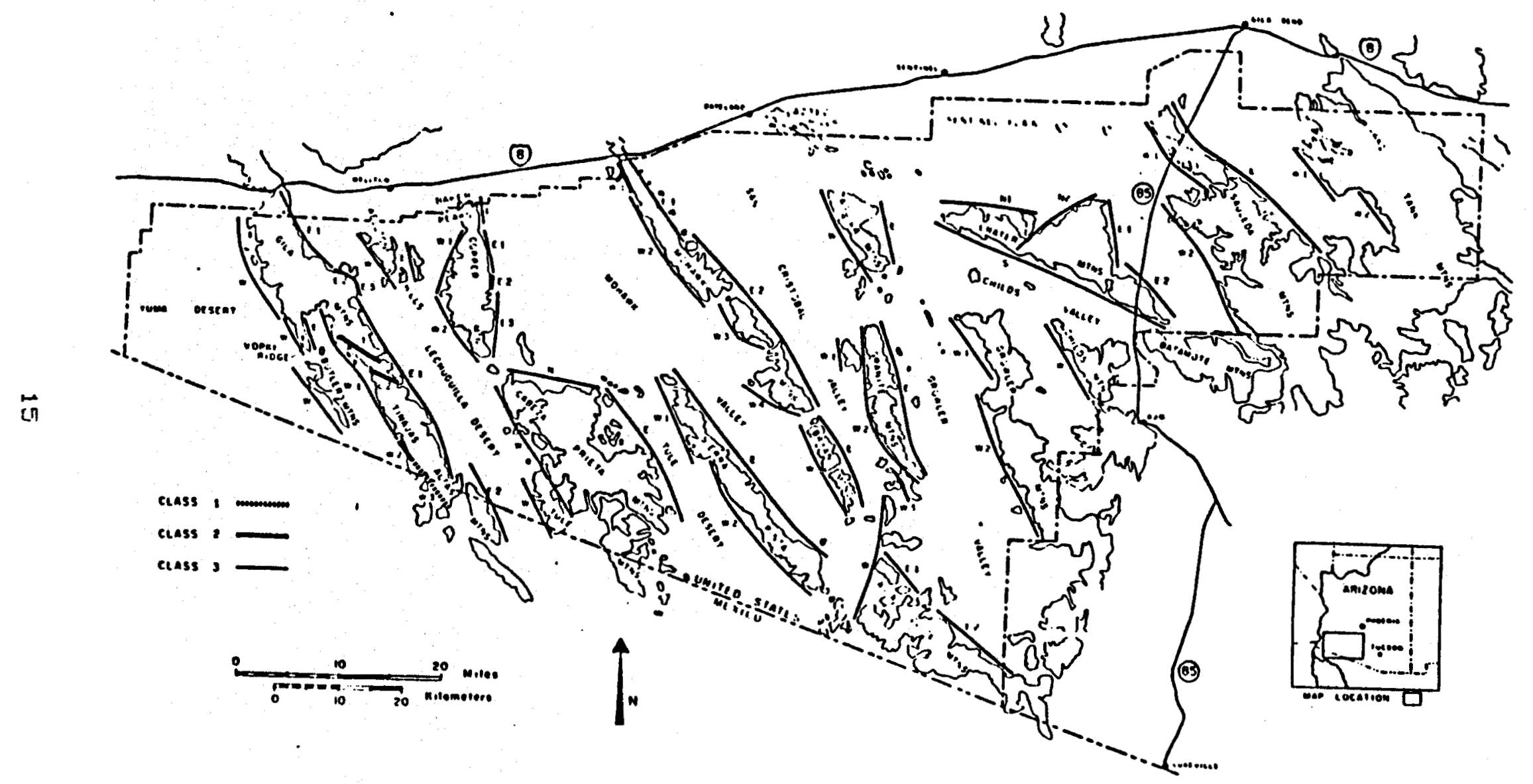




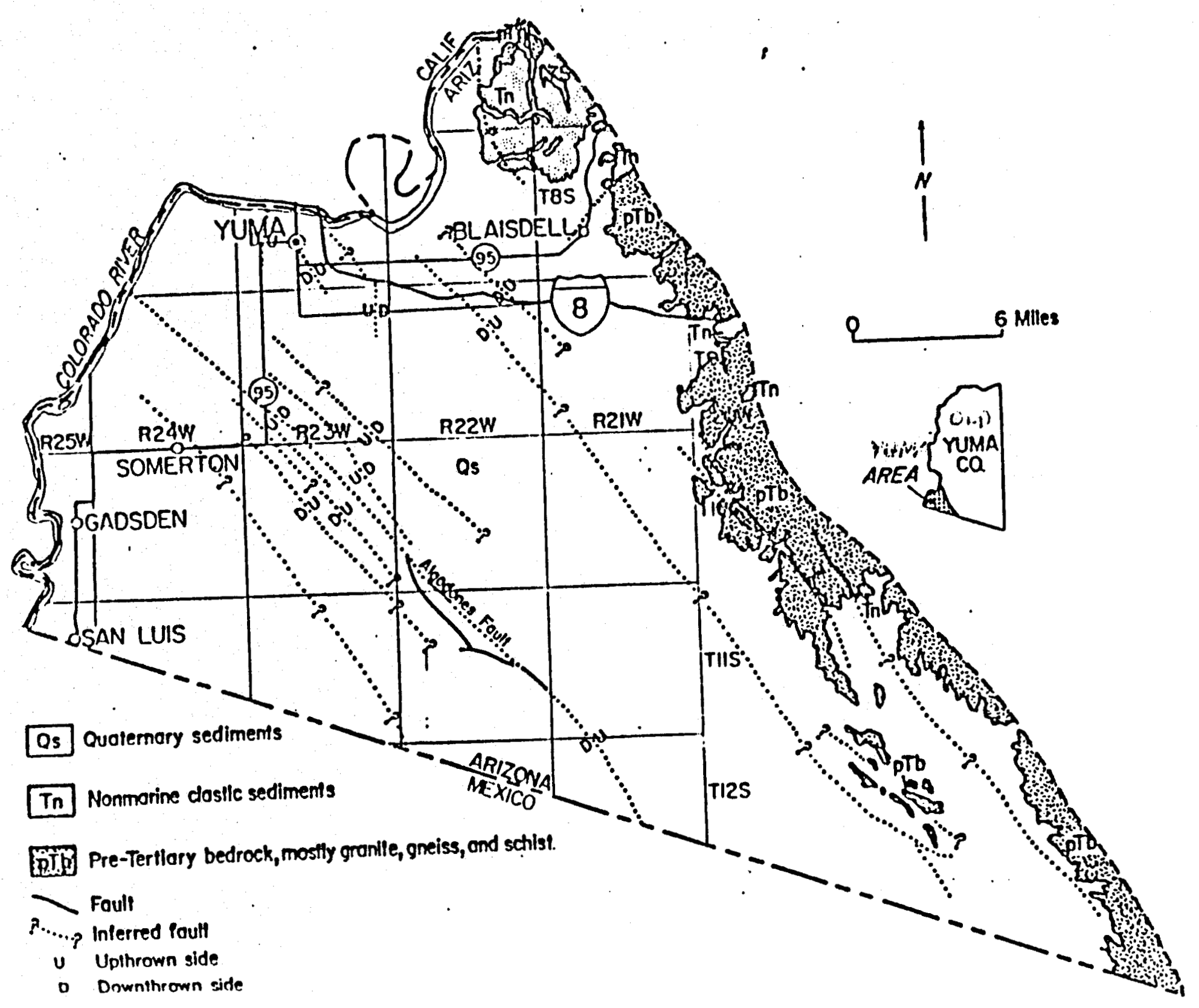




\section{GEOTHERMAL RESOURCE EVALUATION OF THE YUMA AREA}

Ages of 50 - 59 m.y.b.p. have been given to this type of granite. It is proposed by Shafiqullah, and others, that the pluton was emplaced in Cretaceous times and held at depth until the dates obtained. On Digital Map 4, which is based on the Geologic Map of Arizona, but which includes the revisions noted in this report, we refer to this granite as 'Laramide': the period from 75 to $50 \mathrm{~m} . \mathrm{Y} \cdot \mathrm{b} . \mathrm{p}$. which is considered as the great mountain building period of western North America, [Coney, 198.].

Except for the more recent volcanic rock, the age of the rock is not necessarily the age of the topographical structure. The problem of dating the minimum age of formation of the metamorphic and granitic mountains which 1 ie on Luke-Williams Air Force Fange was addressed by Tucker, [Tucker, 1980]. He used the following geomorphic parameters to assign minimum ages of tectonic activity:

1. degree of slope of alluvial fans,

2. Fanhead trenching,

3. Age of fan surface,

4. Sinuosity of mountain-piedmont junction,

5. Valley cross section,

6. Preservation of spur facets.

On this basis he assigned classes as follows:

Class 1 - generally active during Holocene, (within the last 10,000 years),

Class 2 - generally active during fileistocene, but not Holocene, $(10,000$ to $2 \mathrm{milli}$ on years old),

Class 3 - inactive throughout Quaternary.

His findings, shown as figure 6, were that only the northwestern flank of the Mohawk Mountains, a short stretch on the eastern flank of the Copper Mountains, and portions of the Tinajas Altas Mountains were tectonically active during the Guaternary Period, and only the southwestern flank of the Tinajas Altas mountains was active during the Holocene Epoch, (the last ten thousand years).

Morrison, and others, in their study of neotectonic, (less than $3.2 \mathrm{mill}$ ion year old), faults in Arizona found no faults less than 4,000 years old, and no neotectonic faults within the study area except in the Yuma desert, CMorrison, et a $1,198$.$] . In the$ course of their geophysical investigations of the Yuma area, Mattick, and others, examined the Algodones Fault. This fault, shown in figure 7 , coincides, or nearly coincides, with the eastern boundary of the Salton Trough as shown on most maps. They found it to be inactive throughout the Holocene, [Mattick, et aI. 1973]. The San Andreas Fault in this area is not even visible at 


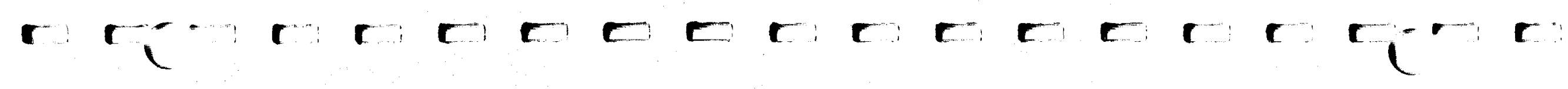

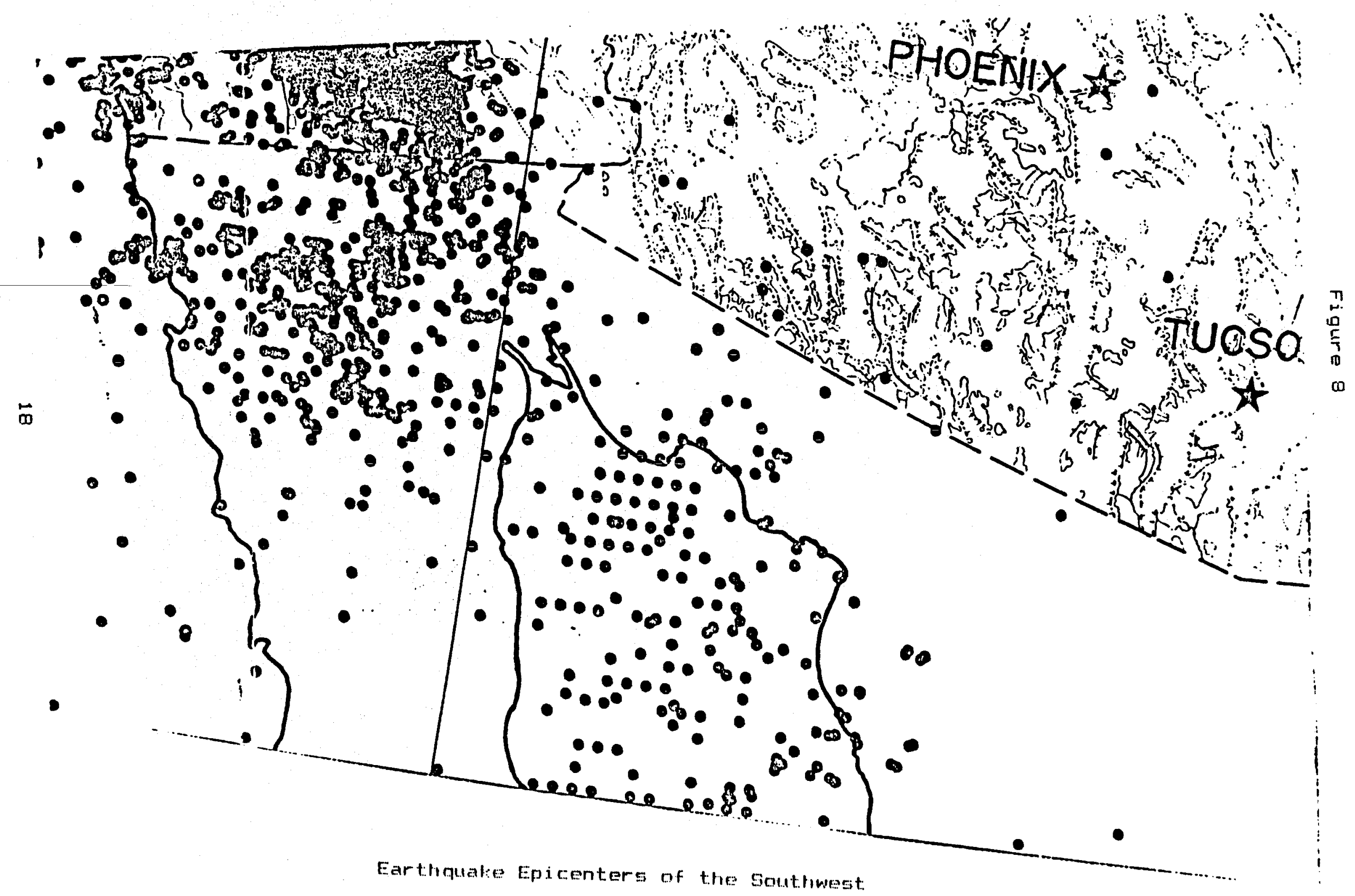




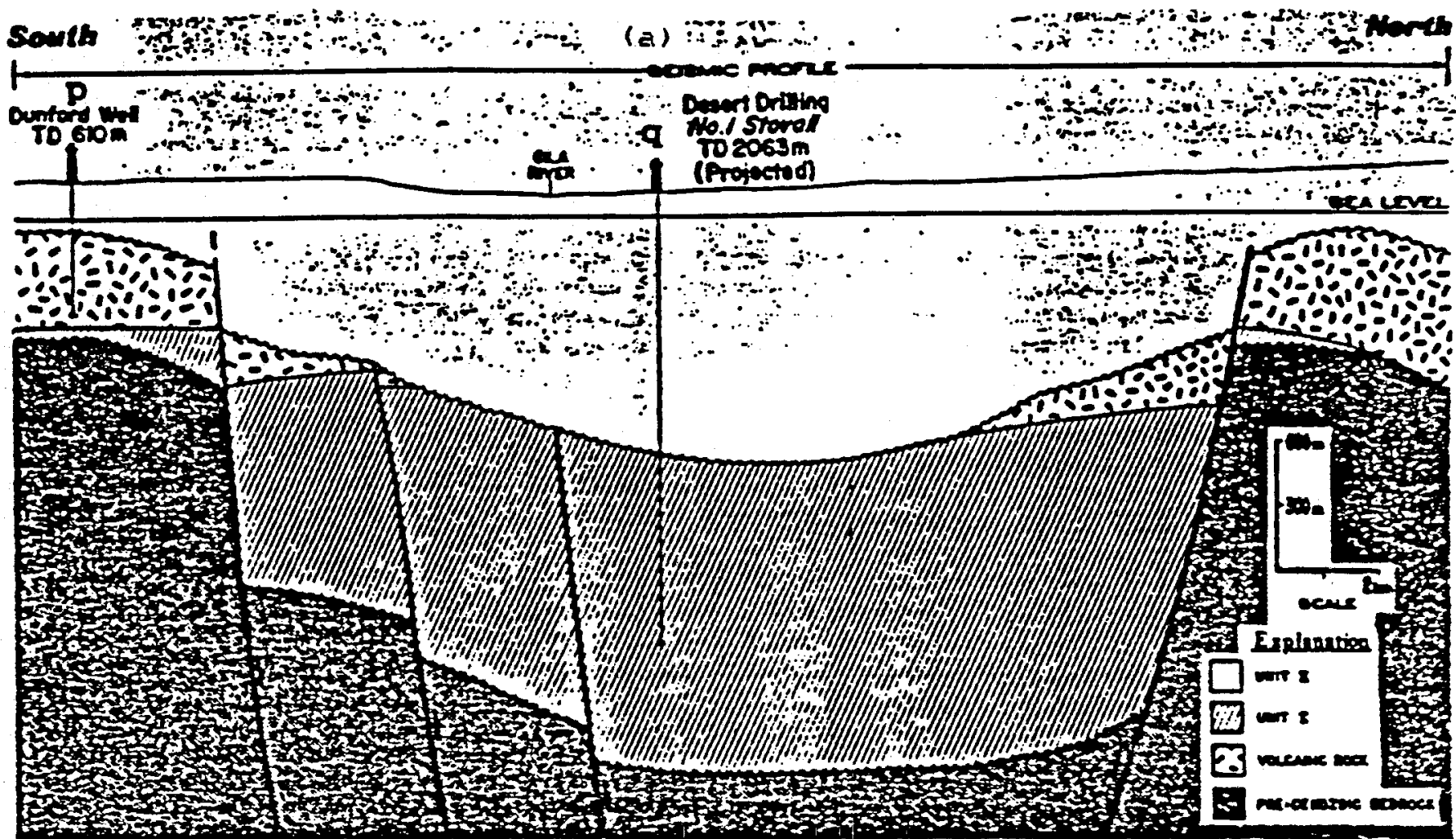

-- - Stroctara coss secion scros Cili trongh

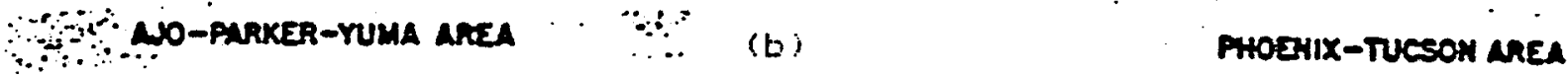

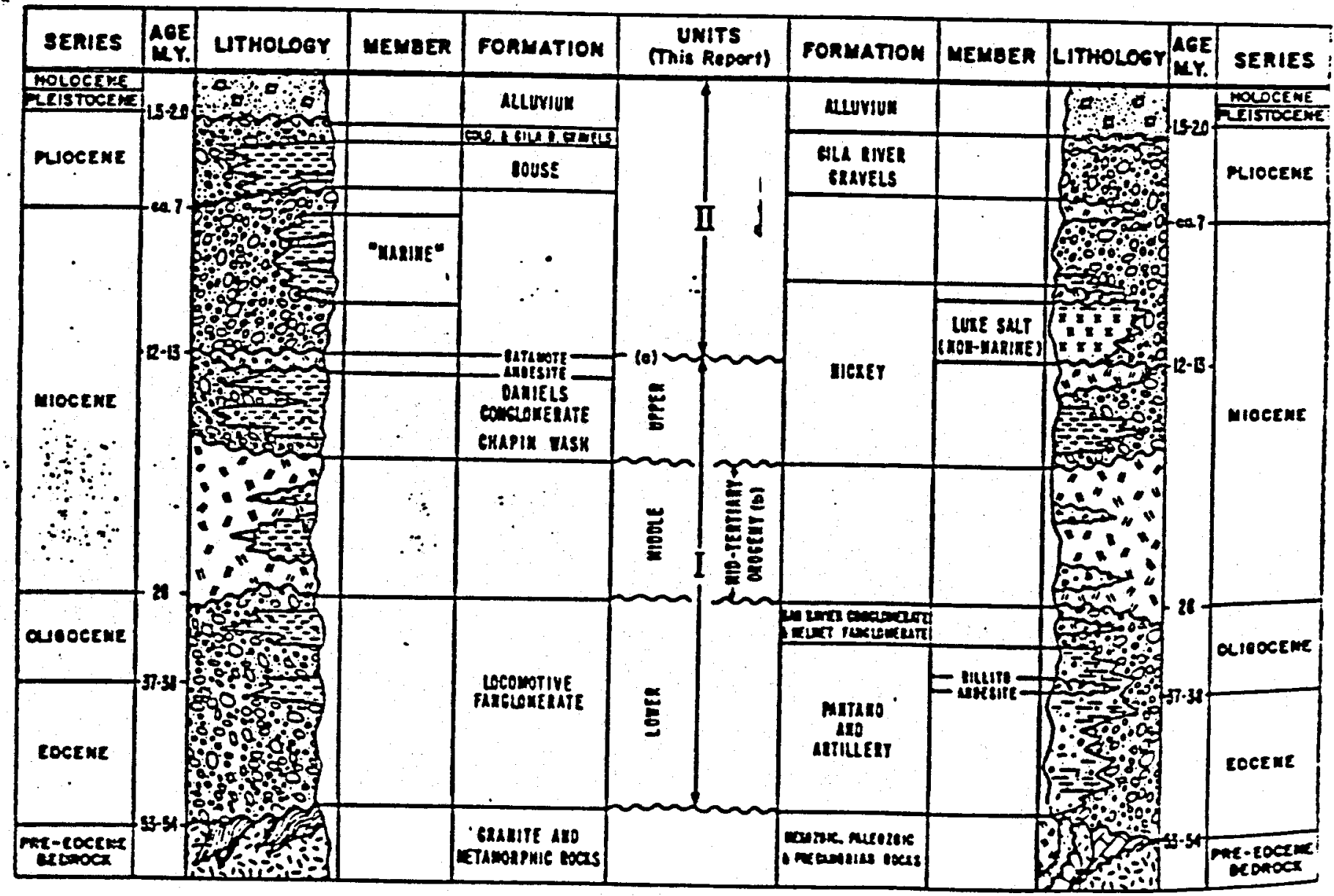

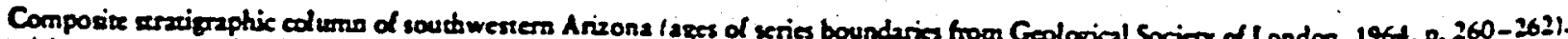

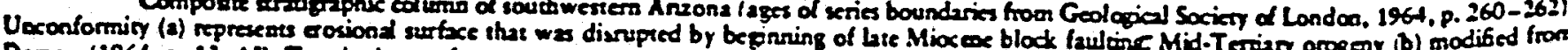
Dason (1964, p. 13-151 Teminology references: Wilson (1933), Gilluh (1946), Lishy and Webber (1949), Heindl (1959), Cooper (1900), Merser (1968). Finndi (1970), Mcker and Andenon (1971). Eacon and orhers (1972), and Matide and ochers (1973). 


\section{GEOTHERMAL RESOURCE EVALUATION OF THE YUMA AREA}

the surface, being inferred as present in the area from gravity mapping. The sparsity of earthquakes in the study area, or in Arizona, for that matter, contrasts markedly with the highly active Salton Trough area, as can be seen in figure $8,[11]$, [Smith \& Eaton, 1978]. Those earthquakes which have occurred in the study area have not, to our knowledge, led to the identification of presently active faults.

5. Geology: Basin Description.

In their landmart: study of the Arizona Basin and Fange Province, Eberly and Stanley classified the sedimentary deposits in basins according to easily recognized unconformities. They designated the lower, well consolidated unit as Unit I, and the upper, poorly consolidated unit as Unit II. Unit I was further subdivided into Lower, Middle and Upper subunits. According to their text and diagram, (see figure 9), the division between Unit $I$ and Unit II occurred 12 - 13 m.y.b.p.; between Upper and Middle Unit I, 17 - 20 m.Y.b.P.; and between Middle and Lower Unit I, 26 m.y.b.p. These sedimentary formations rest on a complex of preEocene (older than 55 m.y.b.p.) crystalline rock, [eberly \& Stanley, 1978]. We quote their description of these sedimentary formations.

"Lower Unit I.

Rocks of the oldest part of Unit I occur as isolated remnants of fluviatile reddish-brown arkosic sandstones and interbedded fanglomerates. In places the thickness of these rocks is as much as several hundred meters. The sandstones are poorly sorted, moderately to well indurated, and composed of quartz, feldspar, biotite and fragments of gneissic and granitic rocks. Weathered iron oxides and a reddish-brown silty matrix give a distinct reddish cast to these sedimentary rocks. The fanglomerates are composed mainly of rounded to subangular cobbles and boulders of gneiss and granite. Both the sandstones and fanglomerates apparently have been derived from nearby source areas. [This unit] ranges in age from Eocene to 1 ate 01 igocene 153 to about 28 to 26 m. y.) and includes some of the earliest middle Tertiary volcanic: extrusions."

"Middle Unit I (Fredominantly Volcanic Roclss).

The lower boundary of the middle subunit of Unit I is marled by the beginning of widespread volcanism associated with the midTertiary orogeny. This volcanic episode modified the geometry of earlier depositional basins and produced great quantities of rhyolitic to andesitic tuffs, breccias, and flows. Sediments intercalated with the volcanic rocks consist of indurated torrential deposits of red sand and gravel and massive beds of fanglomerate. Isolated thin beds of algal limestone and mudstone and associated beds of water-laid tuff indicate intermittent local development of lates. Unconformities are common within this unit." 


\section{GEOTHERMAL RESOURCE EVALUATION OF THE YUMA AREA}

"Upper Unit I.

The Middle Miocene continentel deposits of Upper Unit I consist of grayish-brown, poorly consolidated sandstones, fanglomerates (containing abundant volcanic detritus), varicolored mudstones, and beds of water-laid tuff. Locally these sedimentary deposits are intercalated with and overlain by basaltic lava flows. The tuffs are usually cream to white - less comonly, varicolored. Well preserved fresh-water ostracods are common in the mudstone and tuff beds. Upper Unit I deposition began as the mid-Tertiary orogeny started to wane about 20 to $17 \mathrm{million}$ years ago."

"Unit II.

Unit II can best be described by treating separately three geographic areas in which the sedimentary strata of this unit have distinct and differing characteristics: (1) an eastern area, where thick fluviolacustrine sediments, containing locally thict bodies of evaporites, accumulated in late Miocene time in rapidly subsiding trough-like basins: (2) a central area, where a much thinner fluviolacustrine sequence, without evaporites, was deposited, and (3) a western area, the Yuma basin and the lower Colorado River valley, where marine sedimentation dominated."

In the study area the above mentioned western area 1 ies west of the Trigo, Middle, Laguna, Gila and Tinajas Altas Mountains. The remainder of the study area lies within the central area. The description continues as follows.

"Unit II in the Central Area.

The Central part of the report area lacks the deep Tertiary troughs that characterize the eastern part, and it is probably barren of evaporites. Information from wells drilled by others and from Exxon's seismic data indicates that Unit II in this area is thin and composed of fanglomerates, red-brown clays, and basalt flows. Ross noted a persistent occurrence of red-brown clay in the subsurface of the lower Gila Fiver area and correlated it with similar deposits in the Mesa area, $20 \mathrm{~km}$. east of Fhoenix. Ross concluded that the red-brown clays found in the subsurface of the lower Gila River area were probably lake deposits, indicating termination of lacustrine conditions and the development of exterior-drainage systems. Termination of lacustrine conditions occurred between 10.5 and $6.0 \mathrm{mill}$ ion years ago."

"Unit II in the Western area.

Unit II in the western area consists of a marine wedge of clastic sediments of probable late Miocene age confined to the Yuma basin and the overlying more widespread Pliocene Bouse Formation. Dverlying the Bouse Formation are Colorado Fiver deposits. 
(a)

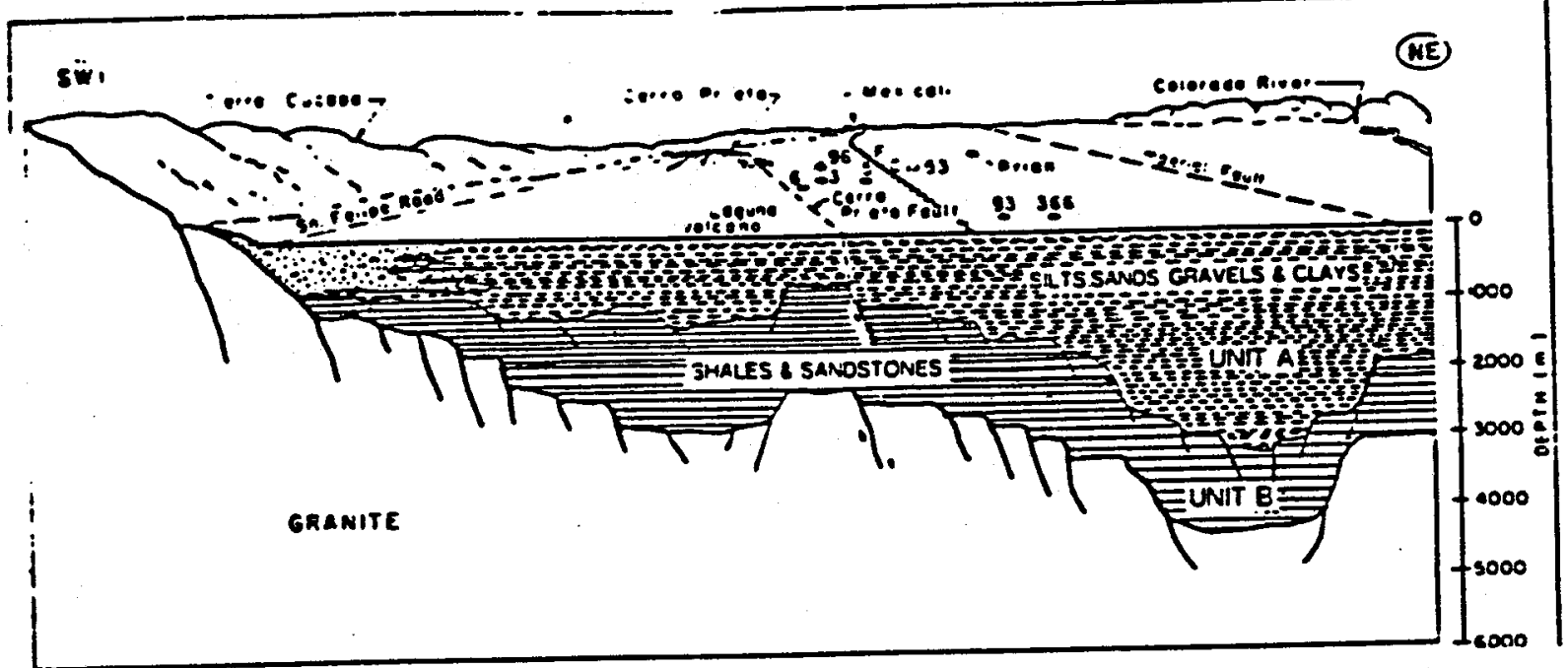

(b)

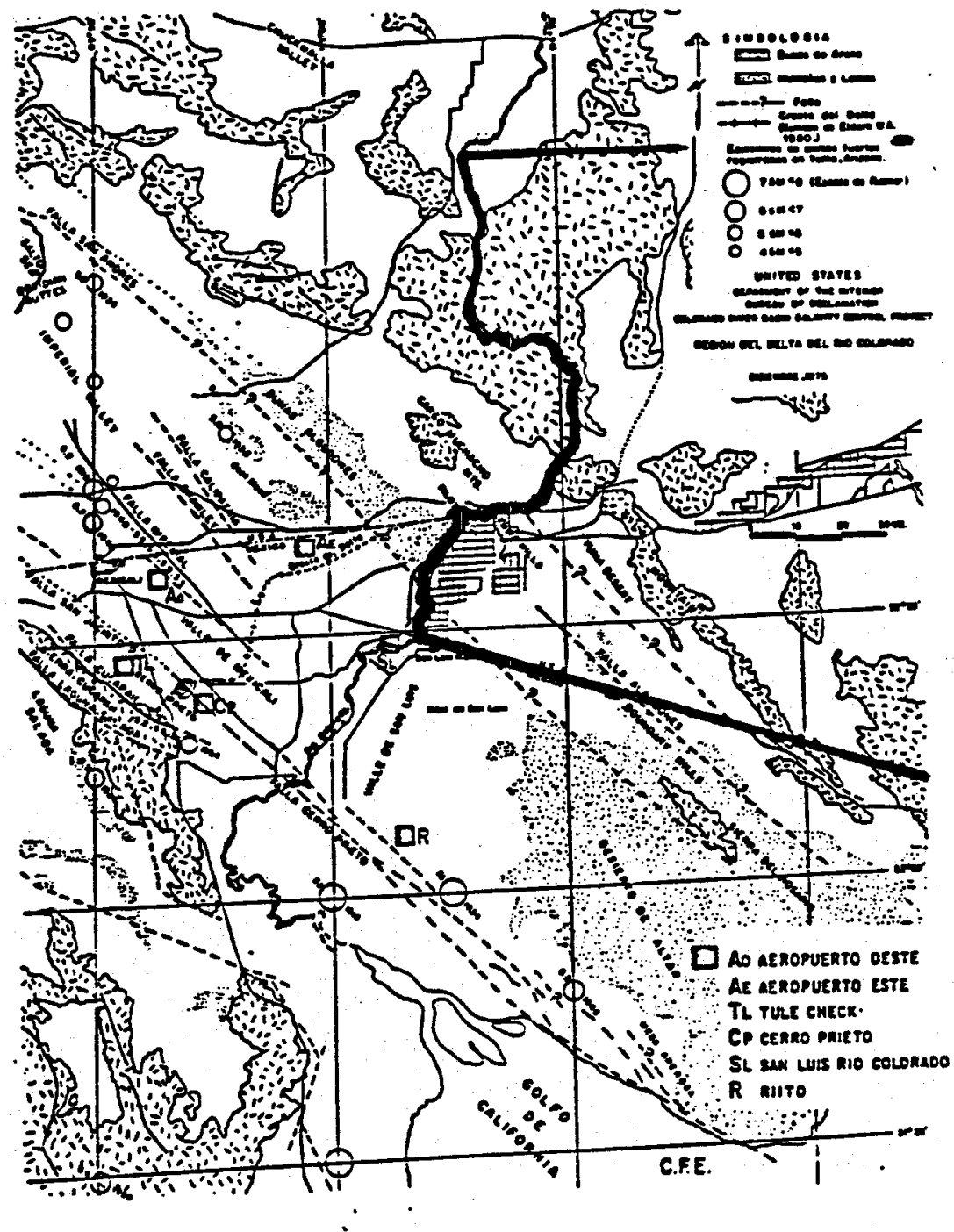

Location map of the regional geology of the Cerro Prieto geothermal field. 

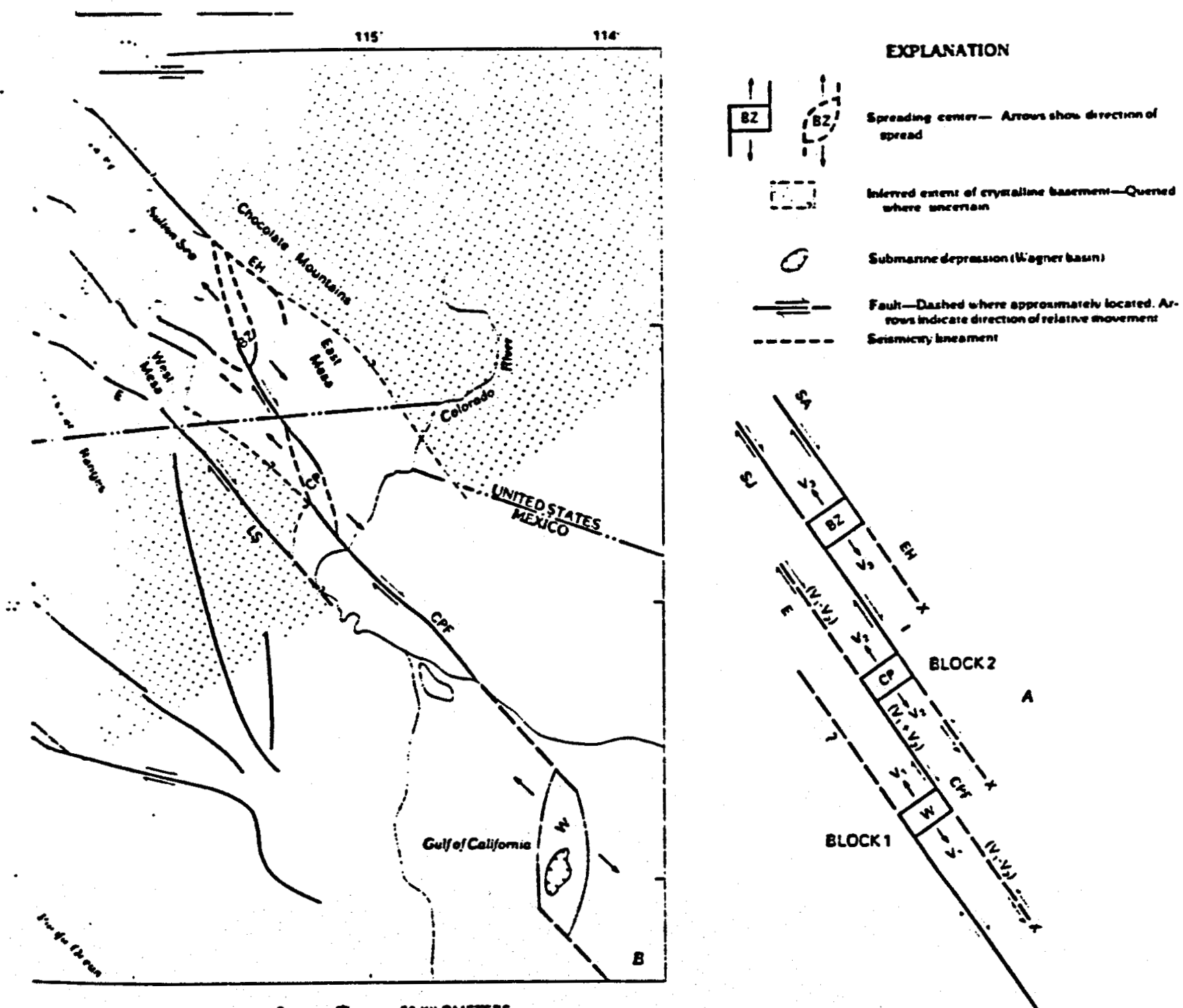

. Plate-tectonic model and map of northern Gulf of California and Salion Trough. mudified from Elde?s and others 11972 . fis. i, :- sized model iA 1 of sketch map $1 B$ i illustrates interrelations of major sprezoing centers: Brawley stismic zune iBZ . Cerru Prietu

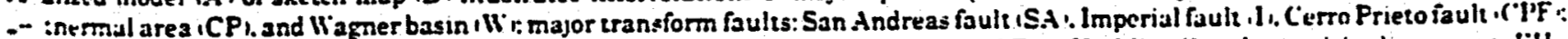

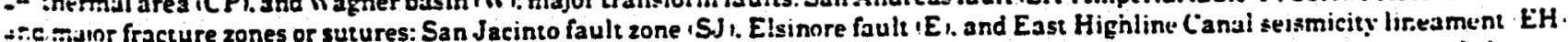
$\because \therefore$ : inst Lapuna Salada fault ILSI. which appears to be the seismically most active extensinn of El:inore fault soutneastward. dive n't

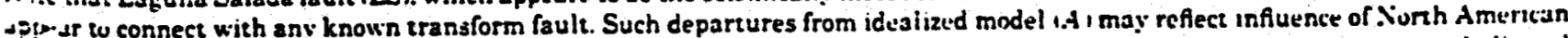
-ritunent. with its preexisting weaknesses. on oceanic plate tectonics. $X$ 's denote fracture $20 n e s$ or sutures that are inaetive in indicatid $\therefore:$ :-'ateral sense. East Highline Canal seismicity lineament appears to be associated with normal dip-ship mutions ifig. $24+1$ there ts wrentis no seismic or geologic evidence for existence of other two proposed sutures. Inactivity along sutures on east side of Ciulf of 1. . Ilisria and Salton Trough requires that spreading centers migrate northwestward from block 2 at their spreading half-rattes. II. .-univ that these half-rates decrease northwestward: $b_{1}<b^{\circ}<l_{i}$. 


\section{GEOTHERMAL RESOURCE EVALUATION OF THE YUMA AREA}

A late Miocene age is assigned to this Marine clastic sequence on the basis of the following relationstips: (1) the beds are overlain unconformably by the Pliocene Bouse Formation; (2) dipmeter data from the Exxon well indicate that the sequence dips gently and overlies with distinct angular discordance the underlying steeply dipping volcanic rocks and intercalated sedimentary rocks, which have been dated on the basis of $K$-Ar analysis as being 16 to $20 \mathrm{~m} \cdot \mathrm{y}$. old (middle Miocene); and ( 3 ) ceismic data indicate that the clastic section predates the late Miocene block-faulting episode (13 to $12 \mathrm{~m} . \mathrm{y}_{\text {.) }}$.

In outcrops the [Bouse] formation is composed of a basal white 1 imestone overlain by an ol ive-gray claystone. Minor amounts of silt, Eand and gravel occur generally throughout the unit, and the silt and sand percentage increases upward. A tuff layer in the basal 1 imestone has been dated as $5.4 \mathrm{~m} . \mathrm{y}$. old. This Pliocene date confirms that the Bouse is probably younger than the red-brown clays of the lower Gila River valley."

The Bouse formation, the marine wedge formation and the Algodones Fault were all found by olmsted, and others, to be of considerable significance in describing the hydrology of the Yuma area, [01msted, et $a I, 1973]$. Patten found that analog simulation of ground water movement in the Yuma Area required the inclusion of these features as parameters of the model, [Patten, 1977 ].

6. Description of the Salton Trough Area.

The Salton Trough, (figure 10), is a basin area which is well known for frequent and sometimes violent earthquakes, e.g., [Rojahn \& Sharp, 1982], and somewhat less well known for its geothermal potential, (see the Geothermal Resources Map of California, [Higgine, et aI, 1980]), and for the successful exploitation of that geothermal energy, as, for example, at Cerro Prieto in the Mexicali Valley and the Salton Sea area, Heber, the Brawley area, and East Mesa in the Imperial Valley. The Dunes area is a moderate temperature (5lightly over $\left.100^{\circ} \mathrm{C}\right)$ resource area in the Imperial Valley for which we know of no current plans for exploitation. Researchers relate the source of heat to the earthquake activity of the area by way of the plate tectonic model. According to this model, the North American and Pacific Plates meet in this area and the Gulf of California, traveling laterally with respect to each other. The differential velocities create pull-apart basins, whose surface manifestations are the enechelon faults found in the area, the earthquakes of this area, and the heat below the surface, due to magma rising into the fractured areas created by the pulling apart of the crystalline and volcanic basement rock. The model is schematically shown in figure $11(b)$, from [Fuis, et $a 1$, 1982], which is attributed to Elders, and others, [Elders, et al, 1972$].$ 


\section{GEOTHERMAL RESOURCE EVALUATION OF THE YUMA AREA}

The sedimentary basins in the Salton Trough have been modeled as consisting of an upper, poorly consolidated Unit $A$, a lower, well consolidated, Unit $B$, and crystalline basement rock, termed Unit $C$, as shown in figure 11 (a). As pointed out by de la fena, and others, the only clear difference between Units $A$ and $B$ is the degree of consolidation, [de la Pena, et al, 1979]. The importance of hydrothermal alterations in affecting the $A / B$ contact has been referred to by Haar and Howard in 1979, and later, more explicitly, by Diaz, and others, in 1981, [Haar \& Howard, 1979], [Diaz, et al, 1981], [Howard, et al, 1981].

Howard, and others, defined the characteristics of the Cerro Prieto field as follows.

"1. A zone of normally compacted sediments, exhibiting primary porosity.

2. A caprock.

3. A zone of chemically altered primary porosity.

4. A zone in which temperatures and transmissivity are such that the resource is exploitable both technically and economically.

5. A zone of extremely low porosity in which, however, fracturing may be significant.

6. A source of heat. system."

7. A set of fluid sources and sinks to the geothermal

The zone of normally compacted sediments is the shallowest part of the field, produced by the normal sedimentary processes of deposition and mechanical compaction.

Grant and 0 'Sullivan have proposed the 'leaky aquifer' model for the Cerro Prieto field. Regarding the 'caprock', they have this to say.

"A supposition that a reservoir must be confined is sometimes carried into geothermal from petroleum reservoir engineering. It is not appropriate. As a static emplacement of fluid trapped for millions of years, a petroleum reservoir must be confined. $A$ geothermal reservoir (other than geopressured) is part of an active hydrological system. In its natural state fluid is discharged, and replaced, continuously: and the reservoir fluid is typically replaced many times over the $10^{\circ}-10^{\circ}$ year life of a geothermal system. 
Figure 11

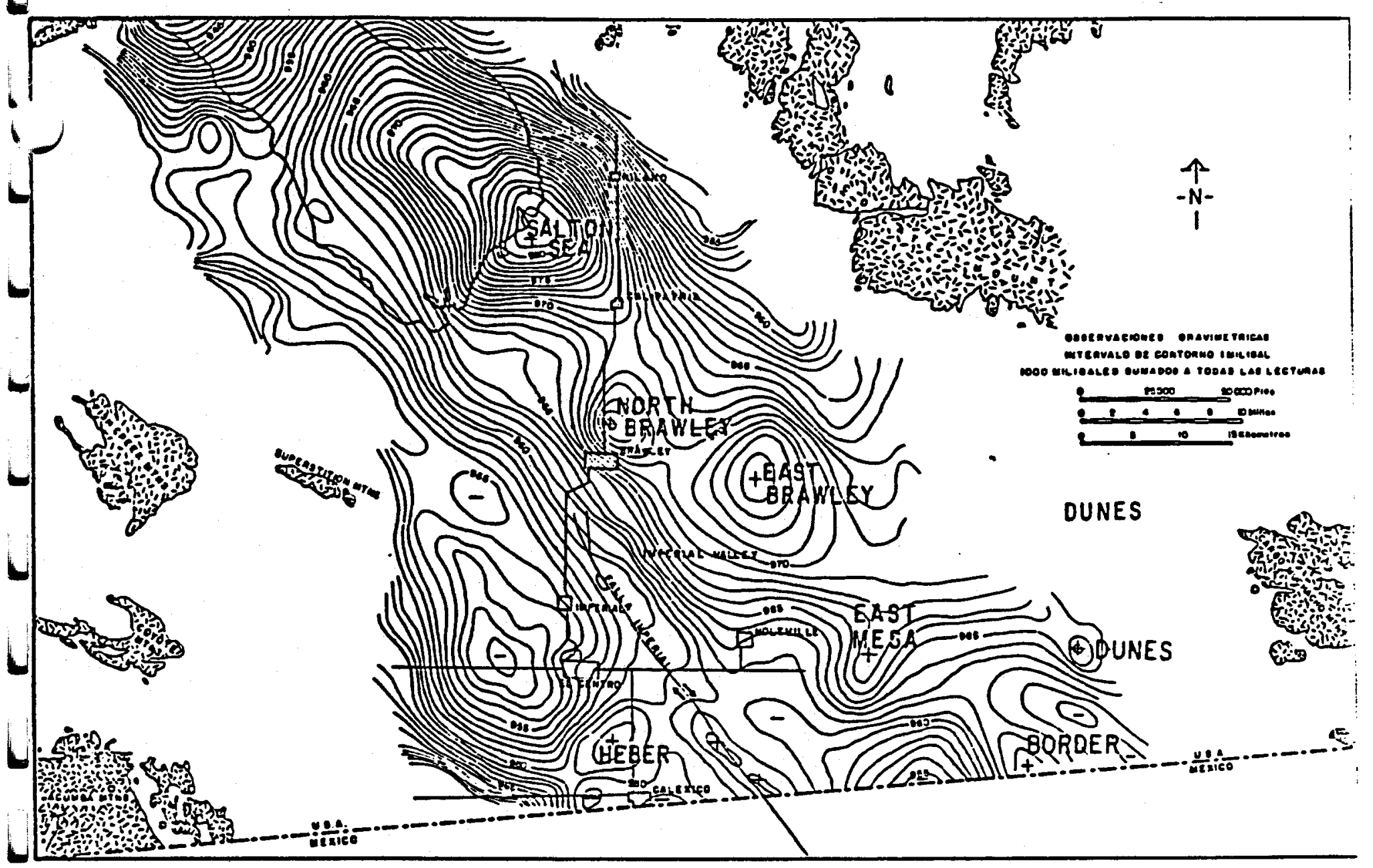

(a) Gravity Map of the Imperial Valley
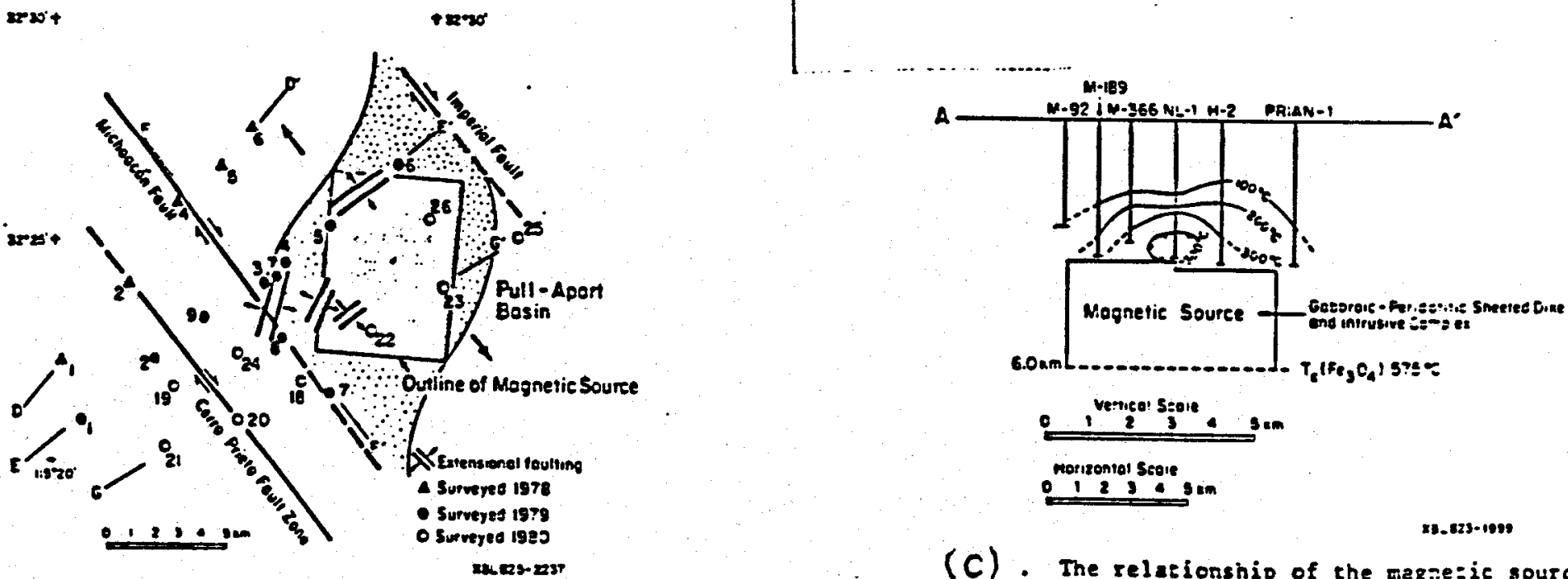

83. $823 \cdot 1998$

(C). The relationship of the magne:ic source and temperatures derived fros logs made in deep vells over and nea: the body.

(b) Relationship of the wagnetie source location to extensional faulting deterwined by weans of earthquakes (Reyes and Razo, 19?9). The stations are MT stations occupied by LEL. 


\section{GEOTHERMAL RESOURCE EVALUATION OF THE YUMA AREA}

The best evidence for the existence of a capping layer at Cerro Prieto is provided by the temperature distribution. ... The top of the reservoir is marked, over most of the field, by a sharp thermal gradient, above which is a region of lower gradient.", [Grant \& O.Sullivan, 1982$]$.

Diaz, and others, refer to the correlation between Bouguer gravity anomalies and the capping layer.

"With new information from the more recent wells, two maps of the top of the hydrothermal alteration zone under the field were prepared ... . Since this configuration represents the distribution of anomalous densities in the field, a clear correspondence with Chase et al's (1978) Bouguer gravity anomaly map of the field was found. As already mentioned, both maps show the same dome-like shape over the reservoir, which is closely correlated with what can be observed in the geologic crosssections. As for clarifying the ambiguity in explaining the Bouguer gravity anomaly map, we would suggest that, based on the above correlation, and at least in the area of the field, the Bouguer map appears to be more closely related to shallow density perturbations, rather than being a reflection of the basement.", [Diaz, et al, 1981$]$.

There is a consistent correlation between the known geothermal fields and residual Bouguer anomalously high values, as shown by figure $11(a)$.

Howard, and others, proposed that the zone of favorable temperatures and transmissivities is contained within the zone of chemically altered primary porosity, so that hydrothermal alterations relate the caprock and the ather two zones mentioned. They treat, however, the role of the zone of extremely low porosity with some caution.

"The zone of extremely low porosity refers to the mass of rock, other than the caprock, within the geothermal resource in which intergranular porosity either never existed or el se has been destroyed through mineral deposition. Fracturing, faulting, and microfracturing may be present. Within the Cerro Prieto reservoir, this zone is the deepest. Further study is required to understand this zone and its role, if any, in recharging heat and/or mass to the exploitable part of the geothermal resource.", [Howard, et a, 19811.

The location and nature of the heat source at Cerro Prieto had been the subject of considerable investigation. In particular, it was mathematically modeled in some detail by Elders, and others, who described it as follows, 


\section{GEOTHERMAL RESOURCE EVALUATION OF THE YUMA AREA}

"The very high temperatures at shallow depth in the Cerro Prieto geothermal field suggest that there should be a heat source which is a young, large, nearby igneous intrusion. Qur preferred model at present is that it is a funnel-shaped gabbro intrusion, probably 30,000 to 50,000 years old, some $4 \mathrm{~km}$ across at a depth of $5 \mathrm{~km}$. Above it there is probably a sheeted dike complex as is typical of ophiolite complexes in ocean spreading centers. Dur numerical models for simplicity assumed that there was a single intrusive event which is now cooling. If, as is likely in a tectonic setting of crustal spreading, there have been repeated incursions of magma for a long period, then the intrusion must be even larger and older. Whatever its form, the existence of the igneous intrusion seems to us to be inevitable. It should be detectable geophysically and perhaps in the future may be found to be accessible by deep drilling. Perhaps before the next century it will be found to be a viable energy source.", celders, et al, 19823.

The paper announcing the discovery of the heat source was presented by Goldstein, and others, at the same conference, [Fourth Symposium on the Cerro Prieto Geothermal Field, 1982J. We quote from the abstract of this paper.

"The broad dipolar magnetic anomaly whose positive peak is centered near Ejido Nuevo Leon, some $5 \mathrm{~km}$ east of the Cerro Prieto I Power Plant, has long been suspected to have a genetic relationship to the thermal source of the Cerro Prieto geothermal system. This suspicion was reinforced after several deep geothermal wells, driled to depths of 3 to $3.5 \mathrm{~km}$ over the anomaly, intersected an apparent dike-sill complex consisting mainly of diabase but with minor rhyodacite. A detailed fit of the observed magnetic field to a computer model indicates that the source may be approximated by a tabular block 4 by $6 \mathrm{~km}$ in area, $3.7 \mathrm{~km}$ in depth, $2.3 \mathrm{~km}$ thick, and dipping slightly to the north."

"Mafic dike chips from one well; NL-1, were analyzed by means of electron microprobe analyses which showed them to contain a titanomagnetite that is paramagnetic at in-situ temperature conditions. As the dike mineralogy does not account for the magnetic anomaly, the magnetic source is believed to be a deeper, magnetite-rich assemblage of peridotite-gabbro plutons. The suite of igneous rocks was probably passively emplaced at a shallow depth in response to crustal extension and thinning brought on by strike-slip faulting. The bottom of the magnetic source body, at an estimated depth of $6 \mathrm{~km}$, is presumed to be at or near that of the Curie isotherm (575० C) for magnetite, the principal ferromagnetic material in peridotite-gabbroic rocks.

The geological model derived from the magnetic study is generally supported by other geophysical data. In particular, earthquake data suggest dike injection is occurring at depths of 6 to $11 \mathrm{~km}$ in an area beneath the magnetic source. Thus, it is possible that heat for the geothermal field is being maintained by continuing crustal extension and magmatic activity.", cGoldstein, et $a 1,1982 \mathrm{~J}$. Also see figures 11 (b) and 11 (c). 


\section{GEOTHERMAL RESOURCE EVALUATION OF THE YUMA AREA}

Suggested fluid sources are runoff from the nearby sierra Cucapa, the Colorado River, and subsurface fluid movement from the Vuma area. Elders, and others, calculated the rate of fluid flow through the reservoir, based on isotopic exchange rates, and estimated a flow rate through a cross section of the reservoir at $6 \mathrm{~m} / y e a r$. They stated, [Elders et al, 1982], "This flow rate is similar to that which might be expected for the flow of groundwater down the delta of the Colorado River from its apex near Yuma, Arizona to Cerro Prieto."

Surface emissions from the Cerro Prieto geothermal area have been identified as a $100 \mathrm{~km}^{2}$ area on the western side of the field, near the volcano, Cerro Prieto, and the lake Laguna Volcano. These surface emissions, discussed by Valette-silver, and others, include hot springs, at about 90\%c; mud pots, mud lakes and mud volcanos, at about $100^{\circ} \mathrm{C}$; vents emitting boiling water; fumaroles, having two ranges of temperature - one of about $450 \mathrm{C}$ and the other between 80 to $100{ }^{\circ} \mathrm{C}$; and warm pools, generally at less than 450 C, [Valette-Silver, et al, 1981]. In the Imperial Valley, the California Geothermal Resources Map, [Higgins, et al, 1980], notes such surface manifestations only in the Salton Sea area. Thus surface manifestations are not a necessary feature of a geothermal resource, the fields at Brawley, Heber and East Mesa, having none. It is possible that geothermal brines which leak from a hotter and deeper reservoir may form a shallower and cooler one in another location. The Dunes reservoir may have just such a relationship to the East Mesa resource.

Research has been conducted in Mexico to find possible reservairs to the east of the Cerro Prieto - Nuevo Leon area. According to a personal communication by Dr. Goldstein of Lawrence Berkely Laboratories, they have discovered only cold water in the area closer to Arizona.

7. Geological History of the Area.

Although the ages of the basement rocks range from pre-1440 to 50 m.Y.b.p., the present day topography of this area can be thought of as a creation of the past $30 \mathrm{milli}$ on years, in the sense that whatever existed prior to that period has been thoroughly reworked and obscured by later activity. Thus the andesitic and rhyolitic flows in the area have been dated from approximately 30 to $17 \mathrm{~m} . y . b . p$, and the block faulting and subsidence which overprinted and destroyed many previous features is dated from 20 to $12 \mathrm{~m} \cdot \mathrm{y} \cdot \mathrm{b} . \mathrm{p}$. Thus these block faulting episodes are roughly concurrent with pre-Quaternary basaltic volcanism, between 17 and $\theta$ m.y.b.p. The Salton trough is also dated from about 17 m.Y.b.P., with the Gulf of California entering the area about $6 \mathrm{~m} . y . b . p$. The onset of sea floor spreading in this area is thought to be about $4 \mathrm{~m} . \mathrm{y} . \mathrm{b} . \mathrm{p}$. , or about the same time as the Gulf receded to approximately its present location. 


\section{GEOTHERMAL RESOURCE EVALUATION OF THE YUMA AREA}

The present drainage system of the Colorado and Gila Rivers (the Gila River flowed in this area until the building of Roosevelt Dam in the early $1900^{\prime} \mathrm{s}$ ) is also a recent event. Thus from Shafiqullah, and others:

"We suggest the following history for the evolution of the Colorado River. The Colorado River became a through-flowing stream in its present course after $5.9 \mathrm{~m} . \mathrm{Y.b} . \mathrm{P}$. , in the earliest Fliocene time. At that time it began unloading the extensive deposits of sediments that had accumulated in the basins of the colorado Plateau, and it began to cut the Black Canyon gorge at the rate of $390 \mathrm{~m} / \mathrm{m} . \mathrm{y}$. Since then the Colorado Plateau has been rebounding, initially at the rate of $130 \mathrm{~m} / \mathrm{m} . \mathrm{y}$.. resulting in the continuous cowncutting by the Colorado River and its tributaries within the Colorada Plateau. As a consequence of the work of the Colorado River in sediments from the Colorado Plateau, the plateau has been subjected to differential uplift and erosion. The net effect is the scouring and lowering of basins, the retreat of scarps, and the uplift of isolated plateau areas, even though the average elevation of the plateau is decreasing, except for the tectonically active high plateau region along the intermountain seismic belt."

"Evolution of the Gila River system was controlled by the Basin and Range disturbance. Basin subsidence disrupted an ancestral Gila River, creating internal drainage for a period of time. Gradually the basins filled and the Gila eventually became tributary to the Colorado River, draining much of southern Arizona into the Gulf of California. The critical events in the evolution are the initial disruption and eventual reintegration."

"The first key event, disruption of the older drainage pattern, was caused by the beginning of basin subsidence at the onset of the Basin and Range disturbance. Thick deposits of halite and anhydrite, accompanied by stringers of fine sediments, which occupy the basins west and south of Phoenix, an area calied the Gila low by Peirce, indicate regionally integrated but internally directed drainage during the early part of the Basin and Range disturbance."

"The second key event, integration of the rivers to the Gulf of California, is constrained by the $5.5 \mathrm{~m} . \mathrm{y}$. age of the Bouse Formation, which predates river deposits in the northern Gulf. Probably both the Gila and Colorado Rivers became connected to the sea at about the same time. If evaporite accumulation began soon after eruption of the $15 \mathrm{~m} . y$. old lava flow in the Picacho basin, drainage within the lower Gila system was internal for $10 \mathrm{m.y} . "$ 


\section{GEOTHERMAL RESOURCE EVALUATION OF THE YUMA AREA}

\section{GEOTHERMAL ANALYSIS DF THE AREA}

1. Qverview.

In this chapter we develop the methods used to answer the following questions: "How hot is the resource?"; "How deep is the resource?" and "How extensive is the resource?". Here we use the distinction between Hot Impermeable Rock and Convective Hydrothermal resources. The essential information for a preliminary evaluation of hot dry rock resource potential consists of the thermal gradient at the location in question. Even a preliminary evaluation of an area for its geothermal brine potential requires not only an estimate of the thermal gradient, but also an estimate of the depth, thickness, and geothermal brine content of the reservoir which is expected to contain the fluid at the desired temperature.

In order to accomplish our objectives we shall engage in a crude, straightforward analysis, as follows.

1. We estimate the thermal gradients for the area, using existing data.

2. We make an initial classification of the study area into potential hot dry rock and potential geothermal brine sites.

3. Potential hot dry rock sites are eliminated if the thermal gradient is too low.

4. We make a crude classification of geothermal brines by means of temperature levels.

5. Depth to bedrock estimates are used to eliminate basin areas from consideration within each temperature level.

6. The shallowest isotherm levels are used to choose most favorable geothermal sites.

7. Depths to various units are estimated as a basis for continuing work.

B. Estimates are made for the shallow ground water temperatures on the basis of thermal gradients and the estimated depth of Unit II.

The remainder of this chapter is devoted to these eight steps and the conclusions of this analysis. In order to conduct this analysis we used computer generated digital maps for calculating the results and to provide illustrations of the results. We discuss the production of these maps first, and then proceed to examine each of the above eight points in more detail. 


\section{GEOTHERMAL RESOURCE EVALUATION DF THE YUMA AREA}

2. Digital Maps.

All digital maps were produced on a scale of 1 pixel to 1 Equare mile. With the exception of the thermal gradient maps, all digital maps were either restriced precisely to the study area or to the study area and Range 10 West, south of the Gila - Salt River Baseline, (a six mile wide strip of land added to the eastern border). The thermal gradient maps were contoured for an area which included the Salton Trough geothermal areas. Specifically the thermal gradient maps represented the rectangular area from $116^{\circ}$ west longitude to a point $160 \mathrm{miles}$ to the east (approximately $B$ miles east of the eastern boundary of Yuma County), and from the Gila Salt River Baseline (approximately 33.3750 north latitude) to a point $96 \mathrm{miles,}$ or 16 Townships south, or approximately to $32^{\circ}$ north latitude.

The problem with digital mapping is that detail is inevitably 10st. The resolution of a digital map is precisely the pixel, whereas the resolution of a drawn map is much finer. This is not a problem in the case of the Thermal Gradient or isotherm maps, where the order of magnitude of error is expected to be greater than that introduced by the digital method, or the maps used for purposes of orientation, but did show up in other maps which were copied, pixel by pixel, from reference maps. These were the Surface Responsibility, Geological, Water Pumpage, Depth to Bedrock and Depth to the Bouse Formation maps. A rule was required to assign values to pixels in cases where the drawn maps provided several alternatives. The predominant value was chosen for the Surface Responsibility and Water Pumpage maps. For the Geologic map, the general rule of preference was, in descending order, Recent Volcanic, older Volcanic, Granites, Metamorphic, older Sedimentary and Recent Sedimentary rocks, al though occasionally a pixel was assigned the value of a sparse formation when that formation was set within the general background of a single, well represented formation. Digital maps 1 and 2 are simply recoded versions of the digital geologic map. Other maps will be discussed in detail in the appropriate section.

3. Thermal Gradient Maps.

The principal innovation of this section was the use of a hot and a 'cool' map to set upper and lower bounds for thermal gradients within the area. We were also interested in examining the effect of the Salton Trough hot spots upon Arizona, and the effect of a possible hot spot at Cerro Colorado. 


\section{GEOTHERMAL RESOURCE EVALUATION OF THE YUMA AREA}

For the 'hot' map we assigned the thermal gradient value of $185 \circ \mathrm{c} / \mathrm{km}$ at Cerro Prieto, Brawley and the Salton Buttes area, corresponding to a temperature of $1,000^{\circ} \mathrm{C}$ at $6 \mathrm{~km}$. This is consistent with the observed temperature of $340^{\circ} \mathrm{C}$ found at approximately 1800 meters in wells M109 and M129 in Cerro Prieto, [Rivera, et a 1, 1982], although these high temperature readings at that relatively shallow depth are the result of convective effects, rather than conduction. This high value is also consistent with the hypothesized upper limit of dike injection at Nuevo Leon, [Goldstein, et al, 1982]. At Cerro Colorado we assigned a more conservative gradient of $80 \circ \mathrm{c} / \mathrm{km}$ for the 'hot' map. Other locations were assigned the same values for both the 'hot' and 'conl' versions.

For the 'cool' map we assigned no value to cerro colorado, thus treating it as a heat sink, and we assigned $B 5 \circ \mathrm{C} / \mathrm{km}$ to the Salton Trough hot spots. This is consistent with a temperature of $1000 \circ \mathrm{C}$ at a depth of $12 \mathrm{~km}$, somewhat lower than the lower depth limit hypothesized for dike injection at Nuevo Leon.

Heat $f l o w$ data, in $\mathrm{mW} / \mathrm{m}=$, was converted to thermal gradient data by dividing by a conductivity factor of $2.2 \mathrm{~mW} / \mathrm{m}-\infty \mathrm{C}$. Conversely, the thermal gradient map can be considered as a heat flow contour map (in units of $\mathrm{mw} / \mathrm{m}^{2}$ ) by multiplying thermal gradient values by this factor. In addition to published heat flow and thermal gradient data, and the Salton Trough and Cerro Colorado values, we used an inferred thermal gradient for Radium Hat Springs, as discussed in Appendix A.

The method of contouring was based on a method discussed by Davis, [Davis, 1973], with the following exceptions:

1. thermal gradient data was weighted inversely proportional to the square of the distance rather than inversely proportional to the distance, [11]. The primary purpose for this was to increase the weight of nearby data and to reduce computer time.

2. In order to further reduce computer time, a two-step process was used to perforn the calculations. In the first pass the calculations were made for a set of coordinates which formed the vertices of $4 \times 4$ grids for the rectangul ar area. That is, the calculations were first made for every fourth point from every fourth horizontal line. Then, on the second pess, the interiors of each grid were calculated from the values which had been obtained for the four vertices.

3. Calculations for the first pass used data from points which were within seventy miles of the map area, and data from points which were farther than seventy miles from the contour point were not used at all. Again, this was done to reduce computer time. The set of data used in this first pass is collected in Appendix $E$. 


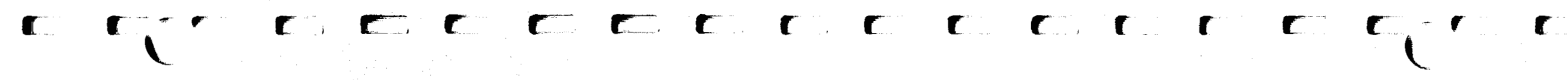

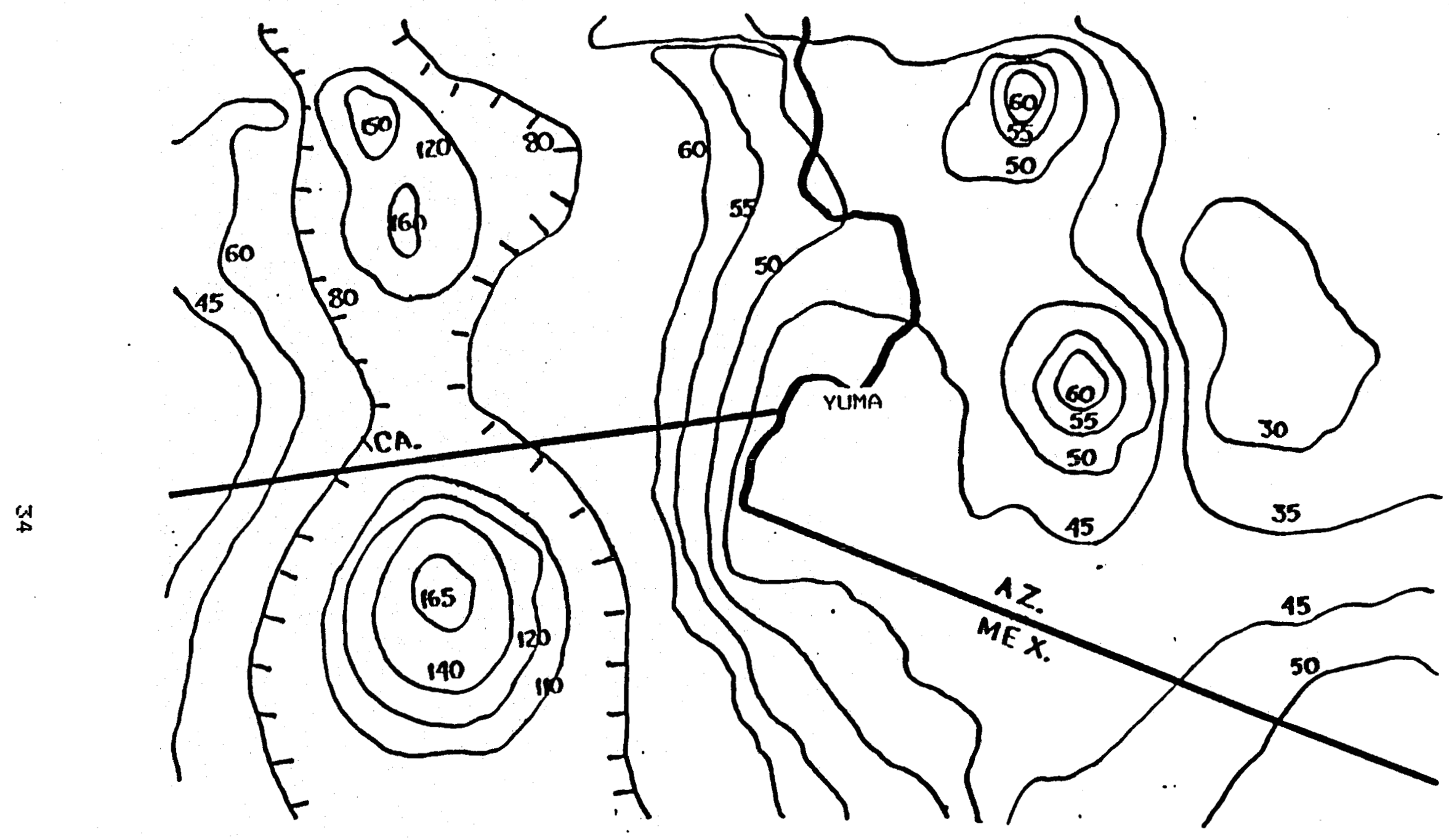

THERMAL GFAD CONTOUF: (ALL ND.S IN C/KM) 
C C r c cececererer

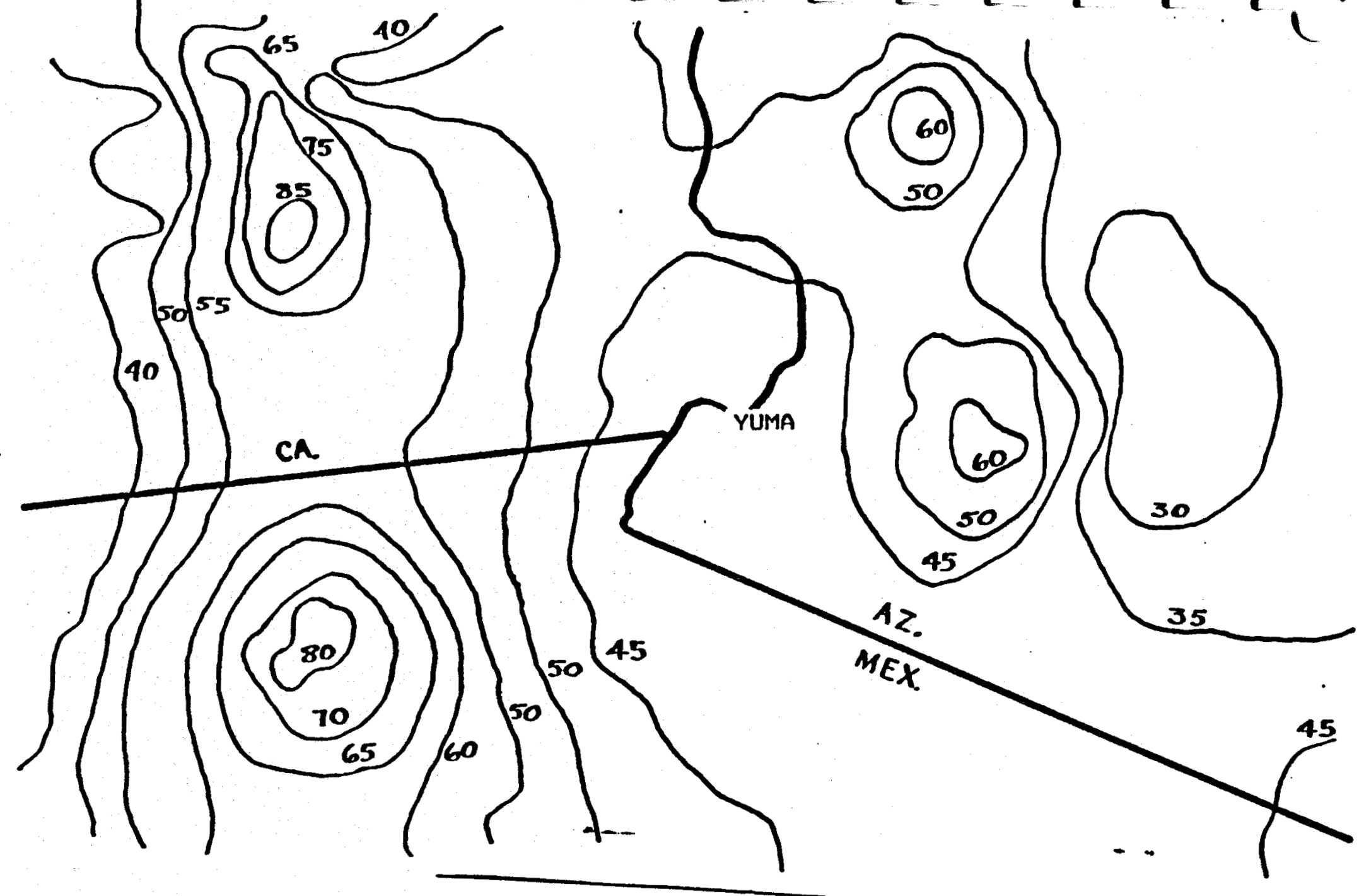

TMEFMAL GFAD CONTOUFS

(ALR NO-S IN C/KM) 


\section{Digital Map 5}

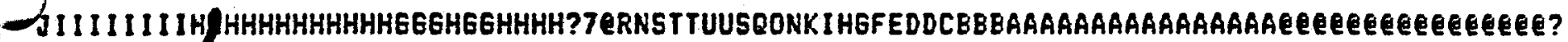

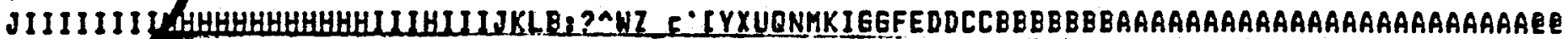
JJIIIII KKKJJIIII IHHHHHHIIIJJJJJKKLKKORTUWZ[IIZXWURONLJIHGFEEDDCCCEBBBBAAAAAAAAAAAABBBEBEBBBBBAA KKKKJ IIIH IHHHHH IIIJJJJKKKLLHNDQSTUVX ZXVUUSPNMLJ IHGGFEEDCCCBBBBAAAAAAAAAAABBBBBBBBBBBEBB KKKKJJJJII IIIIIIIIIJJJJKKKKLNMNOPPRSSSSSEPONHLKJIHEGFEEDCCCCBBBBAAAAAAAABBBBBBBECCCCCDDCC KKKKKJJJJIIIIIIIIIJJJJJKKKLLHKNODPPQQPDOONLKKJ IHHGFEEDDCCCBBBAAAAAAAAABBBBBBBBCCCDDDDEEE KKKKKJJJJI IIIIIIIIIJJJJJJJKKLLLMHLMNNNNKMMLKJJIHHGGFEDDCCBEAAEE EE EAAAAEBBBBCCCDDEEFEG6GH

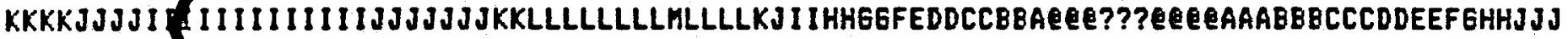
KKJJJIIIIIIIIIIIIIIIIIIIIJJJKKKKKKKJKKJJJIIHHGGFFEDCCBACQ?〉) )=>???CEAABCCDDEFGHIKLLNO

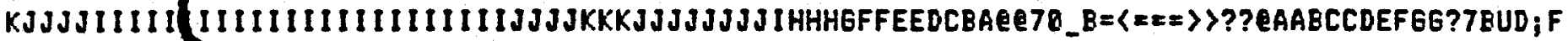
KJJJJIIIIHH

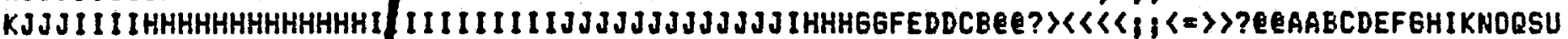

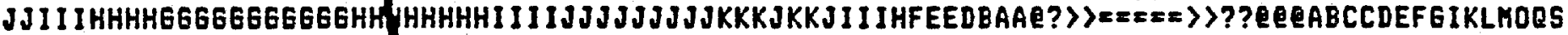

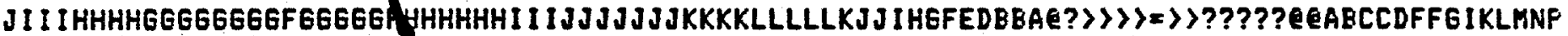

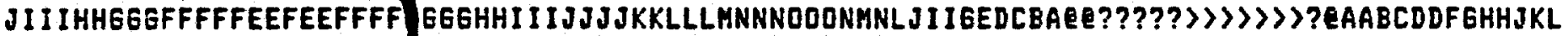

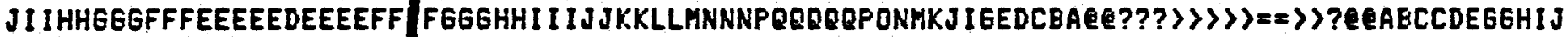

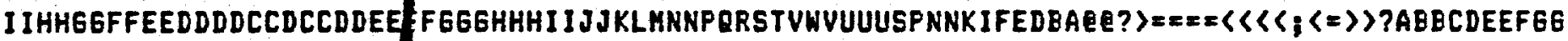

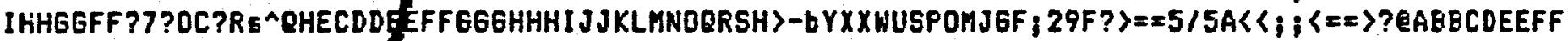

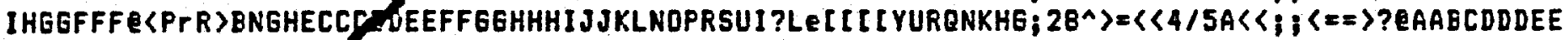

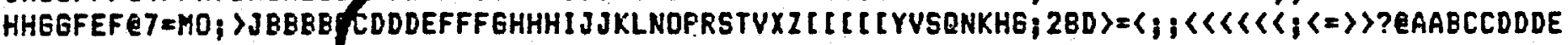

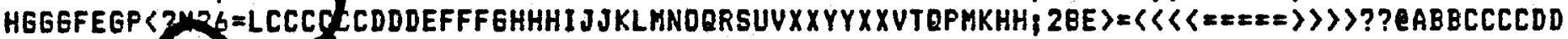
HGEGFEEE DODDU HEG6FE FEDDDDDDDDDDDDEEEEFFF 666HIIJKKLLMNOOPRRRRRRQPONMKI6GEDBBAE??\)?????EQEQAAABEBCCDDDD HEGFF EEEDDDDDDDDDDDEEEEFFFFG6GHHIJJKKLLMNNOOPPPOOPNMLLKIGFEDCCBACECEQ? Q CEAAAABEBBCCDDDDD HGFF EEEEEEEDDDDDEEEEEEEFFFF66GHIIIJJJKLLLMMNMNNMMLLKJJIHGFEDDCBBBAAABAABBBBBCCCCDDDDDDDE GFF EEEEEEEEEDDDEEEEEEEEFFFF6666HHI IIJJJJKLLLLMLLLLKJJJIHGGFFEDDCCBBCBBBCBBCCCCCDDDDDDDDEE GFE EDDDDDDDEEEEEEEEEFFFFFFFGGGHHHHIIIIJIIJJJJKKJJJJIHHHGGGFEEEDDDDCDDDCDDDDDDDDEEEEEEEEE GFF $\{4 ; \mathrm{KDDDDDEEEEEEEEFFFFFFFFGGGGHHHHHIIIIIIIIJ} \mathrm{IJj} \mathrm{IIHHHHGGGFFEEEEDDEDDDEDDDEDDEEEEEEEEEFE}$ GFF 4; KDDDDDEEEEEFFFFFFFFFFFFFF666666GHHHHHHHHHIHHHHHHHHGGGFFFFFFFFEFFFEFFFEFFFFFFFFF6GF HEF TEDDDDDDEEEEFFFFFFFFFFFFFFFF66666666HHHHHHHHHHHHHHHHG66GGFFFFFFFFFFFFFFFFFFFFF66666HG

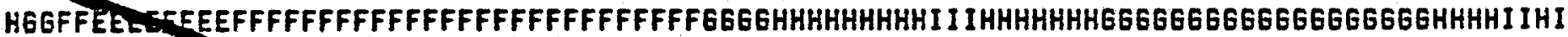

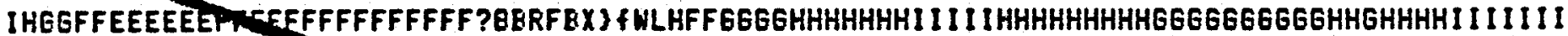

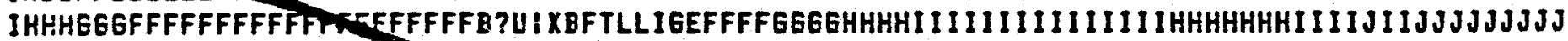
JIHHHHEG GFFFFFFFFFFFFFPRER8?PU >ANEEEEEFFFF6G66HHHHIIIIIIIIIIIIIIHHIIIJJJJJKJJJKKJKKK

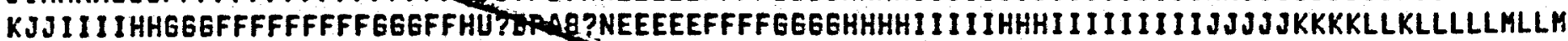

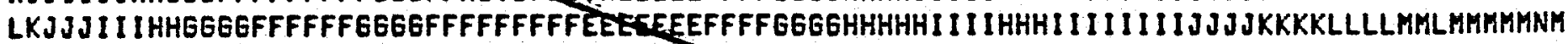
LLLKJIIIHHHHHHHGGGGGGFFFFFFFFFFFFFFFFFFFFKEEG 66GHHHHHHHHIIIIIIIIIJJJJKKKKLLLMMNNNNONNOOONO MLLKKJ IIIHHHHHHHHGGEGFFFFFFFFFFFFFFFFFFFFFG6 MHLLKJJJIIIIHHHHHEG6G66666666666666GFFFFF66666G6HHAHHLUIIIIIJJJJKKKKLLLMMNNNOPPPPQQQQRQQQ

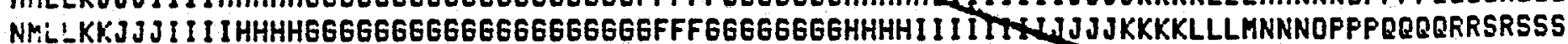

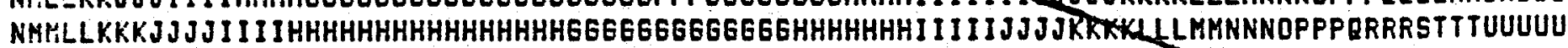

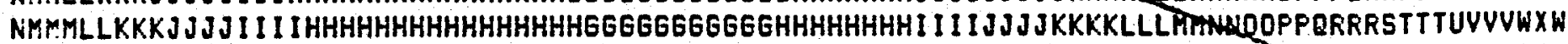
NKMMLLLLKKKKJJJJIIIIIIIIIIIIIIIHHE666666GHHHHHHHHIIIIJJJJJJJKKKKLLMMNNOOPQARRSTTUVUWXYZZII

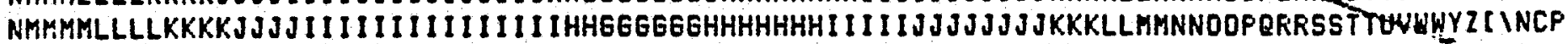
NNINMMMMLLLLKKKJJJJIIIIIJJJJJJIIHHHHHHHHIIIIIJJJJJJJJJJJKKKKLLLKMNNOOPPQRSSTUVUWYYZZYSEDS SCUC9EUE8BTABASE7ERE7?Q?7ERE7ERE6?P >6>F?6?Q?7ERE7ERE7ERE7ASA8ATE9CVC: DYE; GIG=I J?LdMBOjQET

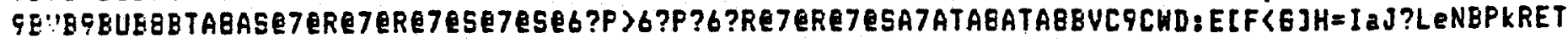


TABLE 1

CODES AND TEMPERATURE GRADIENTS FOR THE TEMFERATURE GRADIENT MAF

CODES GRADIENTS

\begin{tabular}{ll}
+ & 15 \\
\hline & 16 \\
\hline & 17 \\
0 & 18 \\
1 & 19 \\
1 & 20 \\
2 & 21 \\
3 & 22 \\
4 & 23 \\
5 & 24 \\
6 & 25 \\
7 & 26 \\
8 & 27 \\
9 & 28 \\
$Z$ & 29 \\
$I$ & 30 \\
$E$ & 31 \\
$=$ & 32 \\
$Y$ & 33 \\
$?$ & 34 \\
$G$ & 35 \\
$A$ & 36 \\
$B$ & 37 \\
$C$ & 38 \\
$D$ & 39 \\
$E$ & 40 \\
$F$ & 41 \\
$G$ & 42 \\
$H$ & 43 \\
$I$ & 44 \\
\hline & 45
\end{tabular}

\section{CODES GRADIENTS}

$\mathrm{J} \quad 46$

K $\quad 47$

L $\quad 48$

$M \quad 49$

N $\quad 50$

$0 \quad 51$

P $\quad 52$

Q. 53

F 54

$5 \quad 55$

T 56

U $\quad 57$

$v \quad 58$

W 59

$x \quad 60$

$Y \quad 61$

$Z \quad 62$

[ 63

164

J 65

1 66

- 67

69

b 70

c 71

d 72

e 73

$+\quad 74$

g 75

h 76 


\section{Digital Map 6}
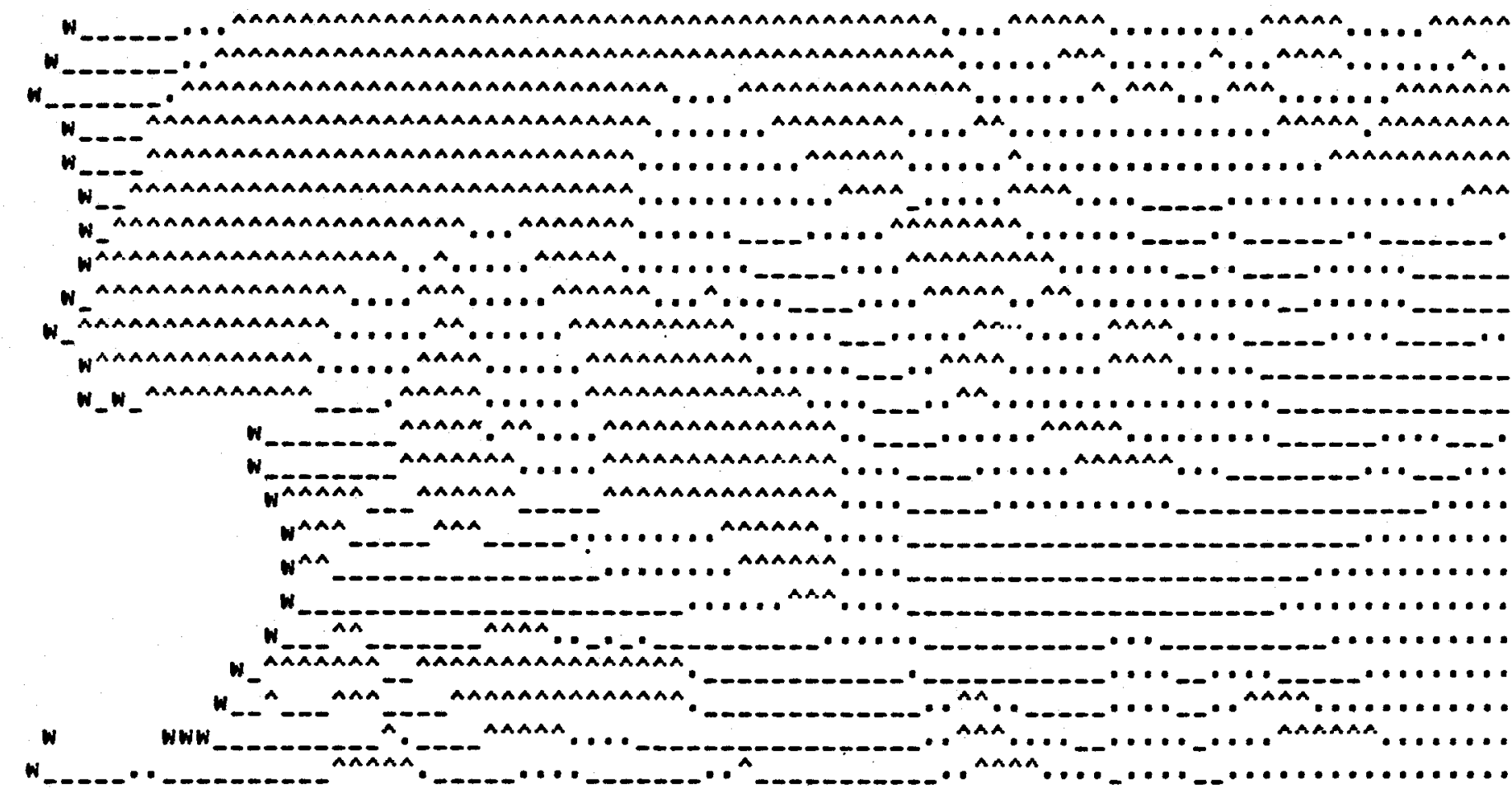

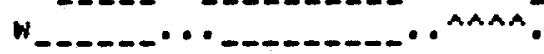

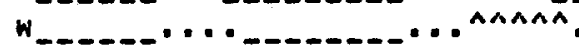

n

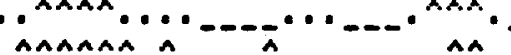

\section{SUEFALE FUMFAGE}

\section{W : Colorado River}

- : 50 to over $2,500 \mathrm{gpm}$

- 10 to $180 \mathrm{gpa}$

A : to $10 \mathrm{gpm}$ or hard rock area 
Digital Map 7

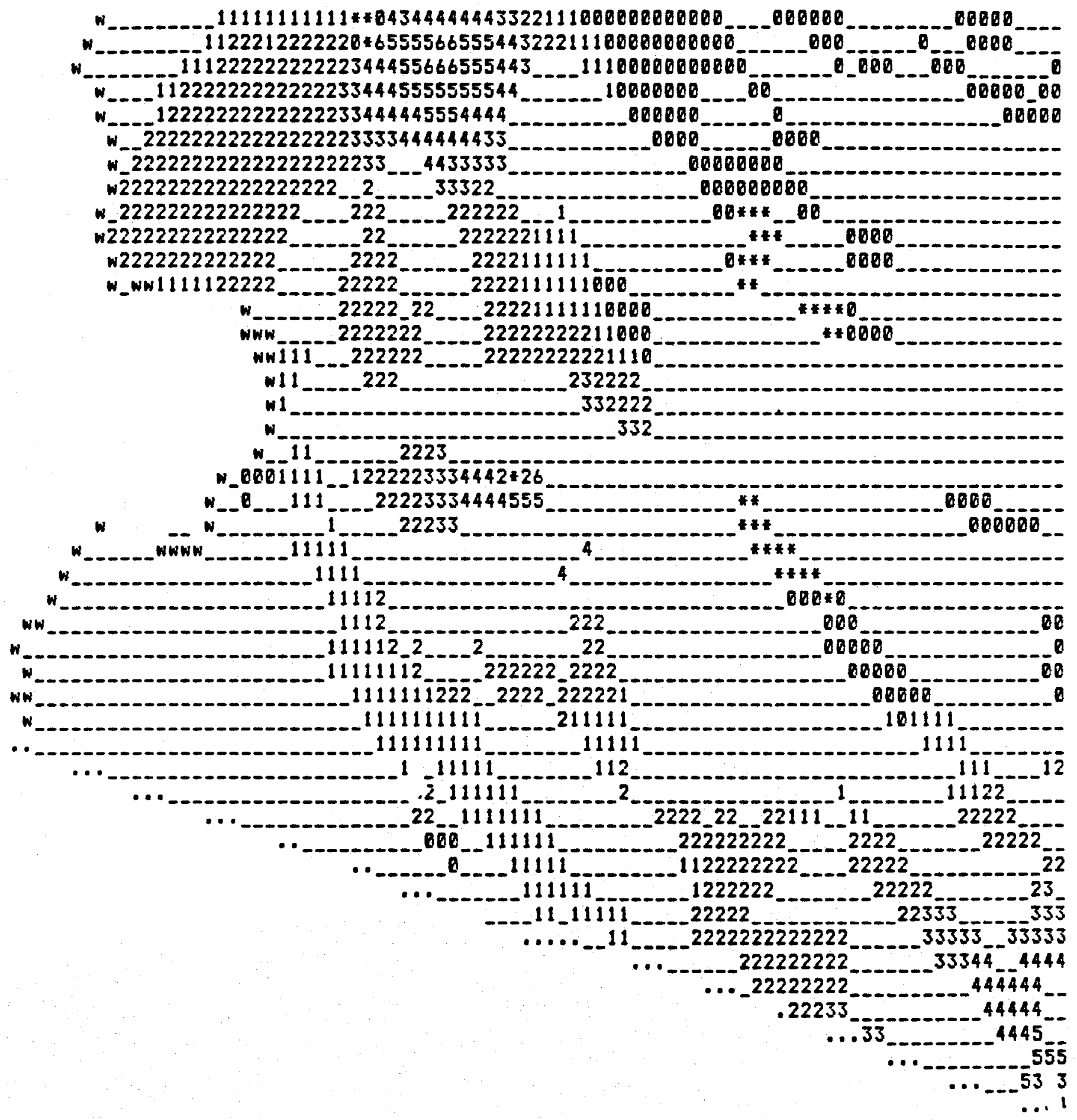

HOT DRY ROCK GRADIENTS IN DEGREES CELSIUS/KILOMETER

\begin{tabular}{|c|c|c|c|c|c|c|c|}
\hline & \multicolumn{2}{|r|}{ GRADJENT } & \multicolumn{2}{|c|}{ CODE } & \multicolumn{3}{|c|}{ GRADIENT } \\
\hline$*$ & : & 36 or Less & D & : & 36 & to & 41 \\
\hline 1 & $:$ & 41 to 45 & 2 & : & 45 & to & 49 \\
\hline 3 & : & 49 to 53 & 4 & $:$ & 53 & to & 58 \\
\hline 5 & : & 58 to 67 & 6 & : & 67 & or Gr & reater \\
\hline
\end{tabular}




\section{GEOTHERMAL RESOURCE EVALUATION OF THE YUMA AREA}

4. In the second pass, the values for points lying on lines between vertices, hence having two sets of containing grids, were calculated twice, once for each grid, then averaged.

Contour maps based on the digital 'hot' and 'cool' maps are shown as, respectively, figures 12 and 13 . The final, revised, temperature gradient map is shown as digital map 5 . Codes for this map are given in table 1.

4. Hot Impermeable Rock Evaluation.

As stated above, we used the surface Pumpage map to distinguish potential Hot Impermeable Rock sites from Potential Convective Hydrothermal sites, as shown on digital map 6. This map is based on a USGS 1981 water resources map for Arizona, [USGS water Resources, $1981 \mathrm{~J}$. The 'hot', then later the final, thermal gradient maps were then used to calculate thermal gradients for the potential hot impermeable rock sites. The results using the final map are shown as digital map 7. In chapter 5 we shall discuss the economic implications of the different thermal gradients. However, it takes no further calculation to see that the preferred sites, based on thermal gradient contouring, are the North Castle Dome Mountains, the Southern Sierra Finta Mountains and Red Bluff Mountain in the Muggins Mountains, in that order. There was little difference between the 'hot' map and the final thermal gradient map in this regard. Since we have no data regarding thermal gradients or heat flow in the neighborhood of Cerro Colorado, it is possible that there is only one general area of interest for hot impermeable rock exploitation: the mountainous areas surrounding Castle Dome Plain on Yuma Proving Grounds.

5. Depth to Bedrock and Isotherm Maps.

Dur depth to bedrock map is based on the gravity modeled depth to bedrock map of the Basin and Range Province of Arizona, [Oppenheimer \& Sumner, 1980], with depth corrections for the Gila Trough from the seismic mapping of Eberly and Stanley, [Eberly \& Stanley, 1978], and for the San Luis and Fortuna Basins from the geophysical studies of the Yuma area by Mattick, and others, [Mattick, et al, 1973]. The rule of assigning values to pixels in cases of conflict was to favor the deeper value.

Isotherm maps were obtained from a program in which the desired temperature, $T$, in degrees Celsius, was entered and then the following algorithm employed for each point on the map:

1. If the point was not in the study area, or in a low pumpage area, no calculation was made, the location was coded as a blank, " ", if not in the study area, a "a" in a bedrock area, or a "-" if in a low pumpage basin area, and the program moved on. 


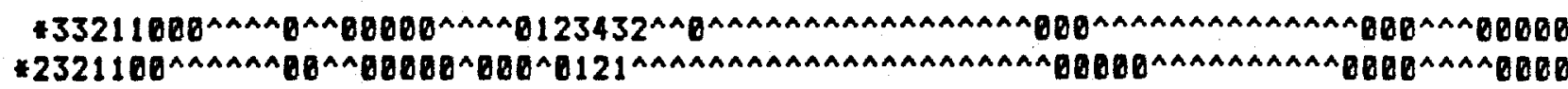

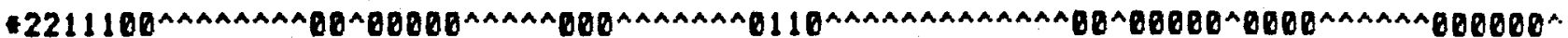

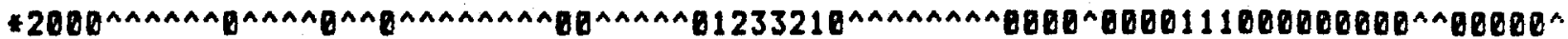

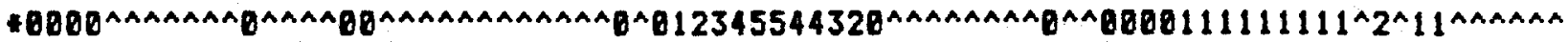

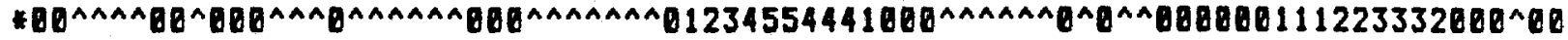

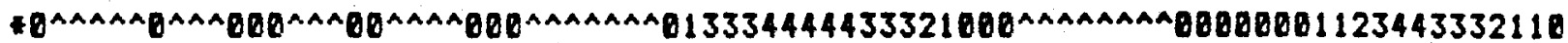

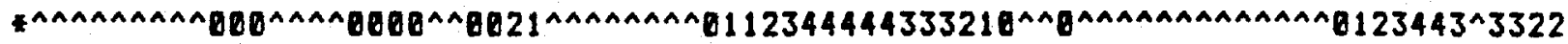

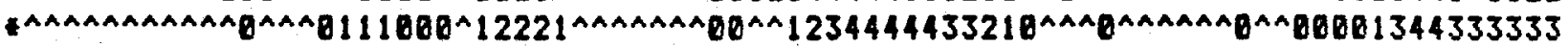

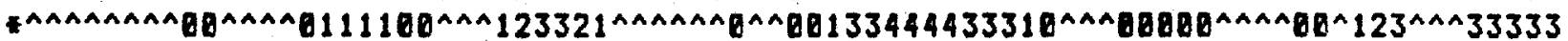

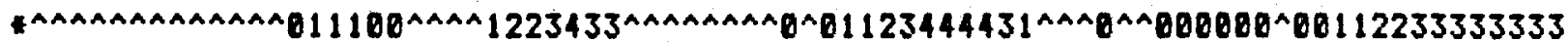

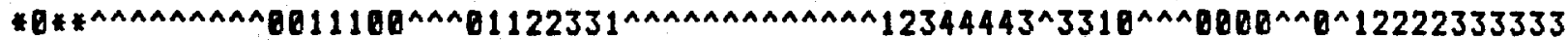

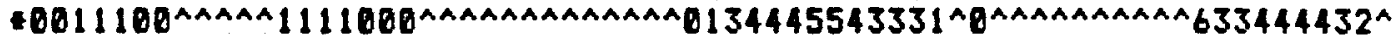

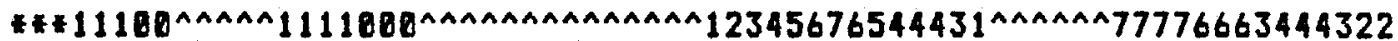

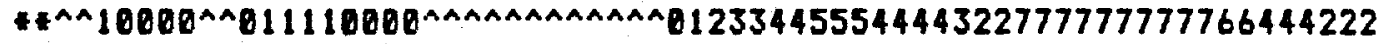

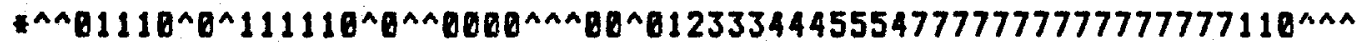

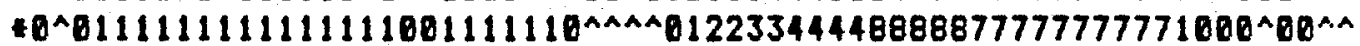
*60^11111100111111111222221108^0112255667788888877777732100^000080

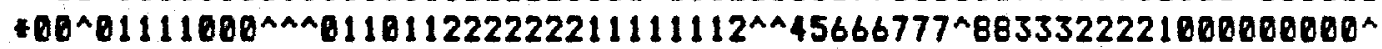

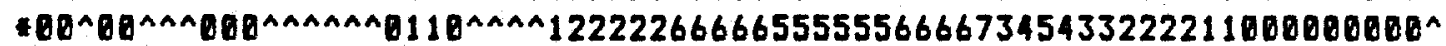

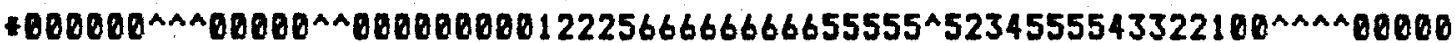

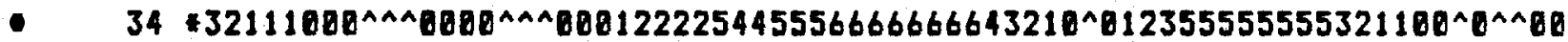

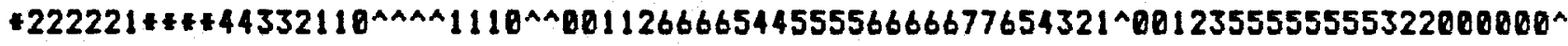

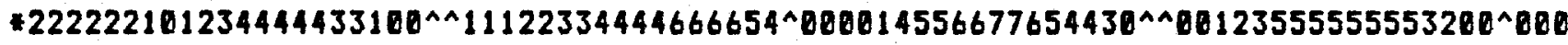

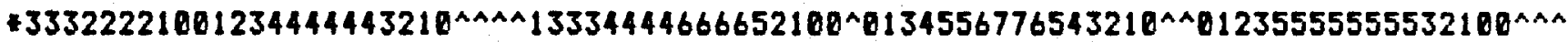

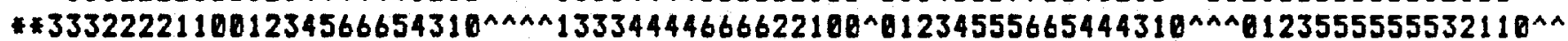

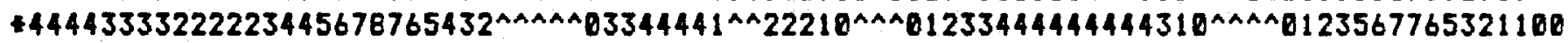

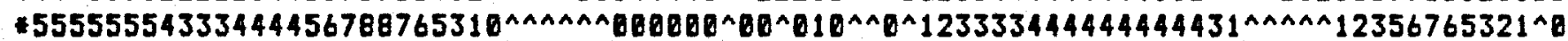

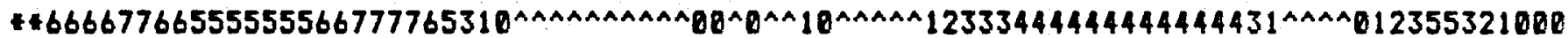

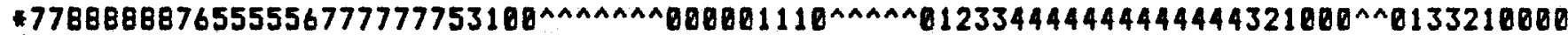

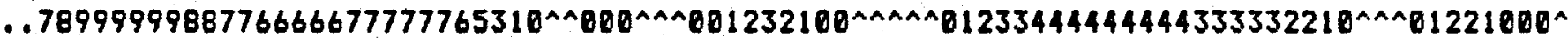

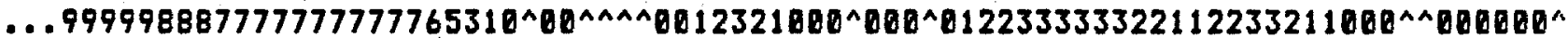

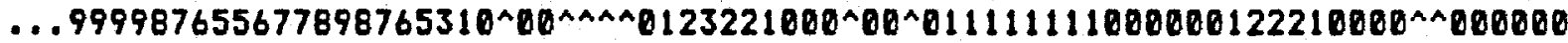

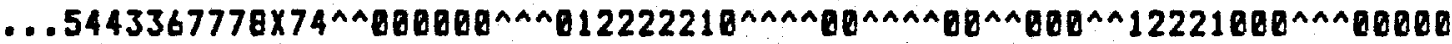

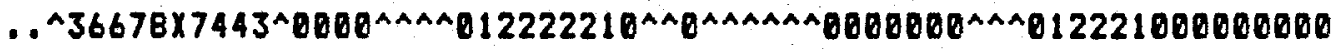

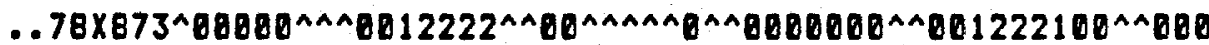

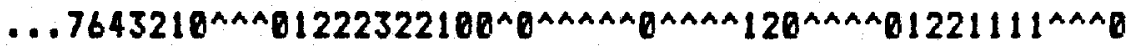

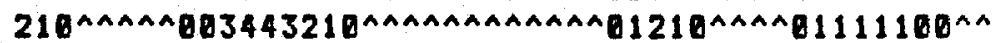

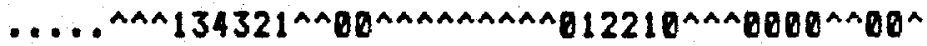

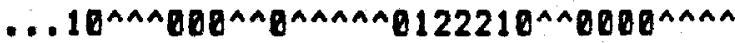

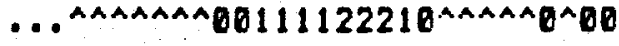

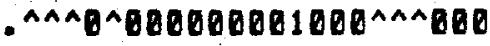
-.. bagogaAaAaboarbog

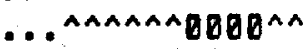
$\cdots \cap 000^{A} B^{A}$ $\ldots \wedge$

DEPTH TO BEDROCK MAP OF THE STUDY AREA

- Colorado River

A Bedrock at Surface

D to $0.125 \mathrm{~km}$.

$1: 0.125$ to $0.25 \mathrm{~km}$.

$2: 0.25$ to $0.5 \mathrm{~km}$.

$3: 0.5$ to $1.8 \mathrm{~km}$.

$4: 1.0$ to $1.5 \mathrm{~km}$.
+ Border with Mexico

$5: 1.5$ to $2.0 \mathrm{~km}$.

$6: 2.0$ to $2.5 \mathrm{~km}$.

$7: 2.5$ to $3.0 \mathrm{~km}$.

B : 3.0 to $3.5 \mathrm{~km}$.

$9: 3.5$ to $4.0 \mathrm{~km}$.

$x=4.0$ to $5.0 \mathrm{~km}$. 


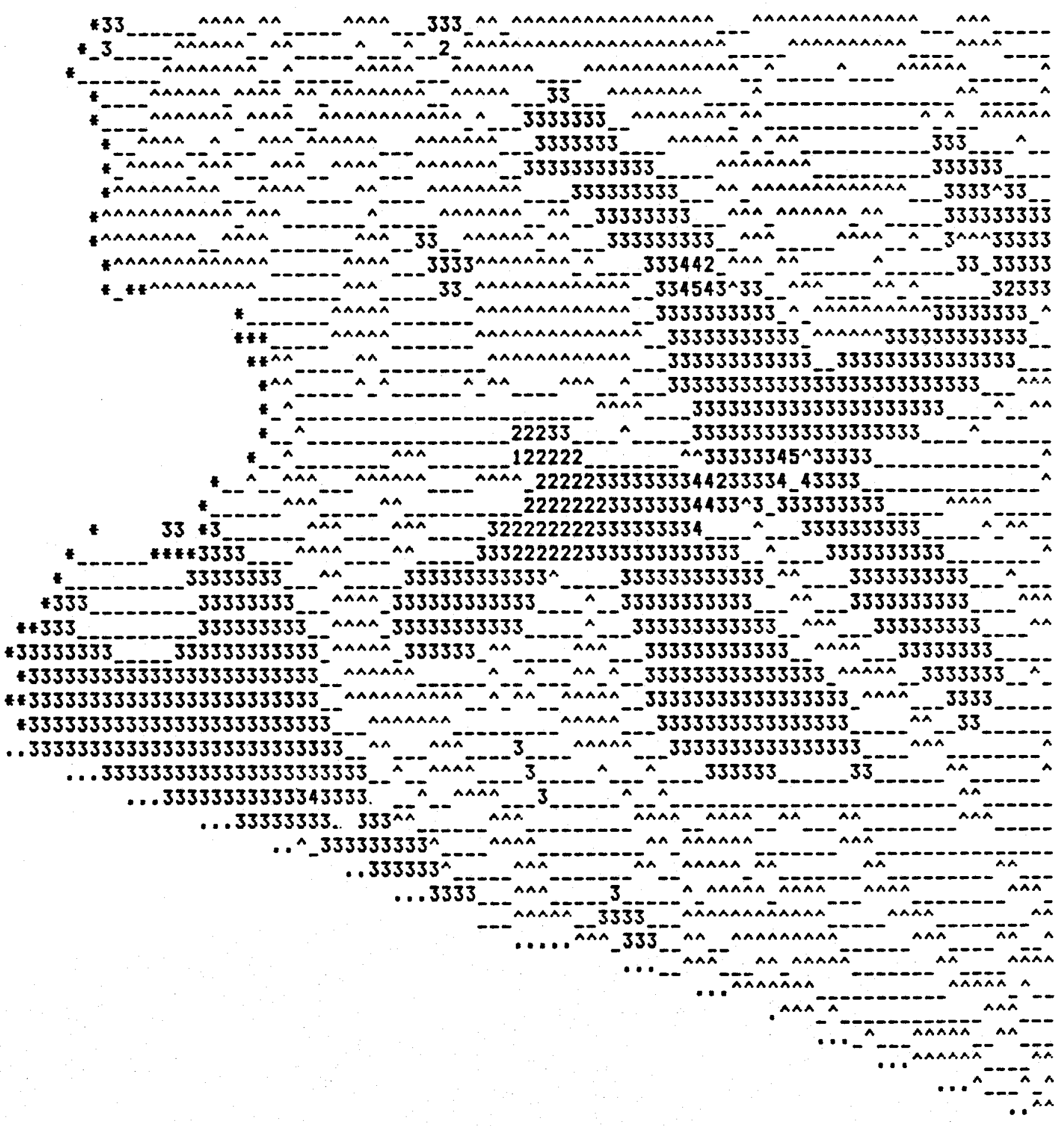

50 DEGREE CELSIUS ISOTHERM LEVELS

* Colorado River

A Bedrock at Surface.

- Border with Mexico

- 50 Degree Isother fron to $0.125 \mathrm{~km}$.

1 : 50 Degree Isotherm fron 0.125 to $0.25 \mathrm{~km}$.

2 : 50 Degree 150 ther from 0.25 to $0.5 \mathrm{~km}$.

3 : 50 Degree 1sothern fron 0.5 to $1.0 \mathrm{~km}$.

4 : 50 Degree Isother fron 1.0 to $1.5 \mathrm{~km}$.

5 : 50 Degree Isothern fron 1.5 to $2.0 \mathrm{~km}$. 


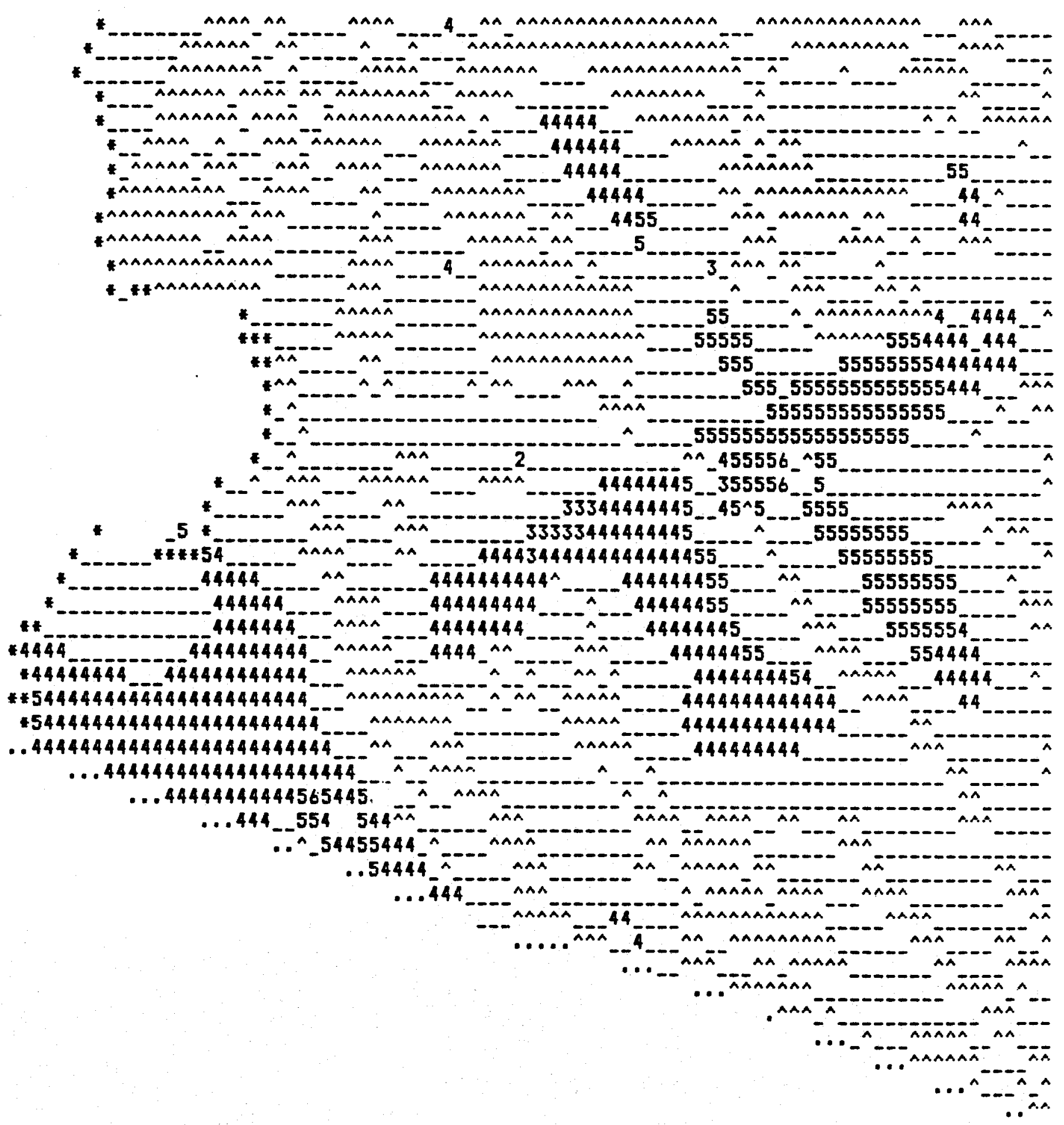

80 DEGREE CELSIUS ISOTHERM LEVELS

- Colorado River

A Bedrock at Surface.

1 : 80 Degree Isotherm fron $0 . \overline{1} 25$ to $0.25 \mathrm{~km}$.

2 : Degree Isothern fron 0.25 to $0.5 \mathrm{~km}$.

3 : ED Degree Isotherm fron 0.5 to $1.0 \mathrm{~km}$.

4 : 80 Degree Isotherm from 1.0 to $1.5 \mathrm{~km}$.

5 : 80 Degree isotherm fron 1.5 to $2.0 \mathrm{ka}$.

6 : 80 Degree Isotherm fron 2.8 to $2.5 \mathrm{~km}$. 


\section{Digital Map 11}

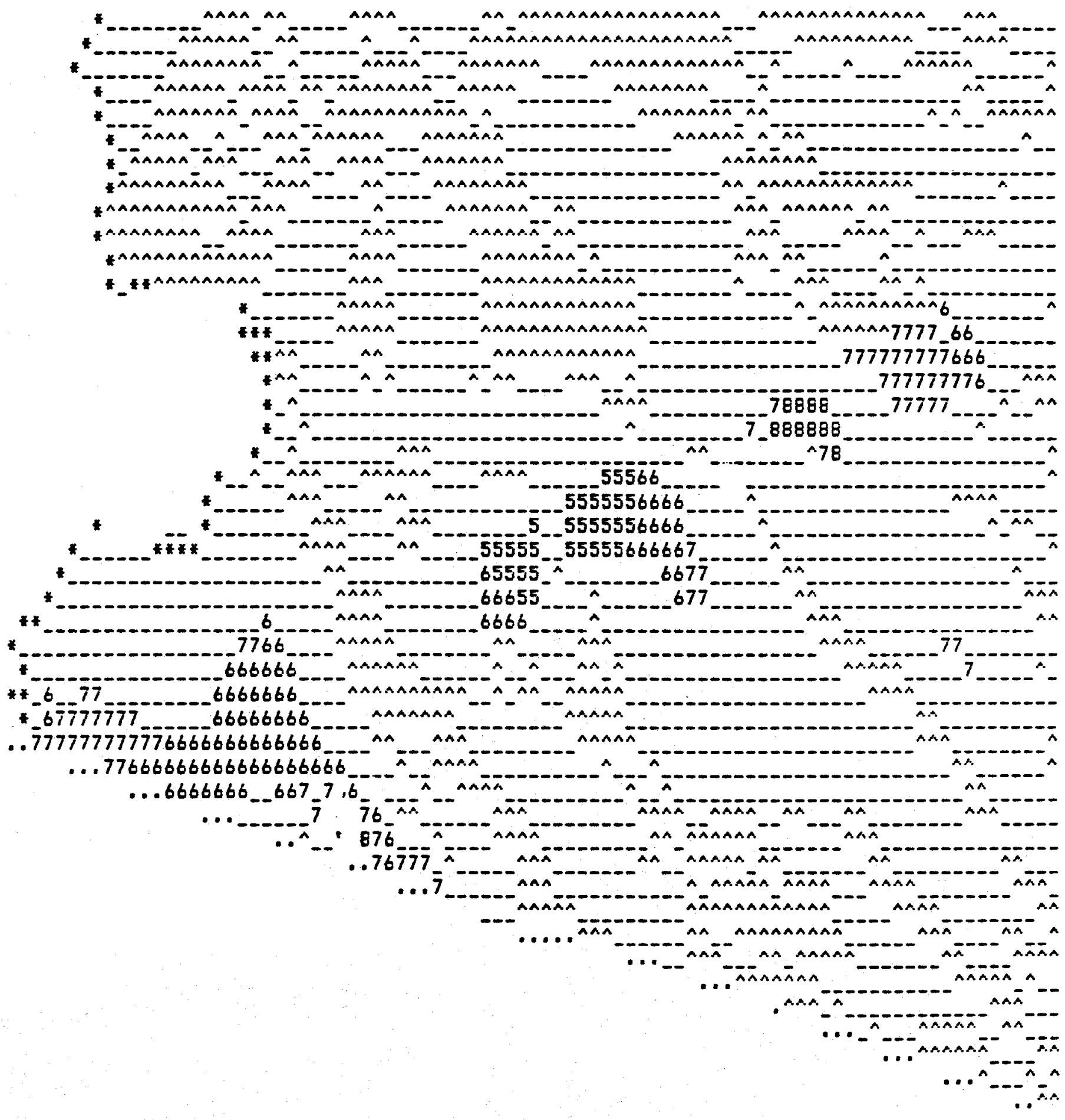

\section{DEGREE CELSIUS ISOTHERM LEVELS}

* Colorado fiver

$\therefore$ : Bedrock at Surface. - 125 Degree Isothere Eelow Bedrock Leve:

3 : 125 Degree Isotherm from 0.5 to $1.0 \mathrm{~km}$.

4 : 125 Degree Isotherm from 1.0 to $1.5 \mathrm{~km}$.

5 : 125 Degree Isothera from 1.5 to $2.0 \mathrm{~km}$.

6 : 125 Degree Isotherm from 2.0 to $2.5 \mathrm{~km}$.

7 : 125 Degree 150 therm from 2.5 to $3.0 \mathrm{~km}$.

8 : 125 Degree isotherm from 3.8 to $3.5 \mathrm{~km}$. 


\section{Digital Map 12}

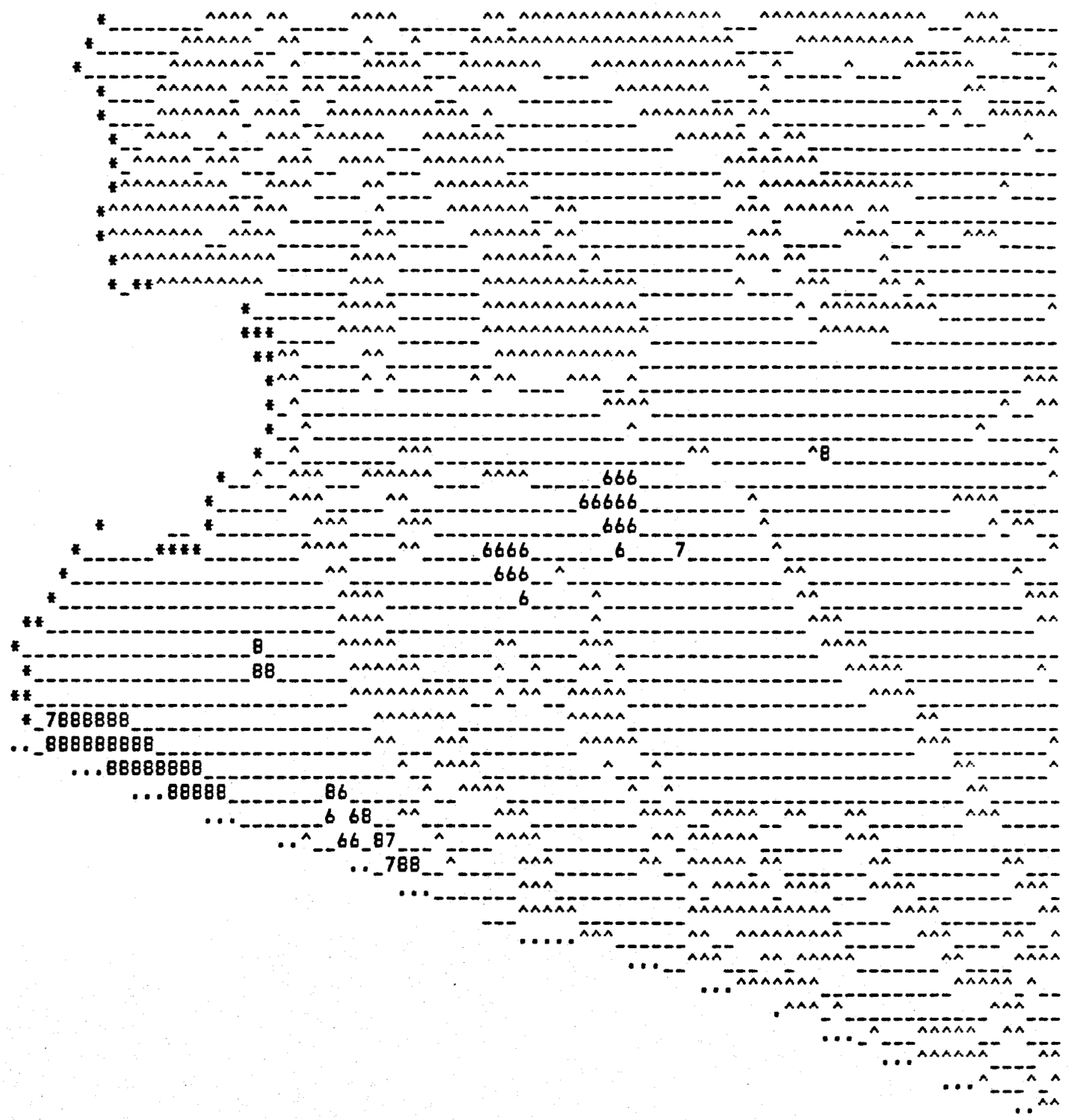

\section{DEGREE CELSIUS ISOTHERM LEVELS}

* Colorado River

A Bedrock at Surface.

- Border with Mexico

4: 150 Degree Isotherm from 1.0 to $1.5 \mathrm{~km}$.

5 : 150 Degree Isothern fron 1.5 to $2.0 \mathrm{~km}$.

6 : 150 Degree Isother from 2.0 to $2.5 \mathrm{~km}$.

7 : 150 Degree Isothern from 2.5 to $3.0 \mathrm{~km}$.

8 : 150 Degree Isothera from 3.0 to $3.5 \mathrm{~km}$.

$9: 150$ Degree Isothern from 0.5 to $1.0 \mathrm{~km}$. 
Digital Map 13.1

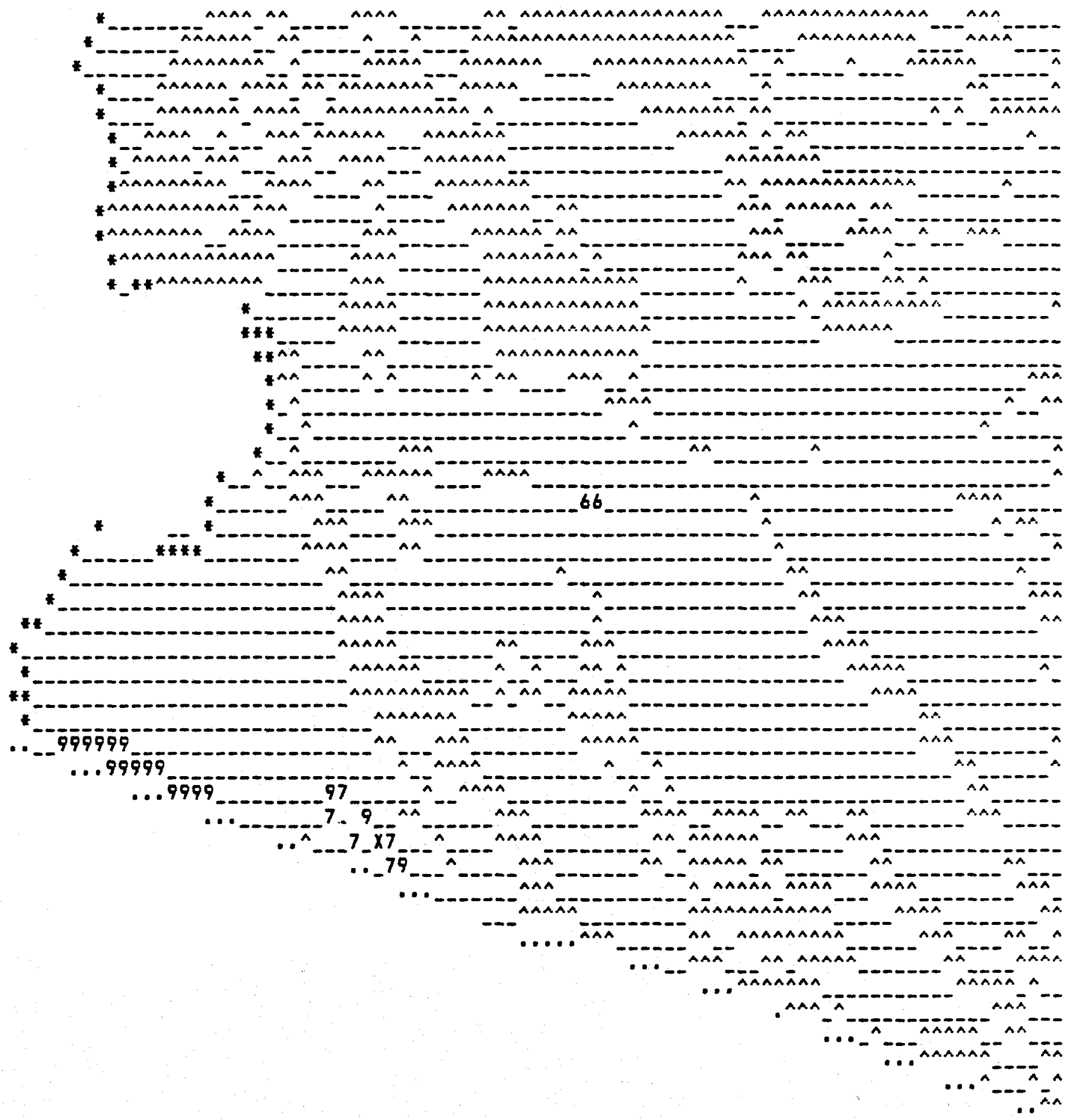

170 DEGREE CELSIUS ISOTHERM LEVELS

* Colorado River

- Bedrock at Surface.

$4: 170$ Degree Isothera from 1.0 to $1.5 \mathrm{~km}$.

5 : 170 Degree Isotherm fron 1.5 to $2.0 \mathrm{~km}$.

6: 170 Degree Isotherm from 2.0 to $2.5 \mathrm{~km}$.

7 : 170 Degree Isotherm from 2.5 to $3.0 \mathrm{~km}$.

8: 170 Degree Isotherm from 3.0 to $3.5 \mathrm{~km}$.

9 : 170 Degree Isothera from 3.5 to $4.0 \mathrm{ka}$.

$x$ : 170 Degree Isothern fron 4.0 to $5.0 \mathrm{~km}$.
- Border with Hexico

fee Isothera Below Bedrock Level 


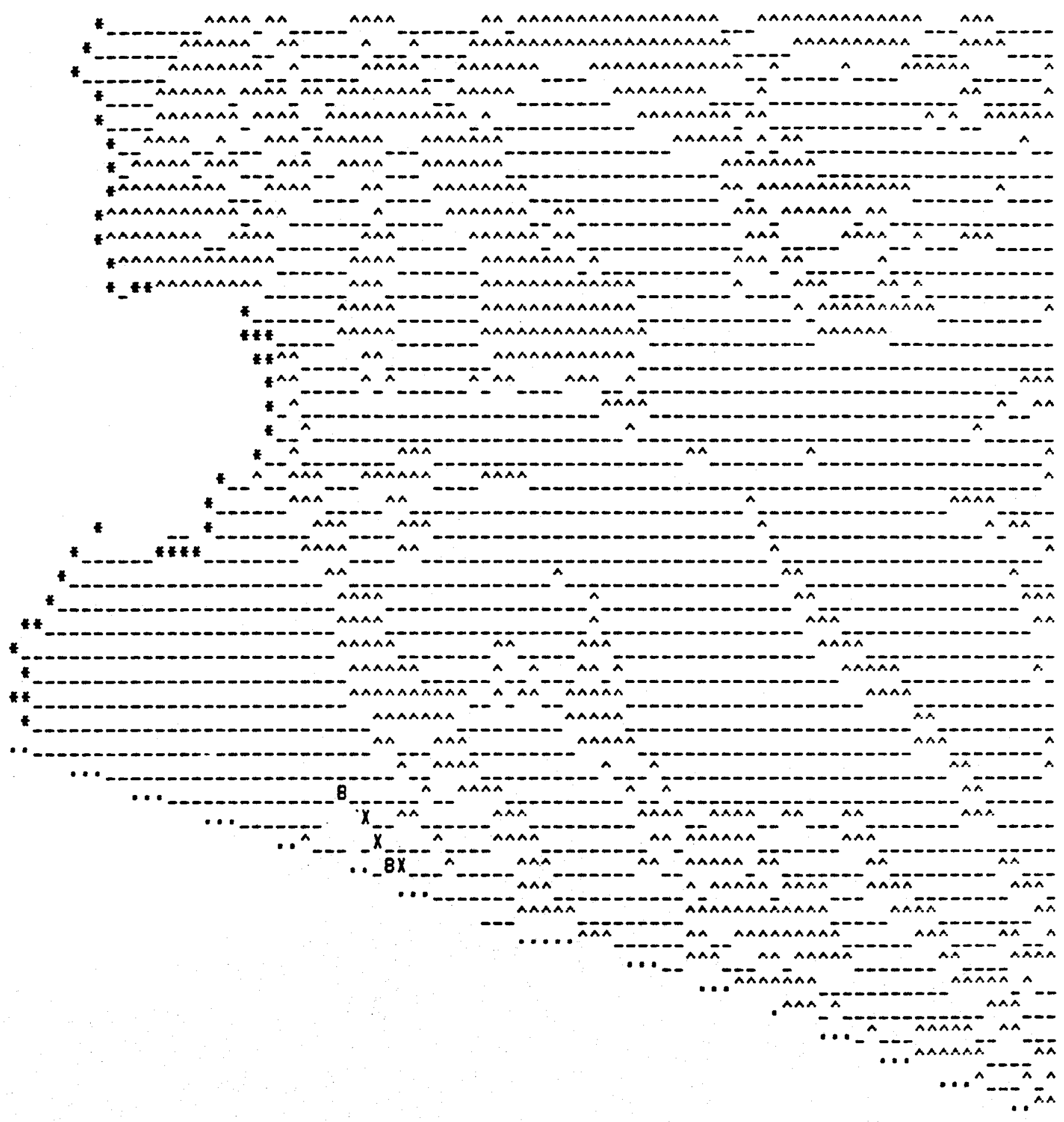

\section{DEGREE CELSIUS ISOTHERM LEVELS}

* Colorado River

A Bedrock at Surface.

4 : 190 Degree Isother

5 : 190 Degree Isothern fron 1.5 to $2.0 \mathrm{~km}$.

$6: 190$ Degree Isotherm from 2.0 to $2.5 \mathrm{~km}$.

7 : 190 Degree Isotherm from 2.5 to $3.0 \mathrm{~km}$.

B : 190 Degree Iscthera from 3.0 to $3.5 \mathrm{~km}$.

9 : 190 Degree Isotherm from 3.5 to $4.0 \mathrm{kn}$.

$X: 190$ Degree Isotherm from 4.0 to $5.0 \mathrm{~km}$.

- Border with Mexico

- 190 Degree Isotherm Below Bedrock Level 


\section{GEOTHERMAL RESOURCE EVALUATION OF THE YUMA AREA}

2. In other cases the estimated depth, $z$, to reach that temperature was calculated, using the equation $z=T / r$, where $r$, the estimated thermal gradient at that point was obtained from the

3. The value, $z$, obtained in the previous step, was compared to the depth to bedrock value, d, obtained for that location from the depth to bedrock map. If $d \leq z$ then the location received the "-" code. Dtherwise, if $d>z$, it received the coded value for $d$ from the Depth to Bedrock map.

We have shown the Depth to Bedrock and the Isotherm maps for the $50,80,125,150,170$ and 190 degree Celsius levels as digital maps $8,9,10,11,12,13.1$ and 13.2 , respectively. A clear conclusion of digital maps 13.1 and 13.2 is that there is no area, other than the Fortuna Plain, which offers any prospect for geothermal resources above 170 degrees Celsius. The 170 oc isotherm map shows the Gila Trough near Radium Hot Springs and the San Luis Easin as poseibilities, but with little margin for error. Both of these latter sites have the 170 oc isotherms just above the bedrock level. The lower temperature isotherm maps al so show the Gila Trough from the southeast flank of the Muggins Mountains to the Mohawk Mountains as the preferred basin area for low to moderate temperature $(50-150$ oc) geothermal resources.

6. Depths to Various Units.

Depth to the top of the Bouse formation, with a range of thicknesses as a function of depth, may be found in the works of Qlmsted, and Mattick, and others, [olmsted, et al, 1973], [Mattick, et al, 1973]. Also, the paper by Eberly and Stanley shows the depth to Unit I in the Gila Trough. Thus we mapped the top of the Bouse directly from a map provided by Mattick, and others, and used a graphical linear regression to estimate the depth to the bottom of the Bouse Formation. A similar method was also used to estimate depths to the bottom of the Marine Wedge Formation, which coincides with the top of Unit I in the Yuma area. Both of these graphical estimates were based on a set of cross sections of the Yuma area due to $01 \mathrm{msted}$, and others, (Flate No. 10, [0lmsted, et a1, 1973]). This could be misconstrued to imply that the Marine Wedge Formation is clearly divided from the older sediments. This is not always the case, as was found by olmsted and others, [olmsted, et al, 1973]. However, the regression still gives us an estimate of the depth at which the older (12 -13 million year old) sediments may be found. Simplified estimates were used for the purposes of mapping as follows:

Depth of Bottom of Bouse $=1.25 \times$ Depth of Top of Bouse, and Depth of Top of Unit I $=1.75 \times$ Depth of Top of Bouse. 


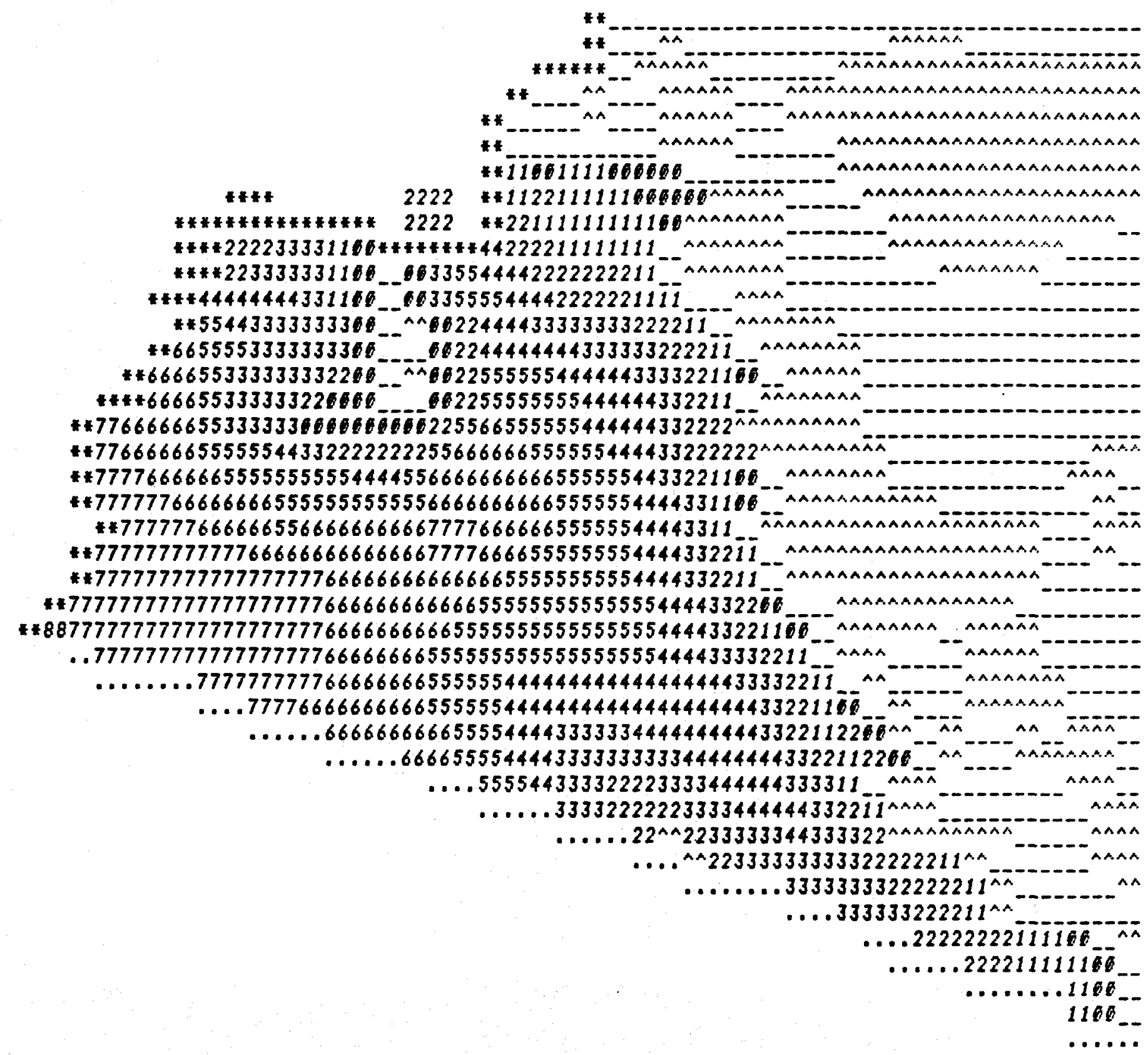

DEPTH TO TOP OF BQUSE FORMATION

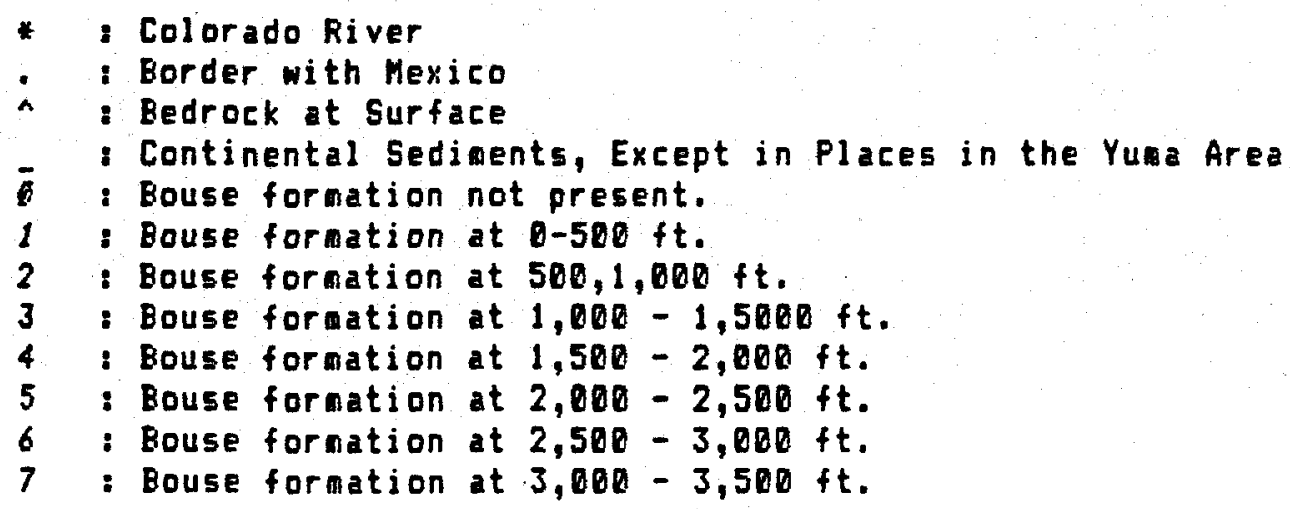




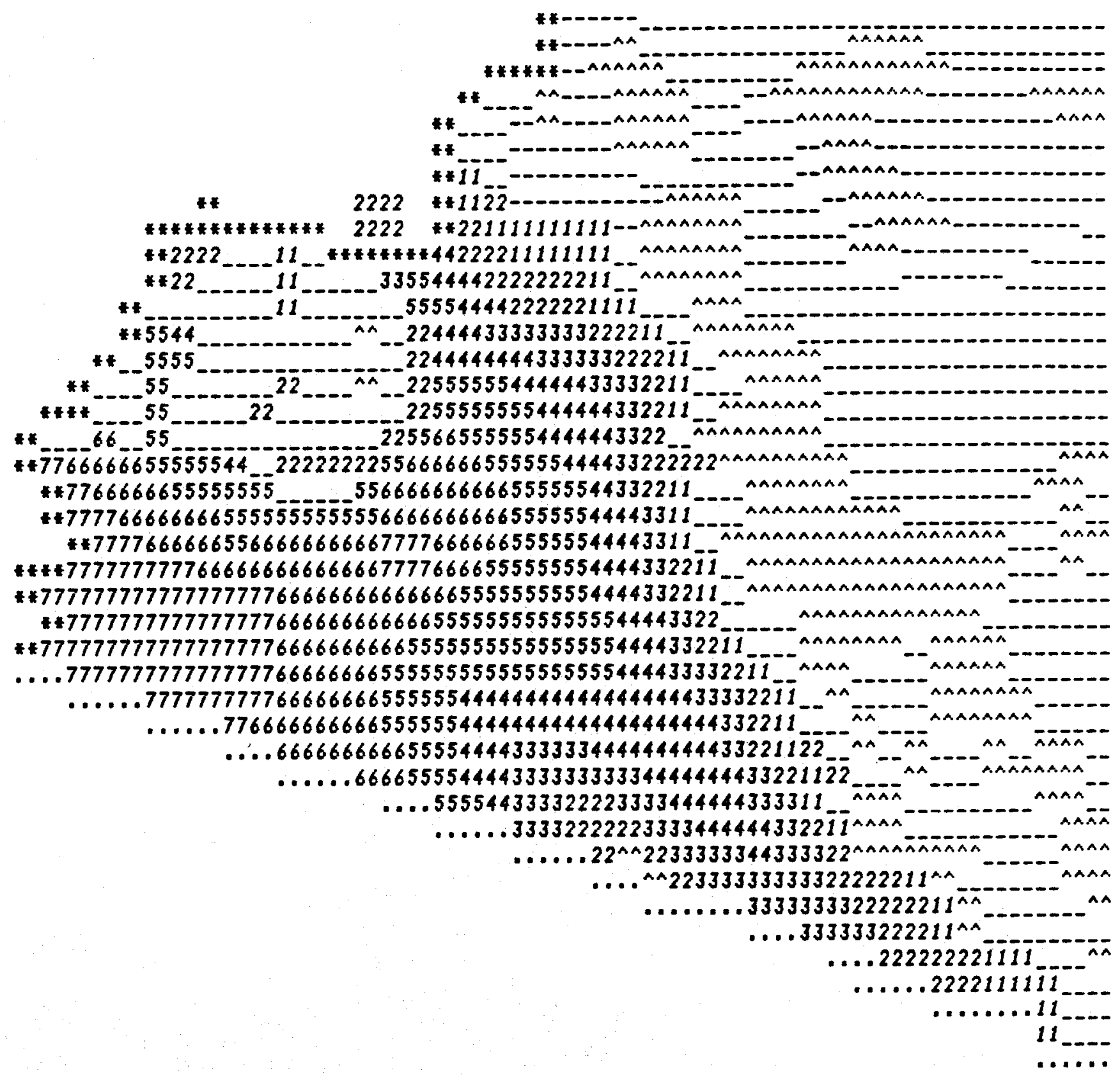

DEPTH TO THE TOP OF THE MARINE WEDGE FORMATION

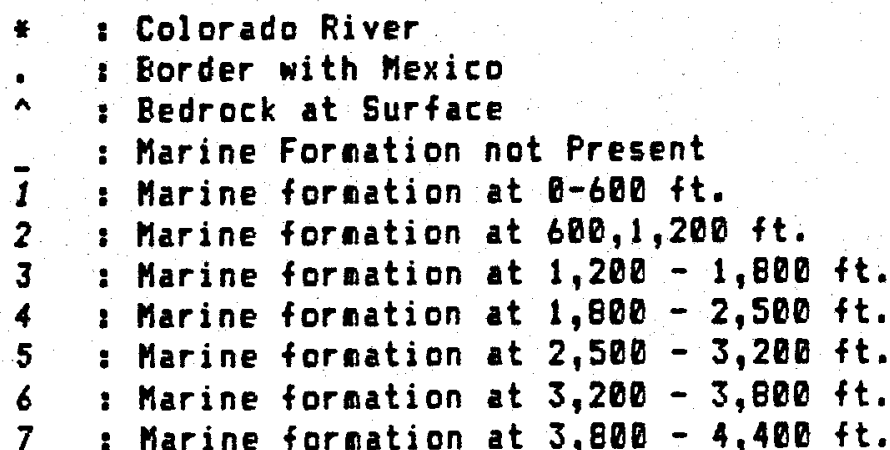




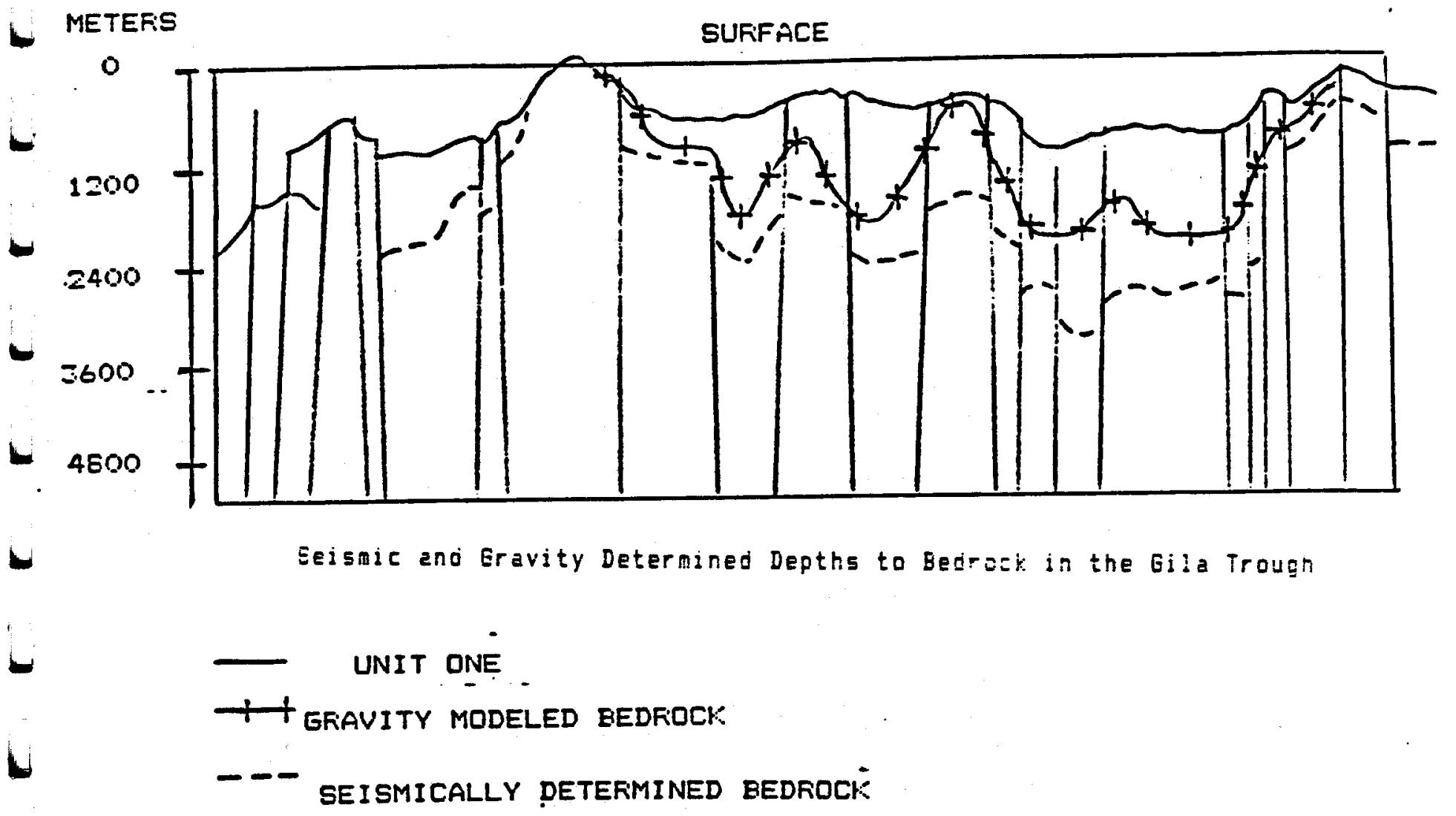




\section{GEDTHERMAL RESOURCE EVALUATION OF THE YUMA AREA}

The depth to the top of the Bouse Formation is shown on digital map 14. The depth to the top of the Marine Wedge formation, (the bottom of the Bouse), is shown as digital map 15. The depth to the top of Unit I combines the method discussed above for the Yuma area with the procedure which we now discuss for the rest of the study area.

Unit I in the Gila Trough was shown in figure 9, and is shown again in figure 14. Examination of the data reveals four clear groupings:

GROUP

1

2

3

4
DEPTH TO BEDROCK

$0 \quad-400$ meters

$400-600$

$800-2,600$

$2,700-3,500$
DEPTH TO UNIT I

Unit I not present, $140-280$ meters,

$400-700$,

$800-1,100$.

Other than that, there is little correlation between the depth to bedrock and the depth to Unit I. This grouping has the property that it divides the depth intervals in a disjoint fashion which covers the entire domain and range of the sample points and that all sample points are within the prescribed intervals. The means are also close to the interval midpoints: the mean depths to Unit $I$ for groups 2,3 and 4 are, respectively, 210,510 and 930 meters. However, in order to conform to the depth to bedrock intervals used in previous coding, we use 5 groups, as follows.

$\begin{array}{cc}\text { GROUP CODE } & \text { DEPTH TO BEDROCK } \\ 0 & 0-125 \text { meters } \\ 1 & 125-500 \\ 2 & 500-1,000 \\ 3 & 1,000-2,500 \\ 4 & 2,500-3,500\end{array}$

DEPTH TO UNIT I

This grouping has all of the properties of the first grouping, except that group means for depth to Unit I are not as close to group medians. 


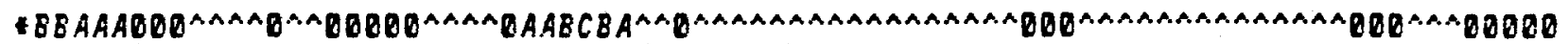

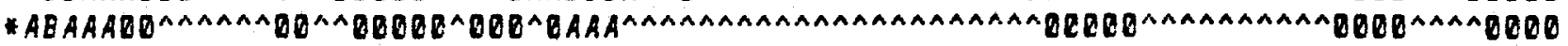

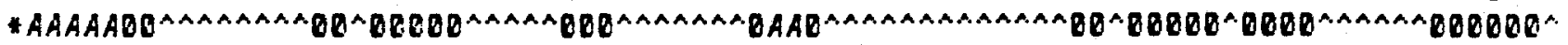

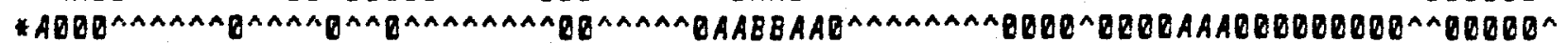

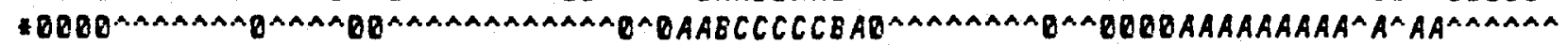

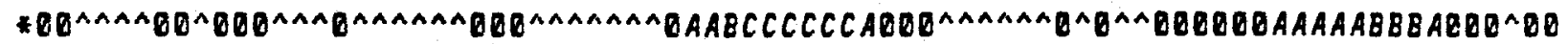

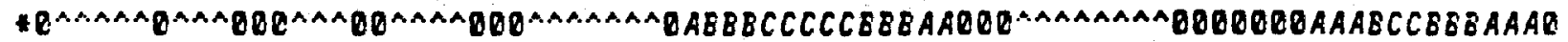

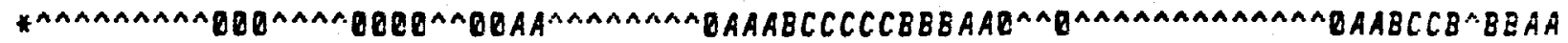

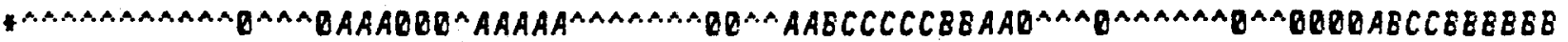

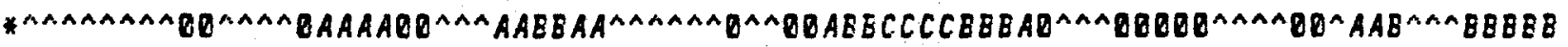

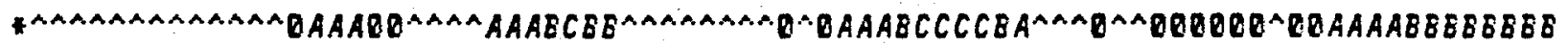

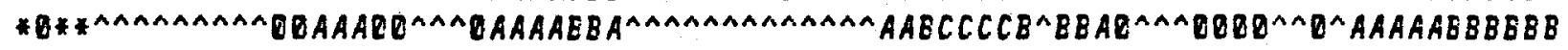
- DQAAABQ

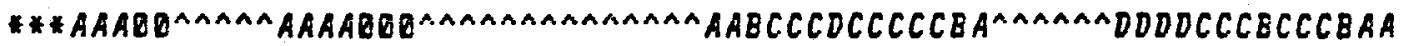

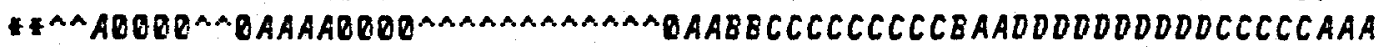

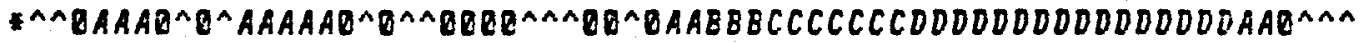

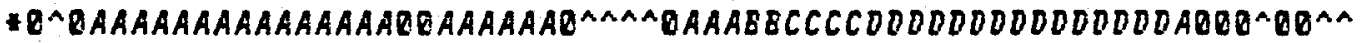

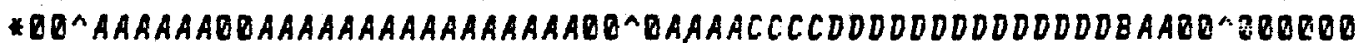

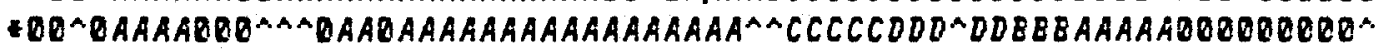

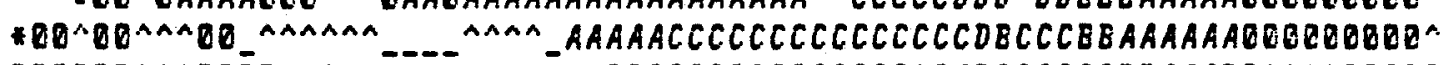

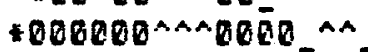

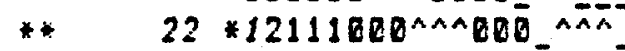
CCCCCCCCCCCCCCC ${ }^{A} A B C C C C C C B B A A A B D^{A A A A Q B D O O}$

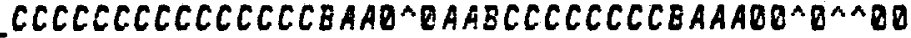

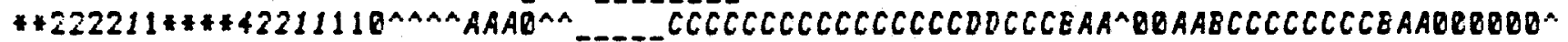

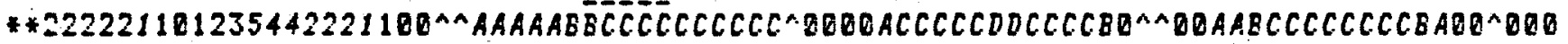

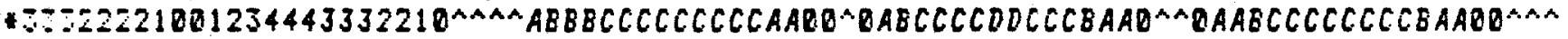

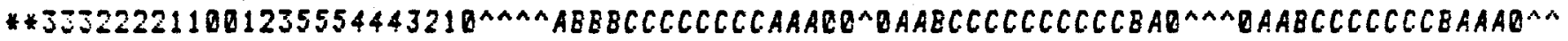

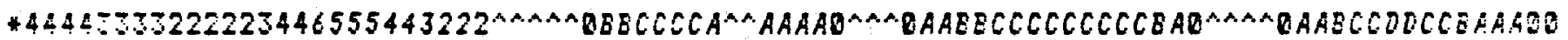

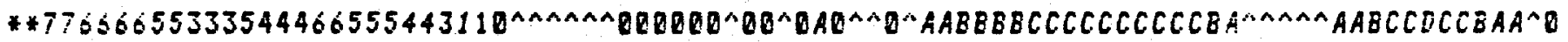

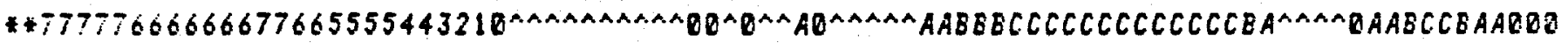

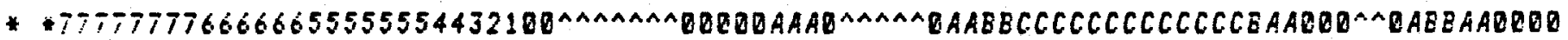

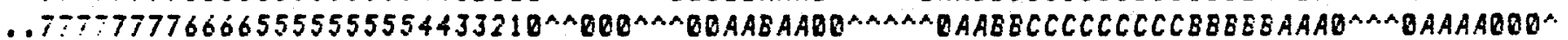

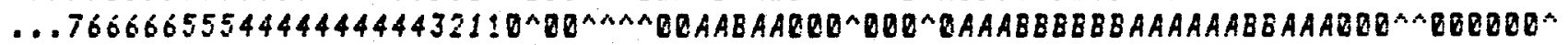

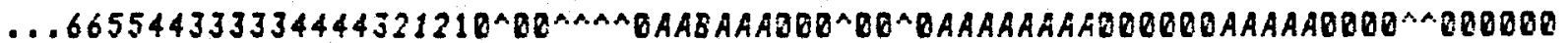

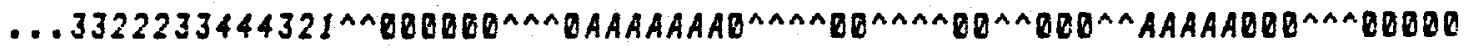

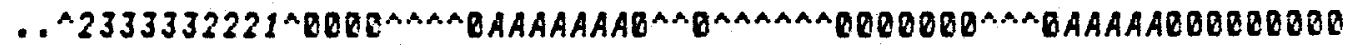

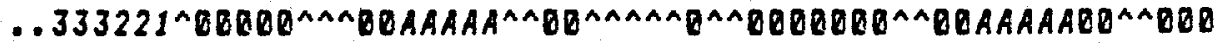

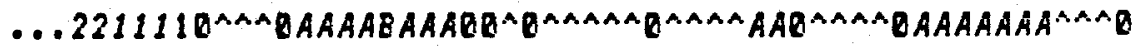

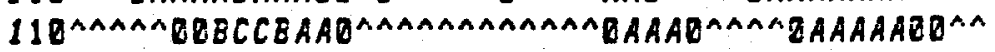

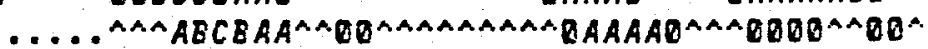

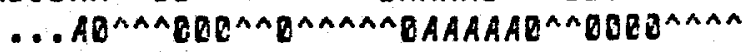

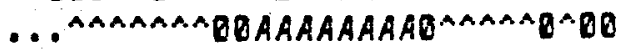

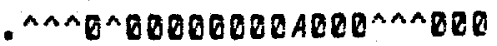

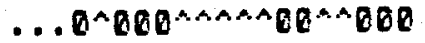

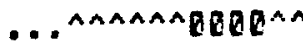
- . A $\ldots \wedge$ A

DEFTH OF INIT 2 IN THE STUDY AREA

* : : ierado siver

$\therefore$ : Eszrocli at Surface $x=0,1$ : Unit I not Present: Eedrock a $4 \overline{0} 0 * i x+1) \mathrm{ft}$. $x=2$ to 9: Unit I not Present: Bedrock at $1600 *(x-1) \mathrm{ft}$. $x=1$ : 7 : Unit I at $x * 900 \mathrm{ft}$. .

A : Unit I at $-400 \mathrm{ft}$.

E: Uijt 1 at $400-1300 \mathrm{ft}$.

$c$ : Unit I at $1300-2300 \mathrm{ft}$.

$D$ : Unit I at $2300-3600 \mathrm{ft}$.
- Border with Mexico

- Unit l at Surface 


\section{GEOTHERMAL RESOURCE EVALUATION OF THE YUMA AREA}

TABLE 2

\section{RECDVERABLE WATER}

TYPE

Continental Sediments

oider Continental Sediments

Volcanic Rocks
POROSITY

$20 \%$

$10 \%$

$5 \%$

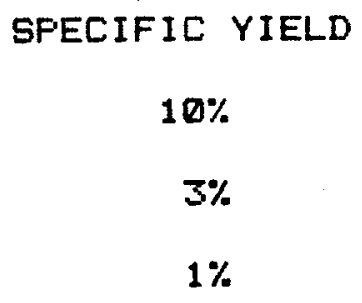

$1 \%$

$$
\text { HYDER VALLEY - FALDMAS PLAIN }
$$

TYF'E

Continental Sediments

Older Continental Sediments

Volcanic Rock
WATEF IN STOFAGE

$32,600 \mathrm{hm}=$

$17,000 \mathrm{hm}=$

$11,000 \mathrm{hm}=$
RECOUERAELE WATEF'

$15,200 \mathrm{hm}=$

$5,100 \mathrm{hm}^{3}$

$2,200 \mathrm{hm}=$ 


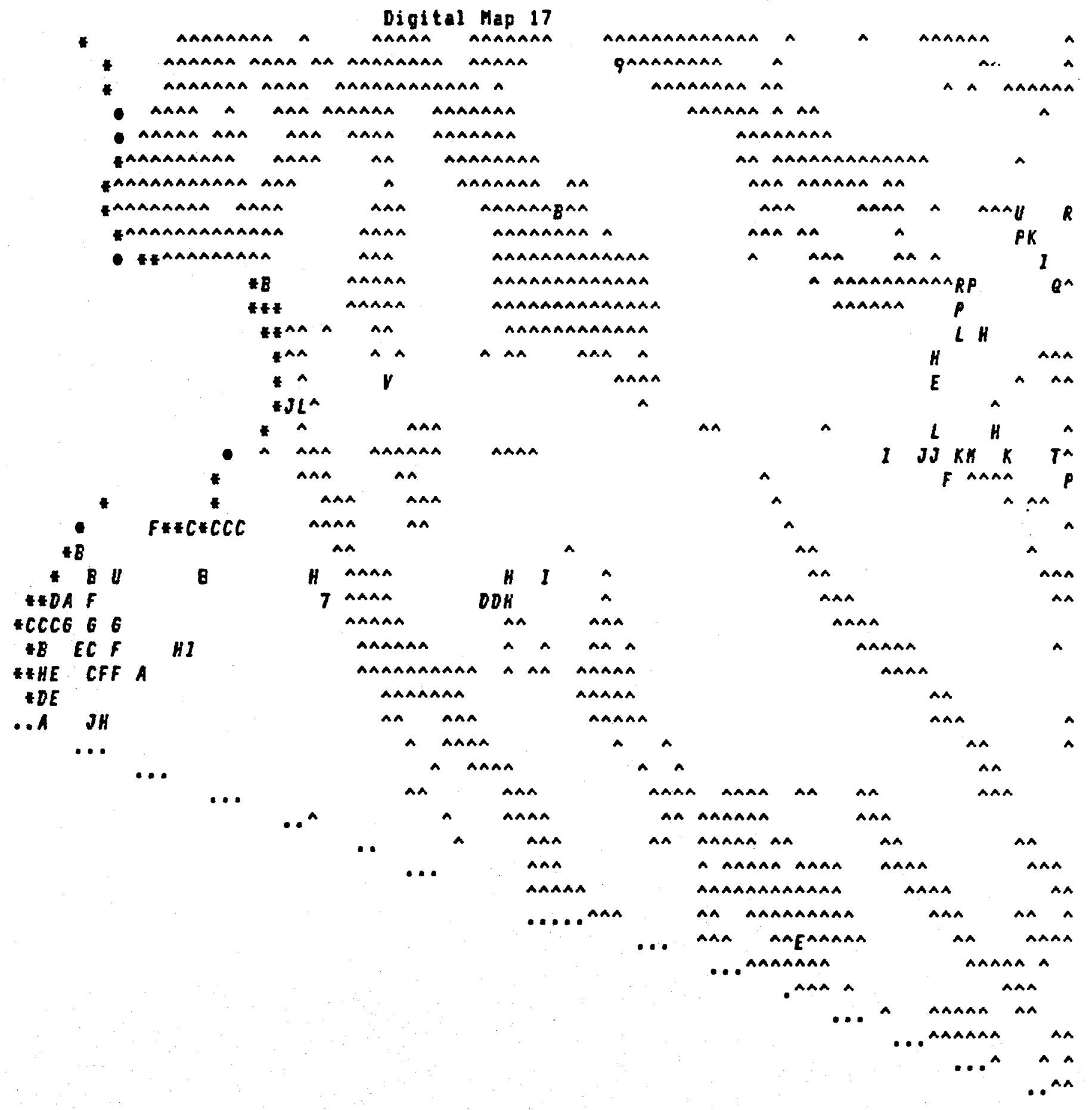

USES GROUND MATER TEMPERATURE DATA

* Colorado River - Border with Mexico

- Bedrock at Surface

TEMPERATURES, DEGREES $C$, AND CODES

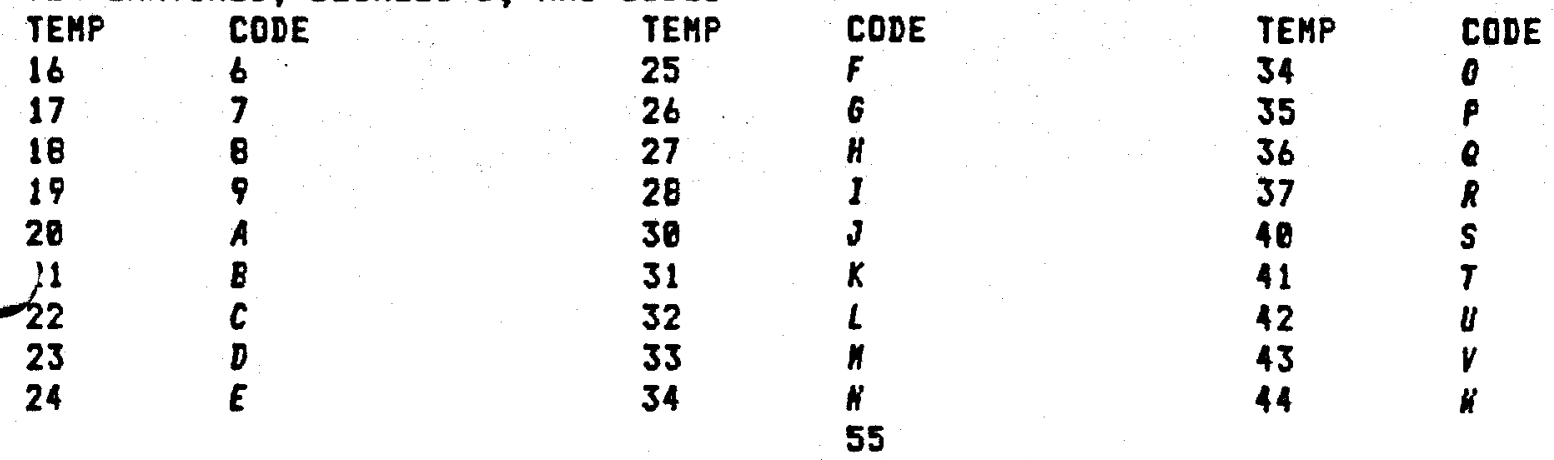




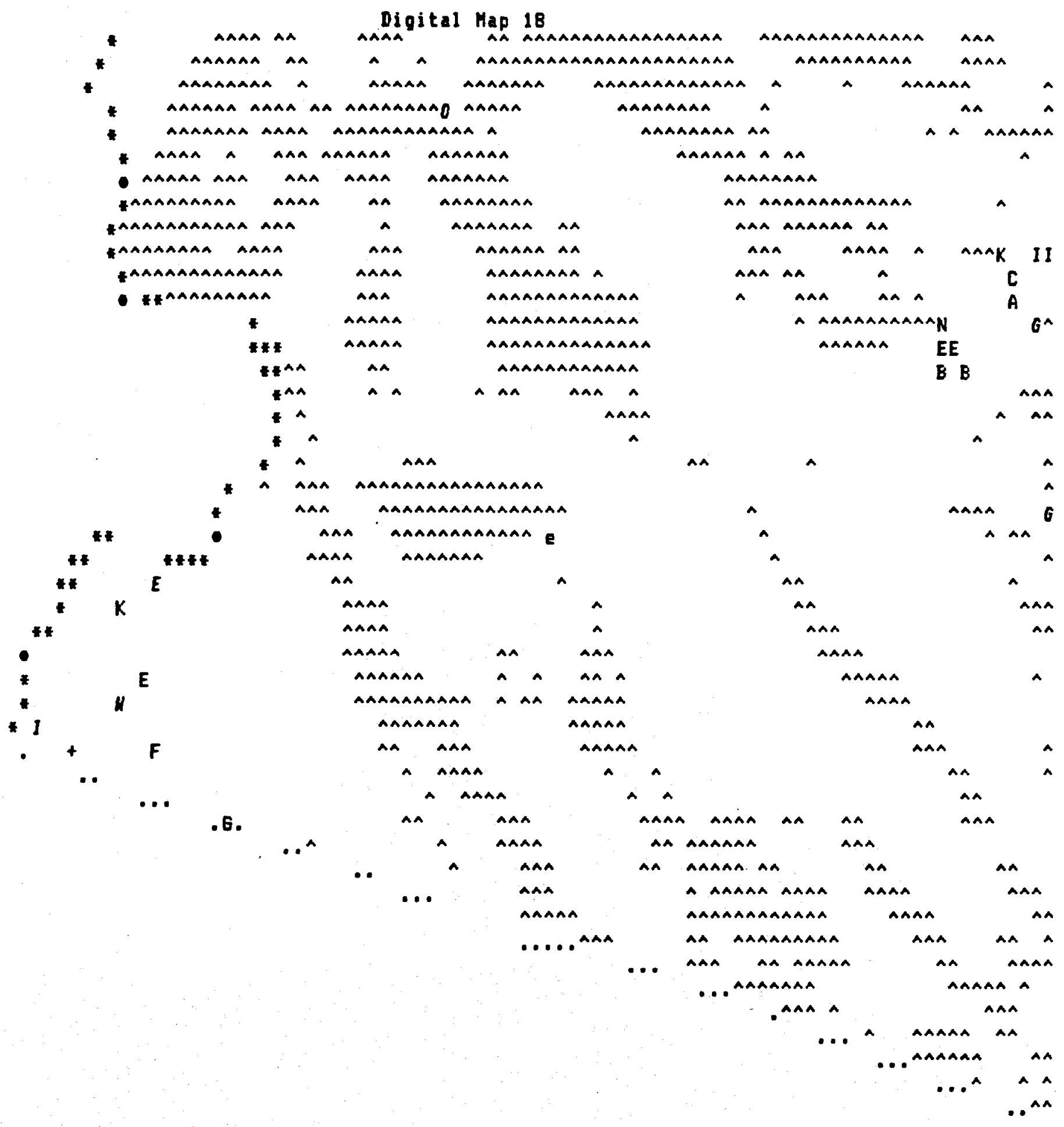

THERMAL WELL TEMPERATURE DATA BORDER FEATURES: : Colorado River

- Border with Mexico

A Bedrock at Surface

MELLS PENTRATINE UNIT I OR BOUSE

HELLS NOT PENETRATING UNIT I OR BDUSE

A to 2: 30 to $56 \mathrm{C}$

A to 2: 30 to 56 C

a to 2357 to 92 C

Deep Hell near San Luis: +

a to 2: 57 to $92 \mathrm{C}$ 


\section{GEDTHERMAL RESOURCE EVALUATION OF THE YUMA AREA}

The above groupings were used to code depth to Unit I outside of the Yuma area. It can only be regarded as a first crude approximation based on the questionable assumption that these groupings are valid outside of the Gila Trough. Furthermore, in areas outside of the Gila Trough the depth to bedrock estimates are highly questionable, as the values depend on residual Bouguer gravity modeling. Oppenheimer and Sumner give a precision of $+/-$ $30 \%$, to their depth estimates, [Oppenteimer \& Sumner, 1980], and, as was noted in the previous chapter, gravity values may be responsive to phenomena closer to the surface than the bedrock. A comparison of the Bouguer modeled and seismically determined depth to bedrock are shown in figure 14. Areas in which the gravity modeling of depth to bedrock are particularly suspect are the Castle Dome Plain, the area west of the Middle Mountains and the area west of Sentinel Plain. It would not be surprising to find that these shallow gravity depths were due to extensive andesitic and rhyolitic flows, now buried due to later block faulting and subsidence, and that crystalline basement rock lies at considerably greater depths beneath the surface. In spite of our reservations, the gravity estimates of the depths to bedrock were frequently all we had, and we used them to code depths to Unit I in the interior, as shown on digital map 16.

The subdivisions of Unit I were highly problematical. After some consideration, we chose not to engage in wild estimation procedures and have not included maps for depths to middle or lower Unit I.

7. Recoverable Water and Water Temperature.

The best estimates we have of recoverable water are from the geothermal exploration report of the Hyder Valley and Palomas Plain areas, [Jones \& Campbell, 1979]. Table 2 is from this report.

Ground water temperatures were of some interest in this report as possible indicators of geothermal resources when these temperatures are anomalously high. Water temperature data is collected as Appendix $E$ and shown on digital maps 17 and 18 . $A$ study of ground water temperature phenomena requires an investigation of the natural convection of water. The basic principles are as follows:

The critical point for the onset of convective activity in porous media is described by the equation,

$r=4.2 * 10^{-7 / k * b=}$, where

$r$ is the thermal gradient, in $0 \mathrm{c} / \mathrm{km}$. ,

$k$ is the permeability, in $m=$, and

$b$ is the 1 ayer thickness, in $\mathrm{m}$. 


\section{GEOTHERMAL RESOURCE EVALUATION OF THE YUMA AREA}

Permeabilities are shown below, in Table 3 , due, as is the above discussion to Turcotte and Schubert, [Turcotte \& Schubert, 1982 ].

TABLE 3

TYPICAL VALUES FOR NATURAL PERMEAEILITIES OF GEQLOGIC MATERIALS

PERMEABILITY (M=)
$10^{-7}$
$10-0$
$10 \rightarrow$
$10-20$
$10^{-22}$
$10-22$
$10^{-13}$
$10^{-24}$
$10-10$
$10-20$
$20-27$
$10-20$
$10^{-2=}$
$10-20$

CLASSIFICATION

PERVIOUS

SEMIPERVIQUS

IMPERVIOUS
SAND

MATERIAL

GRAVEL

SANDSTONE

LIMESTONE

GRANITE 


\section{GEOTHERMAL RESOURCE EVALUATION OF THE YUMA AREA}

8. Testing the model.

Dur interest in convective cells is focussed on Unit II, where we have the evidence of various ground water data, including geothermal wells to support the existence of convective activity. The model we propose for a first approximation is that mean ground water temperatures will approximate mean temperatures within convective cells in Unit II, with high temperature readings being approximately equal to unit II - unit I interface temperatures, exceeding these values occasionally - when deeper levels have been tapped by the well. The Unit II/Unit I interface temperatures can then be approximated as follows:

$T_{1}=T_{0}+2 * r$, where

$T_{2}$ is the interface temperature,

To is the mean ambient temperature at the surface,

$z$ is the depth to Unit I, and

$r$ is the local temperature gradient.

Dur approximation for the median Unit II temperature is the average of the surface and interface temperatures:

$T_{m}=T_{0}+(z * r) / 2$.

For the Yuma area we chose to use the top of the Bouse Formation as the interface which corresponds to the Unit I interface with Unit II in the interior. We generated a digital map of expected shallow ground water temperatures based on the above equation. This could be termed the fault-less, flow-less model, as it takes no account of the effects of either faults or subsurface water movement in basins. We were sure that the Yuma area would not fit the model very well, but were surprised to find that values for the area near Sentinel Plain were consistently large underestimates of actual values. This led us to make an estimate for the thermal gradient at Agua Caliente, as discussed in Appendix $A$, and to produce a revised thermal gradient contour map. This new thermal gradient map uses the low values of $85 \circ \mathrm{c} / \mathrm{km}$. for the Salton Trough geothermal areas, but also includes 80०C/km. for Cerro Colorado and, of course, the $610 \mathrm{c} / \mathrm{km}$. for Agua Caliente. 


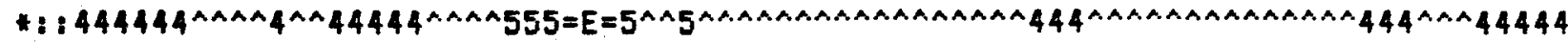

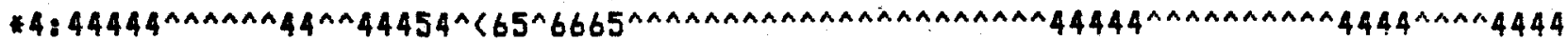

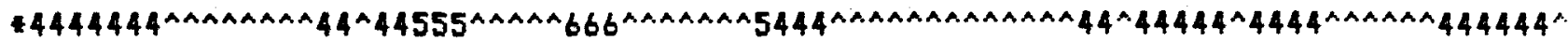

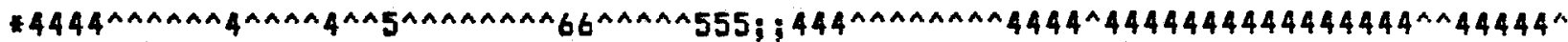

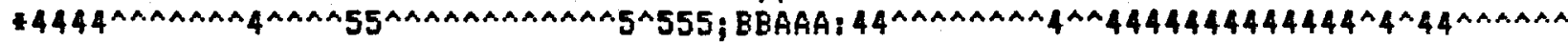

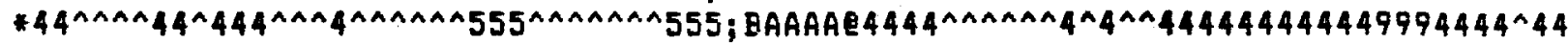

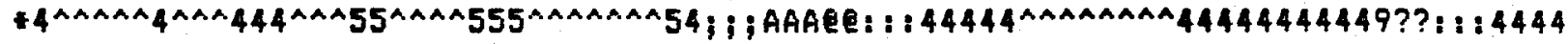

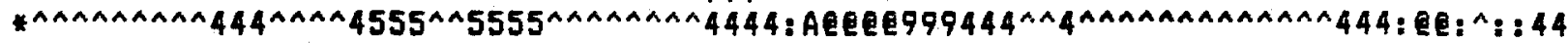

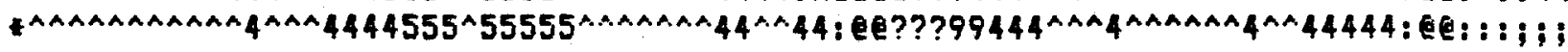

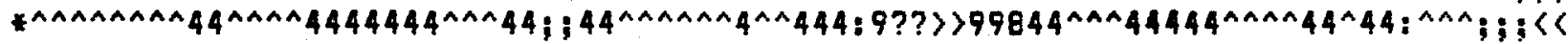

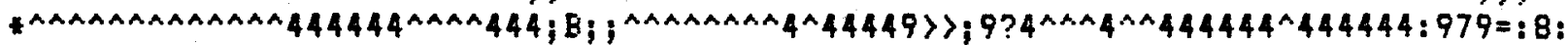

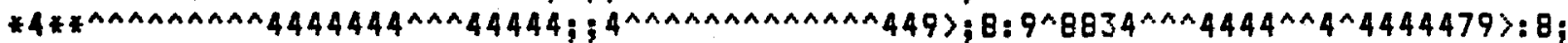

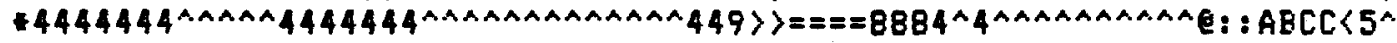

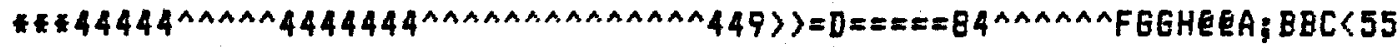

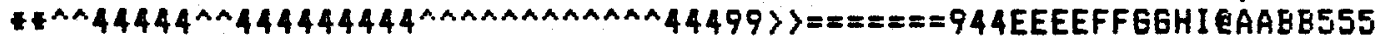

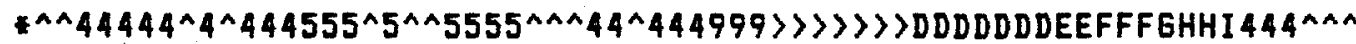

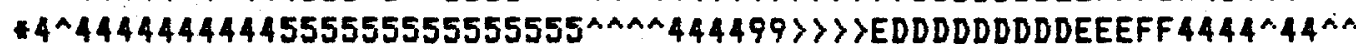

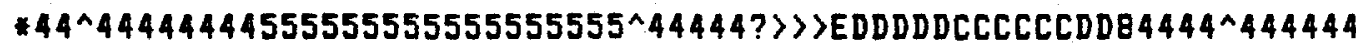
$\$ 44^{\wedge} 44444444^{\wedge A \wedge} 5555544 ; 6555555555444^{\wedge \wedge}\langle Q\rangle==D ?\left\langle{ }^{\wedge} F C 88844444444444444^{\wedge}\right.$

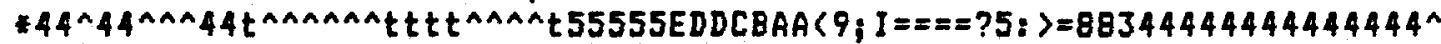

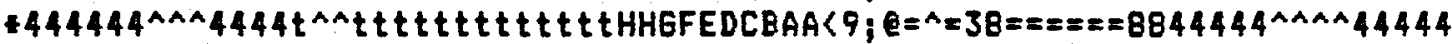

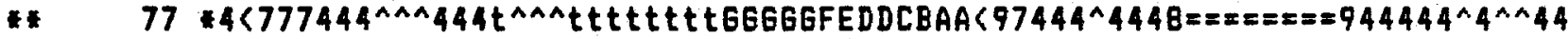

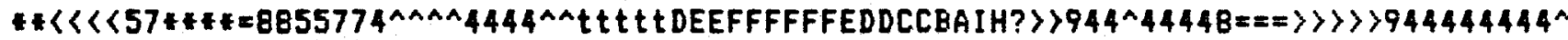

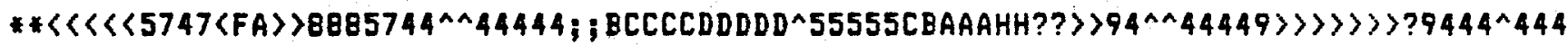

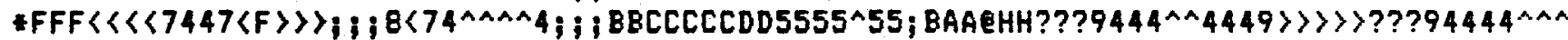

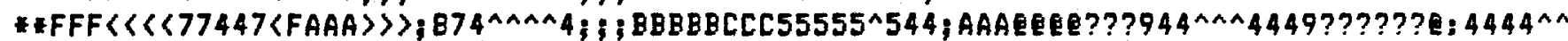

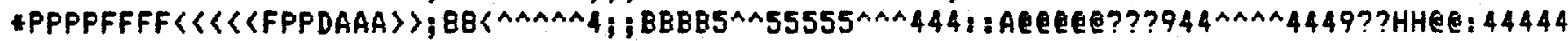

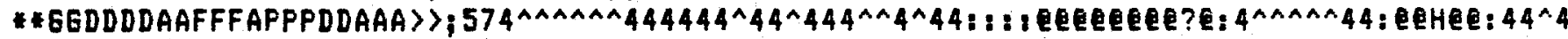

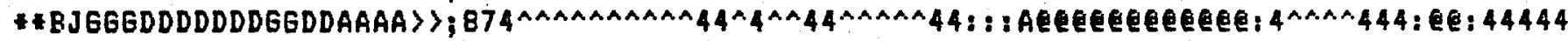

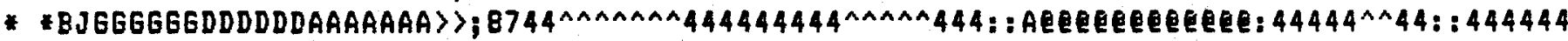

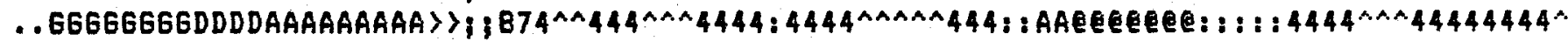

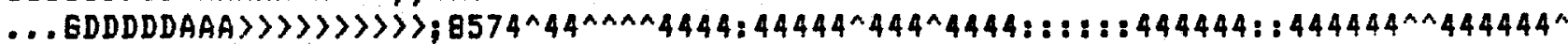

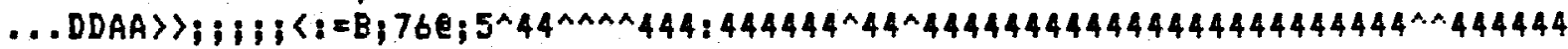

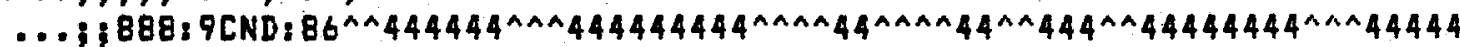

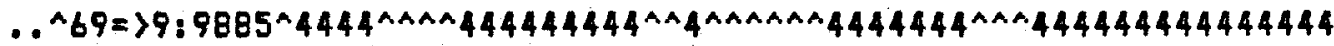

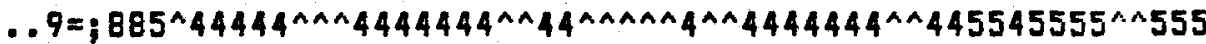

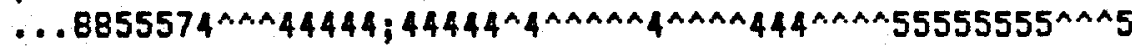

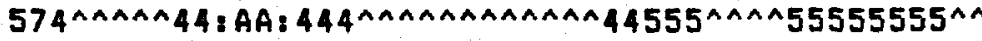

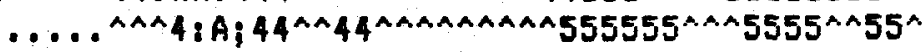

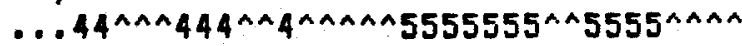
...AAAAAAA55555555555AAAAA5A55 - AAA5^555555555555^^^555 ...5^555^AAAA $55^{\wedge \wedge} 555$ ... $\ldots \wedge \wedge$

ESTIMATED UNIT II INTERIOR TEMPERATURES IN THE STUDY AREA (Eee Table 1 for Detailed Temperature Codes)

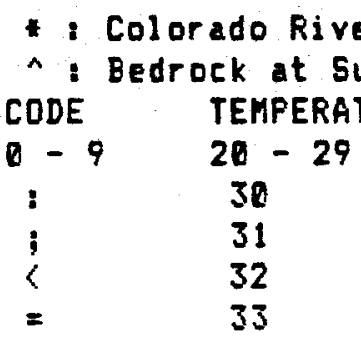

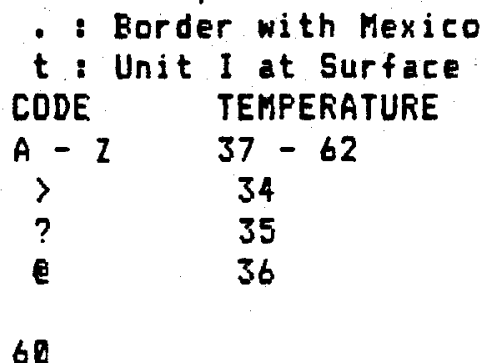


Digital Map 20

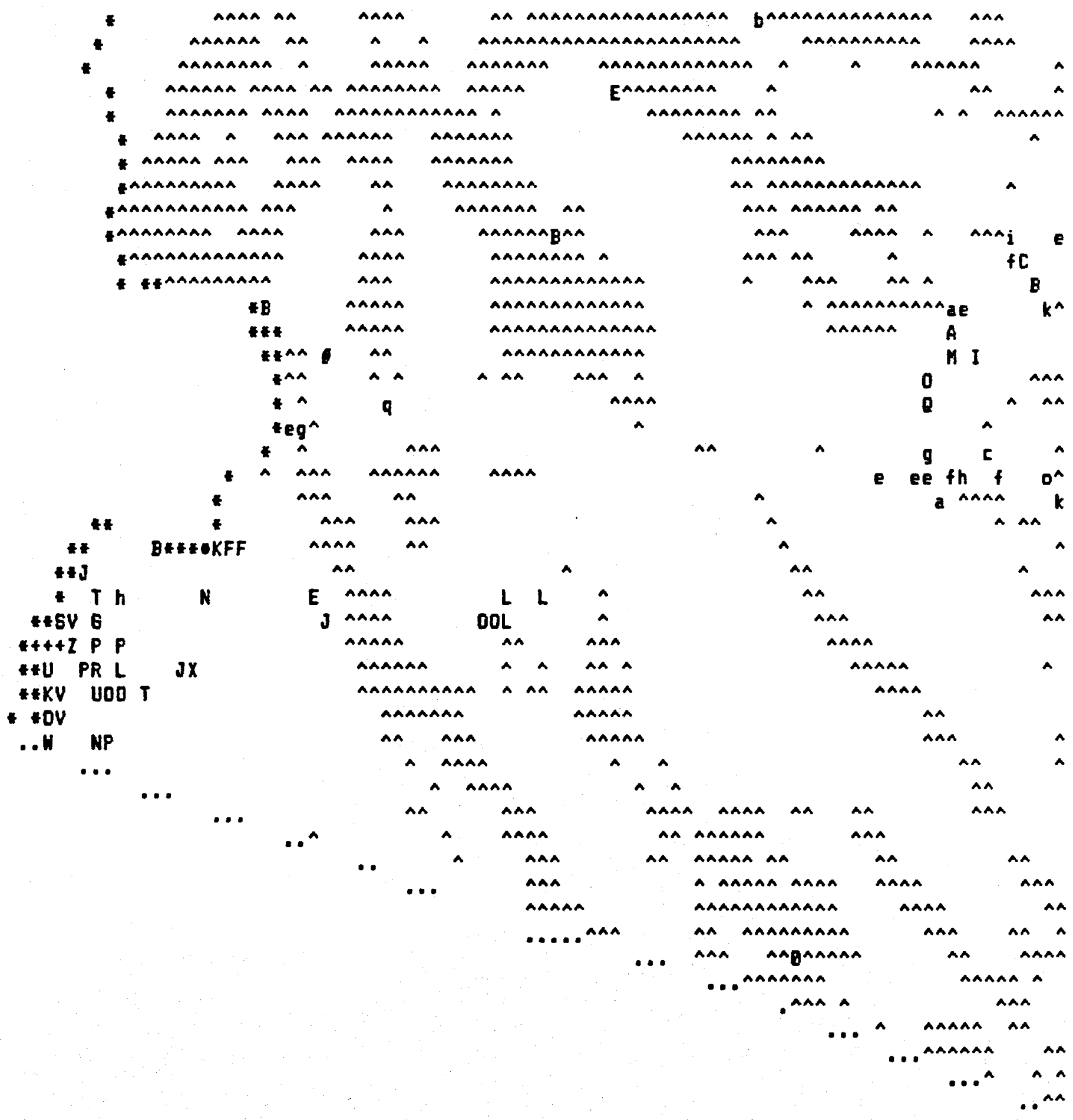

ESTIMATED UNIT II INTERIOR - ACTUAL GROUND UATER TEMPERATURES

CODES:

8: D DIFFERENCE

+ DIFFERENCE $>+26$ C

-8 DIFFERENCE $<-26$ C

A - I: DIFFERENCE $=+1$ TO $+26 \mathrm{C}$

- 2: DIFFERENCE $=-1$ TO $-26 \mathrm{C}$ 
Digital Map 21

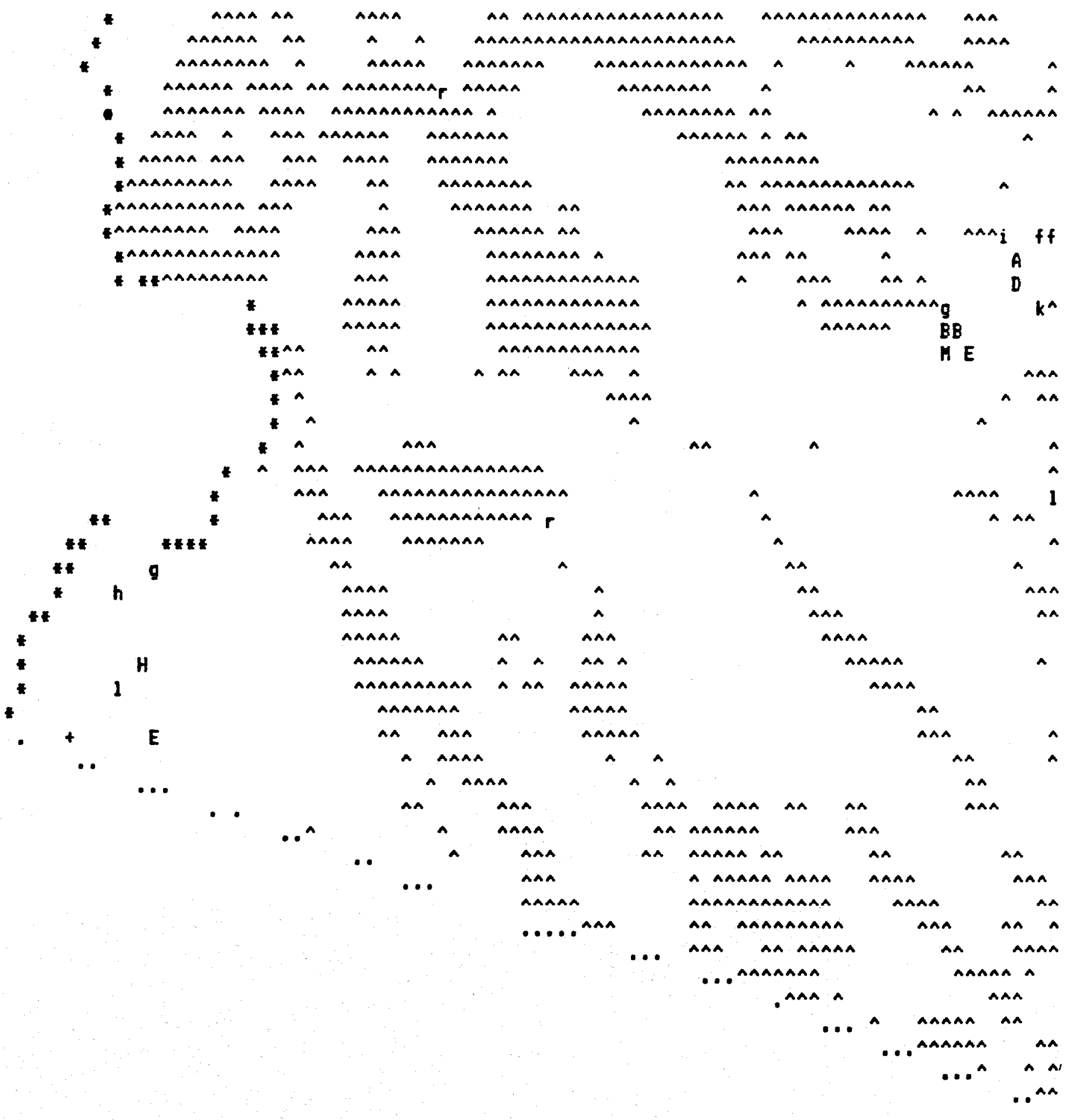

DIFFERENCES BETWEEN MEDIAN UNIT II PREDICTIONS AND THERMAL MELL TEMPERATURES

* Colorado River - Border with Mexico

A Bedrock at Surface

THEORETIC NORMAL MINUS THERMAL WELL DATA

D: Difference $=0$

A to 2: Difference 1 to 26 degrees Celsius

a to 21 Difference $=-1$ to -26 degrees Celsius

$1+$ Difference $>26$ degrees Celsius.

- Difference $<-26$ degrees Celsius. 


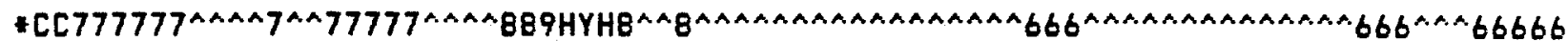

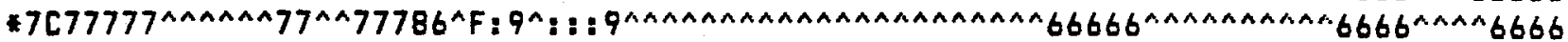

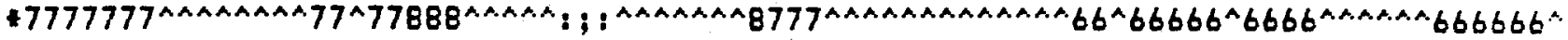

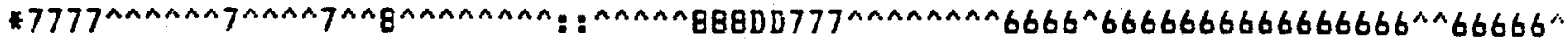

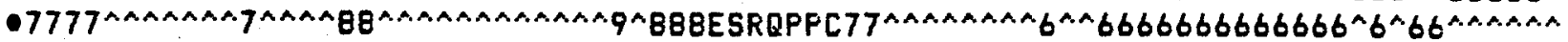

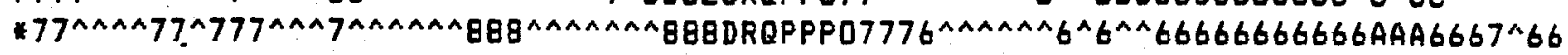

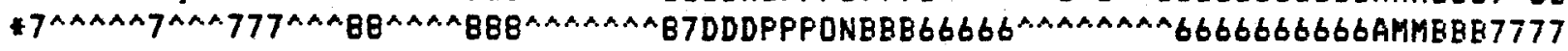

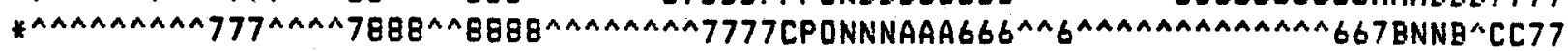

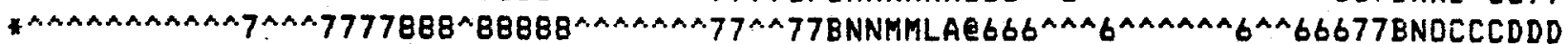

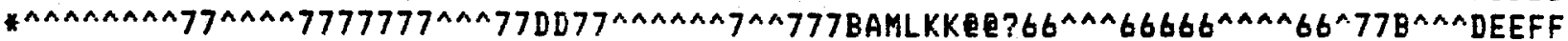

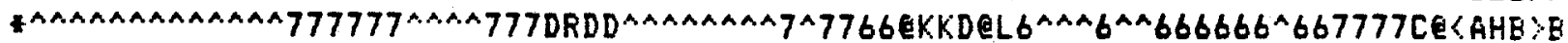

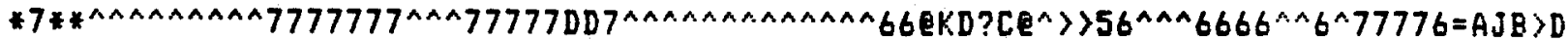

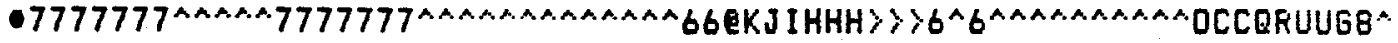

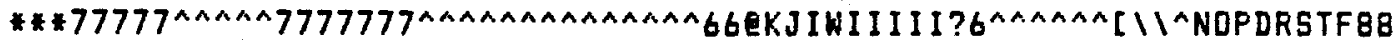

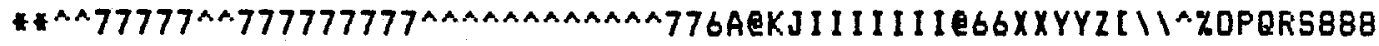

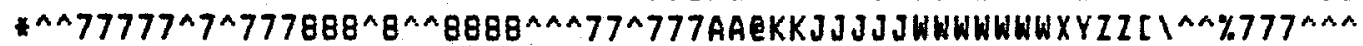

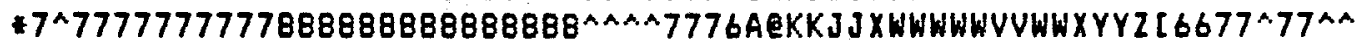

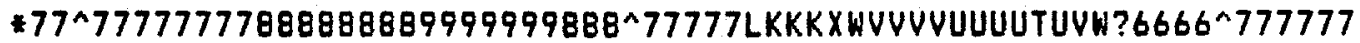

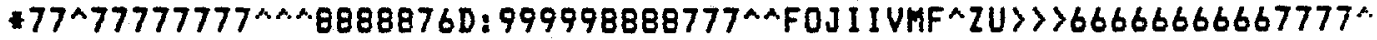

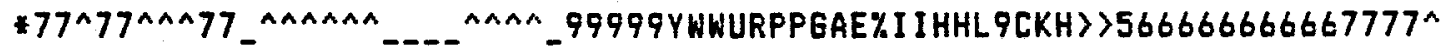
$\$ 677777^{\wedge A \wedge} 77777^{\wedge \wedge}$

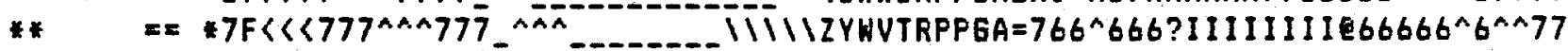

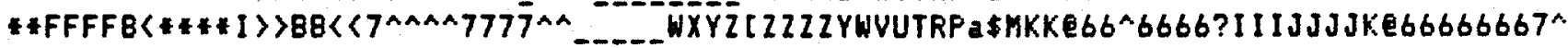

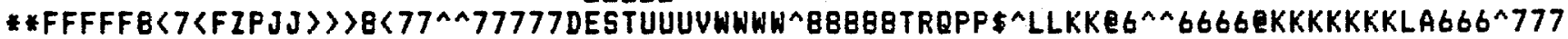

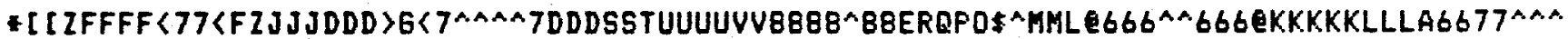

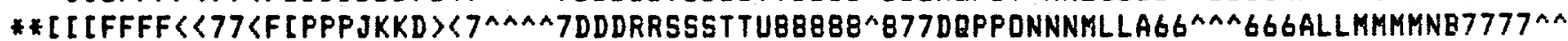

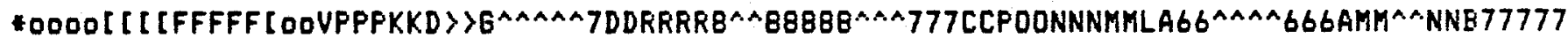

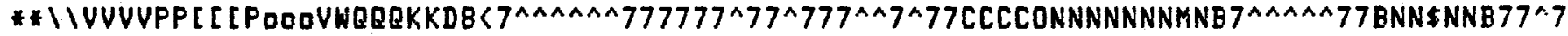

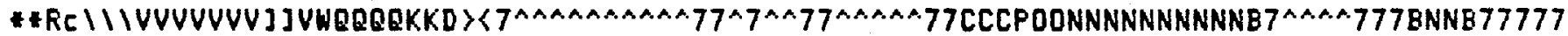

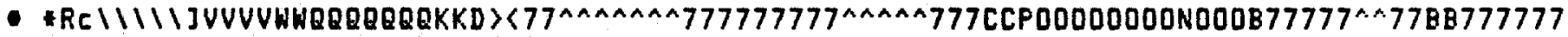

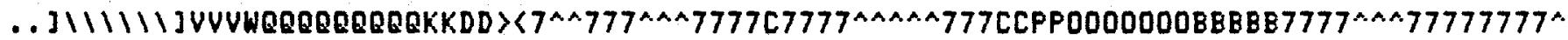

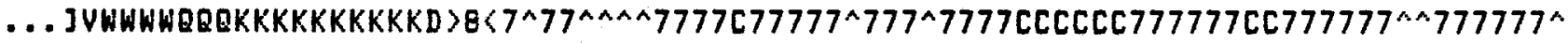

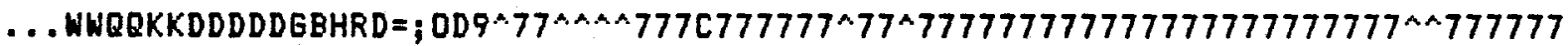

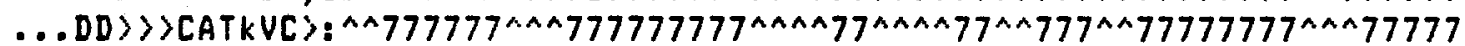
..^: AIKABA $>>8^{\wedge} 7777^{\wedge \wedge A \wedge} 77777777^{\wedge \wedge} 7^{\wedge \wedge \wedge \wedge A \wedge} 7777777^{\wedge \wedge \wedge} 777777777777777$

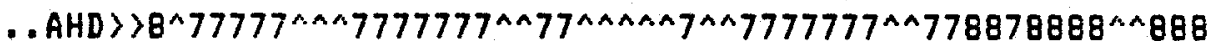

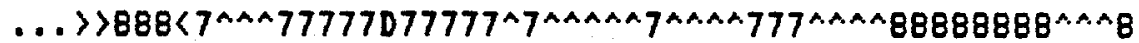

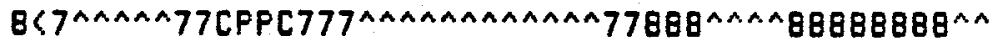

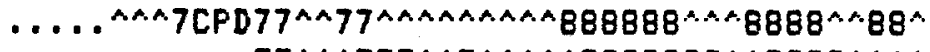

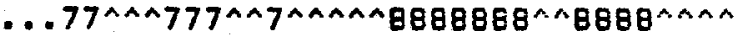

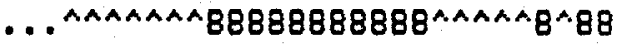

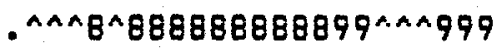
$\ldots .8 \wedge 888^{\wedge \wedge \wedge \wedge \wedge 99^{\wedge \wedge} 999}$

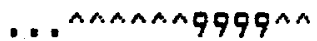

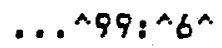
$\ldots \wedge$

ESTIMATED UNIT II/UNIT I INTERFACE TEMPERATURES IN THE STUDY AREA See Table 1 for Detajls of Temperature Codes

- Colorado River.: Border with Mexico - : Bedrock at Surface

- Unit I at Surface CODE TEMPERATURE

O $-9 \quad 20-29$

A $-2 \quad 37-62$

a-2 $97-122$
Temperatures in Degrees Celsius.

CODE TEMPERATURE CODE
30

31

32

33

34

35

36
CODE

$\begin{array}{ll}\text { TEMPERATURE } \\ \text { l } & 63 \\ 1 & 64 \\ 3 & 65 \\ * & 66 \\ 5 & 67 \\ \% & 68\end{array}$


Digital Map 23

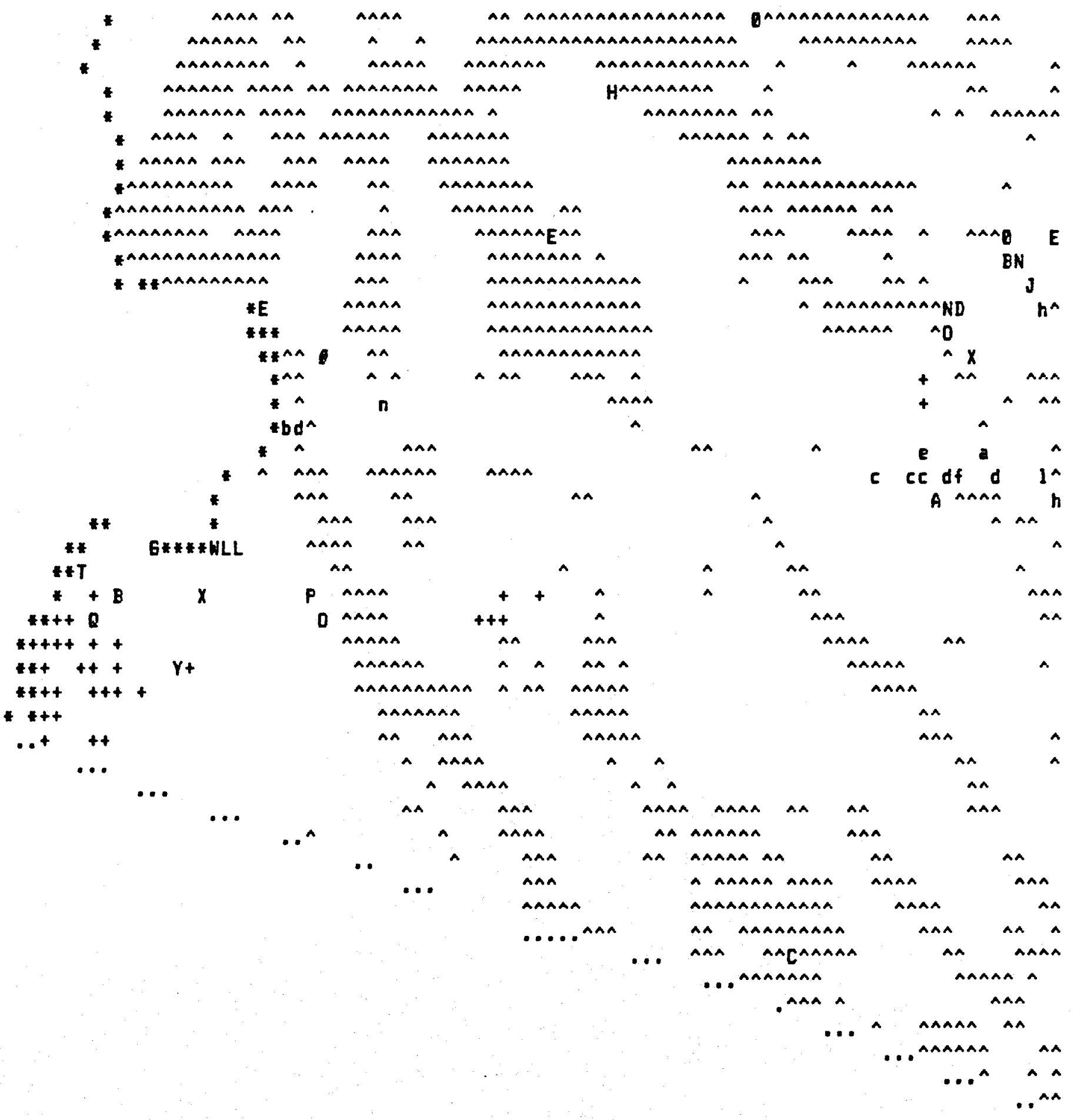

DIFFERENCES: ESTIMATED U2/U1 INTERFACE - ACTUAL GROUND WATER TEMPERATURES

CODES:

D: D DIFFERENCE

+ DIFFERENCE $>+26$ C

$-\rightarrow$ DIFFERENCE $<-26$ C

4 - Zi DIFFERENCE $=+1$ TO $+26 \mathrm{C}$

- 2: DIFFERENCE $=-1$ TD $-26 \mathrm{C}$ 
Digital Map 24

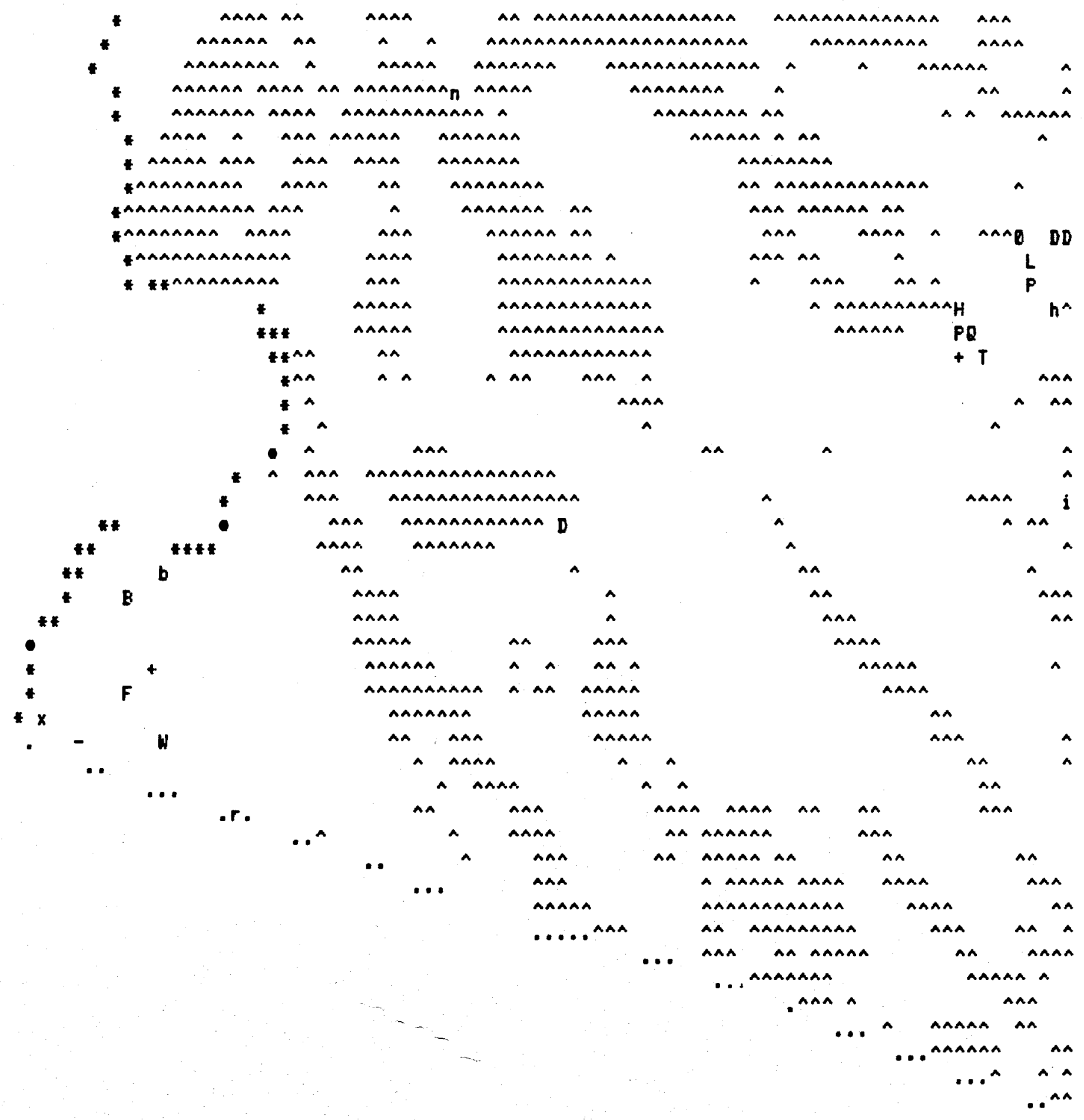

DIFFERENCES BETWEEN U2/UI INTERFACE PREDICTIONS AND THERMAL WELL TEMPERATURES

- Colorado River : Border with Mexico

THEORETIC NORMAL MINUS THERMAL WELL DATA

D Difference $=0$

A to 2: Difference $=1$ to 26 degrees Celsius

a to 2 : Difference $=-1$ to -26 degrees Celsius

$+\quad$ Difference $>26$ degrees Celsius.

- Difference < -26 degrees Celsius. 


\title{
GEOTHERMAL RESOURCE EVALUATION OF THE YUMA AREA
}

\begin{abstract}
Based on the revised thermal gradient contours, estimates were made of median Unit II and Unit II/Unit I interface temperatures, as shown on maps 17 and 18 , respectively. Values from the USGS ground water temperature data are shown on map 19, with differences between theoretical and actual values shown on maps 20 and 21, respectively. Thermal well data is shown on map 22, with differences between estimated and actual values shown on maps 23 and 24 , respectively.

The difference maps show that we have the basis for a model, but that it is in no way complete. Even this rudimentary beginning is informative, however. Thus the larger (more than 5 degree Celsius) temperature overestimates coincide with areas of intensive irrigation and steep gradients of the Unit II/Unit I interfaces. The larger (more than 10 degree Celsius) underestimates are for wells lying within areas of possibly underestimated thermal gradients or underestimated depths to bedrock.
\end{abstract}

Dur conclusions regarding this model are that it requires the inclusion of fluid flow modeling with some factor to include the effects of faults. It has still shown its usefulness in pointing out areas where thermal gradients could be higher or lower than originally contoured. A more challenging and rewarding use of these methods would be to use them to actually contour thermal gradients, especially where data is otherwise lacking. This is also beyond the scope of this report, although an attractive avenue of further research.

\section{General Conclusions.}

The conclusions of this chapter are as follows.

1. Available thermal gradient evidence suggests that the only certain area for Hot Impermeable Rock exploration consists of the mountainous areas surrounding Castle Done flain. There are possibly high thermal gradients in the southeastern corner of the county, but have no data which we can use to test this hypothesis. An argument can be made in favor of such a gradient on the basis of the high thermal gradients found in the older valcanic fields of Sentinel Plain and the Castle Dome Plain area. It is the purpose of the next chapter to deal with that type of argument.

2. Available thermal gradient evidence suggests that only the deeper regions of the Fortuna Basin have much likelihood of having high enough temperatures (above 170 OC) to support geothermal power production. A final evaluation of this area awaits the economic discussion of chapter 5 . 


\section{GEOTHERMAL RESOURCE EVALUATION OF THE YUMA AREA}

3. Available evidence suggests only two areas for low to moderate (50 to $150{ }^{\circ} \mathrm{C}$ ) geothermal utilization within present day Yuma County: the area surrounding Sentinel plain (including the Hyder Valley, Palomas Plain and the area west of Sentinel Plain) and the Gila Trough area between the Wellton Hills and the Mohawk Mountains, but particularly the area near Radium Hot Springs. The economic prospects of such development are also left to the discussion in chapter 5 .

4. The 'hot' and 'cool' maps suggest that Salton Trough heating has only negligible effect on those parts of the study area which lie outside the Yuma area, and that a 'hot spot' near Cerro Colorado would have only negligible effect within the study area beyond the Cabeza Prieta Wildlife Refuge.

5. The results of our modeling of Unit II median and interface temperatures suggest that a promising avenue of further research is the use of shallow water temperature data to estimate temperature gradients, at least within Easin and Range country where depth to bedrock estimates are reliable. Such a procedure needs to include the effects of fluid flow and faults. 


\section{GEOTHERMAL RESOURCE EVALUATION OF THE YUMA AREA}

\section{SELECTING THE HOTTEST AREAS}

1. Using all of the evidence.

The methods of the previous chapter were highly effective in eliminating areas from further consideration. However, our faith in the results of the application of those methods is somewhat diminished by the sparsity of thermal gradient and heat flow data with which we had to work. It is therefore valid to ask whether there are other areas, suggested by other kinds of data, which may have potential geothermal value. The purpose of this chapter is to answer that question.

In the introductory chapter we compiled a number of instances where data other than specific thermal gradient data was used to support the suggestion that the study area had geothermal potential. We have already pointed out the lack of precision, or even specificity, in that information. What is needed in order to use that information, is a systematic, and preferably a numeric, method of describing the relation of this information to the existence of a geothermal resource. An example of what we would like to have is a method of assigning a probability to a given phenomenon (such as a low Bouguer gravity anomaly) that it is the location of a geothermal resource. Given the present state of our knowledge, this is too much to expect. However, there are methods for comparing various phenomena and assigning subjective valuations to this kind of relationship. The result, although not a probability, can be used for our evaluation purposes.

\section{The General Procedure.}

What we are about to do is collect all of the phenomena which were mentioned in chapter 1 and give each one a numerical value, the value depending on its relative weight with respect to having an associated thermal gradient of $650 \mathrm{c} / \mathrm{km}$. or more. This is a somewhat easier question to answer than one which asks about the existence of a geothermal resource, and it has an immediate relationship to the work of the previous chapter. We will then locate the phenomena geographically, and sum the values for each geographical location. The result is a phenomena evaluation map which will have a value attached to each pixel on the map. The procedures for doing this have similarities to the contouring method for thermal gradients, and the map will be similar to the contour maps of the previous chapter.

We use three-step process in defining the numerical

weights for these various phenomena. 


\section{GEOTHERMAL RESDURCE EVALUATION OF THE YUMA AREA}

1. The evidence with which we deal is classified according to type and sub-type.

2. Weights are assigned to these classes.

3. Phenomena are assigned to these clases, and the class weights are assigned to the phenomena.

3. A Classification of Evidence.

We have classified evidence into four types or states. The types are not disjoint, but any item of evidence can be considered as being in one of these states.

Type I. Direct or Specific Evidence. Examples of direct evidence in the present context are active volcanos, geysers, fumaroles, mudpots and mud volcanos.

Type II. Deductive or Inductive Inference (physical models). An example of this is the inference that Radium Hot Springs has a thermal gradient of $670 \mathrm{c} / \mathrm{km}$. and the further inference - from seismic data - that the adjacent Gila Trough area is deep enough to support at least a moderate temperature geothermal resource.

Type III. Indirect Evidence (Uncorrelated data). This is evidence which has an inexact or poorly correlated relationship to the conclusion. Examples of this are the various anomalies - e.g., thermal, gravity and magnetic, and the interpretations based on that kind of evidence.

Type IV. Conjectural Evidence - a suggestion of possibility based on sparse data. This is evidence which is conjectured to have a relationship to the conclusion, but for which there is insufficient information to establish whether or not there is even a poor correlation with the conclusion. An example of this is the region of muted magnetic contrasts, the relevancy of which is in dispute.

We assigned a triad of subtypes, imaginatively named High, Middle and Low. We could have called them Strong, Moderate and Weak, as they express the level of confidence we have in the support which the evidence gives to the conclusion. In practice, any item of evidence can now be given its type, and then, by a strictly judgment call, given its subtype. An example of this would be the assignment of middle model to Radium Hot Springs. 


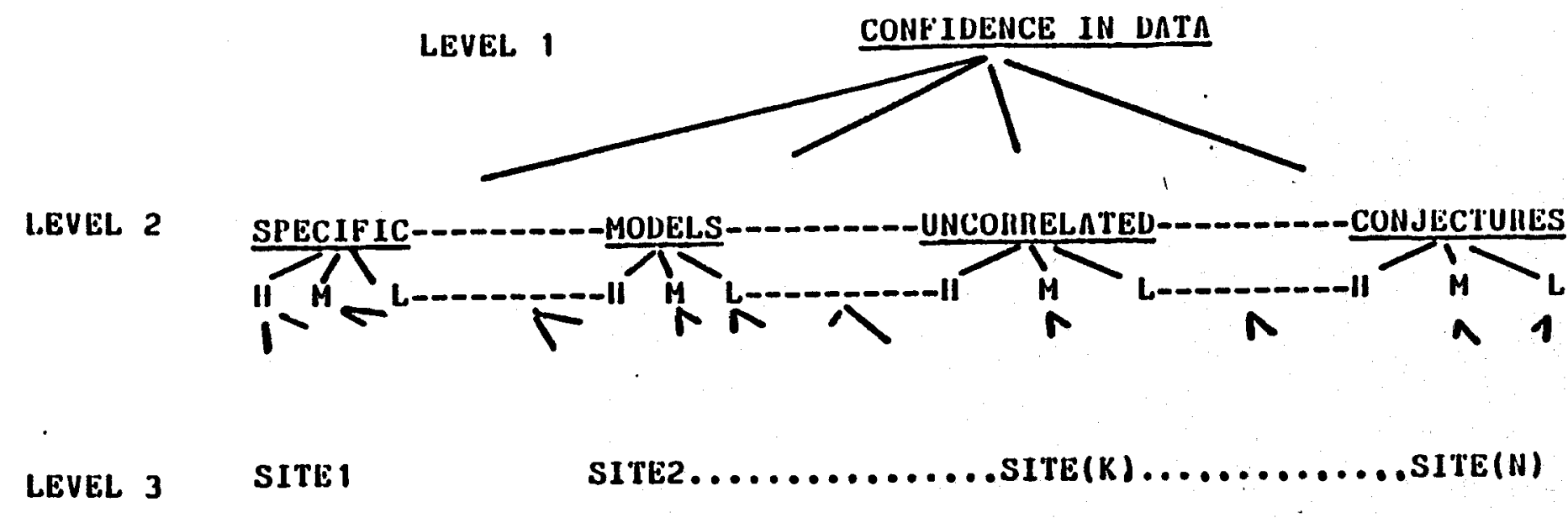

Hierarchy to detehmine the pating fon SITES BASED ON CONFIDENCE IN THFIII RESPECTIVE DATA BNSE.

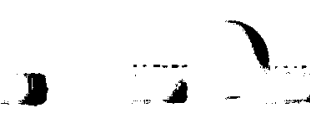




\section{GEOTHERMAL RESOURCE EVALUATION OF THE YUMA AREA}

\section{Assigning Numerical Values.}

The procedure we used for assigning numerical values to the subtypes is the Analytical Hierarchy Process developed by Dr. Thomas Saaty, [Saaty,1982]. We found it to be a satisfactory weighting procedure for our purposes. This procedure, and the typification of evidence discussed above, is treated in detail in Appendix B. A brief description is as follows.

The items to be rated are placed in a hierarchy of levels. The first level has precisely one item: the conclusion, or goal, of the rating system. If the hierarchy is complete, every item on a given level is related to every other item on that level through relations with respect to every item on the previous (higher) level. Not all hierarchies are complete. Ours is not, due to the fact that the high, middle and low levels of confidence for one type of evidence are not the same as the high, middle and low levels of confidence for another type, even though the same terms are used. This can be seen by the diagram of figure 15 .

In our case, types are compared with regard to our confidence that evidence of that type supports the existence of a geothermal energy resource in the relevant area. Then the high, middle and low confidence categories of each type are compared in a pairwise fashion. Not all pairs need to be evaluated, due to the following rules.

\section{An item compared to itself receives the value of 1.}

2. If an item, ' $a$ ', receives the value of $x$ when compared to ' $b$ ', then the rating of ' $b$ ', compared to 'a', is $1 / x$. Thus, if we rate Type I compared to Type II evidence as 3 , then Type II compared to Type I is $1 / 3$.

The pairwise rating system uses only the integers from 1 to 9, and their reciprocals. It can be represented as a matrix, which turns out to be convenient for display and computational purposes. The matrices which expressed our valuation of states are shown below. 
GEOTHERMAL RESOURCE EVALUATION OF THE YUMA AREA

With respect to confidence in the evidence:

$\begin{array}{l:cccc} & \text { Type I } & \text { Type II } & \text { Type I I } & \text { Type IV } \\ \text { Type I } & 1 / 1 & 1 / 3 & 1 / 7 & 1 / 9 \\ \text { Type II } & 3 / 1 & 1 / 1 & 1 / 4 & 1 / 7 \\ \text { Type II } & 7 / 1 & 4 / 1 & 1 / 1 & 1 / 4 \\ \text { Type IV } & 9 / 1 & 7 / 1 & 4 / 1 & 1 / 1\end{array}$

With respect to any type:

\begin{tabular}{c:ccc} 
& Low & Middle & High \\
\hdashline Low & $1 / 1$ & $1 / 3$ & $1 / 5$ \\
Middle & $3 / 1$ & $1 / 1$ & $1 / 3$ \\
High & $5 / 1$ & $3 / 1$ & $1 / 1$
\end{tabular}

The results are normalized and averaged, leading to weights for each item on a given level. Normalization consists of dividing each element of the matrix by its column sum, e.g., $1 /(1+3+5)$. Averaging is by row. Thus the normalized values for the 'Low' row in the above matrix are $1 / 9,1 / 13$ and $3 / 23$, respectively, the average of which is 0.106 . There is also a test for consistency, so that comparisons such as $a<b<c<$ a can be flagged. The results for the comparison of types, above, were:
Specific Evidence:
0.61 ,
Inferential (models):
0.26,
Uncorrel ated Evidence:
0.09 ,
Conjecture:
0.05. 
GEDTHERMAL RESDURCE EVALUATION OF THE YUMA AREA

The High, Middle and Low Confidence levels were calculated to be:
High:
0.63 ,
Middle:
0.26.
Low:
0.11.

Final results are obtained by multiplication. Thus, a phenomenon which is rated as a Middle Conjecture receives the value 0..26 $\times 0.05=0.013$. The complete valuation is expressed by the following matrix.

\begin{tabular}{l:cccc} 
& Type I & Type II & Type II & Type IV \\
\hdashline High & 0.38 & 0.16 & 0.06 & 0.03 \\
Middle & 0.16 & 0.07 & 0.02 & 0.01 \\
Low & 0.07 & 0.03 & 0.01 & 0.006
\end{tabular}

4. Classifying the Evidence.

We now classify the evidence for a geothermal resource in the area which was listed in the introductory chapter. Instead of relating that evidence to the existence of a geothermal resource, we shall relate the items of evidence with respect to the existence of a thermal gradient of $65 \circ \mathrm{c} / \mathrm{km}$. or more. We shall be using only the evidence which was originally quoted as having a bearing on the question.

Specific Evidence. The only specific evidence we have is the thermal gradient and heat flow data, collected in Appendix D. Some of it can be regarded as negative, in that it supports the contrary, or null, hypothesis that there is not a thermal gradient of that order of magnitude. We shall deal with that question later. What we shall do now is classify thermal gradient evidence, positive or negative, according to whether it falls in the high, middle or low category. Some general comments are in order. 
Published heat flow data, with tests of conductivity of the various rock specimens, is generally the most reliable. Even then, it has been pointed out, [Shearer \& Reiter, 1981], that heat flow data from granitic rocks at depths of 650 meters or greater is more reliable than heat flow data from shallower depths and other rock types. The problem in many cases is the presence and movement of free water. In cases where we only have thermal gradients, deep gradients and those from dry areas - those with low pumpage - are likely to be the most reliable. Raw gradients are highly unreliable, and we did not place well data in the specific evidence category at all.

High: The heat flow data from the Yuma area, published by Sass, and others, [Sass, et $a 1,1971 \mathrm{~J}$, and the gradient data from Yuma Federal No. 1, SShearer \& Reiter, 1981], fell in this category. This was actually negative information.

Moderate: The thermal gradient data from the well near stone Cabin, and other published thermal gradient data was placed in this category.

Low: Heat flow data from the Geothermal Resources Map of Arizona, for which we had no independent source, and which we converted to thermal gradient data by dividing by the estimation factor of $2.2 \mathrm{~mW} / \mathrm{m}^{-}{ }^{\circ} \mathrm{C}$, was considered to lie within this category.

Inferential Evidence. The gradients inferred from hot springs and the residual Bouguer gravity low noted by Gutmann are of this type.

High: No evidence.

Moderate: Radium Hot Springs. We did not elassify it as high because of the guesswork involved in estimating the depth of heat source.

Low: The 50 milligal Bouguer anomaly in the North Castle Dome Mountain area, and the $40 \mathrm{milligal}$ Bouguer anomaly in the Cabeza Frieta Mountain area.

Indirect, poorly correlated evidence. Cerro Colorado, the area of the Bouguer long-wavelength low, earthquakes, suspected Holocene faults, warm water anomalies and muted magnetic contrasts, were all placed within this category. In retrospect, the area of muted magnetic contrasts would be more appropriately place in the category of conjectural evidence.

High: No phenomena were placed in this category, although, in retrospect, Cerro Colorado might qualify.

Moder ate: Cerro Colorado.

Low: Earthquakes, Long-wavelength Bouguer gravity lows, possible, but not probable, Holocene faults, muted magnetic contrasts and warm water anomalies.

Conjectural Evidence. The area at the southwest tip of Arizona and Quaternary faults were both placed in the Low category. 


\section{GEOTHERMAL RESDURCE EVALUATION OF THE YUMA AREA}

\section{Making the Maps and Conclusions for this Chapter.}

Pointwise phenomena, such as thermal gradient determinations, hot spring data and earthquake epicenters, were treated precisely in the same way as the thermal gradient data for the thermal gradient maps. Linear, or arc-wise, phenomena, such as faults, were treated as collections of points. Contour maps were generated from these phenomena following the same procedures as described in the previous chapter. There were two maps - one for the positive evidence and the second for the negative evidence. The only negative evidence employed was from the low thermal gradient or heat flow values. These two maps were then added together to form a compsosite.

Values for the area-wide phenomena, such as Bouguer gravity lows and long-wavelength lows, shallow warm water anomalies and the area of muted magnetic contrasts were assigned points within the area of each phenomenon, and then added to the composite map.

The results are shown for the contoured map of figure 16 . The omission of Agua Caliente Data has an obvious effect. Other phenomena which were not included were the high water temperatures in the area south of the Middle Mountains and west of Sentinel Plain, or the apparent Bouguer anomalies in the Gila Trough, shown in figure 11. Agua Caliente was originally not included because it does not lie in the study area. The other phenomena were not included in the original list of items supporting the existence of geothermal resource potential in the study area.

The present contour map does not indicate any new areas for geothermal investigation beyond those inferred from the thermal gradient analysis. The addition of the phenomena described above does not change this general conclusion, as the most weighty items already have appeared on the thermal map. Thus, at most, these phenomena support interest in those areas already indicated by the thermal gradient analysis. 


\section{GEOTHERMAL RESOURCE EVALUATION OF THE YUMA AREA}

\section{ECONOMIC AND INSTITUTIONAL FACTORS}

1. Overview of the Factors.

In this chapter we review the economic, social and institutional factors that are known or likely to have some bearing on the development of geothermal energy in Yuma County. Briefly, these can be considered under the categories of demand, cost, and institutional constraints. It is also useful to classify geothermal resources according to the uses they may have. From the engineering standpoint we distinguish usage by heat engine and heat transfer applications. From the economic standpoint it is more useful to consider the distinction between electric power generation and thermal energy use, s these relate most directly to the energy demands. The engineering and economic aspects overlap in the following manner. Direct heat engine production of electric power uses brine temperatures in excess of $1900 \mathrm{C}$. Brine temperatures of $170^{\circ} \mathrm{C}$ and above have been used for power production in binary systems, which use a combined heat exchange and heat engine system: the brine heats a hydrocarbon compound which then runs the heat engine. Brine from Roosevelt Hot Springs, Utah, has been used to pre-warm water in a fossil-fuel power generating plant, [Elair, et aI, 1982]. Although binary systems are in the early stages of market penetration, with future large scale development in the planning stages, geothermal preheating may be precluded in many areas due to the remoteness of geothermal sites and the logistic and economic problems of coal transportation and transmission costs, [Blair, et a 1, 1982].

Three institutional factors may also be considered. The first involves the surface responsibility of the land in which the geothermal prospector or producer will be operating. The second, is the subsurface rights, and the third involves legal restrictions on the potential use of geothermal energy for heating or cooling purposes.

All of these factors will be discussed briefly in this chapter. Our principal conclusions, however, can be stated here, at the outset. Due to the sparsity of the population, and the low temperatures of the the accessible geothermal resources:

a. District thermal applications are highly unlikely,

b. Individual uses of very low temperature resources $120^{\circ}$ to 500 Celsius) close to the surface are possible but only occasionally of economic value to the potential user.

c. Dther uses of geothermal brines for thermal energy applications are highly unlikely, 


\section{GEOTHERMAL RESOURCE EVALUATION OF THE VUMA AREA}

d. Utilization of geothermal brines for power generation is restricted to the few sites where high enough brine temperatures can be found. Even if reservairs of sufficient size are discovered at these temperatures, their exploitation may not be economically attractive.

e. Hot rock sites are somewhat more promising, but the methods of exploitation have not yet reached the stage of market penetration, so the economics of such ventures are, as yet, untested.

2. Economic Description of Yuma County.

The following set of statistics for Yuma County was obtained from Arizona Department of Commerce brochures, published in 1985.

The population of Yuma County in 1984 was 85,700, having grown 2.3\% since 1980. The City of Yuma has the largest concentration of population with 48,485 , having grown $3.4 \%$ since 1980. The next largest concentrations of civilian population are at Somerton, with 6,535, having grown $3.2 \%$, the Bard-Winterhaven area, in California, with 2,425 , having $0.0 \%$ growth, and Wellton, with 995 and $2.2 \%$ growth.

The military is listed as employing 7,302 peope, with 5,884 at the U. S. Marine Corps Air Station, near the City of Yuma, and 1,418 at the $U$. 5. Army Yuma Froving Grounds (Yuma Test Station). The civilian labor force is listed as 19,529, having dropped from 20,719 in 1980, of which 17,549 are 1 isted as currently employed. The unemployment rate varied from $9.1 \%$ in 1980 to $14.6 \%$ in 1983 , to $10.1 \%$ in 1984.

The major civilian employment sectors are: trade, $23 \%$, public administration, 22\%, agriculture, $20 \%$, and services, $15 \%$. Construction accounts for $7 \%$, manufacturing for $5 \%$, transportation, communications and public utilities for $3 \%$, finance, insurance and real estate for $3 \%$, and mining for $1 \%$.

Electrical service is supplied and distributed by Arizona Public Service, natural gas is supplied by El Paso Natural Gas Co. and distributed by Southwest Gas Corporation, and Propane-Butane by Buckeye Gas Products Co.., Petrolane-Yuma Gas Service and R-Gas. Water is supplied by the City of Yuma Water and Sewage Division from the Colorado Riuver. Peak daily requirements for water are listed as $18.1 \mathrm{milli}$ ion gallons per day. 


\section{GEOTHERMAL RESOURCE EVALUATION OF THE YUMA AREA}

A 1982 estimate of energy consumption [Frank,et al, 1984], for old Yuma County, (now this would be Yuma and La Paz Counties, combined), lists the county as consuming 2.40 trillion ETU's of electricity, 1.49 trillion BTU's of natural gas and 3.83 trillion BTU's of petroleum. We found no record of coal consumption for the county. In terms of statewide energy consumption, this 1982 report has Yuma County accounting for $2.4 \%$ of the electricity, $1.9 \%$ of the natural gas, and $4.3 \%$ of the petroleum.

3. Demand Considerations.

The primary impact of geothermal energy on the energy market is to compete with or supplement services provided by the electric, natural gas and 1 iquid petroleum gas (such as Propane and Butane). There is no appliance industry which is geared to utilize thermal energy directly. This presents us with the following paradox. The most efficient utilization of geothermal resources, from an engineering etandpoint, is through heat transfer applications. This point is made with some force by Wahl, [Wahl, 1977]. However, the preponderant demand is for electric power, except for direct heating and, to a lesser extent, thermal cooling, such as are currently being met by the natural gas and liquified petroleum gas industries. Without the existence of cheap, off the shelf, items to apply thermal energy directly, it is difficult to see direct thermal applications making significant inroads into the current consumer market. The only alternatives to this are district or community thermal applications, such as have been employed in Iceland, or the Eroadlands, in New Zeal and, individual or corporate usage of shallow resources, requiring relatively minor investments, or having a large corporation locate a new facility in an area of moderate geothermal resources.

The greatest district heating and cooling demand is by the City of Yuma and Marine Corps Air Station, which are located in an area of very low (1ess than 50 degree Celsius) geothermal resources. Higher temperature resources are both deep and remote from this relatively high demand area, so it is unlikely that the level of demand would make the exploration and exploitation costs an attractive economic proposition. Individual or corporate exploitation of shallow - less than 2,000 ft. deep - resources is possible. However, all of the indications are that any resource within that depth will also have a temperature of less than 50 , or even 40 degrees Celsius. The exploitation of such a resource is possible, but only occasionally of economic benefit. There is at present no major industry in the area which is likely to have the combination of resources and possible markets which would make full scale exploration and exploitation of deep moderate temperature geothermal resources an attractive economic venture. 


\section{GEOTHERMAL RESOURCE EVALUATION OF THE YUMA AREA}

The legal framework may dampen incentives to geothermal development, at least of thermal applications. Under Article XV of the Arizona State Constitution, "All corporations lother than municipal) engaged in furnishing hot or cold air or steam for heating or cooling purposes shall be deemed as public service corporations". They therefore fall under thejurisdiction of the Arizona Corporation Commission and consequently must comply with all rules and regulations as set forth by the commmission. This compliance would include obtaining a Certificate of Convenience and Necessity in order to service an area with heating or cooling. The State, by issuing such a certificate, assures the utility of a legal monopoly, provided the utility will ake adequate investment and assure competent and adequate service. The certificate poses a problem for a geothermal utility interested in providing district heating or cooling in any area of the state for which such a certificate has already been granted., [Malysa, 1980].

Qur evaluation of this situation is that the only use of geothermal energy for direct thermal energy applications will be occasional on-site usage, at least in the near future. This is applied to the study area, but may also be true for the entire state. The principal implication of this is that the only incentives for extensive or deep geothermal exploration will be in connection with power generation.

\section{Costs and Risks of Geothermal Exploration and Exploitation.}

The principal impediments to geothermal resource development are the cost of exploration and development and the risk involved. The risks are not as great as for oil exploration, but neither are the rewards. Generally, if the target is in the low to moderate temperature range, with low output, the risks are slight. If there is a known resource is at a shallow depth, then costs are within the budget of small corporation. Intermediate temperature geothermal waters have been used in the Klamath Falls, Oregon, area since at least the turn of the century. A description and analysis of this geothermal utilization was given by Lund, and others, in 1975, and includes the following information, based on approximately 400 shallow depth wells, ranging in depth from 27 to $580 \mathrm{~m}$. $(90$ to $1,900 \mathrm{ft.})$ and in temperature from 38 to 110 oc, (100 to 230 of ). 


\section{GEQTHERMAL RESDURCE EVALUATION OF THE YUMA AREA}

Based on 1974 prices, the various items cost:

Hard rock drilling - $\$ 20 / f t$. for 12-in. diameter hole,

Soft rock drilling - \$10/ft. for 12-in. diameter hole,

Steel casing - \$9/ft. for B-in. diameter,

2-in. diameter heat pipe - $\$ 1.65 / f t$.

$3 / 4$ in. diameter water pipe - $\$ 0.56 / f t$.

Average cost of pipe repair over a 14 year period - $\$ 560$,

Average costs of repairs for artesian wells - $\$ 1500$.

\section{estimated.}

Using the above prices, the following total costs were

150-ft. deep well with casing and heating pipe $-\$ 3,830$,

300-ft. deep well with casing and heating pipes - $\$ 7,549$,

600-ft. deep well with casing and heating pipes - \$16,000.

Based on a $7 \%$ rate of return, the total annual cost comes to:

150-ft. deep well - $\$ 336$ per year,

300 ft. deep well - \$603 per year,

600 $f t$. deep well - \$1,142 per year, [Lund, et a 1, 1975].

In 1975 Kennedy and Wolke estimated cumulative costs of various hole sizes drilled to 10,000 feet. Their estimates follow.

$$
\begin{array}{lr}
6 \text { in. diameter } & \$ 37,545, \\
7-7 / 8 & \$ 292,464, \\
8-3 / 4 & \$ 313,906, \\
9-7 / 8 & \$ 326,313, \\
12-1 / 4 & \$ 371,651,
\end{array}
$$

[Kennedy \& Wolke, 1975$].$ 


\section{GEOTHERMAL RESOURCE EVALUATION OF THE YUMA AREA}

In 1982, Blair, and others, estimated deep well cover 2,000 ft.) costs according to a least squares regression analysis, with the following results.

$$
\begin{aligned}
& \text { Sedimentary geology: } c=0.283+0.005 d=\text {, and } \\
& \text { Igneous geology: } \quad c=0.437+0.024 d z \text {, where } \\
& c=\text { cost in millions of dollars, and } \\
& d=\text { well depth in thousands of feet, [Blair, et } a l, 1982] \text {. }
\end{aligned}
$$

A 10,000 foot well, drilled in sedimentary geology would therefore cost, in 1981 dollars, $\$ 783,000$, or a little over twice the estimate for a 12-1/4 inch well in 1974. It is worthwhile noting that, assuming the apparent thermal gradient of $36.4{ }^{\circ} \mathrm{C} / \mathrm{km}$. found at Yuma Federal \#1, and 15\% igneous geology in the fortuna Basin, it would cost approximately $1.5 \mathrm{million} 1981$ dollars to drill a single demonstration hole in Fortuna Plain to the $4 \mathrm{~km}$. depth at which a $170^{\circ} \mathrm{C}$ resource might be found.

Based on our thermal gradient analysis, we can be fairly certain that further geothermal work will involve considerable exploratory work, including intermediate $(1,500-2,000 \mathrm{ft}$.$) to$ deep (over 2,000 ft.) drilling. This involves increased costs and risks. An example of the type of risks involved is given by Kennedy and Wolke.

"On February 20,1974, drilling commenced on the Davis \#1 well. Extensive geophysical, geochemical and geological data werre used to predict a high temperature zone $\left(400+{ }^{\circ} F\right)$ a few thousand feet thick, at the deth of $6,000 \mathrm{ft}$. The zone of geothermal alterations was encountered at 10,354 feet, reservoir thickness was 439 feet and the bottom hole temperature 2860F." [Kennedy \& Wolke, 1975].

In 1975 Barr examined the problem and wrote as follows.

"The drilling of four deep exploratory wells based on a carefully planned strategy, modest land acquisition costs, and a progressive exploration program should lead to at least one commercial discovery of geothermal energy."

He recommended a minimum budget of $6 \mathrm{million}$ dollars and a time period of three years to support an adequate exploration program. This exploration program assumes an initial examination of 30 target areas, screened by evaluation at a cumlative cost of $\$ 150,000$ to 15 , screened by geophysical testing, at a cumulative cost of $\$ 1,125,000$ to $B$, screened by a process of $5 i$ te selection, which frequently involves seismic magnetoteliurics and the drilling of deep thermal gradient holes, at a cost of $\$ 1,521$, 000 to the 4 sites where the deep test wells are drilled, [Barr, $1975]$. 


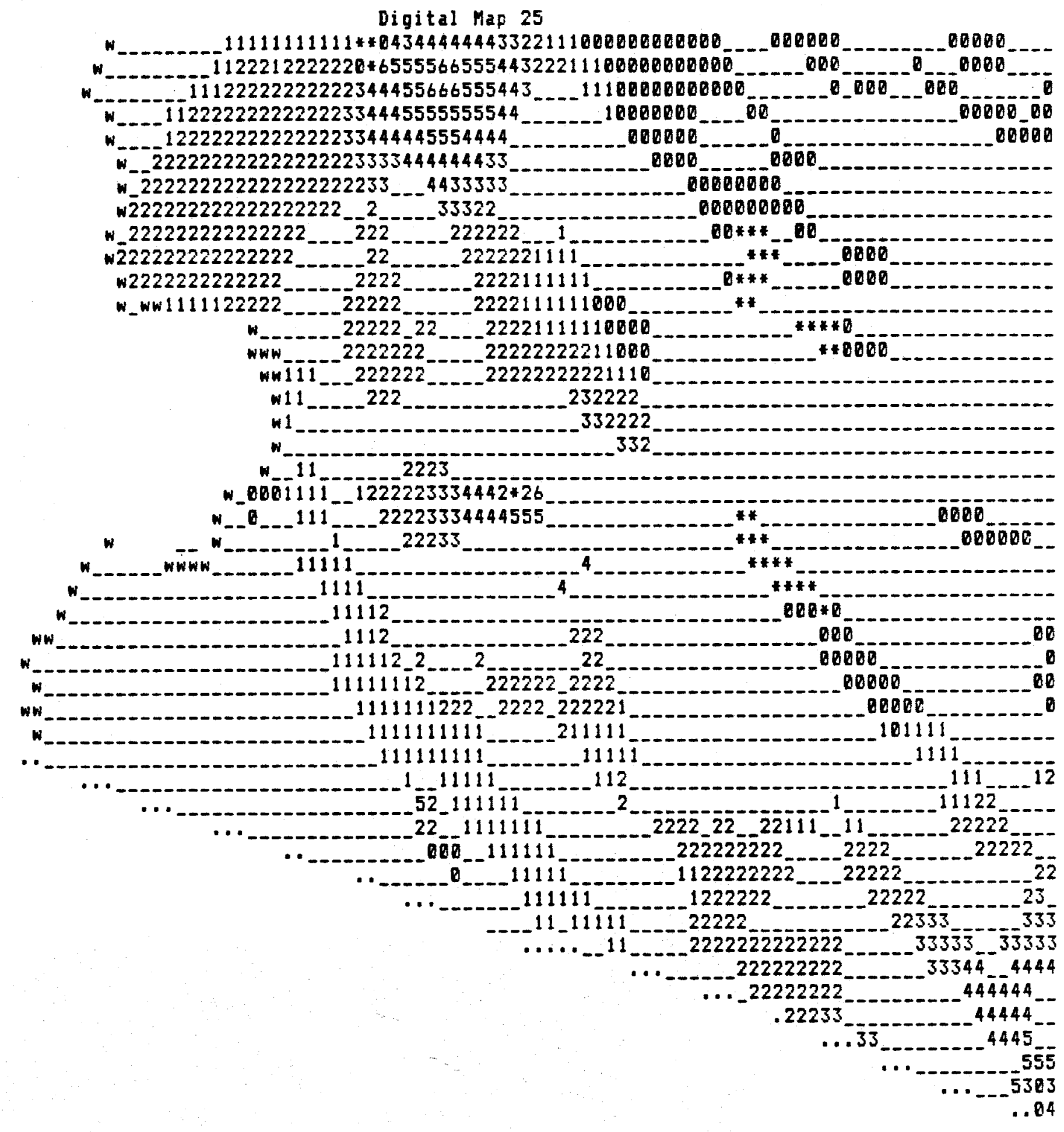

HOT DRY ROCK EXFLOITATION COSTS - MILLIONS OF 1983 DOLLARS CODE $\operatorname{cosT}$

More than 15

10 to 15

8.5 to 10

7.5 to 8.5

7 to 7.5

6.5 to 7

6. 106.5

5 to 6 


\section{GEOTHERMAL RESOURCE EVALUATION OF THE YUMA AREA}

In $1982 \mathrm{Blair}$, and others, found that the industry estimated that the number of deep wells required for confirmation varied from 2 to more than 5, with 3 as the mean. His cost table, which appears in Appendix D, shows that total expensed costs, which exclude certain site specific costs, as just under 6 million dollars. Site specific costs are expected to run $\$ 1,125,000$ plus deep drilling costs. Other site specific costs are piping costs and transmission costs. These cost analyses also appear in Appendix D, [Blair, et a1, 1982].

The previous discussion has not included geothermal development of Hot Impermeable Rock resources. Blair, and others discusses this briefly, providing a graph which is approximated by the equation:

$$
c=a+k\left(r-r_{\infty}\right)=,
$$

where $C$ is the cost in millions of dollars,

$$
\begin{aligned}
& a=\$ 5,000,000, \\
& k=\$ 510.4, \\
& r \text { is the local gradient, expressed as a pure number, } \\
& r_{\infty}=25, \text { and } \\
& s=-1.665 .
\end{aligned}
$$

Quoted costs are $40 \mathrm{million}$ dollars for a 30 oc $/ \mathrm{km}$. thermal gradient and $7.4 \mathrm{million}$ dollars for a $50 \mathrm{c} \mathrm{C} / \mathrm{km}$. thermal gradient. The results, in 1979 dollars, for the study area are shown as digital map 25: This is the same as digital map 7 except that thermal gradients have been replaced by exploitation costs. A discussion of updated 1986 costs appears in Appendix $D$.

\section{Conclusions.}

Dur economic analysis, when combined with the thermal gradient analysis, suggests that the study area is generally unpromising for geothermal exploration, except for possible hot impermeable rock exploration. As far as the use of geothermal brines are concerned, our analysis is as follows:

Dther than Radium Hot Springs, geothermal brines at shallow, (less than $500 \mathrm{~m}$.$) , depths have not exceeded 50 \circ \mathrm{C},\left(122^{\circ} \mathrm{F}\right)$, in temperature. The direct utilization of a resource at this low a temperature is 1 ikely to occur only when there is a well already drilled, or one is planned for other purposes. Dtherwise the capital cost is 1 ikely to be excessive. 


\section{GEOTHERMAL RESOURCE EVALUATION OF THE YUMA AREA}

Low temperature resources start to be widely useful at approximately $80^{\circ} \mathrm{C}$ (1760F). We examined the economic value of sol ar-geothermal hybrids to heat very low temperature resources to this, and comparable, temperatures, and found them to be unpromising. This discussion is the content of Appendix $C$. Drilling to the depth at which such a resource is likely to be found is also not economically attractive. In areas of the highest thermal gradients $\left(65^{\circ} \mathrm{C} / \mathrm{km}\right)$, this means drilling to approximately $1 \mathrm{~km}$. Using the previous formula for deep driliing costs, this would mean an initial capital expenditure in excess of 300,000 dollars at 1981 prices.

As we mentioned earlier, only direct thermal applications are presently envisioned for moderate temperature resources 1100 to 170 OC). In theory, binary systems could operate at temperatures as low as $120 \circ \mathrm{C}$, but the cost of moving the brine through the heat exchange system increases as the temperature of the brine drops, due to the need to move the brine through the system at an increased rate. Thus, $170^{\circ} \mathrm{C}$ is a current engineering requirement for binary systems. Flash systems require temperatures of approximately $190^{\circ} \mathrm{C}$. As we discussed earlier, direct thermal applications are unlikely in the study area.

Only the fortuna Basin is likely to have brines in excess of the 170-C minimum in its deeper regions. There, the depth to that resource is expected to be over $4 \mathrm{~km}$, with an expected drilling cost, for one exploratory hole of $1.5 \mathrm{million}$ dollars, at 1981 costs, assuming $15 \%$ igneous geology. At that depth there may be too little available water to make it an exploitable resource. Therefore, we do not regard this as a promising area.

The best area for hot impermeable rock resources within the study area is the area studied by Gutmann. We suspect that the Sierra Pinacate area may be better yet, but the best place to study that area is in Mexico, particularly in the neighborhood of Cerro Colorado. If hot impermeable rock exploitation still requires government assistance before it is to reach the market place, then a joint U. S. - Mexican geothermal exploration project in that area might be of greater value than a federally assisted project limited to Yuma County, or even Arizona. 


\section{GEOTHERMAL RESOURCE EVALUATION OF THE YUMA AREA}

\section{CONCLUSIONS AND RECDMMENDATIONS}

1. Remarks.

We now turn to answering the questions posed in the introduction.

1. Which subareas of the study area are the most likely prospects, should geothermal exploration actually be undertaken?

2. Based on present information, is there any location in the Yuma area which can be recommended for geothermal development?

3. Will further testing, other than deep drilling, add appreciably to our capability of evaluating the geothermal prospects of the area?

Yuma County?

4. Is geothermal energy a practical energy alternative for

We shall use the information developed thus $f a r$, and also take a broader, more comprehensive, view, in answering these questions.

\section{The Best Prospects}

Based on present information the most promising areas for geothermal exploration are:

a. The area of the $50 \mathrm{milligal}$ residual Bouguer gravity low, recommended by Gutmann for hot impermeable rock investigation is the best site of this type within the study area.

b. The Red Bluff Mountain area is a second best alternative for hot impermeable rock investigation.

c. The Fortuna Plain area is the only basin area which has any prospect of having brines at a temperature in excess of $170^{\circ} \mathrm{C}$, the current minimum for geothermal brine power production.

d. The Gila Basin area in the proximity of Radium Hot Springs is the best moderate temperature site.

e. The Hyder Valley - Palomas Plain area is the next best moderate temperature site. 


\section{GEOTHERMAL RESDURCE EVALUATION DF THE YUMA AREA}

We have virtually no thermal data for the interior of LukeWilliams Air Force Range, the Cabeza Prieta Wildilfe Refuge, or the Sierra Pinacate area in Mexico, (a National Park of Mexico). Based on a possibly high thermal gradient at Cerro Colorado, and higher than projected gradients in the Luke-Williams area, the following areas are worthy of consideration.

a. The southeast corner of the county, in the southern Sierra Pinta Mountains may be an exploitable hot rock area.

b. The area of the $40 \mathrm{milligal}$ Bouguer gravity low, in the Cabeza Prieta Mountains may also be an exploitable hot rock area.

c. The Mohawk Valley, given a high enough thermal gradient, may contain a geothermal brine site for possible power generation.

d. The Gila Basin, between the Castle Dome Plain and the Mohawk Valley, may contain site suitable for power generation.

Basin areas of considerably less likelihood for geothermal power generation have drawn our interest due to possible gross underestimates in gravity modeled depth to bedrock. These are:

a. The Castle Dome Plain, which may have thick andesitic flows covering an older Tertiary sedimentary basin.

b. The area west of Sentinel Plain may have later Tertiary basaltic flows covering an older Tertiary sedimentary basin.

c. The basin area to the east of the Tinajas Altas Mountains, in the Lechiguilla Desert, may be considerably deeper than estimated by gravity modeling.

3. Recommendations for Development.

We can recommend no site within the study area for its convective thermal potential for electric power production. Even if there are higher than expected gradients in portions of LukeWilliams Range, the result would be barely adequate temperatures found at great depths in hardened sedimentary conglomerates with very low water content.

We do not recommend moderate or low temperature geothermal investments in this area at this time. There may, however, be occasions in which warm waters at relatively shallow depths can be made useful.

Hot impermeable rock development is also not recommended at this time within the study area, although the North Castle Dome Plain area was best in the thermal gradient evaluation. Our caution is due to our finding that the present energy situation is unfavorable to such development, and the existence of other areas of interest which have, as yet, been poorly explored. 


\section{GEOTHERMAL RESOURCE EVALUATION OF THE YUMA AREA}

\section{Recommendations for Further Testing.}

It is possible that a drastic change in the energy picture could make the exploitation of hot impermeable rock resources economically desirable. This could come about, for example, with a sharp increase in electric rates or the abandonment of nuclear power projects in this country. In such an event, the further geophysical exploration of Castle Dome Plain and the surrounding mountains, the Sierra Pinacate area and the Cabeza Prieta area are recommended before further action is taken. The results of such geophysical testing would then determine the best site for further development.

The one area which would have the greatest impact on our knowledge of geothermal prospects in the general area 1 ies, for the most part, outside of the study area and of the country. It is the Sierra Pinacate area. This is due to the lack of geophysical information, in particular, of a thermal profile for the area. Geophysical testing, in particular, thermal gradient testing, would lead to confirming or eliminating the area as a potential site for hot impermeable rock energy development, and would undoubtedly affect our assessment of the Cabeza Prieta Mountain area, as well.

A second alternative is thermal gradient testing in the Cabeza Prieta Mountain area. This is also an area of scant geophysical, in particular, thermal information. Information from that area may or may not fundamentally alter our geothermal assessment of the study area.

In all other cases, the results of further testing are not expected to fundamentaliy alter the general conclusions we have drawn regarding the geothermal energy potential of the study area. There are, however, many areas which would reward further study and have some impact on the known thermal profile of the study area.

a. A seismic and thermal study of the Castle Dome Plain would lead to a more accurate thermal gradient profile of the area and to more accurate geological and physical profile of the area.

b. A seismic study of the fortuna Basin would be useful for a deeper evaluation of this potential, but currently unpromising, geothermal site. In particular we are interested in the gravity determined 'saddle area' which was noted by Mattick, and others, [Mattick, et $a I, 1973]$, and which could indicate a region of hydrothermal alterations rather than true depth to bedrock.

c. An investigation of the anomalously high gravity values in the Gila Trough area is expected to uncover moderate temperature reservoirs in those areas. 


\section{GEOTHERMAL RESOURCE EVALUATION OF THE YUMA AREA}

d. A seismic and thermal mapping of the Mohawk Basin would be useful in obtaining more certain thermal and physical profile for that area, and would resolve whether or not the area has any potential at all for high temperature geothermal development.

e. The Sentinel Plain area and its environs is worthy of further thermal gradient investigation. Most of it lies outside of the study area, which is why it has not figured more prominently in this discussion.

Much of the suggested testing can be done without deep drilling, at least for preliminary assessment purposes. Reliable thermal gradient testing and the probing of suspected areas of hydrothermal alterations will require drilling below $2,000 \mathrm{ft}$.

In addition to geophysical testing we recommend the following lines of research.

a. A study of the relationship between warm water anomalies and thermal gradients could lead to less expensive methods of determining at least rough approximations to thermal gradients, which would be useful to geothermal prospecting.

b. Further modeling of the dynamics of fluid and temperature flow in the basins of the Basin and Range Province would be of considerable value in many fields.

c. Further research would be useful in the field of thermal contouring.

d. It would be of general utility to extend the present computer work, in particular the digital mapping of the various parameters of the study area, throughout the Basin and Range Province of Arizona, and possibly the entire State.

5. Final Conclusions.

We view the geothermal resources of Yuma county as a potential which is best left untapped until economic circumstances and the energy situation in the county change radically. In the interim it is expected that improvements in the technology of geothermal exploitation will also increase the economic attractiveness of potential geothermal sites. There is sufficient potential, however, to warrant further investigations which have the end of illuminating the extent of that potential. $A$ comprehensive program of testing and evaluating a large number of prospective sites, over wide area, would serve to have the most promising sites mapped out, ready for development, should the energy picture change and geothermal energy development in the area become desirable, or even urgent. 


\title{
GEOTHERMAL RESOURCE EVALUATION OF THE YUMA AREA
}

\author{
NOTES
}

1. Dur original study area was that area which was studied by the geological surveys of the early 1970's ([0lmsted, et al, 1973], [Mattick, et al, 1973] and [Patten, 1977]. This is the area shown in figure 7. We shall continue to refer to this as the Yuma area. This study area was later widened to include all of what was once referred to as Southern Yuma County - old Yuma County south of the Gila - Salt River Baseline. This is roughly the same as present day Yuma County, as shown in figure 2. In 1983 Yuma County was divided into La Paz County and Yuma County, as shown.

2. Geothermometry is the estimation of deep well or borehole temperatures from the chemical constituents of the brine. Appendix $A$ contains additional details.

3. The thermal gradient is the rate of change of temperature with depth. It is generally highly variable, especially at shallow depths, due to variations in the thermal conductivity of naturally occurring materials, and to the presence of convective effects. Heat flow is the rate of heat transfer from a warmer to a cooler body. They are related by the Fourier equation, which, in the one dimensional case is expressed as:

$q=k * G$, where

q is the heat flow, per unit area,

$G$ is the thermal gradient: the change in temperature with respect to depth, and

$k$ is the conductivity of the medium.

In internationally used units, $G$ is expressed in ${ }^{\circ} \mathrm{C} / \mathrm{km}$, or more properly in ok/km, $q$ in $\mathrm{mW} / \mathrm{m}=$ and $k$ inevitably in $\mathrm{W} / \mathrm{m}$-ok:

4. An alternative classification which is frequently used is vapor dominated, liquid dominated, geopressured, and hot impermeable rock. Vapor and 1 iquid dominated systems are alternate forms of convective hydrothermal syetems. The terms refer to the rel ative presence of steam as opposed to brine in the discharge.

5. A thermal spring is any spring which is $15^{\circ} \mathrm{C}$ warmer than the mean ambient temperature, CWaring, et al, 1965]. A thermal well in Arizona is defined as any well whose discharge is both above 200C and at least $10 \circ \mathrm{C}$ higher than the mean ambient temperature, [Arizona Geothermal Resources Map, Witcher, et al, 1982]. 


\section{GEOTHERMAL RESOURCE EVALUATION OF THE YUMA AREA}

6. The Curie temperature is the temperature at which magnetite loses its magnetism (B510K or 5780C). The Curie depth is the depth beneath the surface at which the Curie temperature is attained.

7. The crustal depth is the depth at which rocks become plastic. There is also a change in chemical composition and an increase in density generally inferred at this point. These inferences are drawn from discontinuities in the seismic data.

8. Geological metamorphism is any change in the physical or chemical properties of a rock through the agencies of heat, pressure or chemical reaction.

9. Igneous rocks are classified in several ways. Two of the most commonly used are according to the method of emplacement and according to chemical composition. Igneous rocks which are emplaced at the surface of the earth are referred to as volcanic or extrusive, as opposed to plutonic or intrusive. Intrusive igneous rocks are also classified as dikes, if they have a more wall-like structure and sills if they have a more floor-like structure. According to chemical composition, basalts are the most basic volcanic rocks. They are also referred to as mafic, because they are rich in magnesium and iron. Their plutonic counterparts are gabbros. Peridotite is regarded as the mantle precursor of gabbro. At the other end of the scale, andesites and rhyolites are the most highly acidic volcanic rocks and are relatively rich in silica and poor in iron and magnesium. The plutonic counterpart is granite. In the middle of the scale are the dacites (volcanic) and diorites (plutonic).

10. Schists are metamorphic rocks with easily visible lines of cleavage in their texture. Gneisses are banded in texture, without cleavage patterns.

11. This earthquake epicenter map shows all California earthquake epicenters for earthquakes of magnitude greater than 1 on the Richter scale, while other areas have epicenters shown for earthquakes of magnitude greater than 3 . Nevertheless, the map serves to make an accurate qualitative comparison. 
B: \APPENDA. DOC

\section{GEOTHERMAL RESDURCE EVALUATION DF THE YUMA AREA}

APPENDIX $A$.

RADIUM HOT SPRINGS, GEOTHERMOMETRY AND THE PHYSICS OF A HOT SFRING

\section{Radium Hot Springs and Agua Caliente.}

Two hot springs flowed in the Gila Basin area earlier in this century. Radium Hot Springs, at 600C, (1400F), lies within the study area, and Agua Caliente, at $40 \circ \mathrm{C},\left(104{ }^{\circ} \mathrm{F}\right)$, just to the east of the study area. Both are now dry. Loss of pressure head at the source of the spring is given as the most likely reason for the quenching of these springs, [personal communication, Dr. Pearce, U.5. Bureau of Mines and Mineral Technology, 1985J. This 1055 of pressure is most likely due to the large scale use of water by agriculture. The magnitude of this use can be grasped by observing that even with present residential and industrial activity, agriculture uses in excess of $90 \%$ of the ground water pumped in Arizona, [U.S.6.S. Water Resources Map, 1978].

Our interest in these springs is due to the fact that they provide estimates of temperatures at the source of the springs, hence of temperature gradients. This'is particularly useful if there are sparse thermal gradient measurements in the area and no deep wells. Both springs lie in such areas of sparse heat flow measurements, particularly Radium Hot Springs. The Radium Hot Springs area was visited and described by Wilson in 1930, and we quote from his report, [Wilson, 1933].

"A group of thermal springs is on the northern bank of the Gila River near the southeastern margin of the Muggins Mountains, in Sec. 12, T. B S., R $18 \mathrm{~W}$. In 1930 it was held by Dr. C. A. Eaton, of Yuma, who was developing the place for a health resort called Radium Hot Springs. From the highway at Tacna, this place is accessible by eleven miles of road."

Here, a small hill of brown sericitized andesite rises less than 100 feet above the flood plain. The thermal water, which bubbles up from the mud flat of the river at the base of this hill, is said by the manager of the resort to have a temperature of approximately 140 of. According to an anlysis made in 1924 by Dr. T.F. Buehrer, of the University of Arizona, this water contains the following: 
GEOTHERMAL RESOURCE EVALUATION OF THE YUMA AREA

Constituents

Total dissolved solids..........

$\mathrm{SiO}=$

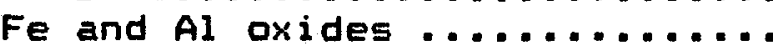

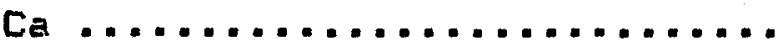

$M g \ldots \ldots \ldots \ldots \ldots \ldots \ldots \ldots \ldots$

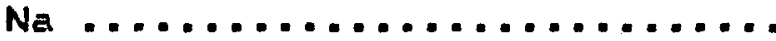

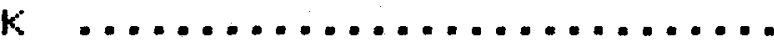

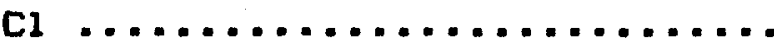

$50_{4} \ldots \ldots \ldots \ldots \ldots \ldots \ldots \ldots \ldots \ldots \ldots \ldots$

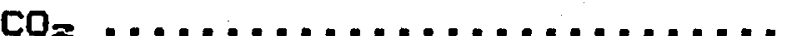

Bicarbonates
PPM

$2,804.0$

101.0

3.9

162.0

none

746.0

17.0

740.0

898.0

none

73.0

Radium element (niton) $1.2 \times 10^{-\rightarrow}$ grams per liter, approx.

According to Dr. Buehrer, the radium emanation of this water is approximately equivalent to that of most hot springs in the western United States.

The heat of this water is probably due to deep-seated, quiescent volcanic activity."

2, Geothermometry

Geothermometry is the estimation of the maximum temperature of ground water based on the chemical analysis of the water. The two principal geothermometers presently used are the Silica and the Sodium-Potassium-Calcium ( $\mathrm{Na-K-Ca),} \mathrm{methods.} \mathrm{The} \mathrm{silica}$ method assumes that the measured silica content is the result of the dissolving of quartz in the hot brine. It is therefore subject to two distorting influences. The first is the presence of amorphous silica in the ground water, perhaps due to some previous thermal event. The second is the fact that the solubility of monomeric silica in water is also a function of the pH level. This function is a local minimum at a $\mathrm{pH}$ of approximately 7.0 and rises quite rapidly as the $\mathrm{pH}$ inereases above $B .0$. In order to handle both problems we introduced a correction term based on values, in parts per million, of the silica present in the ground water of nearby locations. Thus, rather than 101 ppm we used (101 correction term) where the correction terms were determined from samples from the Castle Dome Plain and from the Gila Basin area near Mohawk. This gave us three values: the uncorrected value, the mean value for the Gila Basin area, and the mean value for the Castle Dome Plain, as determined from our samples. 


\section{GEOTHERMAL RESOURCE EVALUATION OF THE YUMA AREA}

The Silica equation [Wahl, 1977], is as follows:

$T\left({ }^{\circ} \mathrm{C}\right\rangle=\left\{2662 /\left(11.2-1 n\left(K_{a}\right)\right)\right\}-273.15$,

where $K_{a}$ is the (assumed) quartz concentration in parts per million.

The three values obtained from our correction procedure were as follows:

$$
\begin{array}{ll}
T \text { (uncorrected) } & =1310 \mathrm{C}, \\
T \text { (CDF correction) } & =113, \\
T(\text { Gila correction }) & =122 .
\end{array}
$$

Given the location of Radium Hot Springs as described by Wilson the Gila Basin correction is the one most likely to give a correct result. It is also the mean and the median of the three.

The pH of the Castle Dome Plain samples rantged from 6.7 to 8.3 with a mean of 7.6. The Gila Easin samples ranged from 7.3 to Q.1 with a mean of 7.7 .

The Na-k-Ca geothermometer is calculated from the equation: $T(O C)=\left\{1647 /\left[\log _{20}(\mathrm{Na} / K)+b * \log _{20}\left(s \mathrm{Ca}^{\prime} / \mathrm{Na}\right)+2.24\right]\right\}-273.15$, where $\mathrm{Na}=$ (sodium concentration, $\mathrm{ppm}$ )/23000,

$$
K=\text { (potassium concentration)/39100, }
$$$$
C a=\text { (Calcium concentration)/40080, }
$$

and we have used a value of $b=1 / 3$.

We have used the Na-K-Ca equation from the 'GEOTERM' program of Truesdel1, [Truesdel1, 1975]. The maximum temperature calculated by this method for Radium Hot Springs was 118 oC. 


\section{GEOTHERMAL RESOURCE EVALUATION DF THE YUMA AREA}

3. A Physical Model of a Hot Spring.

The following is extracted from Geodynamics by Turcotte and Schubert, [Turcotte \& Schubert, 1982]. If we assume that the water flows through an aquifer channel with an annular path, with:

R the outer annular radius,

$r$ the channel radius,

5 the distance measured along the aquifer (channel) from the entrance,

$x$ the angle to the point where $s$ is measured, $x=5 / R$,

$u$ the mean velocity in the aquifer,

T the flow-averaged temperature of the aquifer fluid,

Tw the wall temperature,

$D$ the fluid density,

c the heat capacity of the fluid, and

$h$ the heat transfer coefficient, then,

balancing the heat convected along the aquifer against the heat lost or gained by conduction to the walls, we can write:

$$
* r=* D * c * u *(d T / d s)=2 * * r * h *\left(T_{m}-T\right) .
$$

If we now use the relation:

$$
s=R * x,
$$

and assume that the wall temperature of the aquifer is related to the local geothermal gradient, $G$, by

$T_{m}=R * G *(\sin x)+T_{\infty}$,

where $T_{0}$ is the surface temperature, and $G$ is assumed to be constant, we obtain the equation,

$$
\left[r=* D *[* L / R] *(d T / d x)=(48 / 11) *\left[k * R * G *(\sin x)+T_{\infty}-T\right] .\right.
$$


E: \APFENDA. DOC

\author{
GEOTHERMAL RESOURCE EVALUATION OF THE YUMA AREA \\ number. \\ This equation can be simplified by introducing the feclet \\ $P e=D * c * u * r / k$, \\ where $k$ is the thermal conductivity of the fluid. \\ If we now define the dimensionless temperature, $t$, by, \\ $t=\left(T-T_{0}\right) /(* R)$, we obtain the differential equation,

$$
(11 / 4 \theta) *(r / R) * P E *(d t / d x)+t=\sin x .
$$ \\ The solution, $t(e)$, at the exit, where $x=$ is given by, \\ $t(e)=x *[\exp (x)+1] /[1+x]=$, where \\ $X=(48 / 11) * P e * r / R$.
}

It can be shown that the exit temperature of the hot spring is a maximum for $r * P e / R=5$. Thus for given values of all parameters other than the mean velocity, there is a particular flow rate through the aquifer that maximizes the exit temperature of the fluid. The maximum exit temperature is about one-half of the maximum wall temperature at the base of the aquifer, since $t(e)=1 / 2$ corresponds to

$t(E)=T_{0}+(G * F / 2)$, and

Tw at $x=12$ is:

$T_{0}+G * R$ for $T_{0}<<G * R$.

The maximum exit temperature occurs because at lower or higher flow rates there is no spring. If the flow rate is low, say $r * P e / R=1$, then the fluid temperature follows the wall temperature because of the large heat transfer, the exit temperature equals the wall temperature and there is no hot spring. For a high flow rate, say $r^{* P e} / R=15$, there is very little heat transfer and the awater does not heat up. In the limit, r*Pe/R $\rightarrow$, the fluid temperature everywhere in the aquifer equals the entrance temperature and again there is no hot spring. At the maximum exit temperature, $r * P e / R=5$ and $t(E)=0.52$.

The implied value for Radium Hot Springs is therefore $60 / 0.48$ $=125 \circ \mathrm{C}$. For Agua Caliente it is 40/0.48 = B.30 C. 


\section{GEOTHERMAL RESOURCE EVALUATION OF THE YUMA AREA}

4. Estimating the Gradient.

In the previous section we obtained a maximum value for the aquifer temperature at Radium Hot Springs as $122+1-9 \circ \mathrm{C}$ and an approximation at Agua Caliente of 830C. Our initial estimate for the depth to bedrock in the neighborhood of Radium Hot Springs was $1.5 \mathrm{~km}$. , while a maximum depth to bedrock estimate at Agua Caliente is $1 \mathrm{~km}$. Assuming an ambient temperature of $21.5{ }^{\circ} \mathrm{C}$ for both locations, the thermal gradient is estimated to be $67{ }^{\circ} \mathrm{C} / \mathrm{km}$ at Radium Hot Springs and $61{ }^{\circ} \mathrm{C} / \mathrm{km}$ at Agua Caliente.

In their geothermal analysis of the Hyder Valley and Falomas Flain areas, Jones and Campbell reproduce a graphical analysis of the thermal data for Yuma County by Giardina and Conley, CGiardina \& Conley, 1978], which suggests a maximum thermal gradient within Yuma County of approximately b6 ${ }^{\circ} \mathrm{C}$, [Jones \& Campbel 1, 1979]. Results obtained by us do not appear to contradict that analysis. 
B: $\triangle A P P E N D E . D O C$

\section{GEOTHERMAL RESOURCE EVALUATION OF THE YUMA AREA}

APPENDIX $\mathbf{B}$.

\section{Introduction}

In August of 1984 the Arizona Solar Energy Commission embarked on a program funded by DOE, to determine the geothermal resource potential in the Yuma area.

The direction the program took was, in part, guided by a statement written by Dr. John C. Davis of the Kansas Geological Survey, in his 1973 text: STATISTICS AND DATA ANALYSIS IN GEOLOGY (pg. 5, par. 5) that applies to any observational science: "When carefuliy and dispassionately analyzed, many geologic interpretations deteriorate into a collecion of guesses and hunches based on very little data, most of which is of a contradictory or inconclusive nature." That is, given any observational science, its conclusions are generated by hunches and guesses guided by information, training, experience and intuition. (Note: The term data and information are not interchangeable. Information is data that has been processed, manipulated and categorized.)

We recognize that frequently hunches, guesses, etc. are all that one may have to work with. What is desirable, however, is some method of displaying these hunches, etc., and the relative importance we have given them. Such an approach to analyzing complex problems has been developed by Dr. Thomas L. Saaty of the University of Pittsburg and the methodology is called the Analytic Hierarchy Process (AHP). This technique does not, in any way, replace expert opinion, but rather structures a system and its environment into mutually interacting parts and then by rating the "interactions" of these parts on each other and on the entire system (e.g., the geothermal resource of the Yuma region), using a knowledge base and rules, the technique enables the user to evaluate a system.

To be more specific, the AHP breaks down complex issues or problems into "clusters" or "chunks" and then breaks each of these into smaller clusters and so on. Afterward, relative to a given criterion, or attribute, the clusters are rated in a pairwise fashion. This criterion is represented by other cluster or chunks which are part of the next higher level of a hierarchy, hence, the name AHP.

The AHP technique lends to ranking or rating processes a structured decision path for all to follow. While no one single technique is a panacea, the AHP process has been widely applied by Saaty and co-workers in a variety of applications with good results. This is in no way meant to be thesis for AHP to replace more traditional methods that geologists have so successfully used for many years, however, the authors do believe that the use of AHP can allow a documentation of the interactions or influences of various factors in the decision process, especially, with a complex system as pointed out above. 
B: IAFPENDE. DOC

\title{
GEOTHERMAL RESOURCE EVALUATION OF THE YUMA AREA
}

\author{
2. Rating a Geologic System by AHP.
}

Fully characterizing an area geologically is an expensive and time consuming business (see Chapter 5 and Appendix D). Moreover, more often than not, some kind of decision as to the viability of a geologic resource must be reached without having as much data as desireable. In addition, if an area is rated a "good region for geothermal resource of moderate to low temperatures" this characterization is made using "clusters" of the known gealogic properties, such as surface anomalies, or the specific fact that moderate to low temperature springs or wells are present in the area. In our opinion, such characterizations are really assignments of "degrees of membership." That is, one area that may possess more of one kind of evidence to be called a "good geothermal area, and the other "good" area another kind of evidence. Indeed, it is clear that geologic areas, as physical objects, have characteristics which differ in "degree" rather than "kind", so that, although they may $=$ very "close together" for most of the proerties or characteristics being studied such as seismic activity, volcanism, hydrology and so forth, it would be misleading to categorically state that both equally fit into a particular "geologic slot".

Thus, any region can only be assigned a "degree of membership" to a particular complex geologic category and not an "absolute membership". Basically, what this means is that because of its complexity, a geologic setting can be a very "fuzzy" concept to deal with as is any complex system. What Saaty's method does is to provide a technique to measure the degree of membership that an area has with respect to a particular collection such as "a good geothermal area". Such techniques are used with varying degrees of sophistication in all endeavors requiring observations and judgments. As an example, the 1981 report of the Nevada Department of Energy authored by Maggie Pugsley, entitled: "Geothermal Resource Area \#3, Elko Development Flan" used a rating technique to give numerical weights to known geothermal resources of Elko County, Nervada, and so, ranked them as geothermal resources having various degrees of viability.

The Nevada report is, in our opinion, an outstandingly useful one because it allows the user to quickly come to terms with the question of: "How does the geothermal resource prospect rate here?" rather than be lost in an inundation of "fuzzy" relations such as appear in the statement: "The presence of warm water and very low resistivities in the subsurface, and the high geothermal gradients strongly suggests the presence of geothermal energy." Such relations are "fuzzy" because, specifically, what does the sentence "The presence of warm water..." mean? That is can mean a lot of different (related or close) kinds of situations is immediately clear to anyone. Now, to classify a statement as "fuzzy" is not to impugn its usefulness, because, any object we talk about generally involves a "fuzzy" concept. The main reason why concepts or notions are "fuzzy" is that they are composite, 
B: IAPPENDE. DOC

\section{GEOTHERMAL RESOURCE EVALUATION OF THE YUMA AREA}

complex, i.e., they involve a complexity of simpler concepts and by breaking the concept down into ts simpler components it can become easier to analyze.

This is basically what AHP does.

3. A Specific Hierarchical Example.

As mentioned, Saaty's method allows a composite concept to be broken down into more elementary concepts and these concepts are then structured into a hierarchy. The hierarchy has as its top level (or focus) the composite concept with the bottom level being the object or action to be evaluated and the intermediate levels are formed by the components of the concept and action or object.

Structuring the hierarchy is a non-trivial exercise and, in fact, is the most critical and difficult part of the task. But, while being difficult, the task also serves a very important purpose, namely, to force the users into looking at a very complex issue in terms of its more elementary parts and their individual interactions.

As an example of constructing a hierarchy the following is given. First, the "focus" or "composite concept" or "objective/goal" is listed which is a fuzzy attribute such as "Optimal Cooling System", "Best Site for a Geothermal Resource", "Good Research Project" , etc. that you believe a collection cor set) of objects to possess in varying degrees. Next, a set of purposes or properties of this collection of objects with respect to the focus must be written out. Each succeeding level of the hierarchy starting from the bottom to the top should contain purposes or properties (with respect to the focus) that are shared by some (or all) of the elements in the immediate preceding levels above it and below it. Technically, the elements in, say level 1 are said to "dominate" or "cover" some or all of the elements in level 2. Then the elements in level 2 cover or dominate some or all of those in level 3 with respect to the focus and so on. The example shown will only have two levels for simplicity. It is a hierarchy whose focuse is "Most Likely to Develop a Hot Rock. Resource (HRR)". That is, the goal or focus is "Most Likely to Develop a HRR" and each given element in Level 2 possesses this attribute to some degree (or possibility).

The level below the focus consists of locales in the Yuma area. Namely, state or BLM lands, the Yuma Test Station and the Luke-Williams region along the U.S. Mexican border. The rating will be to determine on which of these locales would a developer most likely promote a HRR.

Level 1: Focus: Most Likely to Develop HRR

Level 2: State/BLM Lands Yuma Test Station Luke-Williams 


\section{Table 4}

\section{Conditlonal Rating scale}

to rank the

Antecedent A relative to the aubsecuent B relative to an objective or goal (Focus)

Assign a No. $(1-9)$ based on:

Rating

Scale

1

2. 3 or 4 . Weak importance or value of

Weak importance or value of
antecedent relativa to subsequent

5 or 6

7 or 8

Definition

Equal importance or value or antecedent relative to subseguent

Essential or strong importance or value of antecedent relative to subsequent

Demonstrated Importance or value of antecedent relative to subsequent

Absolute importance or value of antecendent relative to subsequent
Exception

Hone

If aubsequent is

of weak importance

relative to

antecedent then enter

$2 / 2,1 / 3$ or $1 / 4$ in

score

If subsequent is

of essential or

etrong Importance

relative to

antecedent, then $1 / 5$

or $1 / 6$ in score

If subseqquent is of demonstrated

importance relative to antecedent, then enter $1 / 7$ or $1 / 8$ in score

If subsequent is

of absolute

importance relative

to antecedent, then

enter $1 / 9$ in score 
E: \APPENDE.DOC

\section{GEOTHERMAL RESQURCE EVALUATION OF THE YUMA AREA}

Basically the AHP for the above hierarchy works as follows:

1. Given the focus or objective, the rating method proceeds by taking each element in Level 2 (one by one) and comparing it with all of the others in Level 2 relative to the focus in a pairwise fashion. So, the element state/BLM Lands forms the antecedent of the pair, and any of the other two elements form the subsequent member.

2. Assign a number rating to the pair as per Table 5 .

3. Using Table 4, form a matrix of ratings as follows:

\begin{tabular}{l:ccc}
$\begin{array}{l}\text { Likely spot to } \\
\text { develop HRR }\end{array}$ & State/BLM & YTS & Luke-Williams \\
\hdashline State/BLM & 1 & $1 / 6$ & $1 / 2$ \\
YTS & 6 & 1 & 2 \\
Luke-Williams & 6 & $1 / 2$ & 1
\end{tabular}

This matrix then gives a listing of the ratings of this particular hierarchy. Next, an eigenvector is (approximately) given by $(0.104,0.549,0.346)$ which means that the Yuma Test Station is rated as much more likely a place to develop an HRR on than any State/BLM land site. A Luke-Williams site on the border is rated as having anintermediate likelihood of developing a HRF on.

The ratings were given under the following assumptions:

1. The Yuma Test Station is the most likely spot to develop a HRR because the military would be interested in energy selfsufficiency if a high temperature source was present, and, would very likely have ready funds to develop the resource as part of the National Defense.

2. The Luke Williams Border area is one that is less likely to develop an HRR on than Yuma Test Station because of its remoteness from potential users (e.g., a military base); however, military interest in high temperature resources make it more viable than State/BLM lands, since it would be possible to develop a high temperature HRR to generate electrical power and then wheel it to military bases. 


\section{GEOTHERMAL RESQURCE EVALUATION OF THE YUMA AREA}

3. State/ELM lands generally are more likely to become populated and, hence, valuable or to remain remote withlittle likelhood to have nearby users. Therefore, it would be inferior in ratings relative to developing a HRR on it when compared with Yuma Test Station or Luke-Williams Border. With users present the 1 and costs would be very high and with no users present the power would not be there.

The example, as given, is simple and the AHP method is very straightforward to use for such a simple task, However, the types of ratings for geothermal exploration usually encountered are much more complex and are dependent on the nature (or state) of the data. That is, the data may be well documented and reliable or date that is.sporadic and not well correlated to anything. To measure the effect of the states of data the following classifications of the states was assigned.

4. States of Physical Data.

The states of physical data that are used to classify a geologic region can be categorized into the four following types:

I. Specific Physical Evidence (Information)

II. Physical Models

III. Uncorrel ated Data

IV. Possibilities Based on Sparse Data

State I. Specific Physical Evidence is a category of physical data that has been analyzed by specific kinds of analysis such as: chemical, physical and/or statistical. The data is then said to be transformed into Evidence or Information which cn then be used to support a given hypothesis or to categorically establish a hypothesis. In the latter case the Stat is called Certain Specific Evidence.

State II. Physical Models is a category that represents a stage of data processing where the information is used to develop a mathematical model that represents the physical characteristics of a region. The reliability of such a modelis then determined by the accuracy of its predictions compared to new dati that is acquired.

State III. Uncorrelated Data is a category of data that is primarily in "raw" form. That is, it has not yet been analyzed to a sufficient degree to label it as Information, however, it may be used to weakly support a hypothesis. 


$$
\text { Tatile } \cdot \text {... }
$$

\section{Definition of Terms:}

\section{Specific Physical Evidence (or Information)}

1. Certain: There exists the specific physical object that is being sought after that conclusively establishes the hypothesis.

2. Middle: There exists documented and categorized physical evidence which strongly supports a given hypothes1s. The evidence is not of a nature that conclusively establishes the hypothesis but it does give high credibility to the conjectures. That is the level of controversy will be low after this kind of evidence is presented.

3. Low: There exists documented and categorized physical evidence that supports a given hypothesis but only weakly. That 1s, there is room for some controversy.

\section{Models}

1. High: Because there exists documented and categorized data that weakly -supports a given hypothesis a physical/mathematical model can be constructed that is based on the hypothesis supported by this data. Then this model can be used to generate data that can be subjected to fleld confirmation and so be used as a guide to further exploration and acguisition of specific physical evidence.

2. Middle: There exists some documented and categorized data ... but this data does not clearly support a giver hypothesis. A physical/mathematical model can be constructed that is based on this data and some hypothesis not at odds with the data. The model can be used to consider the physical feasibility of this hypothesis and can then be used as a rough guide for further exploration of speciflc physical evidence.

3. Low: There exlst only uncorrelated and unanalyzed data about a region. A physical/mathematical model which is based primarily on regression, analysis of veliance or lactorial analysis of this data can be constructed as a first step in the analysis and categorization on the data. such models, since they are based purely on statistical analysis methods cannot be used with high degrees of reliability to guide further exploration. Although the model could be used as a rough guide for classification purposes. 
Table 6

$\because: \therefore-\quad \therefore$

\section{Uncorrelated Data:}

1. High: There exists a large amount of uncorrelated physical data which could have oignificance regarding an hypothesis, such as earthouakes, magnetic anomalies, gravity anomalies but it is not generally agreed that it does and the data has not been analyzed.

2. Kiddle: There exists episodic physical data, In smaliex quantities, that could have slgniflcance regarding an hypothesis but there ore some gaps in the data. Moreover, the existing data is arguable with respect to supporting or not supporting the hypothesis. Also, the data has not been analyzed.

3. Low: There exists episodic physical data, in small guantities, that could possibly support a hypothesis

- but there are many gaps in the data, in some cases it is entirely missing. In addition the guantity and ciality of the data is such that it is argumentative as to whether or not it can be used to support a bypothesis.

\section{Conjectures:}

1. High: No direct physical data exists to support a hypothes 1s, however, there exists significant structural simliarities of one region under consideration to regions that are known to support the same hypothesis. So, through the use of taxonomic methods, the region can be classified and some inference made.

2. Middle: No direct physical data exists to support a hypothesis, however, there exists some structural physical sinilarities to sites that support such a hypothesis. Therefore, taxonomic methods can be used to support a preliminary inference.

3. Low: No direct physlcal data exists to support a hypothesis and few, If any, similarities in structures are present that are the same as structures of regions that support such a hypothesis. However, by using some prelimary taxonomy a tentative hypothesis can be formed. 


\section{GEOTHERMAL RESOURCE EVALUATION OF THE YUMA AREA}

State IV. Possibilities Based on Sparse Data is a category that represents a situation of only sparse raw data or just some preliminary observations that may concern the phtysical structure of the site, such as anomalies or the proximity of another site which possesses or is suspected to possess a giviirermal resource.

Table 6 .

A further breakdown of these terms is given as Table 5 and

Given a particular region and a state of geologic information or data about that region a decision maker can come to some conclusion about that region's rating as a potential geothermal site. Now, this conclusion (or action) will be generally made (or taken) under the following circumstances:

a. Certaintyi: A KGR is present on the site, such as at the Geysers, Cerro Prieto or in the Imperial Valley. Therefore it is certain that geothermal usage is possible.

b. Risk: The geologic data shows that there are hot wells or hot rocks in the area but their flow rate, sites, temperatures and other parameters are not specifically known. However, there is sufficient data known about the region (Specific Data) to determine an empirical risk factor for the action or decision (e.g., to go ahead with the project).

c. Uncertainty: The geologic data is not sufficient to know if there are hot wells or hot rocks in the area, and only data that relates to anomalies is obtainable. Moreover, that data is sparse and episodic in nature. $\because \cdots$

Therefore the decision maker comes to a conclusion or action using information or data under certain conditions, risky conditions, or uncertain conditions and in terms of the states of Physical Data, the following breakdown is possible:

Certainty (C): Covers the Certain Specific Data category only.

Risk (R): Covers the Middle Specific Data category to the Low Model category.

Uncertainty (U): Covers everything from the High Uncorrelated Data Category to the Low Conjecture category. 


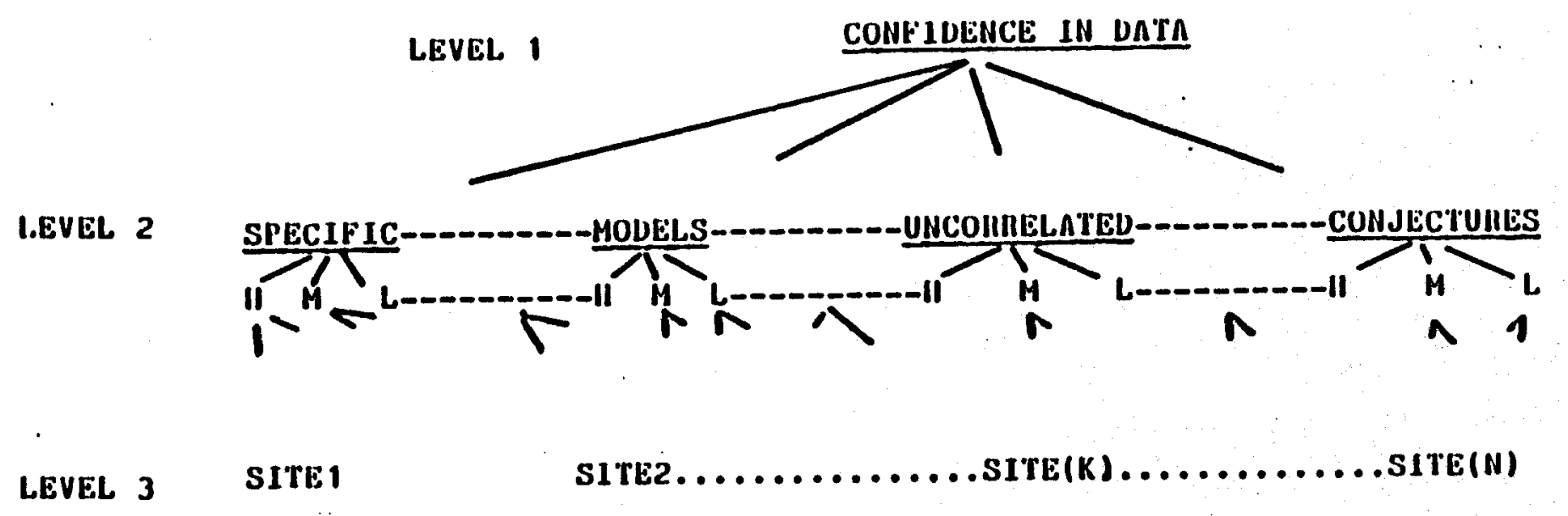

n

a

方.

HIEHARCIIY TO DETEHMINE THE MATING FOH SITES BASED ON CONFIDENCE IN THFIA NESPECTIVE DATA BASE. 
Figure 18

Page 16t

RATING MATRIX FOR LEVEL 2 SUPER-CRITERIA

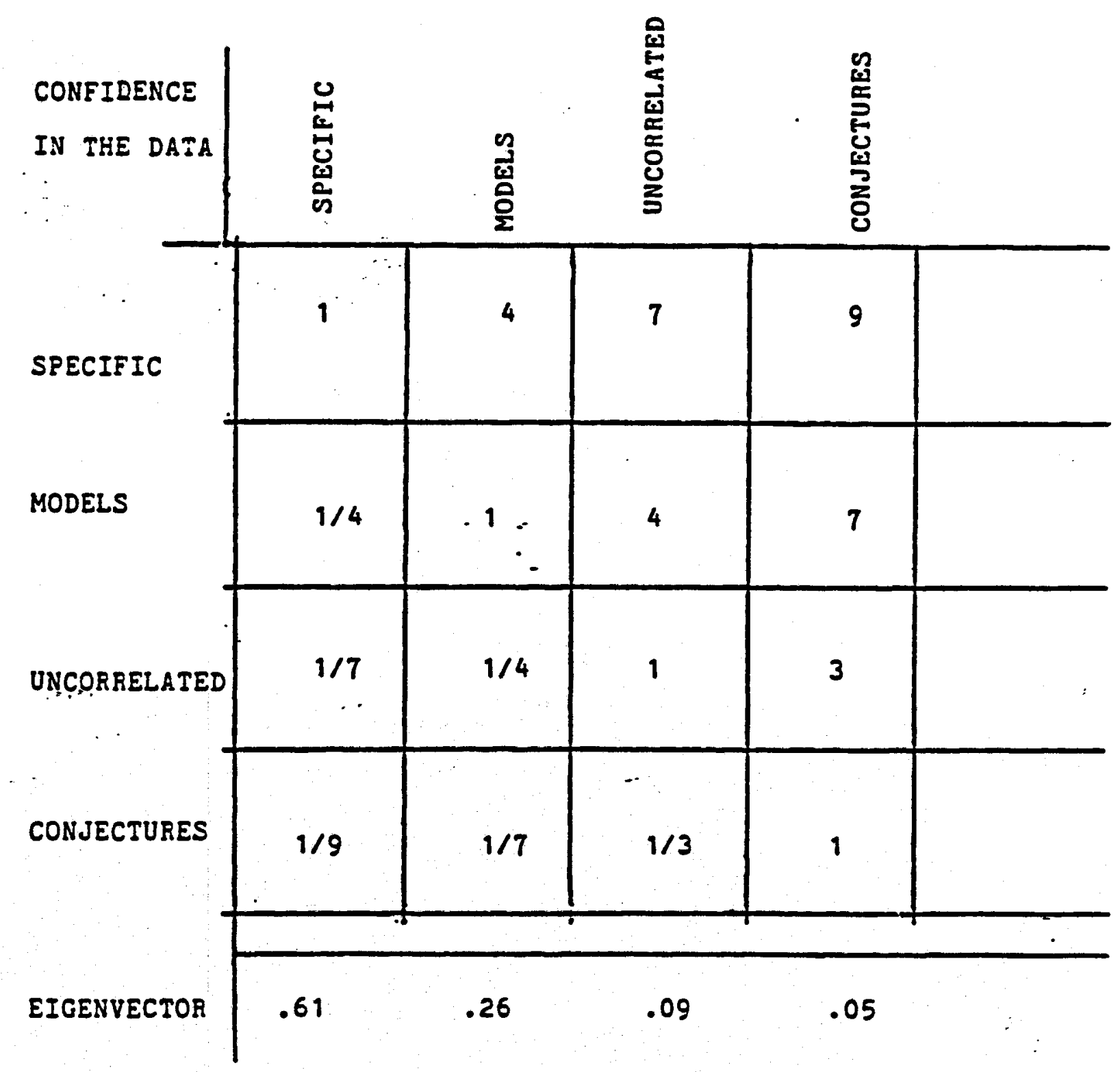


Figure 19

\section{- BAIING MATRIX FOR LEVEL 2 SUB-CRITERIA}

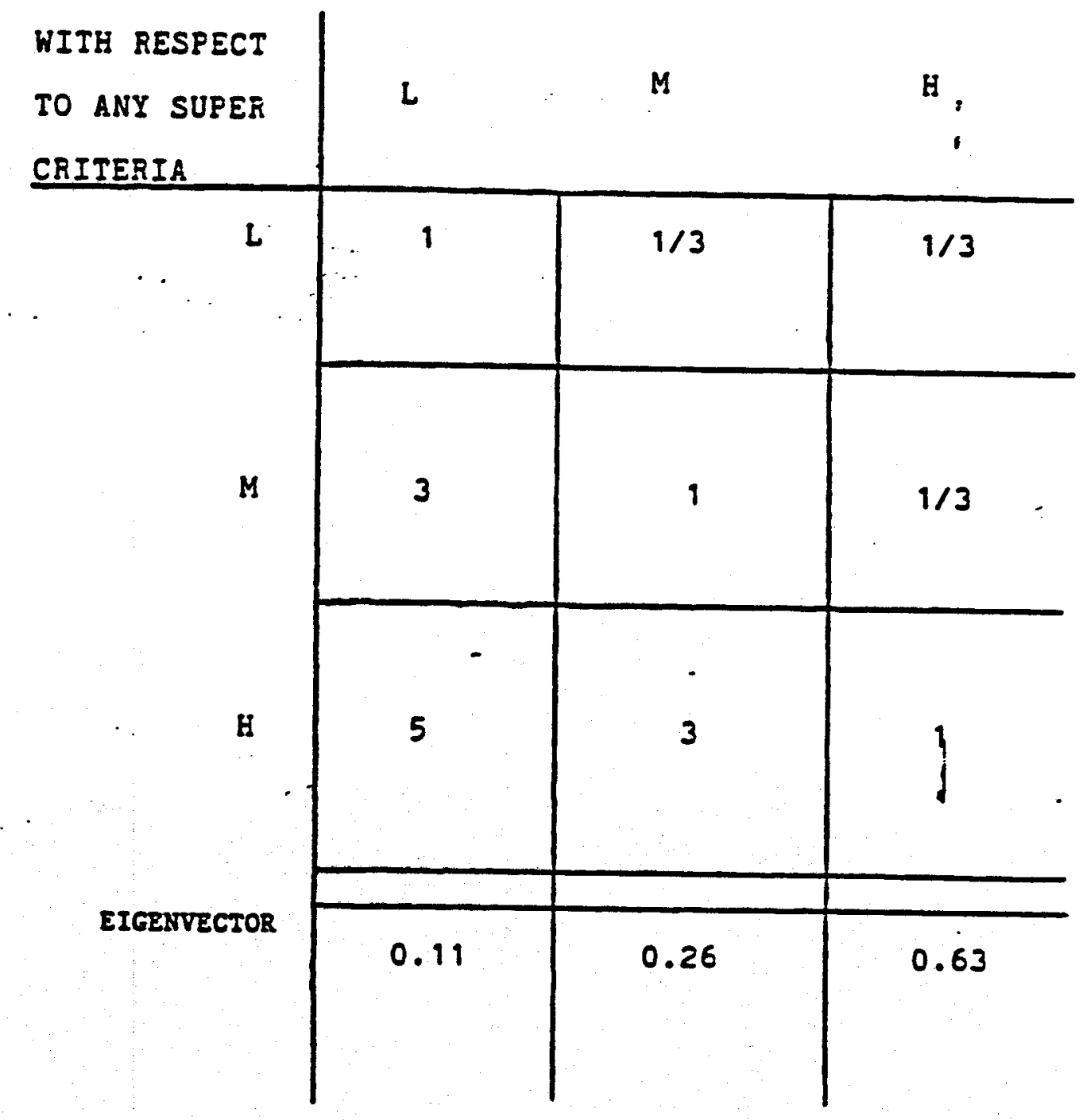




\section{GEOTHERMAL RESOURCE EVALUATION OF THE YUMA AREA}

5. Example

Based on this classification an AHP analysis was conducted to rate the specific data types as to the criteria of: CONFIDENCE IN DATA. This is shown as figure 17.

To determine the ratings for the sites based on confidence in their supporting the conclusion, data regarding the site is assigned a type: specific, model, uncorrelated or conjectural; and then its place of confidence within the type: high, middle or low. The hierarchy of types and subtypes of figure 17 has been displayed as shown in figures 18 and 19 . These have been judgment cal1s. There are instances in which such an AHF tabulation is done on the basis of measurements.

\section{TECHNIQUE:}

A somewhat more general example will be iliustrate the calculations to be performed. Let us suppose we have a hierarchy described by the following diagram.

Focus

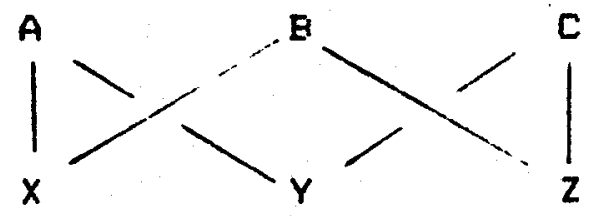

First, pairwise comparisons are made with respect to the focus, say A compared to $B$ is ab, A compared to $C$ is ac and B compared to $C$ is be. The remaining comparisons are all determined by applying the rule that any element compared to itself with respect to anything is 1 , and that the reverse comparison is the reciprocal of the initial comparison. Thus $B$ compared to $A$, (ba), is $1 / a b, C$ compared to $A$ is $1 / a c$ and $C$ compared to $B$ is $1 / b c$. This series of calculations generates the following matrix.

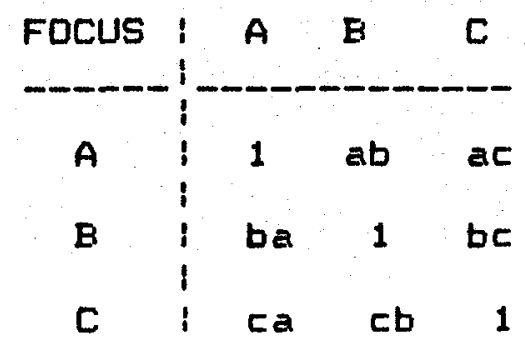




\section{GEOTHERMAL RESOURCE EVALUATION OF THE YUMA AREA}

The values for $A, B$, and $C$ with respect to the Focus comprise the normalized eigenvector with respect to the above matrix, that is the eigenvector whose elements sum to 1. A simpler calculation produces a result which approximates that eigenvector, and we shall describe that below. For the moment, assume we have given values $a, b$ and $C$ to $A, B$ and $C$, with respect to the focus.

In the next step (s) we compare $X$ to $Y$ with respect to $A$ ( $Z$ is not covered by $A$ ), say that value is $x y ; \quad X$ and $Z$ with respect to $B, \quad x z$; and $Y$ and $Z$ with respect to $C$, $Y Z$. This leads to values of $X$ with respect to $A, X(A), X$ with respect to $B, X(B)$, $Y$ with respect to $A, Y(A), Y$ with respect to $C, Y(C)$, and finally $z$ (B) and $z(C)$. This procedure can be traced through the hierarchy diagram. The values for $X, Y$ and $Z$, (the purpose of all of these calculations) are

$$
\begin{aligned}
& x=x(A) * a+x(B) * b, \\
& y=y(A) * a+y(C) * c, \text { and } \\
& z=z(B) * b+z(C) * c .
\end{aligned}
$$

To see how these values are calculated, let us start with the simplest case: $2 \times 2$ matrices such as arise with the comparison of $x$ to $Y$ with respect to $A$. For definiteness, we reproduce it in its most general form as follows.

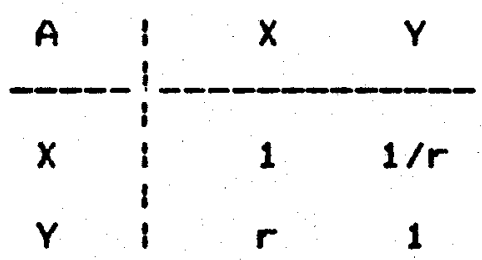

We begin by normalizing the matrix by columns: this means summing the elements in the columns and then dividing the matrix elements by the column sums. Thus, the normalized matrix is:

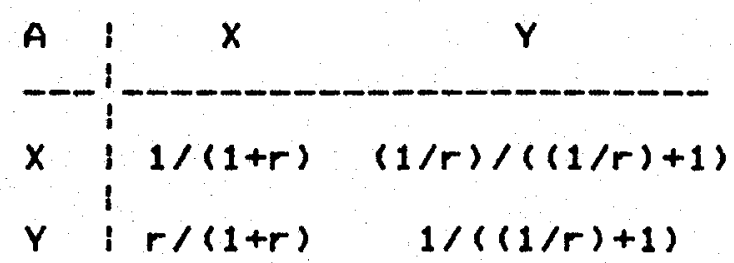




\section{GEOTHERMAL RESDURCE EVALUATION OF THE YUMA AREA}

In this particular case the two columns are identical, giving rise to the vector $[x(A), y(A)]$ where $x(A)=1 /(1+r)$ and $y(A)=$ $r /(1+r)$. A brief matrix calculation shows that this vector is, indeed, the eigenvector of the original matrix. That is, there is a number $r$ (in this case $r=2$ ) such that $M * v=r * v$, where $M$ is the original matrix, and $v$ is the vector $[x(A), y(A)]$. In the general case things are not so simple because the eigenvector is not so easily determined. Although the existence of an eigenvector with the desired properties is assured for the types of matrices we deal with, (see e.g., [Saaty, 1977]), its determination requires the solution of a polynomial equation of degree equal to the dimension of the vector, which may require a numerical approximation. There is a simpler method, also developed by Saaty, [Saaty, 1982]; which yields a good enough approximation for this methodology. This method will be demonstrated with the $3 \times 3$ matrix developed for our evaluations, as shown in figure 25.

As before, the first step is to normalize the matrix by dividing matrix entries by the sum of the column elements. The next step is to average by rows. The vector of the row averages is the desired approximation to the eigenvector. The normalized matrix and the averaged vector is shown below.

$\begin{array}{l:ccc} & \text { Low } & \text { Middle } & \text { High } \\ \text { Low } & 1 / 9 & 1 / 13 & 3 / 23 \\ \text { Middle } & 1 / 3 & 3 / 13 & 5 / 23 \\ \text { High } & 5 / 9 & 9 / 13 & 15 / 23\end{array}$

Low $=[(1 / 9)+(1 / 13)+(3 / 23)] / 3=0.106$
Middle $=[(1 / 3)+(3 / 13)+(5 / 23)] / 3=0.260$
High $=[(5 / 9)+(9 / 13)+(15 / 23)\} / 3=0.633$




\title{
GEOTHERMAL RESOURCE EVALUATION OF THE YLMA AREA \\ APPENDIX $\mathrm{C}$.
}

\author{
SDLAR/GEDTHERMAL HYBRID SYSTEM
}

1. Introduction.

Most of the known geothermal resources available in the Yuma area are low temperature wells of less than 1300F (54.40C), therefore it was decided early on in this project toexamine the economic viability of using solar energy, which is readil available in Yuma County, and low temperature geothermal brines together to displace electricity as heating fuel. We shall use the term 'fuel' broadly in place of energy or power source. The analysis presented here is not exhaustive, but it clearly can indicate if solar used together with geothermal energy is an economic reality today or can be within the next five (5) years.

First, we will present themethods used in our analysis to give the frameworkin which our conclusions were reached.

We want to look at the net 'savings' obtained by a hypothetical user of a solar/geothermal hybrid system over a standard time period which we choose to be a year. The savings function is denoted by $S$ and it is dependent on several variables, namel y:

1. The unit cost of fuel (electricity or natural gas), denoted by $F$ ( $\$$ /MMBTU),

2. The required energy, E (MMBTU/yr),

3. The cost, (including installation cost), of Solar Collectors, $C(\$ /[s q f t])$,

4. The amount of energy that is provided by the geothermal wel 1: (E - L), where $L$ is the required backup energy" (MMETU), that is, the energy supplied by both the sol ar and conventional fuel.

5. The initial capital cost, $z(\$)$ of the well, i.e., the total geothermal system.

6. The period, N(yrs) over which a loan is taken out.

7. The rates of inflation (e) and interest (i).

8. The fraction of the energy provided by the solar unit:

$f *(E-(E-L))=f * L$ (MMETU),

9. The portion of the energy provided by the 'conventional backup unit':

$(E-(E-L)-f=* L)=f-* L$, 


\section{GEOTHERMAL RESDURCE EVALUATION OF THE YLMA AREA}

10. The 'solar fraction' $i$, :thich expresses the porion of the energy provided by the solar unit, and, isa fuction of the collector area, $A_{C}, s_{0} f=f\left(A_{C}, A, B\right)$. A and $B$ are parameters that are determined from empirical data and are site-specific. That is, $A$ and $B$ are dependent on the area or site under consideration.

To analyze the solar portion of the hybrid system, data for the Yuma area, and hence $f(A c, A, B)$, was obtained from the $W-$ CHARTrm which is a computational technique copyrighted by the Solar Energy Design Corporation of America (1981) (SEDCOA). In $W-$ CHARTrm, $f\left(A_{C}, A, B\right)=A * L n\left(1+B\left(A_{C} / L\right)\right.$, where $L$ is the backup energy' defined in (4) and ' $L n$ ' is the natural logarithm function.

The savings per year, denoted by $S$ is simply given as:

(1) $S=\cdot(\$ / y r$ value of the energy provided by the geothermal well and the solar unit)

- ( $\$$ /yr costs due to the loans assumed for the well installation, the solar unit and the energy provided by the conventional backup unit).

Dne of the explicit assumptions in our analysis is that the cost of conventional fuel undergoes inflation, so, in our computations we are going to use the average value of the fuel c ost over the time period $N$, or,

(2) Average $=\left[F+F *(1+e)+F *(1+e)=+\ldots+F *(1+e)^{N-x}\right] / N$

$$
\begin{aligned}
& =(F / N) *\left[1+(1+e)+(1+e) 2+\ldots+(1+e)^{N-2}\right] \\
& =(F / N) *[(1-(1+e) N) /(1-(1+e))] \\
& =(F / N) *[((1+e) N-1) / e] .
\end{aligned}
$$

Letting $H=\left[(1+e)^{N}-1\right] / e$,

(3) Average $=F * H / N$.

Also, C*Ac represents the total cost of the sol ar system and $Z$ represents the cost of the geothermal system. It is well known from financial theory that:

$C * A c *\left[i *(1+i)^{\left.N /(1+i)^{N-2}\right]=\$ / y r}\right.$ to amortize the sol ar loan.

(5) $Z *\left[i *(1+i) N /(1+i)^{N-2}\right]=\$ / y r$ to amortize the geothermal loan. 



\section{GEOTHERMAL RESOURCE EVALUATION OF THE YUMA AREA}

(10) $S=[E * F * H / N]-[C * G * L *\{\exp (1 / A)-1\} / E]-Z * G$.

Now, equation (10) gives the * savings per year of a Solar/Geothemal Hybrid system where the solar portion provides all of the backup energy $L$. And, from this we can make crude but reliable estimates of the maximum amount one could invest in a Geothermal well and still accrue positive savings each year over a time period of $N$ years, with given interest and inflation rates and solar system costs.

The term $C * G * L *\{\exp (1 / A)$ - 1$\} / B$ represents the cost of the solar system in terms of the energy $L$ it must provide.

If $L=0$, that is, the geothermal well can provide all of the required energy, then the savings per year can be represented by

(11) $S=[E * F * G / N]-Z * G$.

This relation can given an estimate of the maximum amount one can invest in a geothermal well and still realize positive savings under existing conditions of energy required, fuel cost, inflation rate of fuel nad interest rate. The maximum $Z$ would be bounded by

\section{(12) $E * F * H / G * N>Z_{\max }$.}

To make it even easier to use equation (10) for estimates of what the maximum $Z$ could be, we express $L$ as a fraction of $E$. For example, let $L=r^{*} E$, where $D<r<1$, then (1) could be written as: $\cdots$

(13) $S=E *[S * H / N)-r *[* G *\{\exp (1 / A)-1\} / B]-Z * G$.

2. Examples.

Suppose a resident of Yuma county requires $28.5 \mathrm{MMBTU} / \mathrm{yr}$ of energy in the form of hot water at $150^{\circ} \mathrm{F}\left(66^{\circ} \mathrm{C}\right)$. This corresponds to 100 gal/day of water heated to $1500 \mathrm{~F}$ from $750 \mathrm{~F}$ with $25 \%$ allowance for heat losses). Further, suppose that there exists a geothermal well which is able to provide one of the following portions of this energy/yr requirement:

1. $20 \%$ of $E=28.5$ (Wel 1 temperature $90 \circ F$ ) $r=0.8$,

2. $47 \%$ of $E=28,5$ (Well temperature 110 of): $r=0.53$,

3. $73 \%$ of $E=28.5$ (Well temperature 130 of $) r=0.27$,

4. $87 \%$ of $E=28,5$ (Well temperature 140 of $): r=0.13$,

5. $100 \%$ of $E=28.5$ (Well temperature 150 of $): r=0.0$. 
Table 7 .

Location: Yuma

Required Energy/Yr: $28.5 \mathrm{MMBTU}$ Fuel Displaced: Electriclty

Fuel Cost (\$MRBIU): \$25

Interest: 124

Fuel Cost Inflation: $12 \%$

Loan Perlod:
Location: Yuma

Required Energy/Yr: 28.5 MMBTU

Fuel Dlsplaced: Natural gas

Fuel cost (\$MMBTU): \$7

Interest: 128

Fuel Cost Inflation: 128

Loan Period:

5 yxs

\section{$\mathbf{z}_{\max }$}

\$

$\begin{array}{ccccccc}90 & 80 & 1131 & 90 & 80 & \text { No Go } \\ 110 & 53 & 1853 & 110 & 53 & \text { No Go } \\ 130 & 27 & 2547 & 130 & 27 & 193 \\ 140 & 13 & 2921 & 140 & 13 & 567 \\ 150 & - & 0 & 3269 & 150 & 0 & 915\end{array}$


Table 8

Location: Yuma

Reguired Energy/yr:

(a) 28.5 MMBTU

(b) $250 \mathrm{MMBTU}$

Fuel Displaced: Electricity

Fuel cost (\$/MMBTU): $\$ 25$

Interest

Fuel cost Inflation: 128

Loan Period : 5 yrs
Location: Yuma

Reguired Energy/yr:

(a) 28.5 MMETU

(b) 250 MABSTU

Fuel Displaced: Natural Gas

Fuel cost ( $\$ / M M E T U):$ : 7

Interest : $22 \%$

Fuel cost Inflation: 228

Loan Feriod : 5 yrs

\begin{tabular}{|c|c|c|c|c|c|c|c|}
\hline${ }_{\text {Well }}{ }_{O_{F}}$ Temp. & $\begin{array}{l}\text { t of } \\
\text { solar } \\
\text { Backup }\end{array}$ & $\begin{array}{l}\mathrm{z}_{\max } \\
(\mathrm{a})\end{array}$ & $z_{\max }$ & $\begin{array}{c}\text { Well Temp. } \\
\rho_{F}\end{array}$ & $\begin{array}{l}\text { f of } \\
\text { solar } \\
\text { Backup }\end{array}$ & $\mathrm{z}_{\max }$ & $\mathbf{z}_{\text {max }}$ \\
\hline 90 & 80 & 405 & 9,156 & 90 & 80 & No-Go & No $G$ \\
\hline 110 & 53 & 1126 & 15,484 & 110 & 53 & No-Go & No $G$ \\
\hline 230 & 27 & 1821 & 21,577 & 130 & 27 & No-Go & 966 \\
\hline 240 & 23 & 2195 & 24,858 & 140 & 13 & No-Go & 4248 \\
\hline 150 & 0 & 2542 & 27,905 & 150 & 0 & 193. & 7295 \\
\hline
\end{tabular}




\title{
GEOTHERMAL RESOURCE EVALUATION OF THE YUMA AREA
}

\begin{abstract}
Using equations $(10)$ and (11) the following values for $Z_{\max }$ are obtained, given a fuel (electricity) cost of \$25/MMBTU (equivalent to $\$ 0.085 / \mathrm{kwh}$ ) an interest rate of $12 \%$ per year and a fuel inflation rate of $12 \%$ per year, with a five (5) year period to retire the costs $(N=5)$, we have Table 7 .

Now, according to Lund, Culver and Svannevik (Klamath Falls hot water well study: Klamath Falls, OR., Oregon Institute of Technology: for LLL, UCRI-13614, 1974), the annual Qverhead and Maintenance costs such as taxes, electricity for pump motors, well maintenance, and heating pipe replacement and repair costs totaled about $\$ 64 / y r$ in the early 70 's at Klamath Falls, Oregon. Since we did not, for the first example, include $0 / M$ costs because of the uncertainty associated with such costs for a technology such as a Geothermal/solar hybrid we believed that using Lund's (et-al) figure of $\$ 64 / y r$ increased to $\$ 200 / y r$ for the 80 's, would give some order. of magnitude correctness to our previous figures. Lund's (et-al)' \$64/yr $0 / M$ estimate was for 3 different well depths: $150 \mathrm{ft} ., 300 \mathrm{ft}$. and $600 \mathrm{ft}$. The figures were redone, this time with the right side of equation (13) having an additional term of -200 to represent this estimated $\$ 2000 / M$ cost:
\end{abstract}

(14) $S=E *[[F * H / N)-r * C * G *\{\exp (1 / A)-1\} / B-200$.

Also, the annual required energy was taken to be $28.5 \mathrm{MMBTU} / \mathrm{Mr}$ and 250 MMETU/yr. The first energy requirement, 28.5MMETU/yr, corresponds to heavy residential use of hot water, while 250 MMETU/yr corresponds to light commercial usage of hot water such as might be found in a laundromat. As a means of comparing expensive fuels, electricity at $\$ 25 / M M B T U$, to inexpensive fules like natural gas, \$7/MMETU, a section was added to Table 8 . If "fuel oil prices.should fall to about $\$ 0.70$ cents per gallon then this would be the same as \$5/MMBTU, which makes the prospects for sol ar/geothermal hybrids even more dismal.

What Table 7 tells us is that given a fuel inflation rate of 12\% per annum, with a $12 \%$ per annum loan rate, a fuel cost of $\$ 0.085 / K W H$ (electricity) and a loan period of only 5 years, a residential user should only spend up to $\$ 2542$ to have access to just geothermal water. If solar is used in conjunction, the picture gets progressively bleaker. For example, with about $53 \%$ of the load provided by the solar unit, which corresponds to a well temperature of $110^{\circ} \mathrm{F}$, which is then heated to $1500 \mathrm{~F}$ by the solar unit, anly $\$ 1126$ maximum should be invested in the well: It must be noted that $Z_{\text {max }}$ gives the 1 imit at which the investment provides positive savings. If $Z_{\max }$ is exceeded then the yearly savings will represent a negative cash flow. Similar behavior is true for the case where 250 MMBTU/yr is required. 


\title{
GEDTHERMAL RESDUTitiE EVALUATION OF THE YUMA AREA
}

\begin{abstract}
Natural gas is another story. If a residential user requires 28.5 MMBTU/yr (i.e., water at 1500F at the rate of 100 gal/day) and has access to a geothermal well of 1500F, so no solar is required, then at most $\$ 193 \mathrm{can}$ be spent before a negative cash flow results. In fact, the low-priced natural gas doesn't allow any solar backup to be used. This paints a dismal picture for solar at $\$ 28 /$ sq.ft installed.

Even a laundromat, which could use 250 MMBTU/yr, could not employ a substantial amount of solar at $\$ 28 / 5 q . f t$. and have a positive cash flow. Only when the solar unit is reduced to providing less than $32 \%$ of the backup energy does the cash flow become positive.

However, if a user had access to a $150 \circ \mathrm{F}$ well, so did not require a solar backup the maximum amount that could be spent and allow a positive cashflow would be about $\$ 7300$. This could only prove feasible for a shallow (less than $200 \mathrm{ft}$.) well. No shallow wel is at that temperature have been found in Yuma county. The expectation, based on what has been found to date, is that shallow well temperatures will not exceed 1040F (400C), and that moderately deep (less than $2,000 \mathrm{ft}$. ) well temperatures will not exceed $120 \circ \mathrm{F},(50 \circ \mathrm{C})$.
\end{abstract}




\title{
GEOTHERMAL RESOURCE EVALUATION DF THE YUMA AREA
}

\author{
APPENDIX D.
}

\section{COSTS OF GEOTHERMAL DEVELDPMENT}

\section{Exploration Costs.}

This appendix is intended to provide some of the cost analyses used in geothermal work. It is not complete, and, as the most up to date work quoted was done in 1982, costs can be assumed to be in 1981 dollars, if not stated as an earlier date. If we assume an inflation rate of $12 \%$ per annum this means multiplying quoted costs by a factor of 1.75 for a rough estimate of 1986 costs. The same inflation rate applied to the period from 1974 means that 1974 costs should be multiplied by a factor of 4 for a rough cost estimate. This means that the moderate depth drilling costs of $\$ 10$ per foot for soft rock drilling, and $\$ 20$ per foot for hard rock drilling reported in 1974 translate to \$40 per foot and $\$ 80$ per foot, respectively. These costs are for wells of moderate depth - $600 \mathrm{~m} .(2,000 \mathrm{ft.})$ or 1ess. These well costs, reported by Lund, and others, [Lund, et a1,1975], were for well known geothermal resource area.

In the Yuma area it may be assumed that geothermal brine resources with temperatures exceeding 500C will be discovered either by accident, due to drilling for other purposes, or as the result of a geothermal exploration. Our primary concern here is to investigate the costs of exploration, which we assume to be with the purpose of discovering a power production site. The comparisons of the results obtained and the costs of various exploration methods were investigated by Duprat and Omnes. We $\because$ 'report only on their conclusions with respect to costs.

"The unit of cost is the cost of a high-sensitivity aeromagnetic coverage per equare kilometer for a $400 \times 800 \mathrm{~m}$. grid. Cost ranges are indicated by lines: densities of measurements per square kilemeter are:

800 $\times 400-m$ for Figh-sensitivity aeromagnetics,

21 ine $\mathrm{km}(25 \mathrm{~m}$ between stations) for ground magnetometry, $400 \times 400-m$ to $200 \times 200-m$ grid for gravity,

1 line $\mathrm{km}$ for refraction,

1 dc electrical sounding,

1 low-frequency magnetotelluric sounding,

4 telluric stations

4 roving dipole total field stations,

4 electromagnetic soundings (audiofrequency range)

4 audio-magnetotelluric soundings,

1 line kilometer for reflection (six-fold coverage, $60 \mathrm{~m}$ between traces, processing included),

1 thermal gradient drill hole $150 \mathrm{~m}$ deep." 


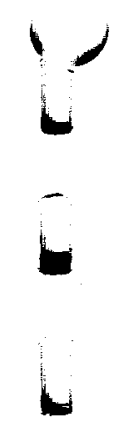

\section{GEOTHERMAL RESOLRCE EVALUATION OF THE MMA AREA}

\section{TABLE 9}

SCALE OF RELATIVE COSTS PER SQUARE KILDMETER (NORTH AMERICA)

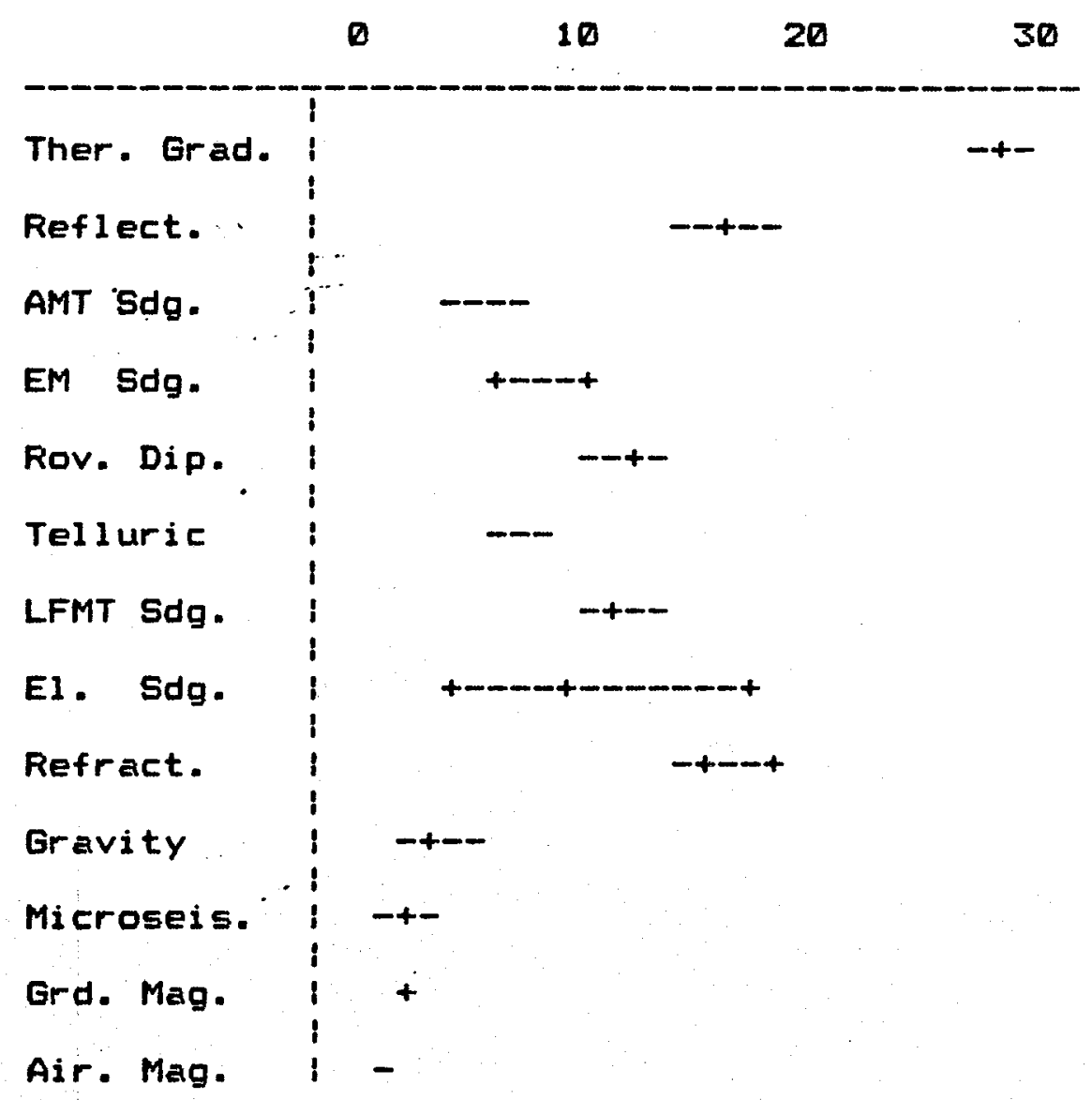

$0++++++++10++++++++20++++++++30$ 


\title{
GEOTHERMAL RESDURCE EVALUATION OF THE YUMA AREA
}

\author{
"Three groups of measurements may be distinguished on Table \\ 2 [our Table 9]:
}

1. Light reconnaissance methods - aeromagnetometry, ground magnetometry, microseismic, gravity ranging from 1 to 3 .

2. The heavier reconnaissance methods - electrical and seismic methods ranging from 4 to 17.

3. The thermal gradient measurements - about 27. The high cost of this method is related to the cost of drilling.

Using Table [9] and combining complementary methods in various ways for the calculation of the cost of a geophysical exploration program to be carried out over a $100 \mathrm{sq} \mathrm{km}$ area, it appears that total expenditures per square kilometer may range from 10 to 20 units depending on the type of geothermal field. Expenditures are expected to be lower over self-sealing geothermal fields than over geothermal fields of the first type [where the cap rock is formed independently of geothermal activity].

The cost of a geophysical program over a $100 \mathrm{sq} . \mathrm{km}$. area may consequently amount to 1000 to 2000 units of cost. This is still much less than the cost of a single 2000-m exploration drill hole which costs about 4500 units or more than twice the cost of the most expensive geophysical program." [Duprat \& Omnes, 1975].

If we apply the $12 \%$ per annum inflation rate to the least squares regression estimate of the cost of deep drilling obtained by Blair [Blair, 1982], we have:

$$
\begin{aligned}
& \text { sedimentary.geology: } \quad c=0.499+0.009 * d=\text {, and } \\
& \text { igneous geology: } \quad c=0.770+0.042 * d z \text {; }
\end{aligned}
$$

for 1986, where $c$ is the cost in millions of dollars and $d$ is the depth in thousands of feet.

To get a rough estimate of the size of the units referred to by Duprat and Omnes, a 2,000 meter $(6,600 \mathrm{ft})$ exploration drill hole in soft rock costs $\$ 890,000$, based on the updated Blair estimate. Thus one unit is approximately $900 / 4.5=\$ 200$.

An example of a successful geophysical exploration. program, conducted in an area without surface manifestations, was at East Mesa. Exploration methods included gravity surveys, thermal gradients based on a sequence of 37 boreholes, ranging from 30 to $450 \mathrm{~m}$ in depth, a seismic noise survey with $1.5 \mathrm{~km}$ spacing between observations, and widely spaced de-resistivity soundings, culminating in the drilling of a test hole to $2,445 \mathrm{~m}$, at which a bottom hole temperature of $200^{\circ} \mathrm{C}$ was found. 
TABLE $10(a)$

Preproduction Cost Estimates for One Producible Hydrotheraal Discovery (Exploration Phase)

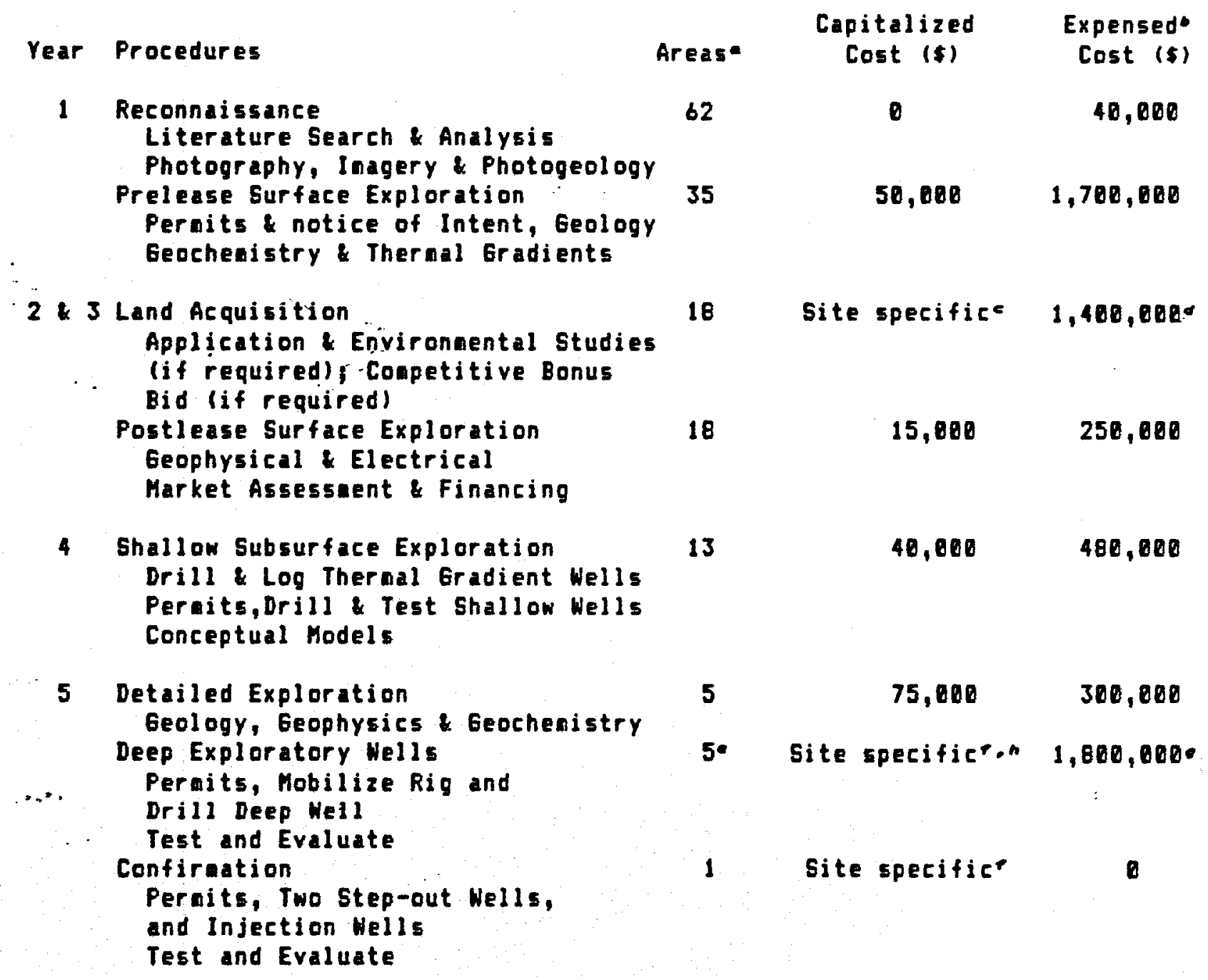

NOTES:

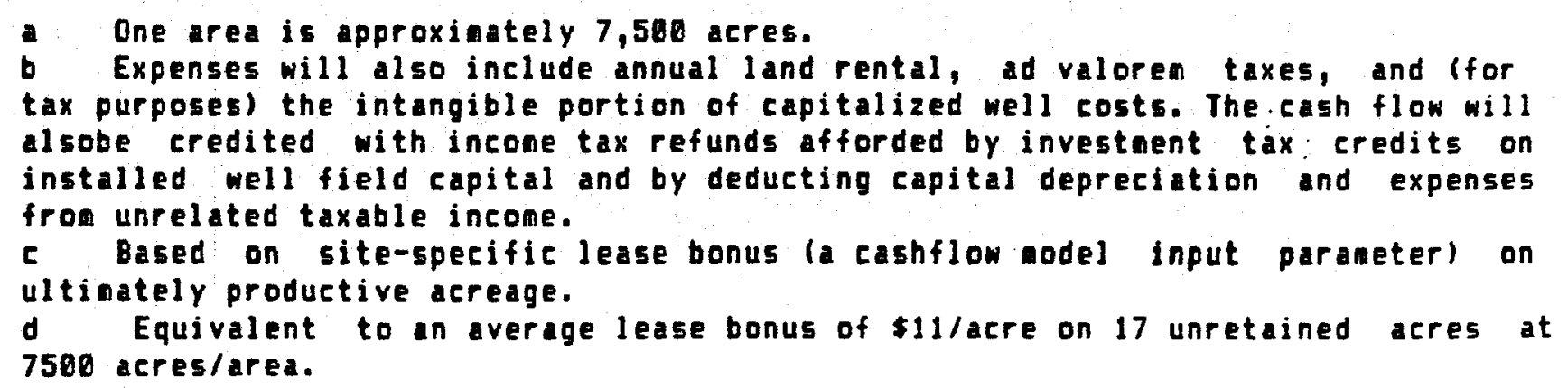


TABLE $10(b)$

Preproduction Cost Estimates for One Producible Hydrotheral Discovery (Exploitation Phase)

\begin{tabular}{|c|c|c|c|c|c|}
\hline Year & Procedures & Areasi & & $\begin{array}{l}\text { Capitalized } \\
\text { Cost (\$) }\end{array}$ & $\begin{array}{c}\text { Expensedb } \\
\text { Cost (s) }\end{array}$ \\
\hline 6 & $\begin{array}{l}\text { Modeling Environaental Studies } \\
\text { Faut Pattrn Deinition } \\
\text { Environmental Assessaents } \\
\text { Consuner Evaluations and } \\
\text { Negotiations }\end{array}$ & 1 & & 800,000 & $B$ \\
\hline 7 & $\begin{array}{l}\text { Well Field Engineering } \\
\text { Pernits and Developnent Plan } \\
\text { Engineer Surface Facilities } \\
.\end{array}$ & 1 & & 125,000 & B \\
\hline $8 \div 9$ & $\begin{array}{l}\text { Construct Surface Facilities } \\
\text { Peraits and Procurenent } \\
\text { Construct Roads and Buildings } \\
\text { Well Field Developnent } \\
\text { Mobilize Drilling Rig } \\
\text { Drill \& Case Producer and } \\
\text { Injector Nells } \\
\text { Construct Surface Piping }\end{array}$ & 1 & Site & specifict,d & Site specific' \\
\hline
\end{tabular}

NOTES:

e Estinated success ratios for deep exploration wells vary fron $1: 15$ (see University of Utah, 1978, p.50) to 5:15 (see Ward, 1977). The 1:5 estinate used here represents a comproaise between thes estieates and is consistent with the $21 \%$ seccess rate for exploratory wells outside well-known areas per University of Utah, 1978,p. 51 .

$f$ Site specific deep well cost is a function of reservair depth and geology. g Assune 3 failures at $\$ 350,080$ and 1 failure with casing run at $\$ 750,000$.

$h$ Industry responses to the question of the number of deep wells required for confiration varied fron 2 to more than 5 with 3 (i.e., 1 successful exploratory well plus 2 step-out wells) being the mean response.

1 Includes active and spare producer wells and injector wells plus additional redrill costs

$j$ Includes dry. wells encountered in field developaent. 


\section{GEOTHERMAL RESOURCE EVALUATION OF THE YUMA AREA}

\section{A Complete Estimate.}

Tables 10, (a) and (b) and the following discussion are taken from Blair, [Blair,1982]. The purpose is to provide cost and time frame estimates for the exploration and exploitation of a geothermal resource. Use a multiplying factor of 2.2 to update these costs to 1986 dollars according to the $12 \%$ per annum estimate.

Site specific costs, which are the variables in these tables, are 1 and acquisition costs, which: we shall not treat here, costs associated with drilling, estimated productivity of the well system, surface piping costs and transmission costs.

Costs associated with drilling are number of producing wells required, estimated drilling costs, which depend on local geology and the equations for which have been cited, modified by estimates of the number of spare, injector and dry wells, and by the estimated requirement for down-hole pumping.

The number of actual producing wells required of a site, $\mathrm{N}_{m}$, can be estimated by the equation

$N_{-}=Q * W / E$, where

$Q$ is the generation capacity being supported (kilowatts)

$E$ is the net specific energy of the power plant, $w=f l o w$ rate per active producer well (1000 lb/hr).

The net specific energy of is estimated by the following equation, $\therefore \quad E=-16.90-0.57 * p+0.0614 * T+2.344 *$ TYPE $-0.534 * b$, where $P=1$ or 0 (in Wh/lb of fluid) depending on the need for downtiole pumping,

$T$ is the resource temperature in degrees Fahrenheit,

TYFE $=0$ if flash, 1 if binary,

$b$ = brine contamination index.

The brine contamination index is:

D for low salinity: less than 2,000 ppm,

1 for moderate salinity: 2,000 to 100,000 ppm,

2 for high salinity: over 100,000 ppm. 


\section{GEOTHERMAL REgQURCE EVALUATION OF THE YUMA AREA}

The ratio of active producer to injector wells, $r$, is commonly about 2:1 according to industry data, whereas the spare well fraction, that is, the fraction of total producing wells which represents spare capacity, varies from 0.25 to 0.10. Total deep well requirements $D$ for field development are therefore

$$
D=[1+(1 / r)+s /(1-s)] * N_{-}=N_{a} *[1+r-s] /[r *(1-s)] .
$$

Here $s$ is the spare well fraction.

During field develommant, a fraction d of the total number ofwells drilled as producers are expected to be unsuccessful dry wells. The expected number of dry wells is therefore

$$
N_{d}=[d /(1-d)] *[1+(s /(1-s))] * N_{a}=N_{a} * d /[(1-d) *(1-s)] .
$$

Unsuccegsful wells are not fully cased and may be estimated at $90 \%$ of the cost of a successful deep well.

At reservoirs requiring down-hole pumping the capital costs of the pump must be added to the hydrothermal well cost. Fump capital costs can be estimated by the equation, (in $\$ / 1$ b/hour)

$$
C_{p}=\exp (-0.607+0.9925 * w)
$$

Annual pump ooperation and maintenance expenses must also be included as a recurring fluid production cost component. These costs are estimated as follows (in $\$ 1000 /$ year)

$$
C_{r}=56.3+24 * \operatorname{Ln}(w) .
$$

Blair, and others, developed regression estimates for surface .:piping costs based on the equation

$$
S P=\exp (A+B * T+C * W+D * b) .
$$

The coefficients and regression statistics, quoted at the $99 \%$ confidence level, are tabulated below.

$\begin{array}{lccccccc} & A & B & C & D & R^{2} & F \\ \text { Flash, Unpumped } & : 9.245 & -0.008 & -1.207 & 0.055 & 0.96 & 826 \\ \text { Flash, Pumped } & : 9.806 & -0.0105 & -1.337 & 0.064 & 0.97 & 652 \\ \text { Binary, Unpumped } & : 9.506 & -0.0109 & -1.347 & 0.071 & 0.97 & 252 \\ \text { Einary, Pumped } & 0.137 & -0.0063 & -1.152 & 0.066 & 0.93 & 208\end{array}$




\section{GEOTHERMAL RESDURCE EVALUATION DF THE YUMA AREA}

Transmission costs depend on the remoteness of the site and the level of power transmission. Examples quoted by Blair are as foll ows.

\begin{tabular}{|c|c|c|c|}
\hline Resource Site & $\begin{array}{l}\text { Threshold } \\
\text { Level } \\
\text { MWe }\end{array}$ & $\begin{array}{c}\text { Bel ow } \\
\text { Threshold } \\
\text { Costs }(\neq / \mathrm{mi} .)\end{array}$ & $\begin{array}{l}\text { Above Threshold } \\
\text { Cost for GoomWe } \\
\text { Increments }(\$ / \mathrm{mile})\end{array}$ \\
\hline Imperial Valley, CA & 100 & 70,000 & 240,000 \\
\hline $\begin{array}{l}\text { Mono and Coso } \\
\text { Hot Springs KGRA, CA }\end{array}$ & 50 & 70,000 & 155,000 \\
\hline $\begin{array}{l}\text { Roosevelt Hot Gpring } \\
\text { and Cove Fort Sulphu } \\
\text { dale, UT . }\end{array}$ & 200 & 78,000 & 122,1000 \\
\hline
\end{tabular}




\section{GEOTHERMAL RESOURCE EVALUATION OF THE YUMA AREA \\ APPENDIX E \\ HEAT FLOW AND WATER TEMPERATURE DATA}

1. HEAT FLOW DATA

FAGE 130

2. WATER TEMPERATURE DATA

PAGE 132

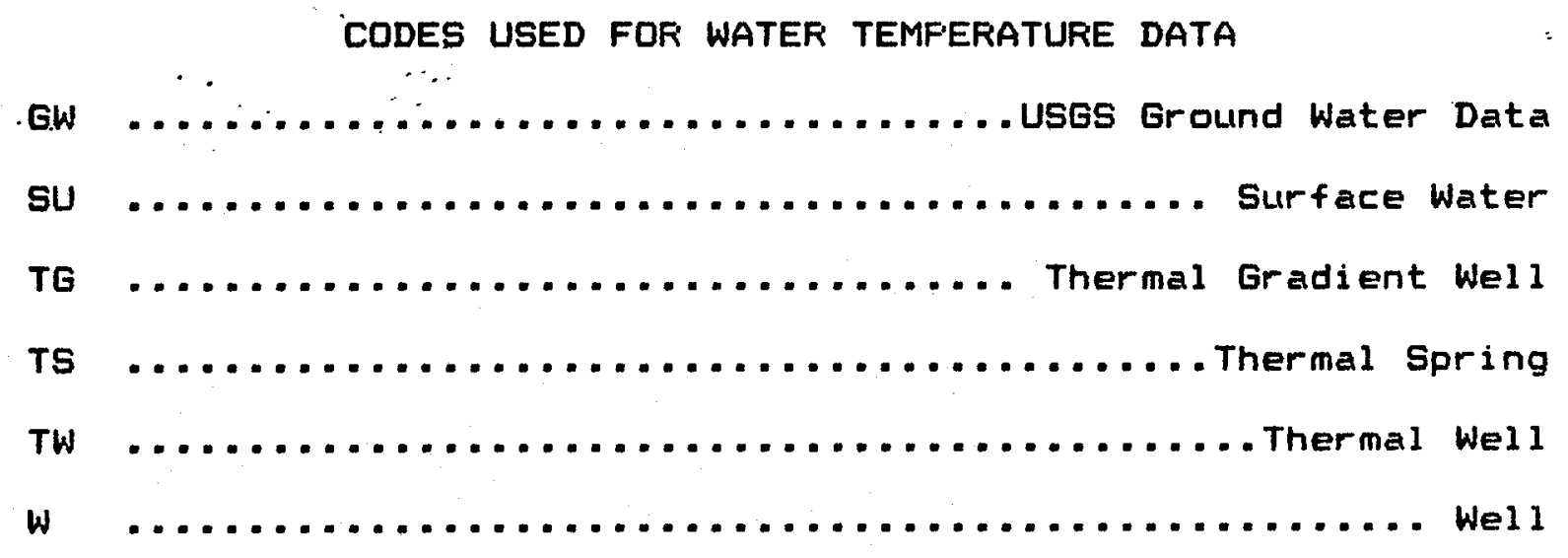


Latitu Minutes Longitu Minute Heat Flow $+/-519$

\begin{tabular}{|c|c|c|c|c|}
\hline 33 & 0.2 & 112 & 29.1 & 92 \\
\hline 33 & 11.3 & 112 & 37.4 & 101 \\
\hline 33 & 14.8 & 112 & 57.2 & 59 \\
\hline 33 & 14.8 & 112 & 58.7 & 59 \\
\hline 33 & 17.3 & 112 & 36.4 & 143 \\
\hline 33 & 19.1 & 112 & 34.3 & 31 \\
\hline 33 & 23.4 & 112 & 46.8 & 126 \\
\hline 33 & 25.9 & 112 & 36.4 & 50 \\
\hline 33. & 26.8 & 112 & 48.9 & 70 \\
\hline 33 & 26.8 & 112 & 45.8 & 118 \\
\hline 33 & 26.8 & 112 & 57.2 & 68 \\
\hline 33 & 27.7 & 112 & 49.9 & 80 \\
\hline 33 & 14.8 & 113 & 9.6 & 80 \\
\hline 33 & 24.2 & 113 & 34.6 & 80 \\
\hline 33 & 25.1 & 113 & 50.2 & 80 \\
\hline 33 & 25.9 & 113 & 10.7 & 80 \\
\hline 33 & 27.7 & 113 & 54.3 & 70 \\
\hline 33 & 29.4 & 113 & 10.7 & 44 \\
\hline 33. & 16.5 & 114 & 13.0 & 163 \\
\hline 33 & 23.4 & 114 & 18.2 & 100 \\
\hline 33 & 23.4 & 114 & 18.2 & 70 \\
\hline 33 & 25.9 & 114 & 26.5 & 94 \\
\hline 33 & 27.7 & 114 & 6.8 & 67 \\
\hline 33 & 8.7 & 115 & 46.5 & 33 \\
\hline 33 & 25.1 & 115 & 25.7 & 54 \\
\hline 33 & 23.4 & 116 & 48.8 & 61 \\
\hline 33 & 25.1 & 116 & 37.4 & 78 \\
\hline
\end{tabular}


Tow Ran Sect Location

$$
\begin{aligned}
& \text { Gila River near Mohawk } \\
& \text { Gila River near Dome }
\end{aligned}
$$

$1515 \mathrm{~W} \quad 12 \mathrm{CBB}$

$1517 W \quad 14 C A C, C A C$

$1517 W \quad 36 \mathrm{CDE}$

$2 S 12 W \quad 12 \mathrm{AA}$

$2517 w$

1 EDA

$2517 W$

$1 \mathrm{BDA}, \mathrm{CCC}$

25.19W 8

$3511 \mathrm{~W} 25 \mathrm{DB}$

$3511 \mathrm{~W} .25 \mathrm{BD}$

$4511 \mathrm{~W} 1 \mathrm{BEE}, \mathrm{BBB}$

$4511 \mathrm{~W} 2 \mathrm{BB}, \mathrm{CB}$

$4511 w 2 \mathrm{BBE}, \mathrm{BBB}$

$4511 W \quad 2 \quad \mathrm{BBB}, \mathrm{BCB}$

$4511 W \quad 5 \mathrm{~EB}$

$4511 W \quad 5 \mathrm{BEB}, \mathrm{BBE}$

$4511 \mathrm{~W}$.

5 EBE

$4511 \mathrm{~W}$

$6 A A B, A A B$

$4511 \mathrm{~W}$

$6 \mathrm{AAB}$

$4511 \mathrm{~W}$

B $\mathrm{BBB}$

$4511 W$

8 EBB

$4511 \mathrm{~W} 11 \mathrm{AB}, \mathrm{BA}$

$4511 \mathrm{~W} 11 \mathrm{ABA}, \mathrm{BAB}$

$4511 \mathrm{~W} 12 \mathrm{BA}, \mathrm{BE}$

$4511 \mathrm{~W} \quad 12 \mathrm{ABE}, \mathrm{BEB}, \mathrm{BBB}$

$4511 W \quad 12 \mathrm{BBE}, \mathrm{ABB}$

$4 S 11 W$ 15 BAA

$4511 \mathrm{~W} 16 \mathrm{~EB}$

$4511 W$
1. Te 2. Te 3. 4. 5. 6. 7.

$\begin{array}{llllll}20 & 22 & 22 & 27 & 27 & 31 \\ 20 & 25 & 27 & 25 & & \\ 26 & & & & & \\ 20 & 20 & & & \\ 24 & & & & \\ 28 & & & & \\ 20 & & & & & \\ & & & & \end{array}$

$20 \quad 18$

44

49

49

$40 \quad 40$

$39 \quad 38$

$35 \quad 39$

$39 \quad 38$

44

$44 \quad 40$

39

38

38

38

40

40

$37 \quad 38$

$38 \quad 37$

$38 \quad 35$

$\begin{array}{lll}38 & 34 & 35\end{array}$

$35 \quad 38$

29

30 


\begin{tabular}{|c|c|c|c|c|c|c|c|c|c|}
\hline 45 & $11 W$ & 20 & $A B B, B A A$ & 35 & 35 & & & & \\
\hline 45 & $11 W$ & 21 & $\mathrm{BA}$ & 32 & & & & & \\
\hline 45 & $11 W$ & 21 & $\mathrm{ABE}, \mathrm{BBE}, \mathrm{BBB}, \mathrm{BEC}, \mathrm{CAA}, \mathrm{DCE}$ & 32 & 30 & 30 & 28 & 28 & 28 \\
\hline 45 & $11 \mathrm{~W}$ & 34 & $\mathrm{BEA}$ & 29 & & & & & \\
\hline 45 & $18 W$ & 25 & $\mathrm{ccc}$ & 20 & & & & & \\
\hline 55 & $11 W$ & 1 & $C D$ & 32 & & & & & \\
\hline 55 & $11 \mathrm{~W}$ & 2 & BEB & 39 & & & & & \\
\hline 55 & $11 W$ & 2 & $\mathrm{BBE}$ & 39 & & & & & \\
\hline 55 & $11 W$ & 4 & $E A$ & 30 & & & & & \\
\hline 55 & $11 W$ & 11 & $A C$ & 37 & & & & & \\
\hline 55 & $11 w$ & 11 & $\mathrm{CAB}$ & 36 & & & & & \\
\hline 55 & $11 W$ & 11 & $\mathrm{CAB}$ & 37 & & & & & \\
\hline 55 & $11 W$ & 11 & CAB $\quad \therefore$ & 37 & & & & & \\
\hline $\mathbf{5 5}$ & $11 W$ & 12 & $\mathrm{BC}$. & 31 & & & & & \\
\hline 55 & $11 w$ & 15 & $A B E, A B B, A B E$ & 36 & 28 & 36 & & & \\
\hline 55 & $11 W$ & 15 & $\mathrm{ABE}$ & 36 & & & & & \\
\hline 55 & $12 W$ & 4 & $\mathrm{CB}, \mathrm{BC}$ & 31 & 30 & & & & \\
\hline 55 & $12 W$ & 4 & $\mathrm{BCB}, \mathrm{CEC}, \mathrm{CDB}, \mathrm{CDD}$ & 30 & 30 & 35 & 36 & & \\
\hline 55 & $12 W$ & 4 & CDE & 35 & & & & & \\
\hline 55 & $12 W$ & 5 & $A A, A A$ & 31 & 31 & & & & \\
\hline sis & $12 \dot{w}^{\prime \prime}$ & 5 & $A A D, A E A$ & 31 & 32 & & & & \\
\hline 55 & $12 W$ & 9 & $\mathrm{~EB}$ & 31 & & & & & \\
\hline 55 & $12 W$ & 9 & $\mathrm{BEB}, \mathrm{CEA}, \mathrm{CBC}, \mathrm{CCA}$ & 32 & 42 & 42 & 41 & & \\
\hline 55 & $12 W$ & 9 & $C C A, C B A, C B C$ & 40 & 43 & 43 & & & \\
\hline 55 & $12 W$ & 15 & $C B, A C, B C, C C$ & 33 & 34 & 34 & 34 & & \\
\hline
\end{tabular}

$1 / 4511 \mathrm{~W} 34 \mathrm{BEA} \quad 29$

$4 \quad 4518 W 25 \mathrm{CCC} 20$

$\begin{array}{lll}5511 W & 1 \mathrm{CD} \\ 5511 \mathrm{~W} & 2 \mathrm{BBE}\end{array}$

$45511 W \quad 2 \mathrm{BBE}$

$45511 W \quad 11 \mathrm{AC}$.

U

$5511 \mathrm{~W} 11 \mathrm{CAB}$

$5511 \mathrm{~W} 11 \mathrm{CAB}$. 11.37

$5511 \mathrm{~W} 12 \mathrm{BC}$. 31

$5511 W \quad 15 \mathrm{ABE}, \mathrm{ABB}, \mathrm{ABE} \quad 3 c$

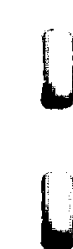

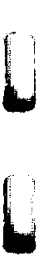


Tow Ran Sect Location

$5 S 12 W \quad 15 \mathrm{CED}$

$5512 W \quad 16 \mathrm{BA}, \mathrm{BA}, \mathrm{CA}, \mathrm{DA}, \mathrm{AB}, \mathrm{BE}, \mathrm{BB}$

$5512 \mathrm{~W} 16 \mathrm{AAB}, \mathrm{AAB}, \mathrm{BAA}, \mathrm{BBB}, \mathrm{BBB}$

$5512 W \quad 16 \mathrm{BEB}, \mathrm{ABA}, \mathrm{AAA}$

$5512 W \quad 21 \mathrm{AA}, \mathrm{BB}, \mathrm{BE}$

$5512 W \quad 21 \mathrm{BEB}, \mathrm{BBD}$

$5512 W \quad 22 \mathrm{BB}$

$5512 W \quad 2 B$ AA

$55.12 W \quad 33 \mathrm{DC}$

$5512 W \quad 33 \mathrm{CDA}$.

$5512 \mathrm{~W} 35 \mathrm{BB}$

$35 \mathrm{BBE}$

$5521 \mathrm{~W} 16$ West of Middle Mountain

$5522 W \quad 13 \mathrm{CE}$

$6511 W$

$4 \mathrm{ABA}, \mathrm{BAE}, \mathrm{BAE}$

6S $12 W$

$3 \mathrm{AB}$

$3 \mathrm{ABA}$

$7 \mathrm{CC}$

$6512 \ddot{W}$

6S. $12 W$

7 DCA, DDA

$6512 W$

$17 A B, A D, B D, B D$

$6512 W$

$17 B D A, D A A, D A A, D B B$

$65 \cdot 12 W$

$18 A C, C C$

$6512 W \quad 18 D A B, D D D$

65 $12 W$

$19 \mathrm{AA}$

$19 \mathrm{AAB}$

$24 \mathrm{BD}$

2 DCA

$33 \mathrm{DD}$

33 DDD
1. Te 2. Te 3. 4. 5. 6. 7.

34

$\begin{array}{lllllll}38 & 33 & 33 & 33 & 35 & 37 & 37 .\end{array}$

$\begin{array}{lllll}34 & 32 & 36 & 37 & 36\end{array}$

$37 \quad 38 \quad 35$

$34 \quad 34 \quad 33$

$34 \quad 34$

34

33

31

31

31

27

21

27

$24 \quad 23 \quad 23$

29

26

28

$28 \quad 28$

$\begin{array}{llll}27 & 24 & 24 & 24\end{array}$

$\begin{array}{llll}26 & 24 & 24 & 24\end{array}$

$25 \quad 24$

$25 \quad 24$

24

24

27

28

24

24 
65 20W 16 between Middle \& Muggins Mtns

65 21W 10 near Castle Dome Wash

$6521 w 32$ Yuma Test Station

$6521 \mathrm{~W} \quad 34 \mathrm{BD}$

$7511 W \quad 19 \mathrm{ACD}, \mathrm{CCC}$

$7511 \mathrm{~W} \quad 24 \mathrm{DBC}$

$7511 W \quad 27 D C, D D$

$7511 W \quad 27 \mathrm{CDD}, \mathrm{DDD}$

$7511 W \quad 28 \mathrm{DCD}, \mathrm{DDD}$

$7511 \mathrm{~W} 36 \mathrm{AD}$

$7511 W 36$ ADD, DAA, DDD, DDD

$75.11 \mathrm{~W} 36$ DAA

$7512 \mathrm{~W} \quad 7 \mathrm{BBE}$.

$7512 W \quad 12 \mathrm{DDC}, \mathrm{DDC}$

$7512 \mathrm{~W} \quad 13 \mathrm{BB}$

$7512 W \quad 13 \mathrm{DCD}$

$14 \mathrm{CD}$

$14 \mathrm{DCC}, \mathrm{DCC}, \mathrm{DDD}$

$7512 W$

$7512 W$

$19 \mathrm{CC}$

$19 \mathrm{CCA}, \mathrm{CCA}, \mathrm{CCA}, \mathrm{CCA}$

$75 \quad 12 w$

$7 \dot{S} 12 \dot{W}^{\circ}$

21 ECD

$23 \mathrm{ABE}$

$24 \mathrm{DB}$

$7512 W \quad 24 \mathrm{BDD}$

$7512 W \quad 32$ AAA
41

31

29

33

32

27

39

$32 \quad 34$

$32 \quad 32$

$30 \quad 31$

36

$\begin{array}{llll}36 & 36 & 34 & 34\end{array}$

36

31

$26 \quad 26$

33

34

34

$32 \quad 34 \quad 34$

34

32

$\begin{array}{lll}31 & 34 & 24\end{array}$

24

30

32

32

25 
Tow Ran Sect Location

$7 S 13 W \quad 16 A A$

$7513 W \quad 16 \mathrm{AA}$

$7513 W \quad 21$ AAA

$7513 W \quad 24$ AAA

$7514 W$

$1 \mathrm{CE}$

$7514 W$

$2 A A$

$23 \mathrm{DDD}$

$24 A A A$

$36 \mathrm{BDD}$

6 DAA.

BS $13 W$

$8518 W \quad 12 \mathrm{CC}$

21 CBA

17 DEE, DEB

$8521 w$

$18 \mathrm{ADD}, \mathrm{CAD}, \mathrm{CDD}, \mathrm{CDD}$

$8521 W$

$32 \mathrm{CC}$

BS $21 w$

$8522 W 13 \mathrm{BDD}, \mathrm{DAD}$

BS $22 W 14$ CDD, DAA

is $22 W^{\circ} 15 \mathrm{AC}$

$17 \mathrm{CCE}$

18 CED

19. CCD

$8522 W \quad 21 \mathrm{DDD}$

$8522 W \quad 22$ CDA, CDA

$25 A D$

29 DDA

30 CAE

$31 \mathrm{CB}, \mathrm{BD}$

BS $22 w$

$8522 W \quad 32 \mathrm{BC}, \mathrm{CC}, \mathrm{DC}$

$8522 W \quad 33 D A, A C, E C, C C$

RS $>>$
1. Te 2. Te 3. 4. 5. 6. 7.

57

57

28

29

26

24

29

29

26

30

60

23

$22 \quad 22$

$\begin{array}{llll}22 & 22 & 23 & 22\end{array}$

26

$24 \quad 22$

$22 \quad 23$

34

22

23

22

22

22

22

23

22

22

$24 \quad 24$

$23 \quad 23 \quad 23$

$23 \quad 23 \quad 23 \quad 23$ 


\begin{tabular}{|c|c|c|c|c|c|c|c|}
\hline 85 & $22 W$ & 35 & $A C, A C, C C, A D$ & 23 & 31 & 23 & 23 \\
\hline $8 S$ & $23 W$ & 12 & DC & 23 & & & \\
\hline 85 & $23 w$ & 21 & $A C, A C$ & 27 & 27 & & \\
\hline 85 & $23 W$ & 21 & CAA & 25 & & & \\
\hline 85 & $23 w$ & 24 & $\mathrm{CDE}, \mathrm{CDB}, \mathrm{DCC}$ & 22 & 21 & 22 & \\
\hline es & $23 w$ & 25 & $A C E, A C E$ & 23 & 22 & & \\
\hline 85 & $23 w$ & 26 & $A C, D C, B D, D D$ & 23 & 24 & 23 & 23 \\
\hline BS & $23 w$ & 29 & $A D$ & 29 & & & \\
\hline 85 & $23 w$ & 32 & $\mathrm{BD}$ & 27 & & & \\
\hline 85 & $23 w$ & 33 & $\mathrm{BC}, \mathrm{DC}$ & 30 & 28 & & \\
\hline 85 & $23 w$ & 33 & CDD & 34 & & & \\
\hline 85 & $23 w$ & 35 & $A A, D A, A C$ & 25 & 25 & 26 & \\
\hline BS & $24 W$ & 33 & $\mathrm{BAB}$. & 22 & & & \\
\hline 95 & $18 W$ & 5 & $\mathrm{BAD}$ & 27 & & & \\
\hline 95 & $18 W$ & 6 & $D A A, D A A$ & 24 & 24 & & \\
\hline 95 & $18 W$ & 8 & $\mathrm{BCA}$ & 27 & & & \\
\hline 95 & $18 W$ & 11 & $\mathrm{BBB}, \mathrm{BBB}$ & 28 & 28 & & \\
\hline 95 & $18 W$ & 19 & $\mathrm{CBD}, \mathrm{CBD}, \mathrm{CBD}, \mathrm{CDE}$ & 26 & 19 & 27 & 27 \\
\hline 95 & $18 W$ & 20 & CEA, CEB & 26 & 26 & & \\
\hline 95 & $19 \mathrm{~W}$ & 24 & DAD & 23 & & & \\
\hline 95 & $21 \omega$ & 2 & $\mathrm{CB}$ & 36 & & & \\
\hline 95 & $21 w$ & 2 & $\mathrm{BCA}$ & 36 & & & \\
\hline 95 & $21 w$ & 3 & DC & 29 & & & \\
\hline 95 & $21 w$ & 4 & $\mathrm{CB}$ & 27 & & & \\
\hline 75 & $21 w$ & 5 & $\mathrm{CE}$ & 26 & & & \\
\hline
\end{tabular}


Tow Ran Sect Location

$9521 \mathrm{~W} 6 \mathrm{BB}$

$9521 W \quad 7$ AA

$9521 W \quad B A A$

$9521 W \quad 9 D C$

$9521 \mathrm{~W} 10 \mathrm{BCD}$

$9521 \mathrm{~W} \quad 12 \mathrm{BD}$

$13 \mathrm{CC}$

$9521 W$

$9521 \mathrm{~W}$

$14 \mathrm{CA}, \mathrm{AB}$

$9521 W$

14 BAC

$9521 \mathrm{~W} 15 \mathrm{DAE}$.

$9521 W \cdot 16$ DA

$9521 \mathrm{~W} 19 \mathrm{CC}$

95 $21 W \quad 20 A A$

$9521 W \quad 21 \mathrm{AB}, \mathrm{CD}$

$9521 W \quad 23 \mathrm{BA}$

$9521 W \quad 23 \mathrm{CBC}$

$9522 W \quad 4 C A, B D$

os $22 W^{\circ} \quad 5$ BE

$9522 W$

6 DA

7 DCC

$9522 W$

$9522 w$

$9 \mathrm{BB}$

$9522 W$

$11 \mathrm{BB}$

$17 \mathrm{BB}$

$9522 W$

$18 \mathrm{DD}$

$9522 W$

(2)

$9522 W 23 A A$

$9522 W \quad 24 \mathrm{BA}, \mathrm{BB}$

$9522 W \quad 2 B \quad B C$

$9522 W \quad 28 \mathrm{CBE}$

$9522 W \quad 2 B \quad C B$

$9572 W \quad 79 \mathrm{RR}$
1. Te 2. Te 3. 4. 5. 6. 7.

24

25

28

29

27

32

34

$31 \quad 34$

35

23

30

27

29

$29 \quad 30$

32

17

$24 \quad 24$

24

24

18

24

24

35

28

26

$26 \quad 26$

36

26

36 
$9523 W \quad 3 \mathrm{CD}$

28

$9523 W \quad 4 \mathrm{BC}$

28

$9523 W \quad 5 A A, D C, D D$

$31 \quad 28 \quad 29$

$9523 W \quad B C D, D D$

$25 \quad 27$

$9523 W \quad 17 \mathrm{BA}, \mathrm{CD}$

$27 \quad 26$

$9523 \dot{\omega} \quad 20 A B, D E, D C$

$\begin{array}{lll}27 & 28 & 27\end{array}$

$9523 W \quad 21 \mathrm{DB}$

24

$9523 w 23 \mathrm{DA}, \mathrm{CD}$

$26 \quad 27$

95 23W 24 AA

26

$9523 W \quad 2 B$ CA

26

$9523 w 29 A A, B B, A C$

25

$28 \quad 26$

$9523 W \quad 30 D C, B C, E C, A D$

28

$\begin{array}{lll}27 & 27 & 27\end{array}$

$9523 W \quad 31 \mathrm{DA}$

28

$9523 \mathrm{~W} \quad 32 \mathrm{AB}$

28

$9523 W \quad 35 \mathrm{CC}$

27

$9523 W \quad 36 \mathrm{DE}, \mathrm{CC}$

25

25

$9524 W \quad 2$ CCD

21

$9524 W$

$B A B$

25

$9524 W \quad 10 \mathrm{BEE}$

21

is $24 \dot{W}$

12 DAC

40

95 24W 12 DAC

40

$9524 W \quad 14$ DBA

26

$9524 W \quad 15$ DED

28

$9524 W$

$17 \mathrm{DBA}, \mathrm{DBD}$

28

22 
Tow Ran Sect Location

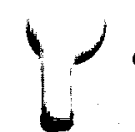

$9524 W \quad 19$ BDD

$9524 W \quad 20 \mathrm{DDD}, \mathrm{DDD}$

$9524 W \quad 22$ ABA

$9524 W \quad 28 \mathrm{CBB}$

$31 \mathrm{BBA}$

$9524 \mathrm{~W} \quad 32 \mathrm{DDB}$

$9524 W \quad 34$ DCB

$9524 \mathrm{~W} 36 \mathrm{AA}, \mathrm{DA}, \mathrm{AC}$

$9524 W \quad 36$ DDD

95 25W 35 ABA, ABA

$9525 W$ 36 AAA

105

$10522 W \quad 7 \mathrm{CA}$

$10523 W \quad 3 A A$

3 AAA

$4 \mathrm{DA}$

$6 \mathrm{BB}$

$7 \mathrm{BB}$

8 CCD

$9 A A$

$11 \mathrm{CC}, \mathrm{CD}$

$10523 w$

11 CCE, DCA, DCD

$10523 w$

$10523 w$

$12 \mathrm{BA}, \mathrm{DE}, \mathrm{DB}$

$10523 W$

$12 \mathrm{ABA}, \mathrm{ABB}, \mathrm{ABBBDA}, \mathrm{BDD}$

$13 \mathrm{CD}$

$14 A A$

$10523 w$

14. AA

$15 A A A, A A B$

16 DCB

$10523 w$

19

$10523 W \quad 18 \mathrm{CC}$

$10.525 \%$
1. Te 2. Te 3. 4. 5. 6. 7.

23

$22 \quad 18$

25

22

22

26

26

$\begin{array}{lll}28 & 28 & 27\end{array}$

26

$22 \quad 22$

22

28

26

25

27

27

27

34

25

$26 \quad 30$

$\begin{array}{lll}26 & 28 \quad 28\end{array}$

$33 \quad 29 \quad 29$

$\begin{array}{lllll}28 & 27 & 27 & 28 & 28\end{array}$

31

32

$25 \quad 26$

27

$2 \theta$ 79 
1

$10523 W \quad 20 \mathrm{BEB}$

.. $10523 \mathrm{~W} 21 \mathrm{BA}$

29

105 23W $22 \mathrm{BA}$

28

$10523 \mathrm{~W} 23 \mathrm{BA}, \mathrm{BC}$

$28 \quad 29$

$10523 W \quad 28 \mathrm{CC}, \mathrm{DC}$

$34 \quad 31$

$10523 W \quad 29 A C, D D$

30

30

$10523 w 31 \mathrm{BE}$

29

$10523 W \quad 31 \mathrm{BE}$

29

$110523 W \quad 36 \mathrm{DD}$

34

$10524 \mathrm{~W} 1 \mathrm{DBD}$

26

10S 24W 2 AAB

18

$10524 \mathrm{~W}$

$4 \mathrm{BBE}$

24

$10524 \mathrm{~W}$

$5 \mathrm{DD}$.

24

$10524 W$

$6 \mathrm{CE}$

22

$10524 W \quad 7 \mathrm{CC}$

23

IOS 24W $9 \mathrm{BBA}$

24

$10524 \mathrm{~W} \quad 10 \mathrm{CDD}$

22

$10524 W \quad 12 \mathrm{CA}, \mathrm{CE}, \mathrm{DC}, \mathrm{AD}, \mathrm{DD}$

26

$10524 W \quad 12$ BCC

25

$10524 W \quad 13 \mathrm{DA}, \mathrm{BE}, \mathrm{CE}$

$26 \quad 26 \quad 25$

iQs $24 W^{\circ} 13 \mathrm{BED}, \mathrm{BED}, \mathrm{BED}$

$25 \quad 26 \quad 26$

$105.24 W \quad 14 \mathrm{DD}$

26

$10524 \mathrm{~W} \quad 15 \mathrm{CD}$

26

$10524 W \quad 15 \mathrm{CD}$

24

$10524 W$ 16 BAA, BAA, EAA

$34 \quad 18 \quad 20$ 
Tow Ran Sect Location

LOS 24W 17 CCC $10524 W \quad 19$ BEB

$10524 \mathrm{~W} 22 \mathrm{ABE}$

$10524 W \quad 23 \mathrm{DD}$

$10524 W \quad 23$ DDC

$10524 W \quad 24 \mathrm{BC}$

$10524 W \quad 24 \mathrm{BEB}$

$10524 W \quad 24 \mathrm{CB}$

$10 S 24 W \quad 28$ BEA

$10524 W \quad 30 \mathrm{AB}$.

$10524 W \quad 31$ ADC

$10524 W \quad 32 \mathrm{DD}$

$1 \mathrm{BE}$

$1 \mathrm{BEA}, \mathrm{BBA}, \mathrm{BEA}$

$10525 W$

$10525 \mathrm{~W} \quad 14 \mathrm{ADE}$

$10525 W \quad 23 \mathrm{DA}$

24 BAD

$26 \mathrm{AB}$

ins $25 \mathrm{w}$

$26 \mathrm{AB}$

$10525 W \quad 35 \mathrm{BE}, \mathrm{AC}$

$10525 W \quad 35$ AAA

$10525 \mathrm{~W} 35 \mathrm{BE}$

$36 \mathrm{CC}$

$4 \mathrm{DD}$

$13 \mathrm{CA}$

$23 A D$

$24 \mathrm{AE}$

9 BEE

$12 \mathrm{DD}$

$11523 W$

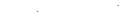

$11523 W \quad 34 \mathrm{BE}$
1. Te 2. Te 3. 4. 5. 6. 7.

20

24

22

26

25

52

25

52

20

22

24

26

22

22

$22 \quad 22$

22

24

27

24

$38 \quad 23$

23

38

23

33

30

31

30

35

30

32

142 
$11524 W$

$8 \mathrm{CA}$

42

$11524 W$

$B A C$

138

$11524 W$

10 $\mathrm{DC}, \mathrm{DD}$

27

30

$J_{11524 W}$

10 DDD

29

$11524 W$

$11 \mathrm{DB}, \mathrm{DC}$

27

$\begin{array}{llllll}26 & 27 & 26 & 26 & 28 & 27\end{array}$

$11524 W \quad 13 \mathrm{BAA}, \mathrm{BAA}, \mathrm{BAD}, \mathrm{BDD}, \mathrm{BDD}$

28

$\begin{array}{llll}28 & 28 & 28 & 28\end{array}$

$11524 W \quad 14 \mathrm{BDD}, \mathrm{BDD}$

$26 \quad 26$

$11524 W \quad 23 \mathrm{CE}$

28

$11525 w$

1 ACB

20

$11525 \mathrm{~W} 2 \mathrm{EE}$

23

$11525 \mathrm{~W} 2 \mathrm{BBA}, \mathrm{BBA}, \mathrm{BBA}, \mathrm{BBA}, \mathrm{BBA}, \mathrm{BBA}, \mathrm{BBC}$

27

$\begin{array}{llllll}24 & 23 & 23 & 23 & 24 & 22\end{array}$

\section{9}

$11525 w$

3 AD. .

21

22

22

$11525 \mathrm{~W} \quad 12 \mathrm{CB}$

23

$11525 w$

12 CBA

20

$12521 w$

$14 \mathrm{AD}$

32

$12521 \mathrm{~W} \quad 17 \mathrm{EC}$

35

$12521 \mathrm{~W} \quad 17 \mathrm{CBC}$

35

$12521 W \quad 25 \mathrm{DA}$

32

$12 \dot{5} 22 \dot{1} "$

$6 A D$

30

$12522 W$

$9 \mathrm{AE}$

36

$12522 W$

$9 \mathrm{BAB}$

\$6

$13520 \mathrm{~W}$

$2 \mathrm{BA}$

38

$13520 \mathrm{~W}$

$2 A B D$

38 
Tow Ran Sect Location

$/ 14514 \mathrm{~W}$

$7 \mathrm{BAD}$

14 AAA

$2 A A$

$95 \quad 24 W$

$9524 \mathrm{~W}$

$19 \mathrm{CB}$

$\Rightarrow=$

5514
1. Te 2. $\operatorname{Te} 3.4 .4 .5 .6$. 27 29

26

22

$=\geq=2=2=$

$9735 \quad 2922$

- Grand Totals for 334 records in this report. 


\section{GEDTHERMAL RESOURCE EVALUATION OF THE YUMA AREA \\ APPENDIX F \\ SELECTED DIGITAL MAPS}

SCALE: 1 DOUELED SYMEOL REFRESENTS 1 SQUARE MILE

MAF

FAGE

1. Digital Map 3: Surface Responsibility .............. 146

2. Digital Map 4: Surface Geology ..................... 150

3. Digital Map 8: Depth to Bedrock .................. 154

4. Digital Map 9: 50 Degree Celsius Isotherms ........... 158

5. Digital Map 10: 80 Degree Celsius Isotherms ......... 162

6. Digita1 Map 12: 125 Degree Celsius Isotherms ......... 166

6. Digital Map 13.1: 170 Degree Celsius Isotherms ........ 170

7. Digital Map 13.2: 190 Degree Celsius Isotherms ........ 174

8. Digital Map 16: Depth of Unit $2 \ldots \ldots \ldots \ldots \ldots$

9. Digital Map 17: USGS Ground Water Temperature Data .... 182

10. Digital Map 18: Thermal Well Temperature Data ....... 186

11. Digital Map 20: Unit 2 Interior - Ground Water Data ... 190

12. Digital Map 21: Unit 2 Interior - Thermal Well Data ... 194

13. Digital Map 23: U2/U1 Interface - Ground Water Data ... 198

14. Digital Map 24: U2/U1 Interface - Thermal Well Data... 202 


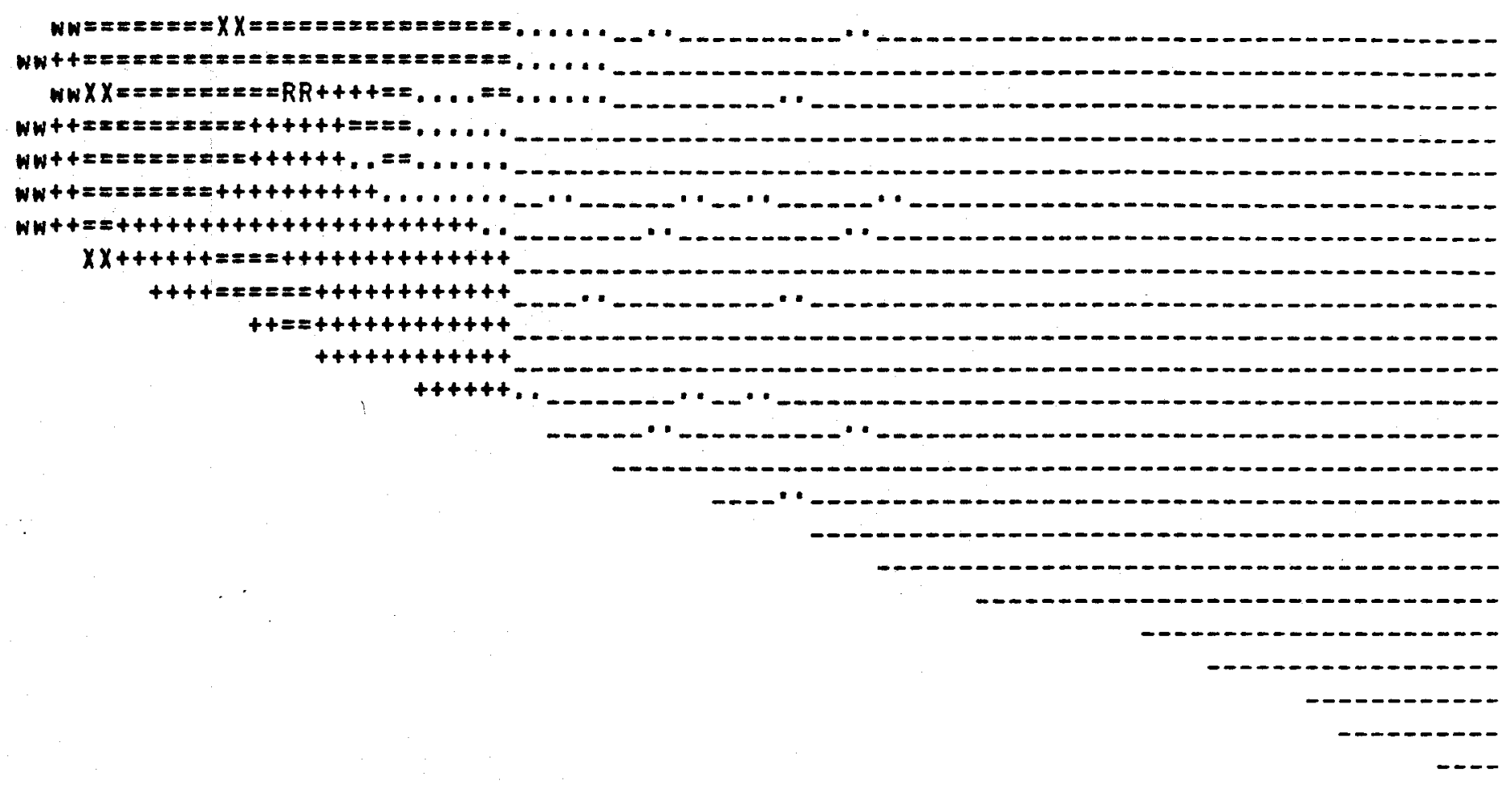

SURFACE RESPONSIBILITY WITHIN THE STUDY AREA

w: Colorado River

- Yuma County Line

* : Wildiife Refuge

* Yuna Test Station

- Luke-Willians Air force Range

† : Bureau of Land Management

- : State Surface Trust

$R$ : Indian Reservation

- Private Ownership

$x$ : Towns

\# : City of Yuma 


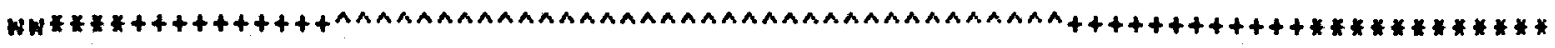

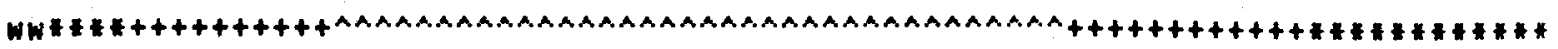

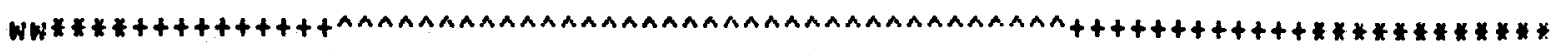

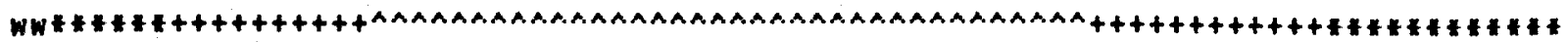

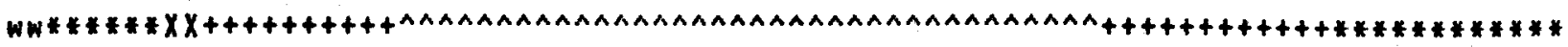

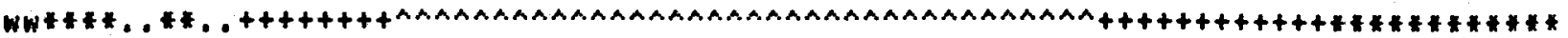

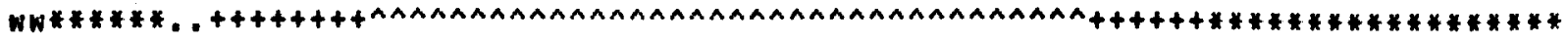

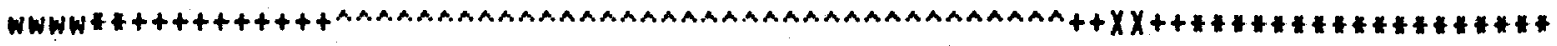

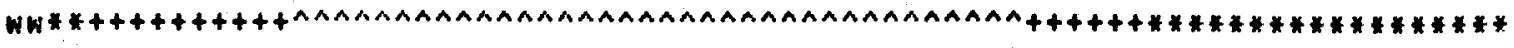

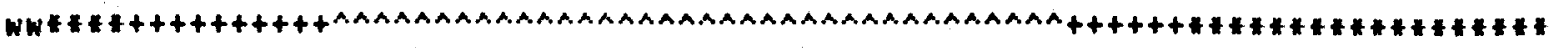

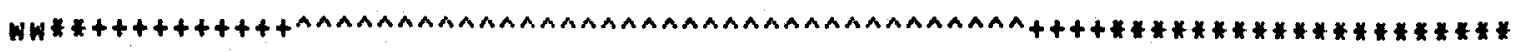

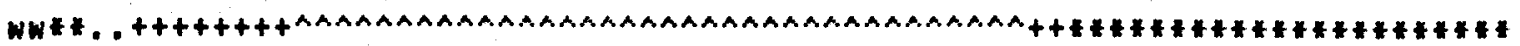

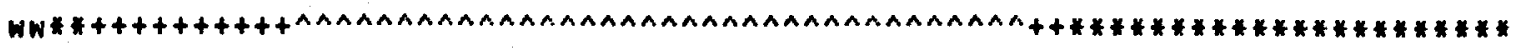
Wh:

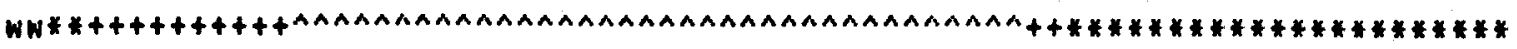

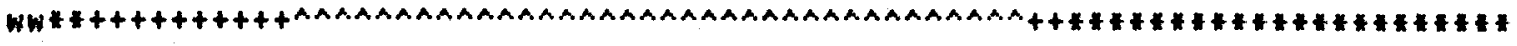

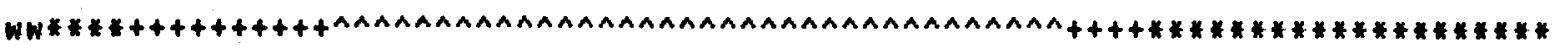

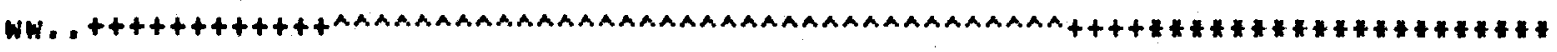

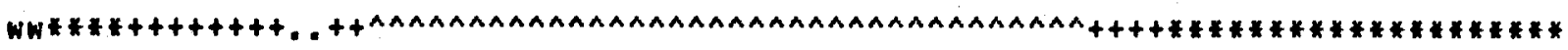

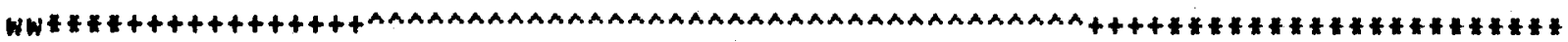

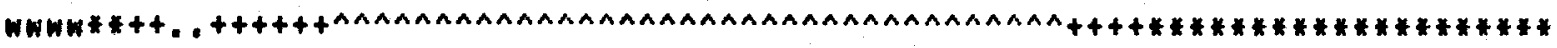

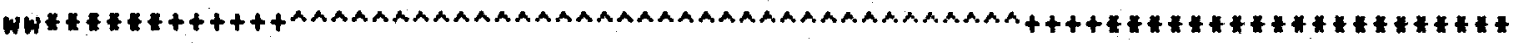

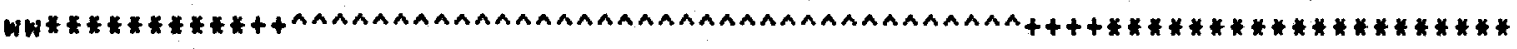

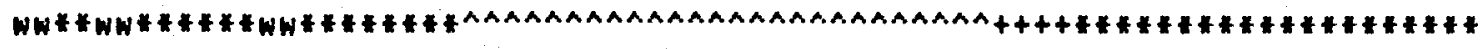

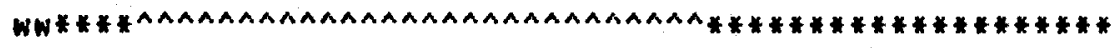

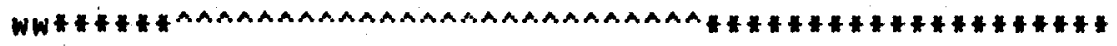

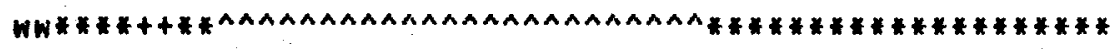

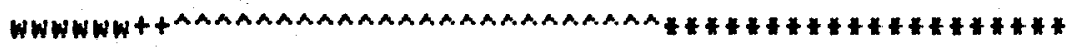

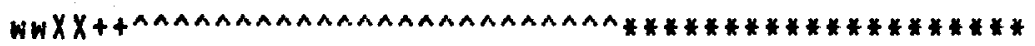

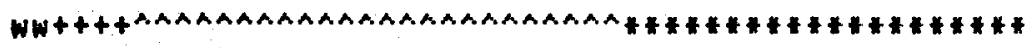

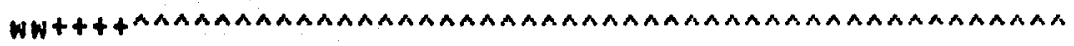

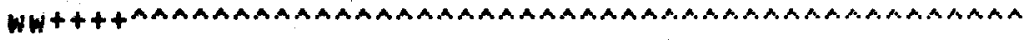

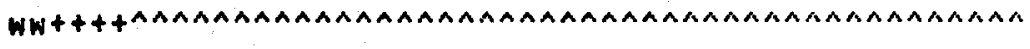

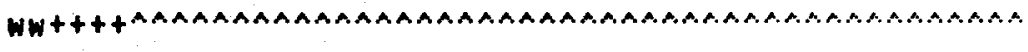

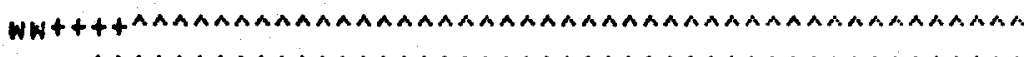

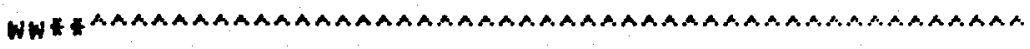

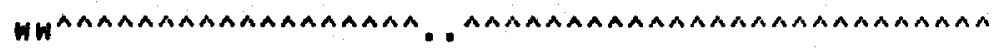

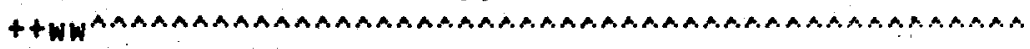
WWWWWWWWAAMAAAAAMAAMAA. . AAAMAAAMAAAMAAAMAMAMAMADAMAMAA

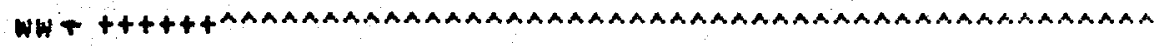

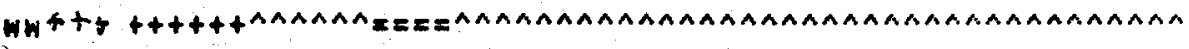

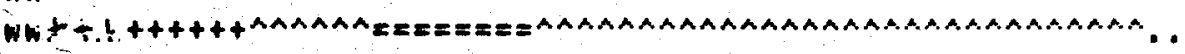

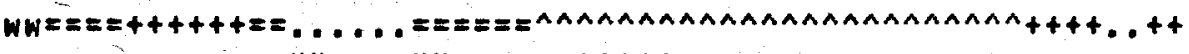

HW

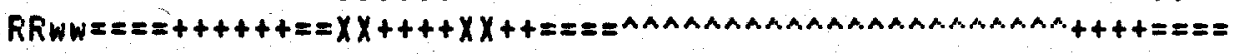

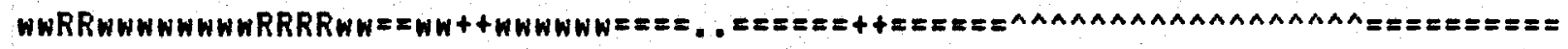

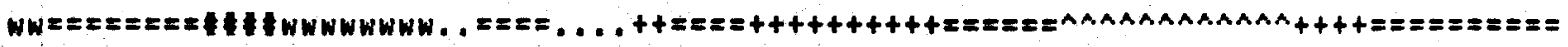

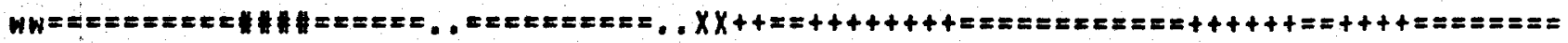

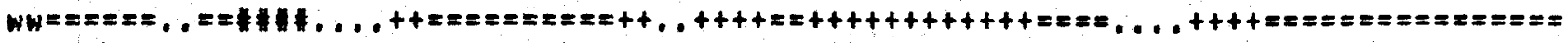

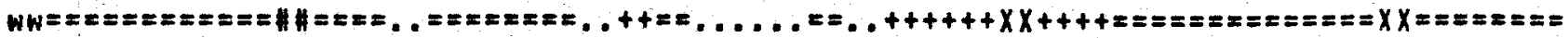

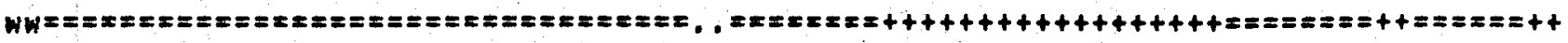

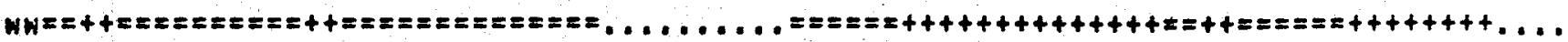

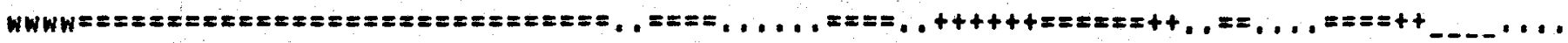

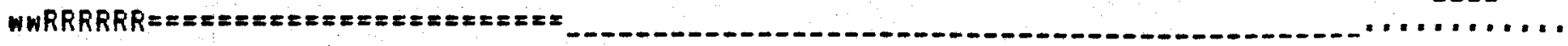

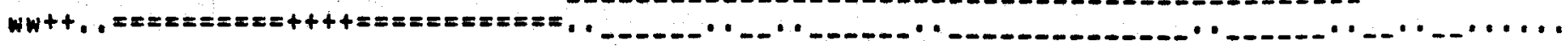


Digital Map $3(c)$

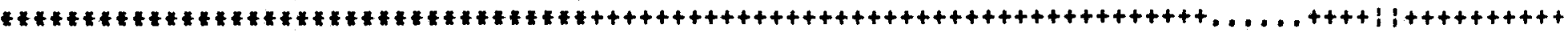

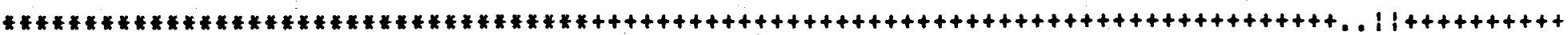

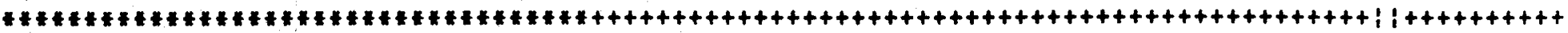

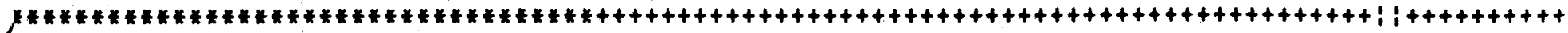

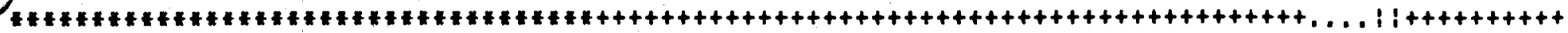

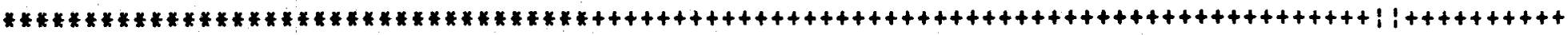

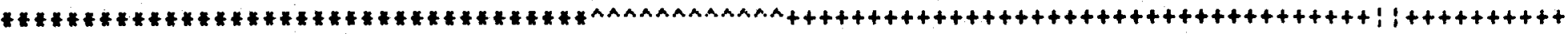

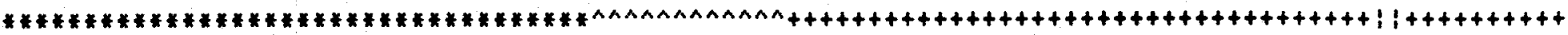

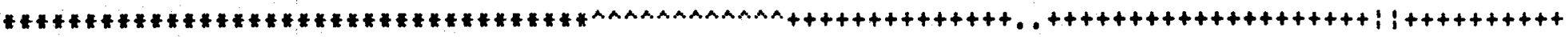

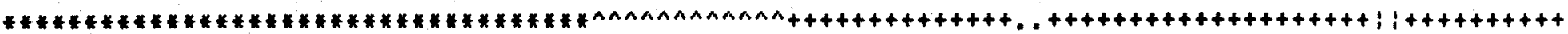

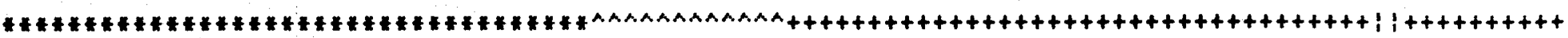

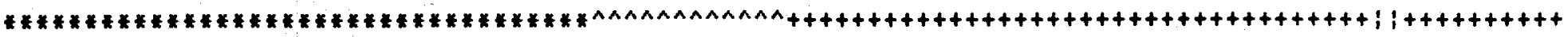

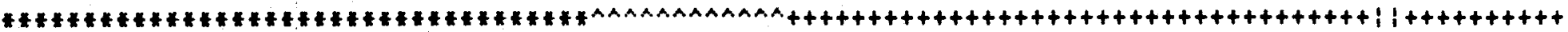

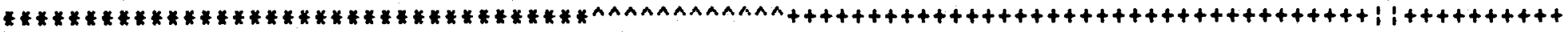

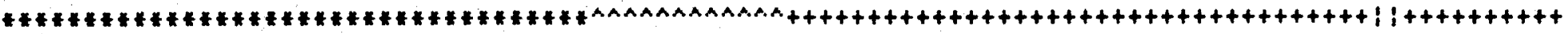

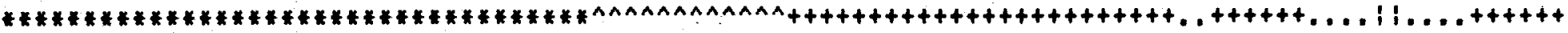

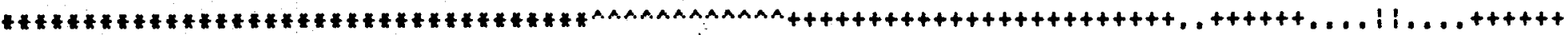

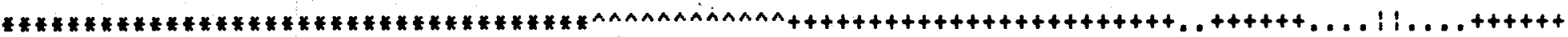

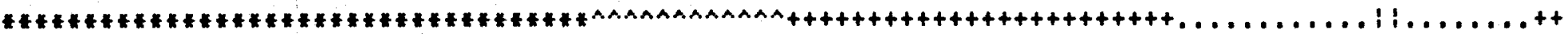

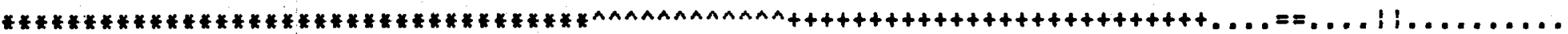

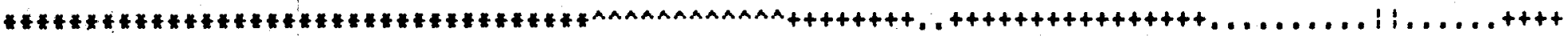

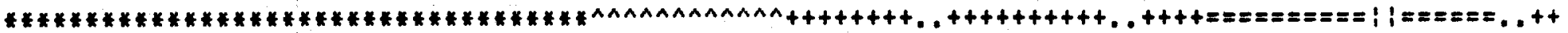

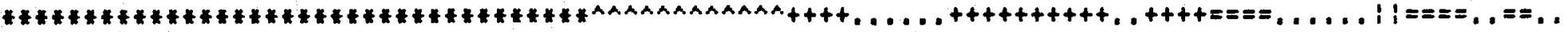

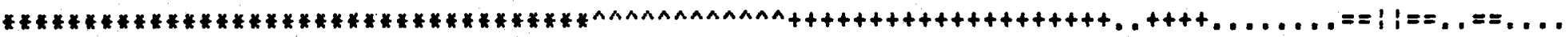

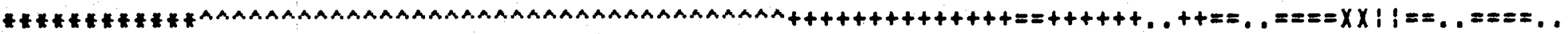

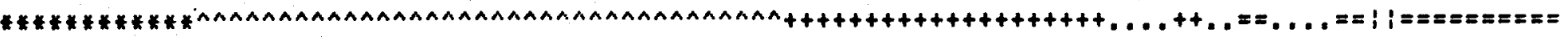

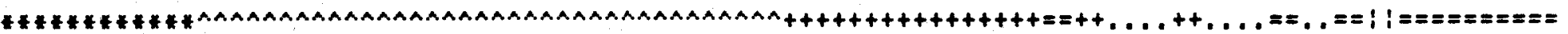

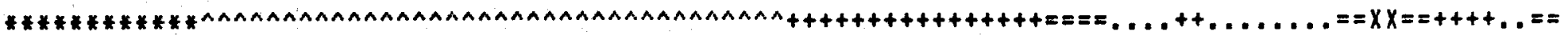

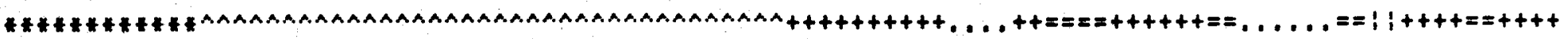

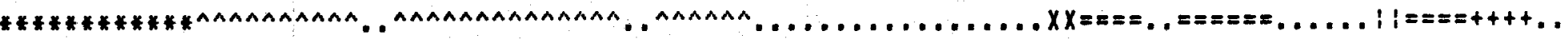

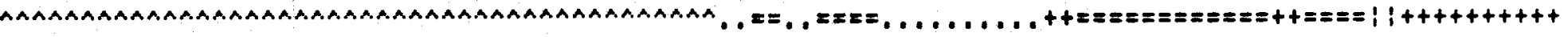

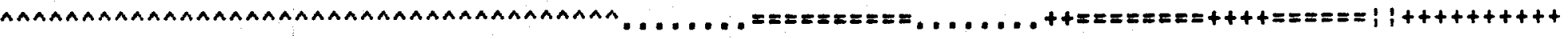

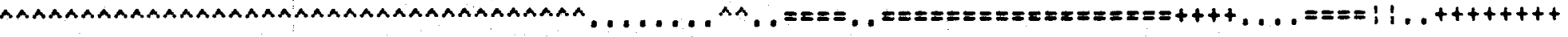

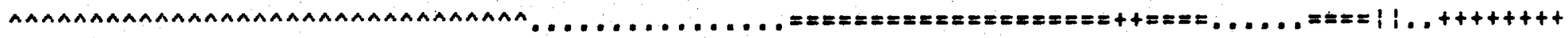

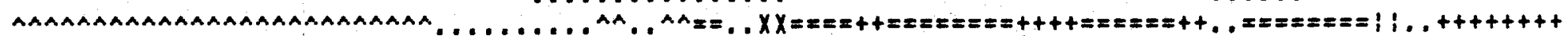

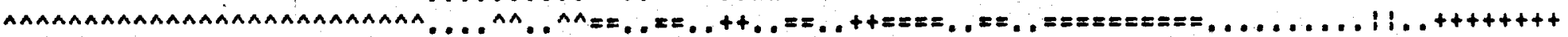

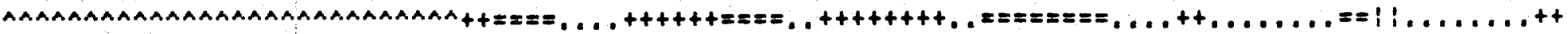

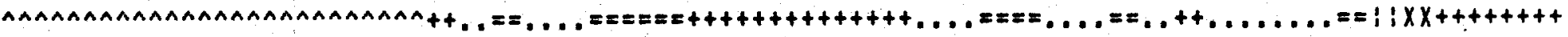

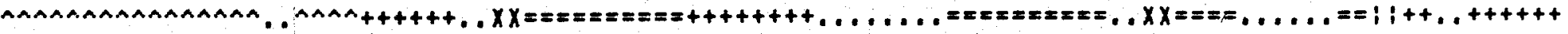

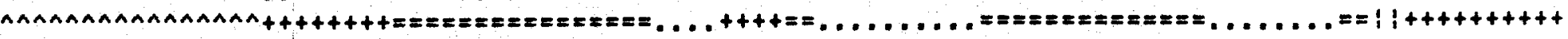

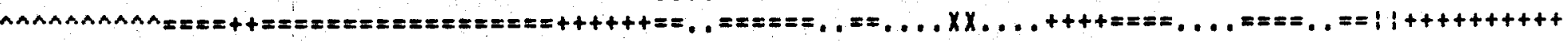

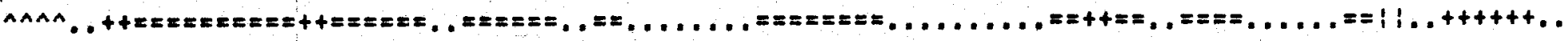

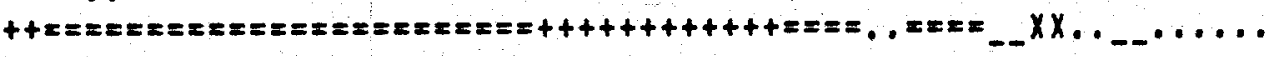

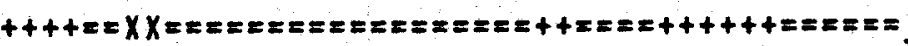

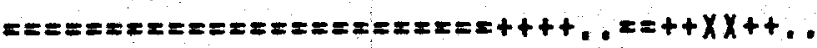
$\cdots+\cdots \cdots$

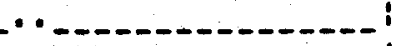

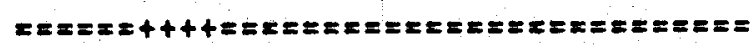

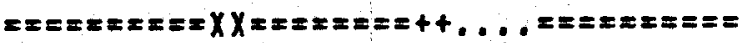
$z=x=x=x=x=x=x \ldots+t x x++\ldots ., z=\ldots \ldots$

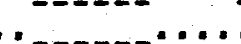
$\ldots .$. $\ldots \ldots \ldots$ $\ldots \ldots$

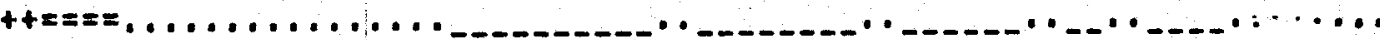

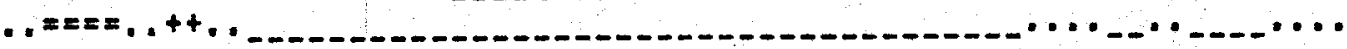

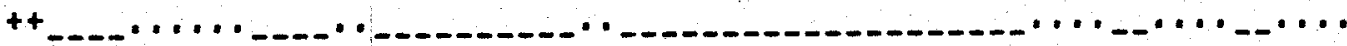
' '<smiles>[121In]</smiles>
$\ldots$ - $\cdot \ldots$ $\ldots \ldots \ldots \ldots \ldots$<smiles>[AlH2]</smiles><smiles>[AlH2]</smiles> 
Digital Map 3 (d)

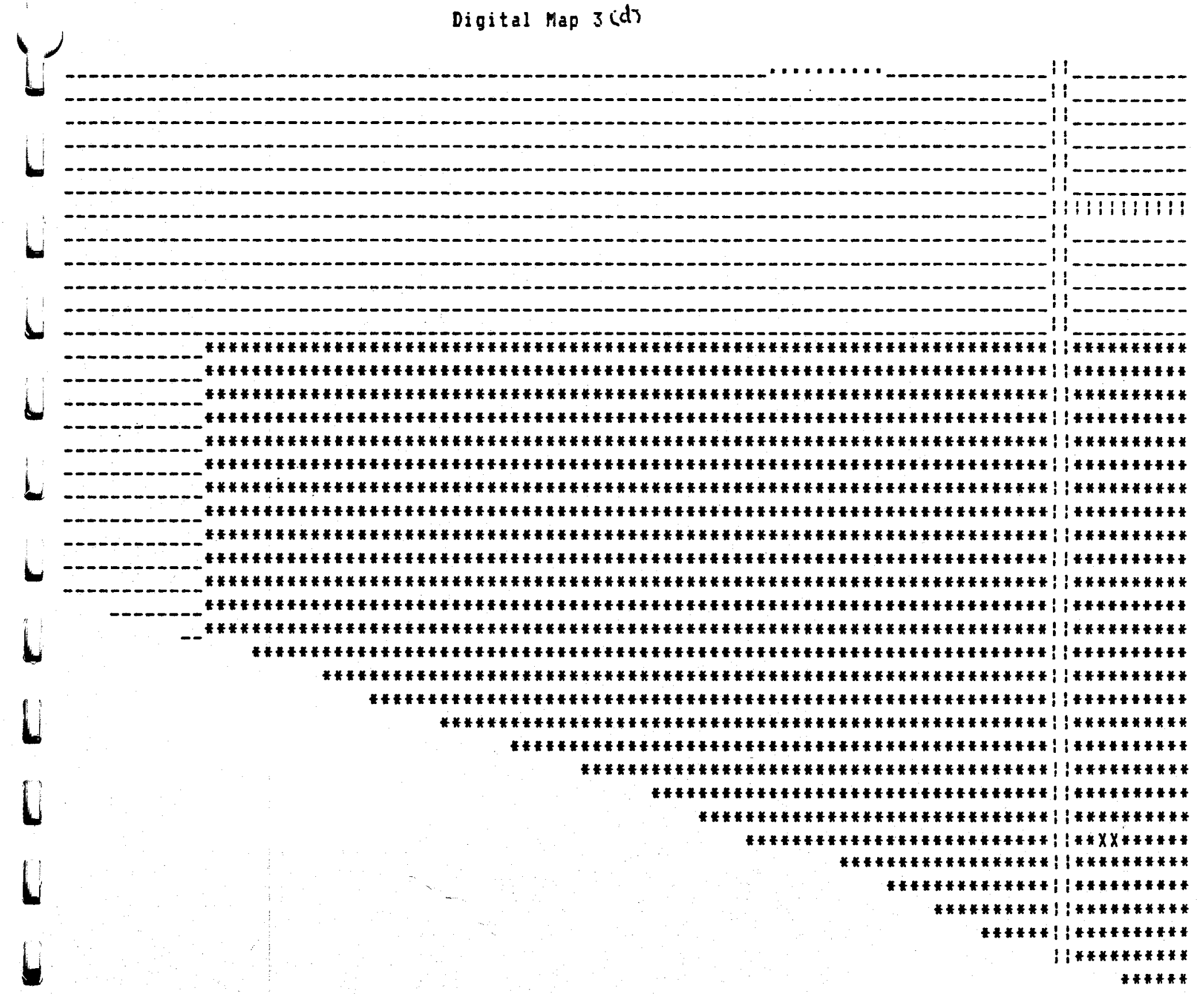




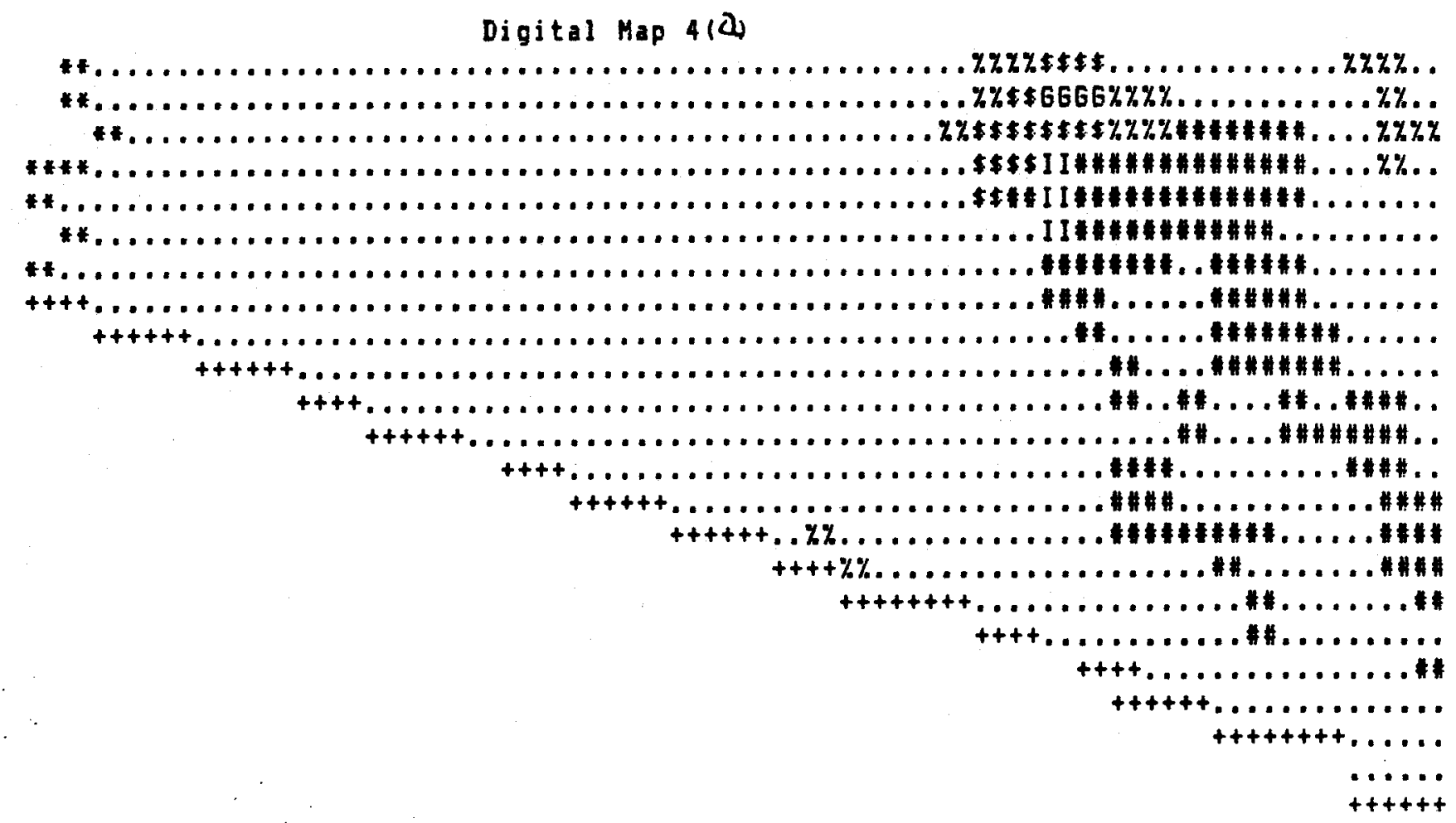

SURFACE GEOLOGY OF THE STUDY AREA

BORDER FEATURES: * : Colorado River SEDIMENTARY FORMATIONS

- Quaternary Sediments

- Quaternary-Tertiary Sediments

$t$ : Mid-Tertjary Deposits

k: Miocene-Cretaceous Deposits

m : Hesozoic Formations

GRANITES

G : Tertiary Granjte

* Gunnery Range (Laramidel Granite

* Pre-Tertiary Granite

e: Pre-Canbrian Granite

VOLCANIC FORMATIONS

+ : Border with Mexico

B: Quaternary Basalts

B : Late-Tertiary Basalts

I: Tertiary Intrusives

A : Mid-Tertiary Andesites

$V$ : Mid-Tertiary Andesites and Rhyolites

$R$ : Mid-Tertiary Rhyolites

METAMORPHIC ROCKS

* : Pre-Cambrian Schist

* Pre-Cambrian Schist, Recrystallized in Places

* : Pre-Cambrian Gneiss, Recrystallized in Places 


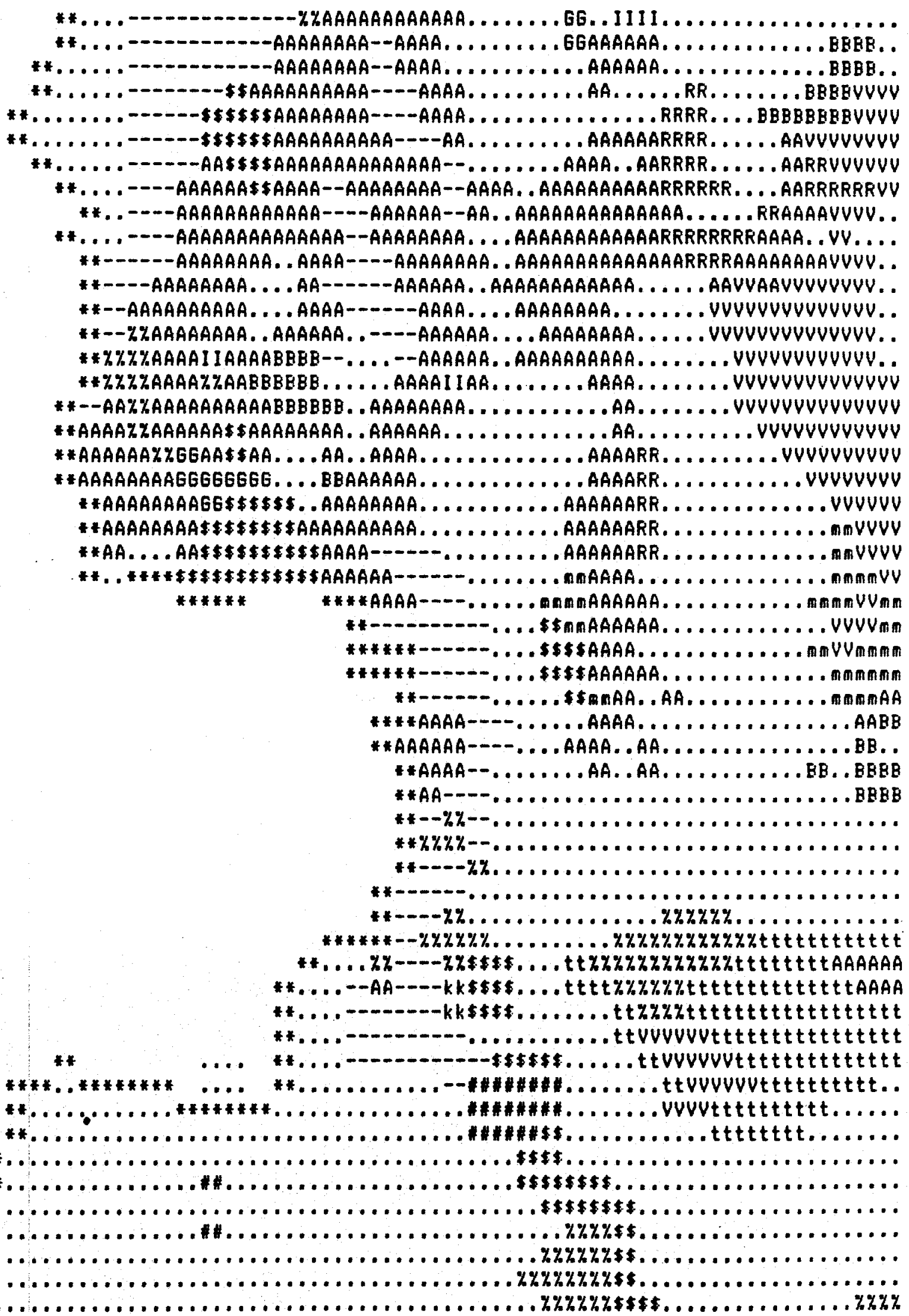




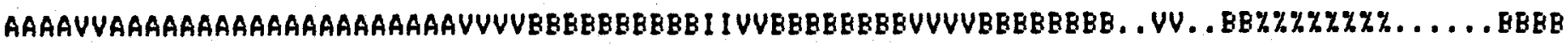
AAVVVUVVAAAAAAAAAAAAAAAAAAAAVVUVVV..... BBVVUVVVBBBBBBBBBBBBBBBBBBBE .

AAAAAAUVBBUVUVUVUYUVUVUVUV

BB. . BBBB. . BBVVVV.... .VV\%\%. . . UVYUEB.....

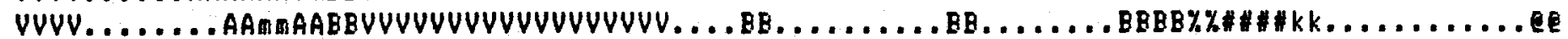

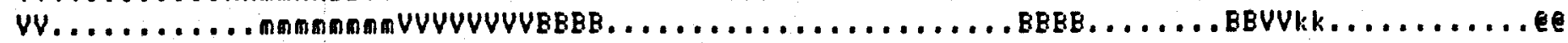

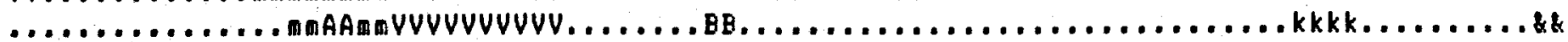

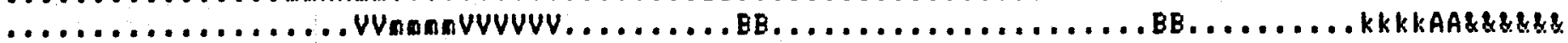
$\ldots \ldots \ldots \ldots \ldots \ldots \ldots$. . . . . . .

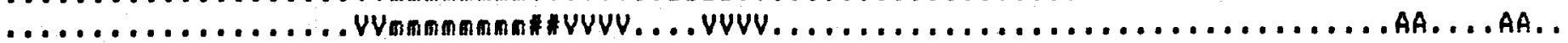

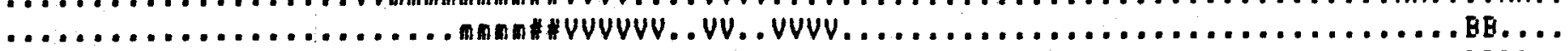

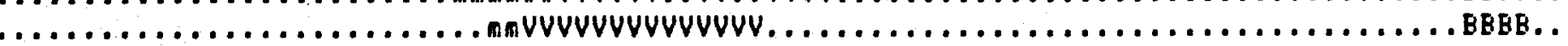

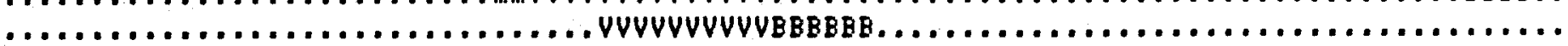

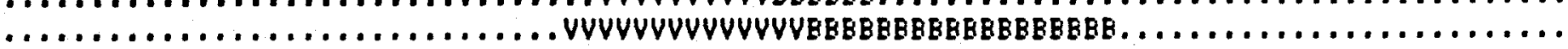

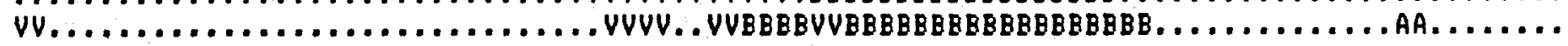

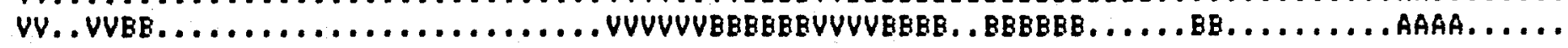
VV.....BBBB. VUVUVV.. BBBBEBBBBBBB. BBBB

VV. . VUVVEB. VUVV. . BBBB. . BBBB $\$ \$ \$ \$ \ldots B E B$.

VUVV...VVUV. VUVVחnUVVUVV. . BB m anVinuVUV. . BB.

maVUVVVVUVVV.

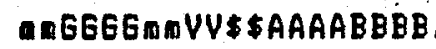

VVmanmmanm \$ $\$ A A A A m n B B$ and and an का \$ \$AAAAAABBBB mmm $n A A A A \$ \$ A A A A A A A A B B$. m $\triangle A A A A A A A A A A A A A A A A B B B E$ AAAAAAAAAAAAAAAABBBE BBBBAAAAAAAAAAAABBBB

BBEBEBEBAA\$\$AAAAAAAA \$\$\$ $\$ \$ \$ \ldots \% \%$
.\$\$\$\$V..........BB\$\$\$\$\$ ...BB.

\section{BBBBBE}

88
$\$ \$ \$ \$ \$ ., B B B B$.
\$\$\$ . . BBBBBB.
BE.
BB...

$\$ \$$.

BBBBBB.

.

kt $k t$ $+\$$ BEBB. BBAABBAa. bBBbaAmmaA. BEBBBBBBBBBE$\ldots$. . BREBBB.

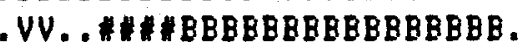
- Wै

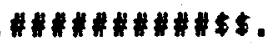
, औौ,

\section{.}




\section{Digital Map 4 (d)}

$\ldots \% \% \ldots \ldots k k k k k \% \%$ $\$ \$ \$ \$ \$ \$ \$ \ldots \ldots \ldots \ldots \ldots \ldots \ldots \ldots \ldots \ldots \ldots \ldots+\ldots \#$

...\%\%......kkkk...\%\%

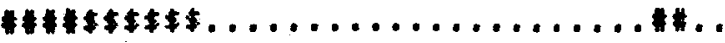

$\% \% \% \%$...kkkkkk...\%\%

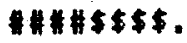

$\% \% \% \%$....kkkkkk\%\%\%.

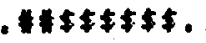

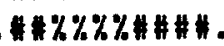

\#\#\#, . $\$ \$ \$ \$$

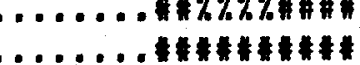

$0 \$ \$ \$$

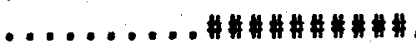

$\$ \$ \$$ \$

….....

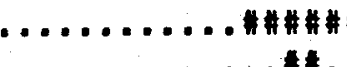

$\$$ \$.......

模.

$\$ \$ \$ \$ \$ \ldots \ldots \ldots \ldots \ldots \ldots$

..............\#\#\#\#,

.\$\$ $\$$

H.............

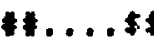

\$\$. . \#\#

$\$$

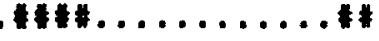

$$
\text { . }
$$

$\mathrm{BB}$

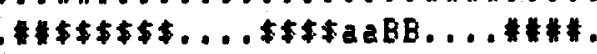

.......

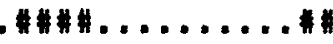

BB...............

H:

Stht.

H\#maa.............

14:4\#.

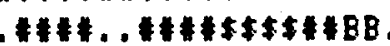

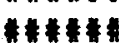

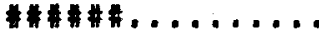

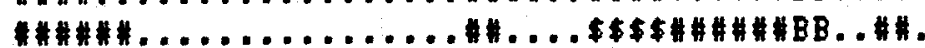

.

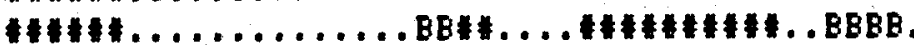

AtH\#.

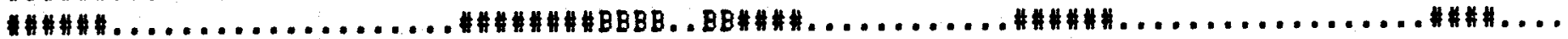

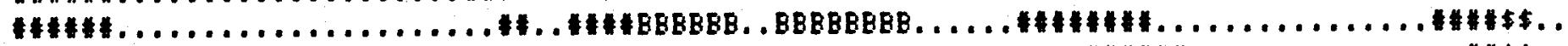

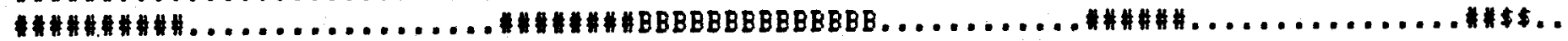

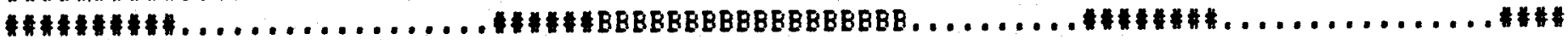

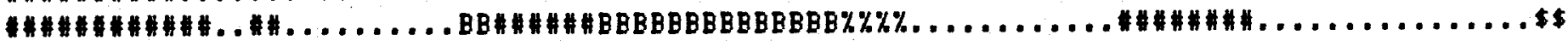

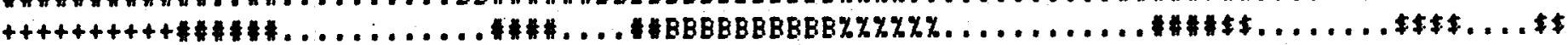

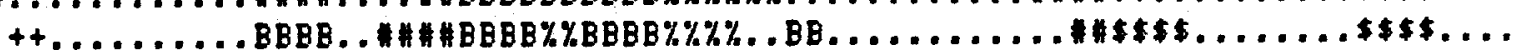

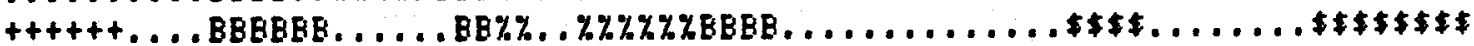
$++++++B B B B \ldots \ldots \ldots . \ldots \% .8 B \% \% \% \% \% \ldots \ldots \ldots \ldots \ldots \ldots \ldots \ldots \$ \$ \ldots \ldots \ldots \$ \ldots \ldots$

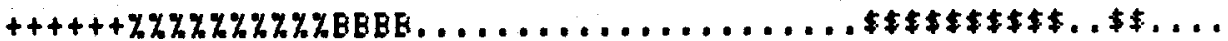
$++++++\% \% \% \% \% B B \% \ldots \ldots \ldots \ldots \ldots \ldots \ldots \ldots \ldots \ldots \$ \$ \$ \$ \$ \$ \$ \ldots$

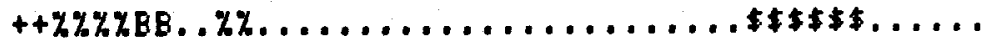

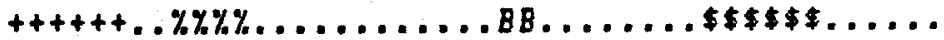
$++++++\ldots \% \% \ldots \ldots . . \ldots B B B B B B 8 B B \ldots \ldots \$ \$ \ldots \ldots$ $++++B B . .8 B B B B B B B B B B B B B \ldots \ldots \ldots \% \ldots$ $++++++B B B B B B B B B B B B \ldots \ldots \ldots \% \%$ $++++B B B B \ldots \ldots \ldots \ldots \%$ $++++++B E \ldots \ldots \% \% \% \%$ $++B E \% \% \% \% \%$

$++++\% \% 8 B$

$+++t$ 
Digital Map $8(a)$

* \$444444444444433222222334444445566778888776655331100AAAAAAAADO11333300BODDAAAADB

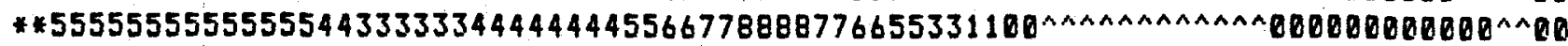

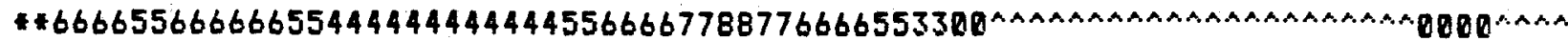

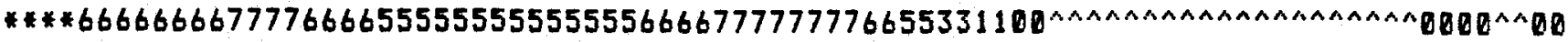

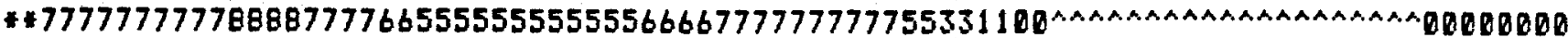

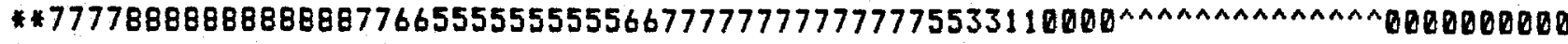

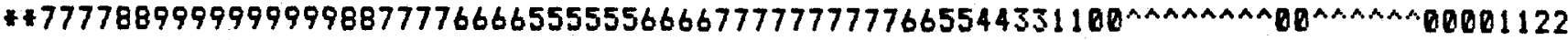

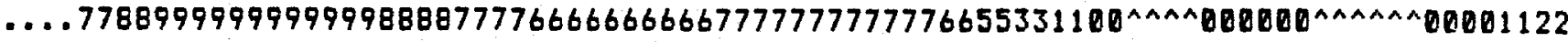

_....999999999999888877777777777777777777777777776655331100^A000000AAAAAAA.001122

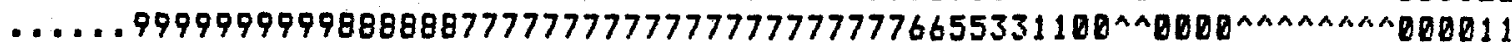

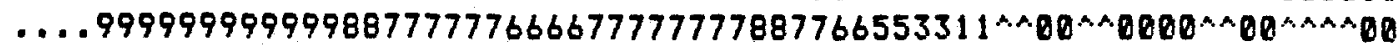

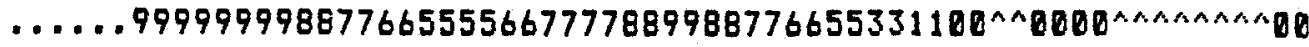

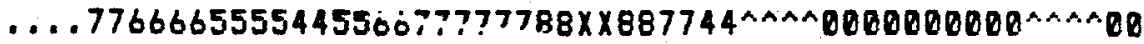

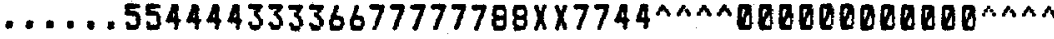

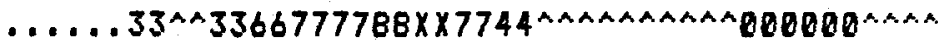

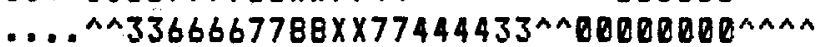

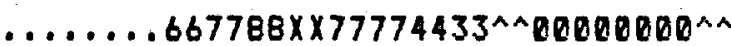

...7788 $\times \times 887733^{\wedge \wedge} 8000000000$

.... $\times \times 77664433221100^{14}$

.....77664433221100

......221108

221100

DEPTH TO BEDROCK MAP OF THE STUDY AREA

* Colorado River

D : to B.125 kn.

$1: 0.125$ to $0.25 \mathrm{~km}$.

$2: 0.25$ to $0.5 \mathrm{~km}$.

$3: 0.5$ to $1.0 \mathrm{~km}$.

$4: 1.0$ to $1.5 \mathrm{~km}$.

$5: 1.5$ to $2.0 \mathrm{~km}$.

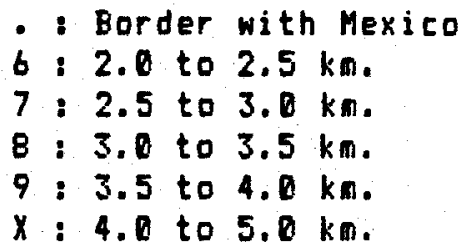

41 


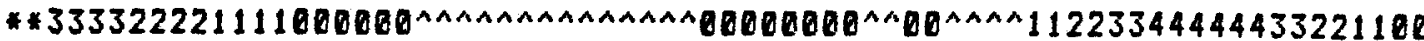

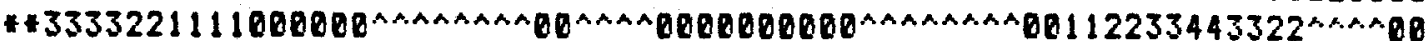

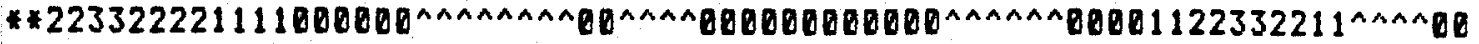

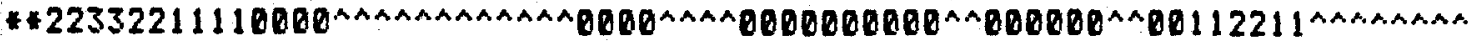

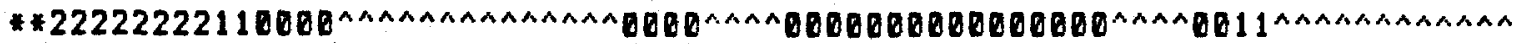

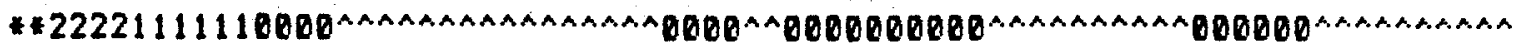

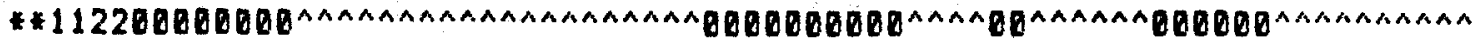

* 22000000

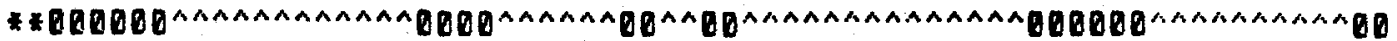

* \#DODDEOB

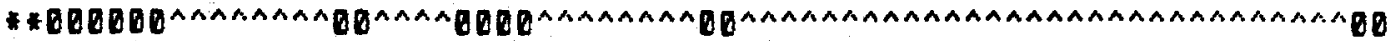

* EDDOQ

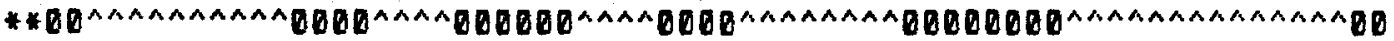

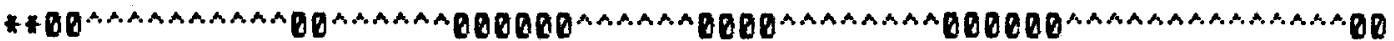

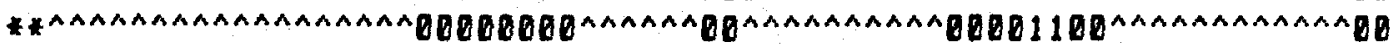

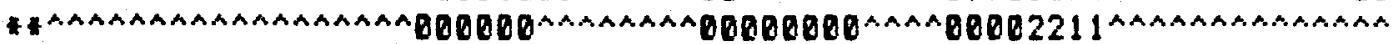

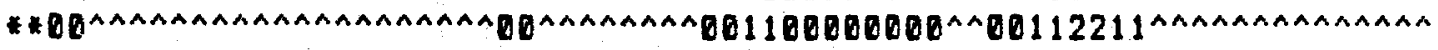

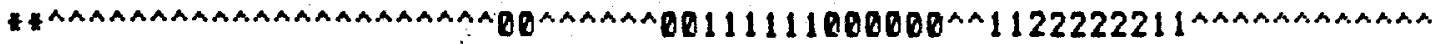

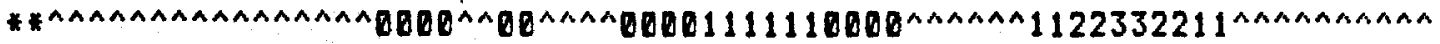

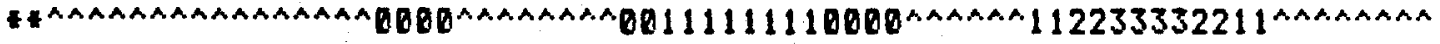

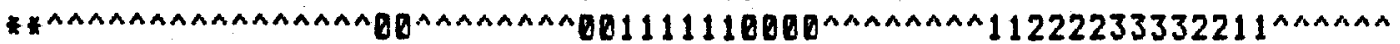

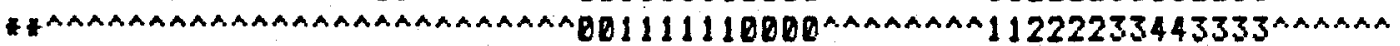

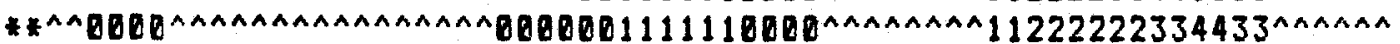

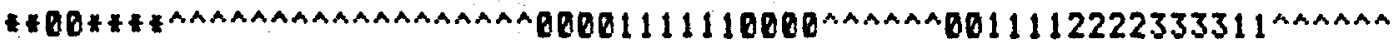
$* * * * * *$

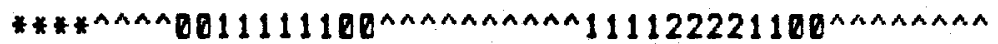

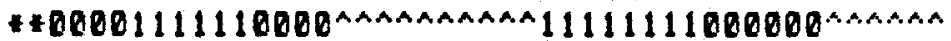

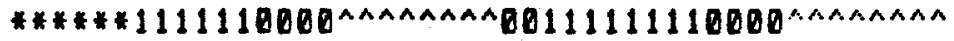
*****1111110000AaAnaAaAaA11111111000800AaAnaA

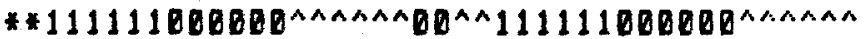

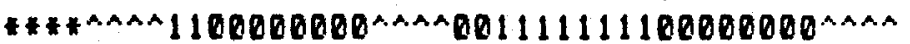

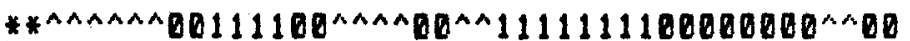

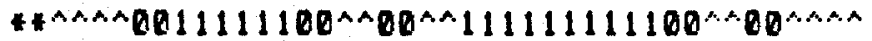
**AAOBOB111111111111111111111111110000AAAs **00AMOB1111111111111111111111111111110000

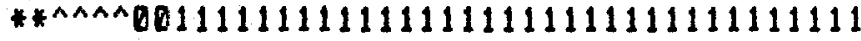
**0800^1111111111110000111111111111111111 **008008001111111111000000000011111111111122

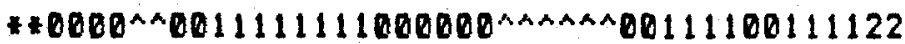

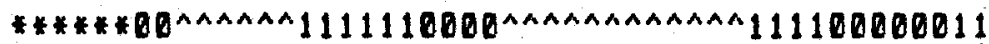

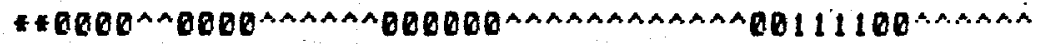

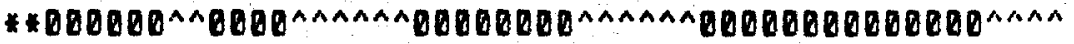

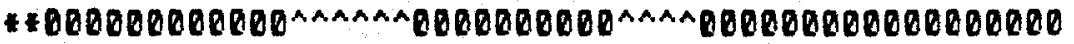

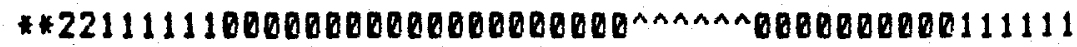

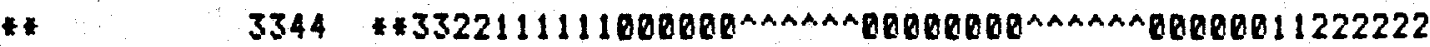

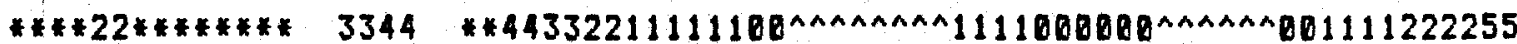

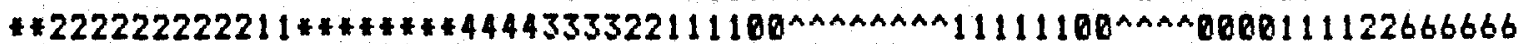

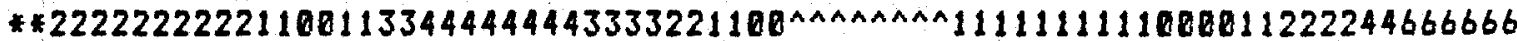
* $+222222222222110011223344444444443333118000 A A A A 1111112222333344444444666666$

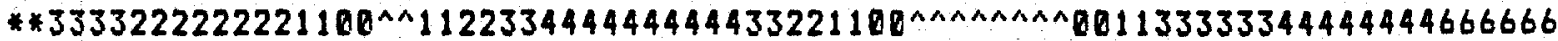
*3333332222222211000011223344444444444433221100AAAAAAAA1133333344444444666666 * *33333322222222221108^^1122334444555555444433221100^A^A^^1133333344444444666666 ***333333222222221111000011223344556666665544331100AAnAAAAA1133333344444444666666

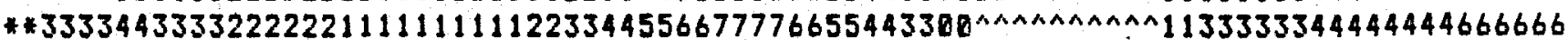

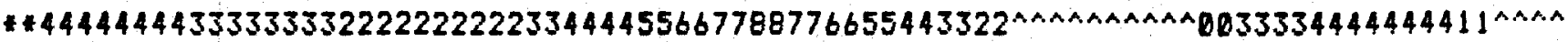




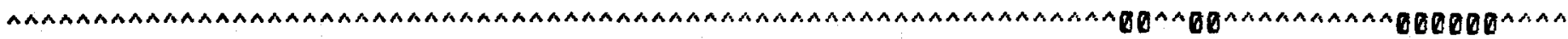

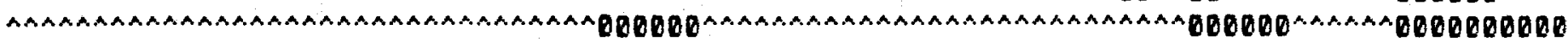

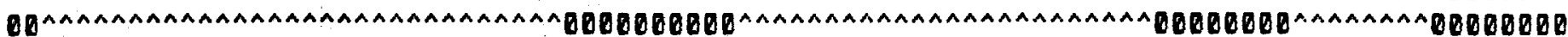

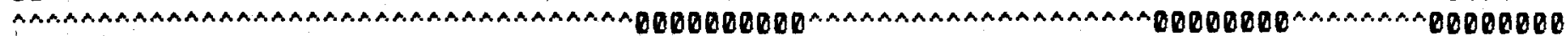

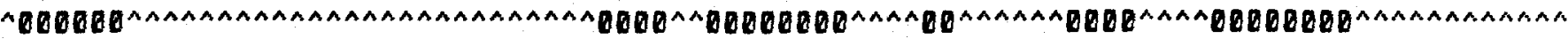

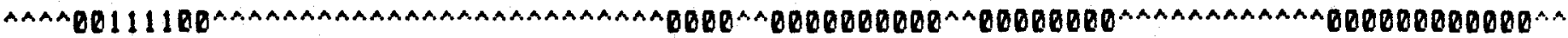

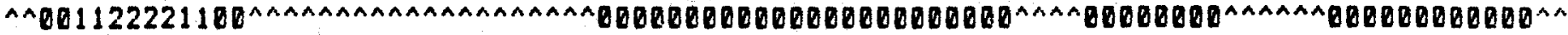

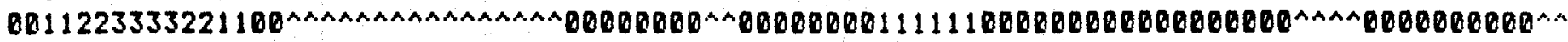

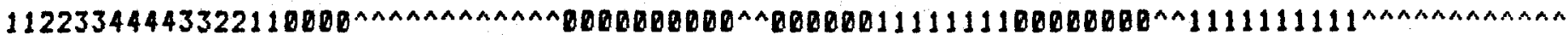

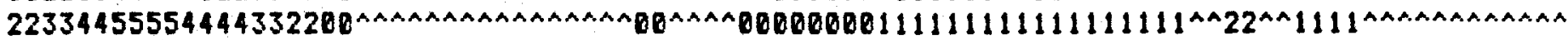
$11223344555544443300 \wedge \wedge \wedge \wedge \wedge \wedge \wedge \wedge \wedge \wedge \wedge \wedge \wedge \wedge \wedge \wedge$

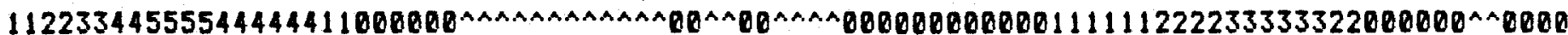

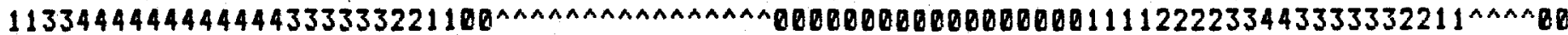
1133333344444444443333332211000000 AAAAAAAAAAAAAAAADO00000000000011112233444433333322111100 $00112233333344444444333333221100 \wedge \wedge \wedge \wedge \wedge \wedge \wedge \wedge \wedge \wedge \wedge \wedge \wedge \wedge \wedge \wedge \wedge \wedge \wedge \wedge \wedge \wedge \wedge \wedge \wedge \wedge \wedge \wedge \wedge \wedge \wedge$ ด0001122444433333333222222

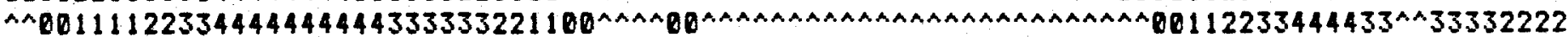

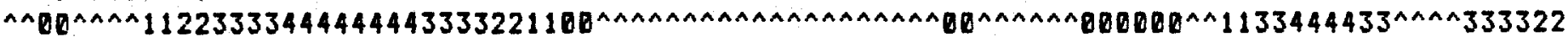

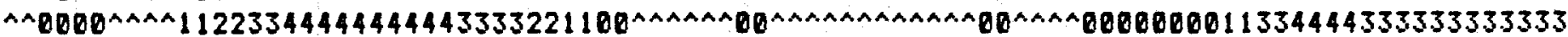

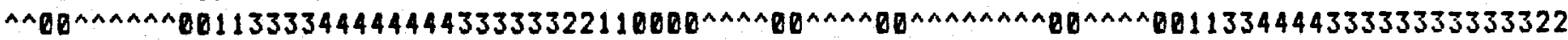

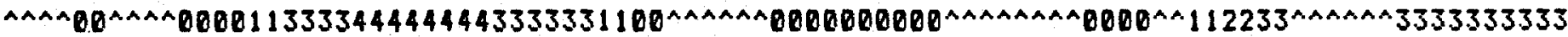

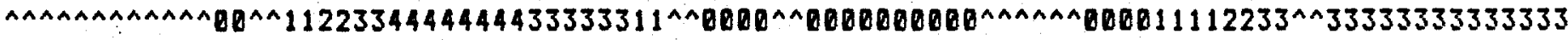

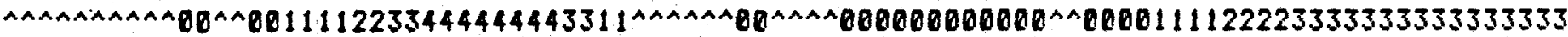

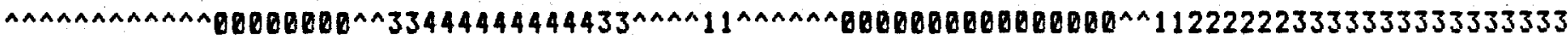

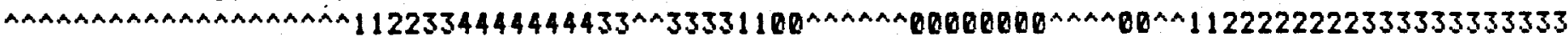

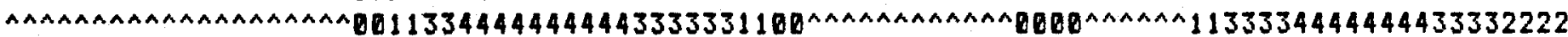

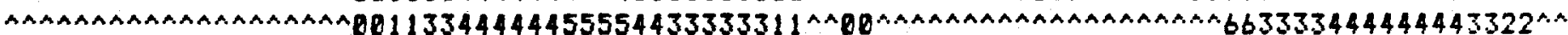

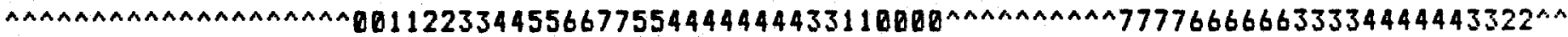

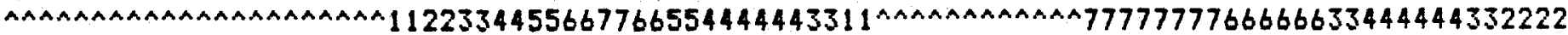

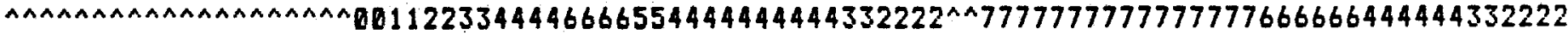

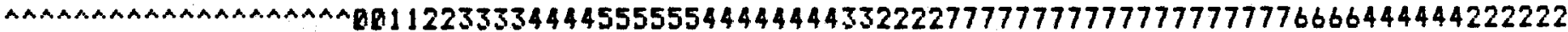

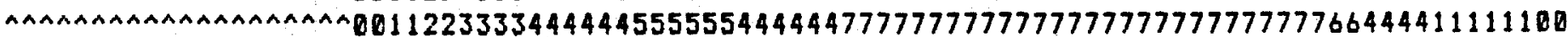

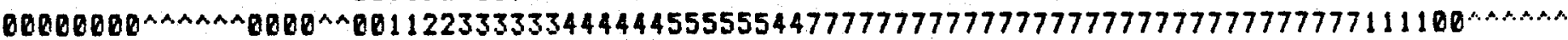

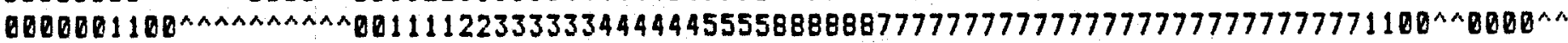

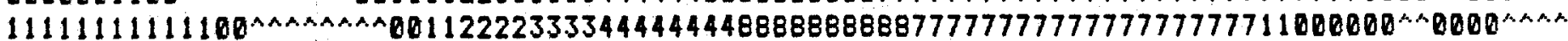

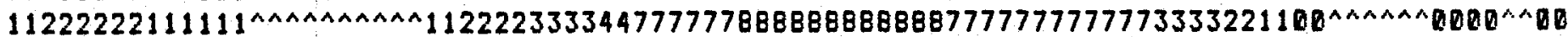
$222222222211110000^{\wedge \wedge} 001111222255556666777788888888 B 8 B 87777777777773322110000^{\wedge \wedge 000000000000}$ $2222222222111100000011111122222244666666777777888888883333333322222222110000000000000000 \wedge \wedge$ $2222222222221111111111111122^{A A A A 4455666666777777^{\wedge \wedge} 88883333332222222211000000000000000 B 00 \cdots A}$ $2222222222222211666666555544444444556666666677773344333333222222221111000000000000000000^{\wedge A}$ AN112222222222666666666655555555555566666666773344554433332222222211111000000008000000008AA

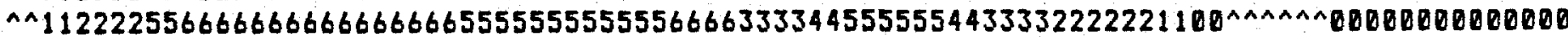

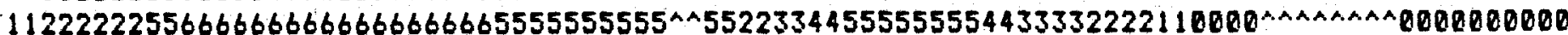

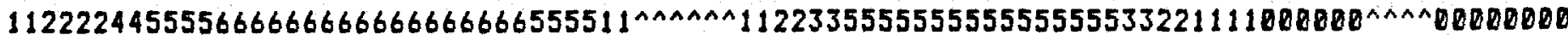
$2255444455555566666666666666664433221100^{\wedge \wedge} 001122335555555555555555332211110000^{A \wedge Q 0} \cdots A \wedge A 000$ $5555444455555566666666667777665544332211^{\wedge \wedge \wedge \wedge 00112233555555555555555533221111000000000000 \wedge \wedge}$

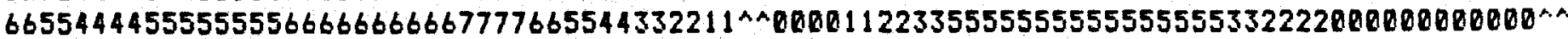

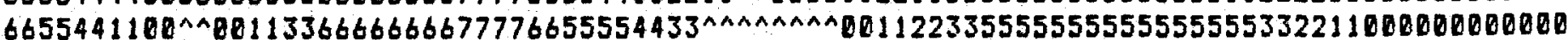

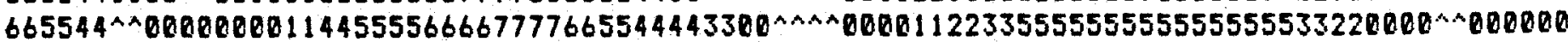
6655220BOBDDOB $12233445555667766554433221100 \wedge \wedge \wedge \wedge \wedge \wedge 08223355555555555555553322110000 \wedge \wedge \wedge \wedge \wedge \wedge \wedge$

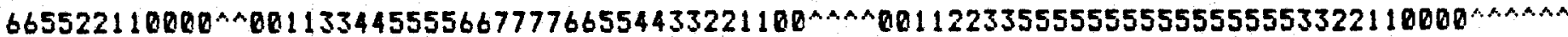

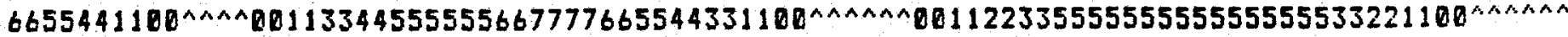
$662222110000 \wedge 0011223344555555666655444444331100 \wedge \wedge \wedge \wedge 00112233555555555555553322111100^{4 A \wedge A}$

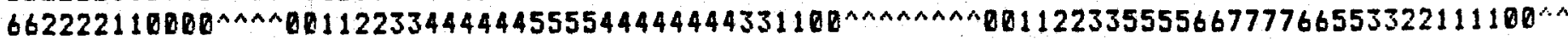
$2222221100^{A A A M A A B O} 11223333444444444444444444331100 M A A M A A \wedge 00112233556677776655332211110000$ 
Digital Map $8(d)$

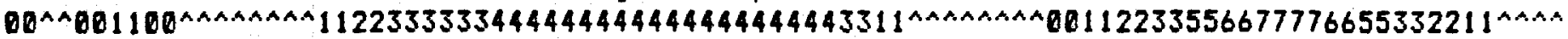

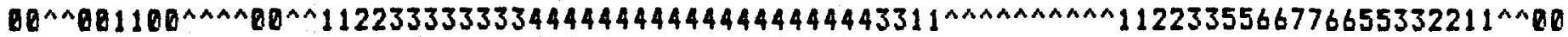

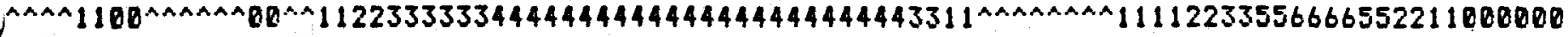

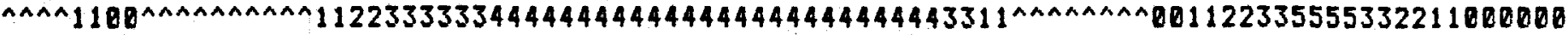

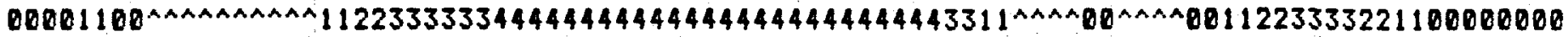
$11111100 \wedge \wedge \wedge \wedge \wedge \wedge \wedge \wedge \wedge \wedge 001122333344444444444444444444444444332211000000 \wedge \wedge \wedge \wedge 00113333221100000000$

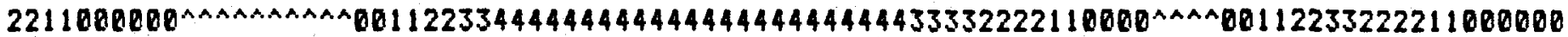

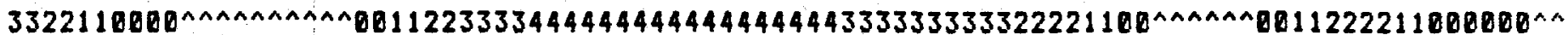

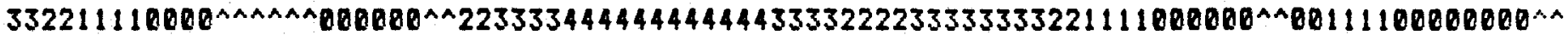

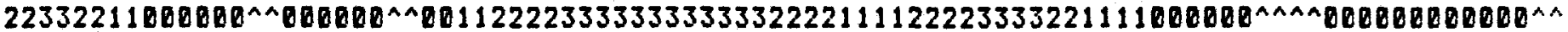

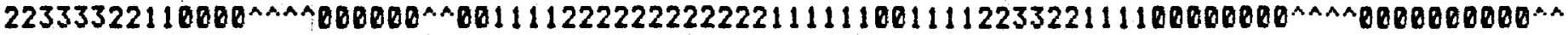

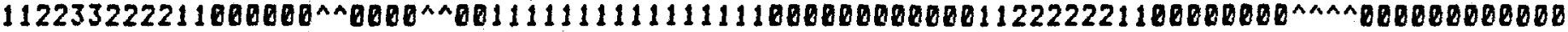
$001122222222221100 \wedge A 00 \wedge A 0000000000080000^{4} \wedge \wedge \wedge$ Q

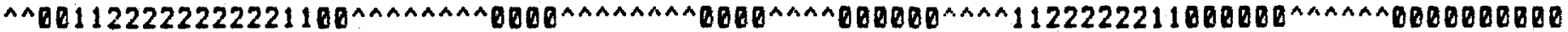

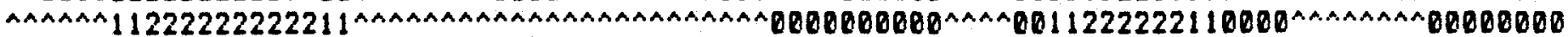

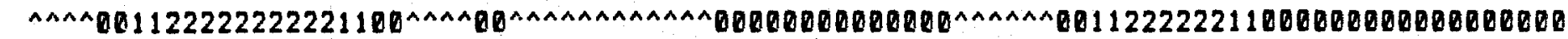

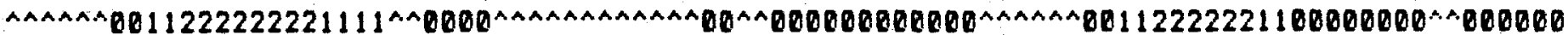

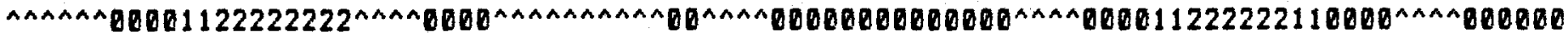

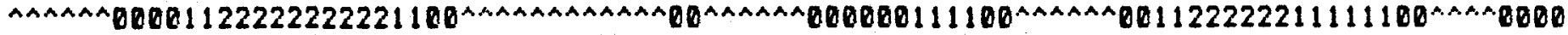

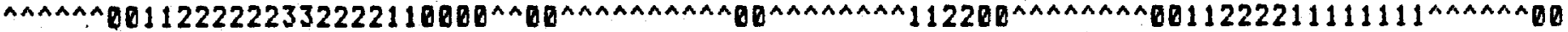

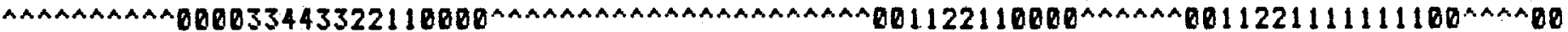

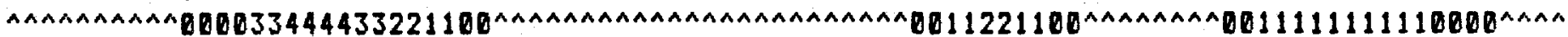

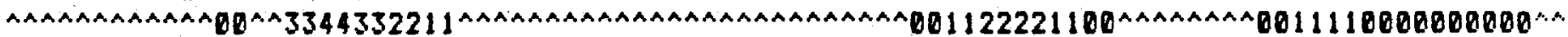

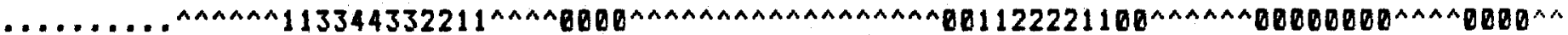

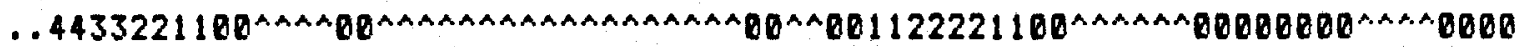

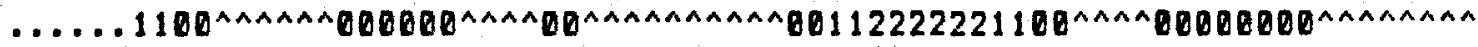

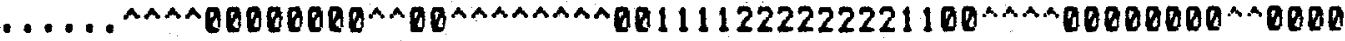

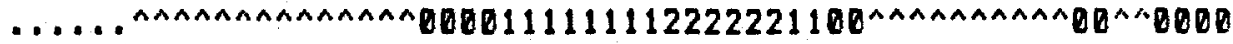

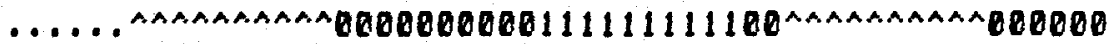

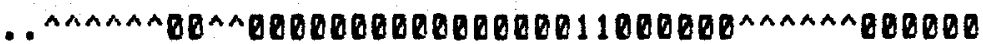

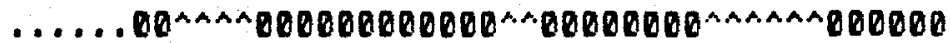

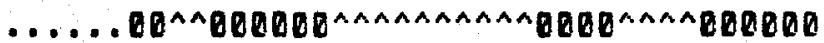

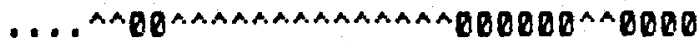

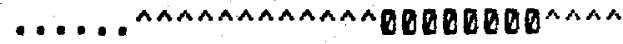

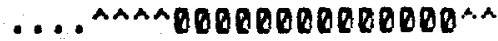

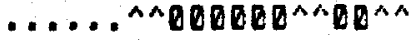
.. AAARAARA -... nana 


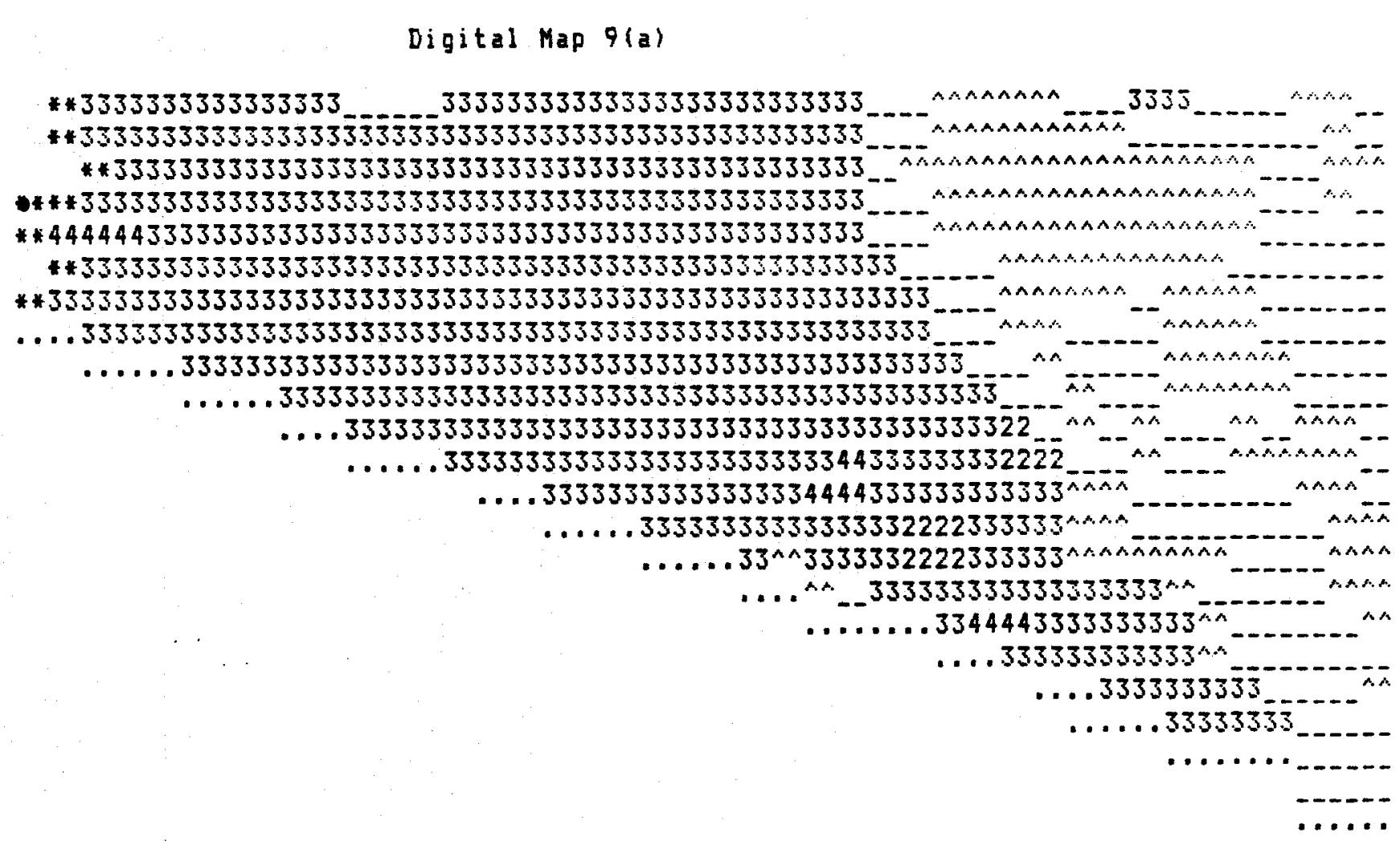

50 DEGREE CELSIUS ISOTHERM LEVELS

* Colorado River

A Eedrock at Surface.

- : 50 Degree Isotherm from to $0.125 \mathrm{~km}$.

1 : So Degree Isotherm from 0.125 to $0.25 \mathrm{~km}$.

2 : 50 Degree Isotherm from 0.25 to $0.5 \mathrm{~km}$.

3: 50 Degree Isothern from 0.5 to $1.0 \mathrm{~km}$.

4 : 50 Degree Isothern fron 1.0 to $1.5 \mathrm{~km}$.

5 : 50 Degree Isotherm from 1.5 to $2.0 \mathrm{~km}$. 
Digital Map $9(b)$

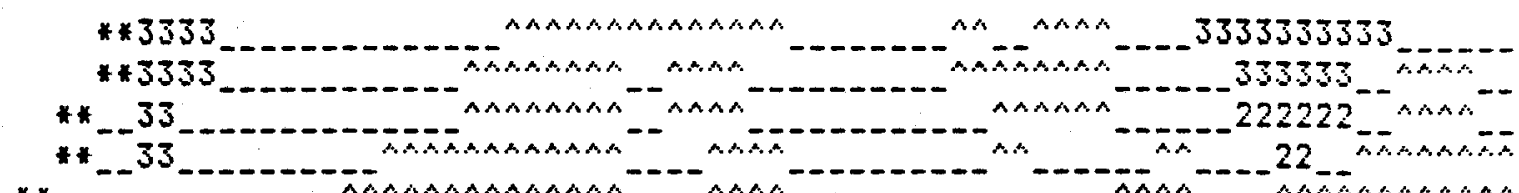




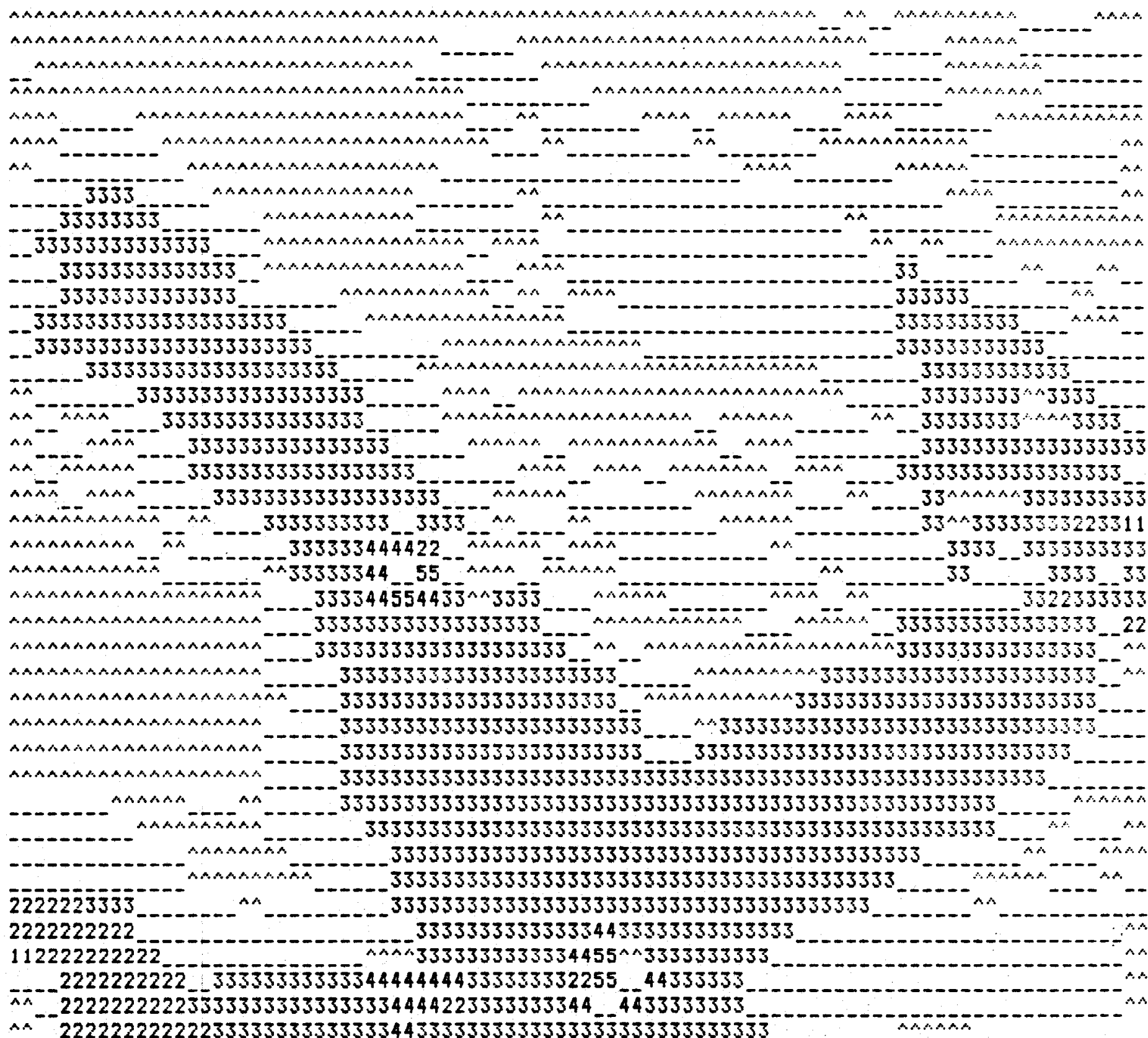

\section{A A 22222222222233333333333333443333333333333333333333333333}

_. $222222222222223333333333333344443333^{\wedge} \wedge 33 \ldots 33333333333333333 \overline{3}$

22222222222233333333333333444444

$\overline{2} 2222222222222333333333333333344$

222222222222223333333333333333333333

33333333333333335333

$2222222222223333333333333333333333333 \overline{3}$

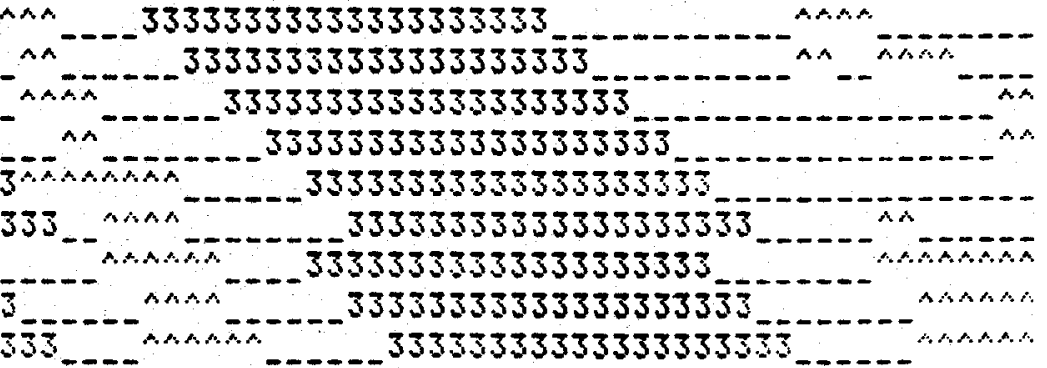

333333

$333333^{\wedge \wedge}$

3333

3333

333335

$33 \ldots \ldots \ldots \ldots$

33 . 333333333333333333333333

$\sin \sin ^{-1}$

$\operatorname{AsmanAB}$ MAAAANAA
333333333333333333

333333333333333355 3333333333333333 


\section{Digital Map $9(d)$}

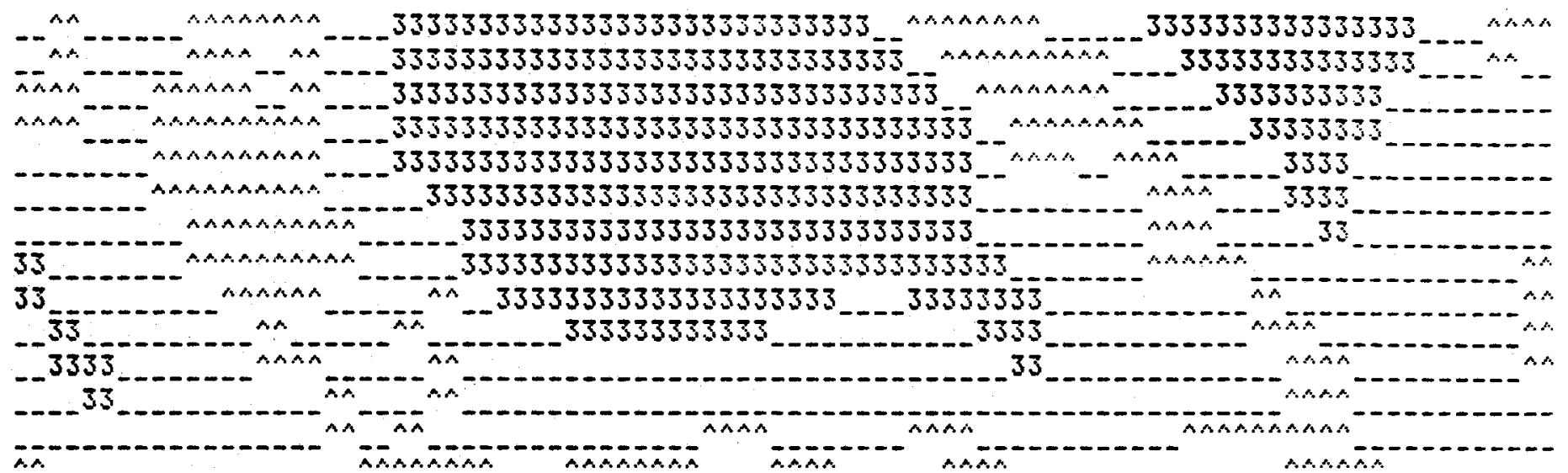

Алйй

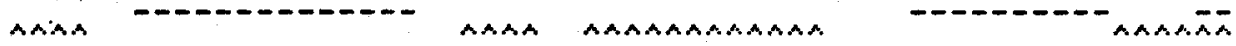

АлмАла AAAMAR Алямая ARAMAA АААААА AAAAAAAAAA -13333333

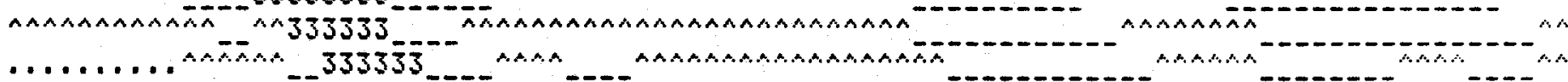
-.3333 B -...'-- … .... AMAAAA - . - -

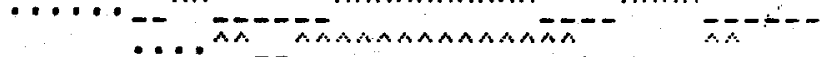
- . - An . . AMAA . . . . .

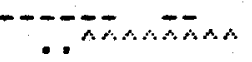
-.... 
Digital Map 10(a)

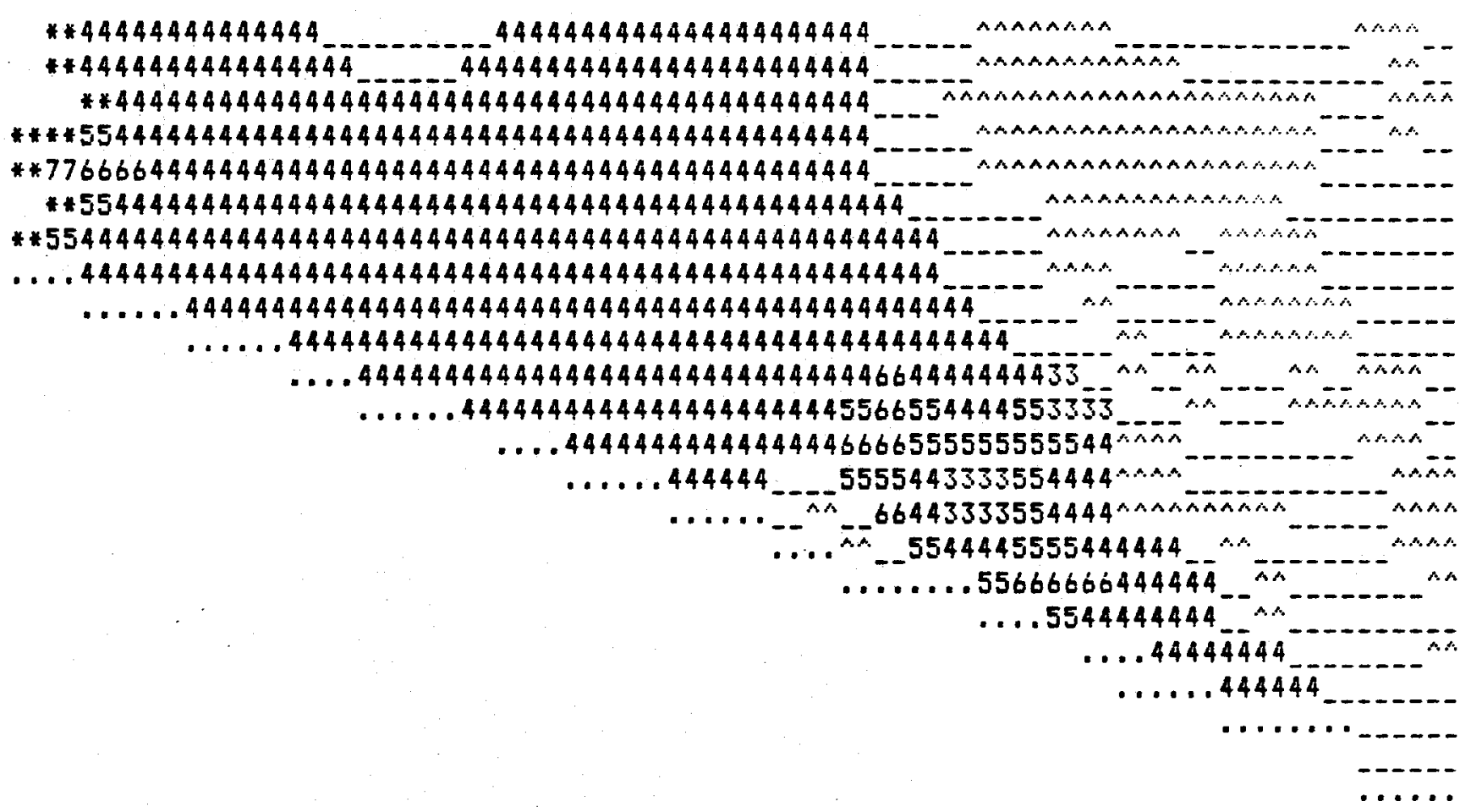

80 DEGREE CELSIUS ISOTHERM LEVELS

* Colorado River

- Border with Mexico

A Bedrock at Surface.

$1: 80$ Degree Isotherm from $0 . \overline{1} 25$ to $0.25 \mathrm{~km}$.

2 : BD Degree Isotherm from 0.25 to $0.5 \mathrm{~km}$.

3 : BO Degree Isotherm from 0.5 to $1.0 \mathrm{~km}$.

4 : 80 Degree Isotherm from 1.0 to $1.5 \mathrm{~km}$.

5 : 80 Degree Isotherm from 1.5 to $2.0 \mathrm{~km}$.

6 : 80 Degree Isotherm from 2.0 to $2.5 \mathrm{~km}$. 
Digital Map 10 (b)

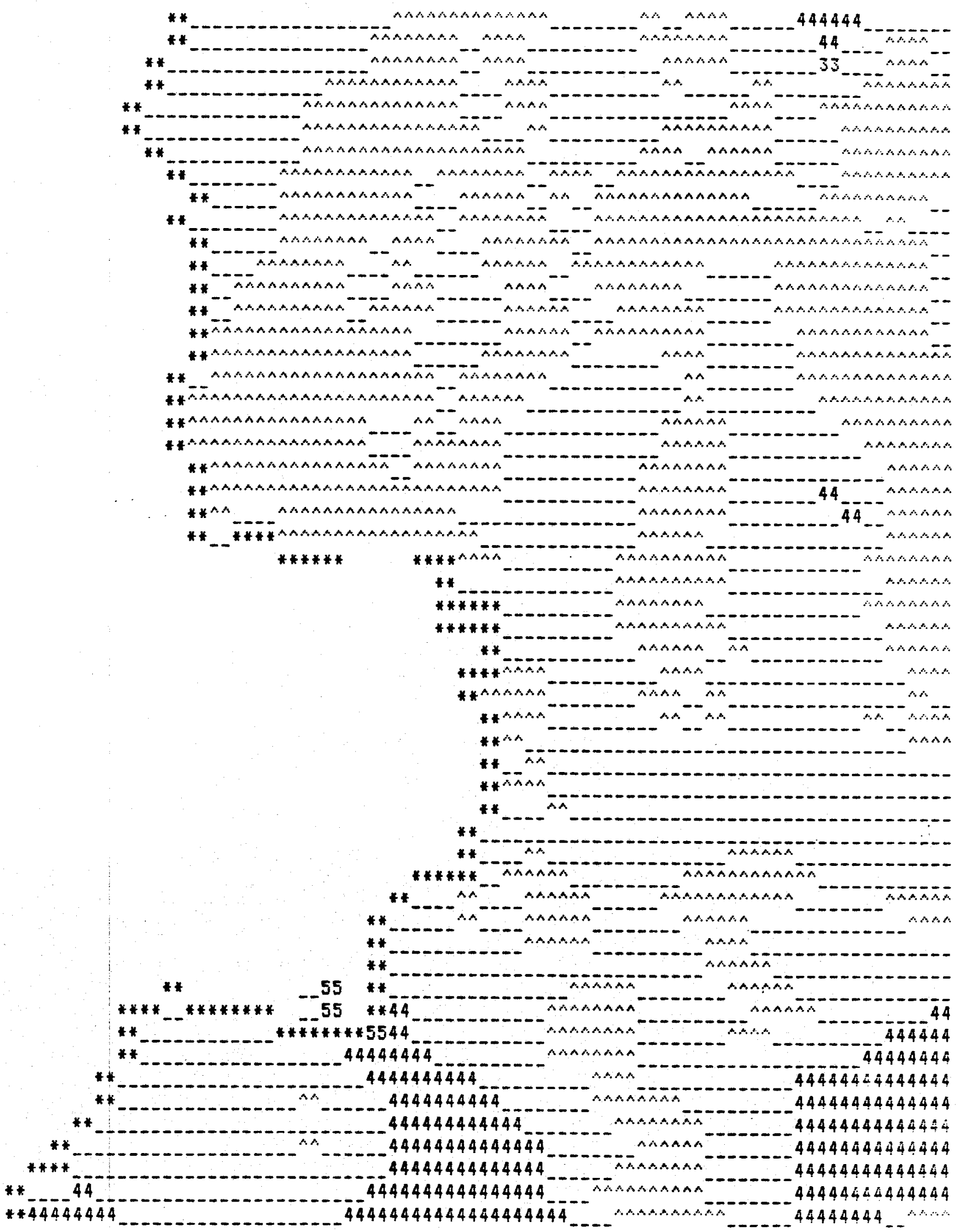

163 
Digital Map 10(C)

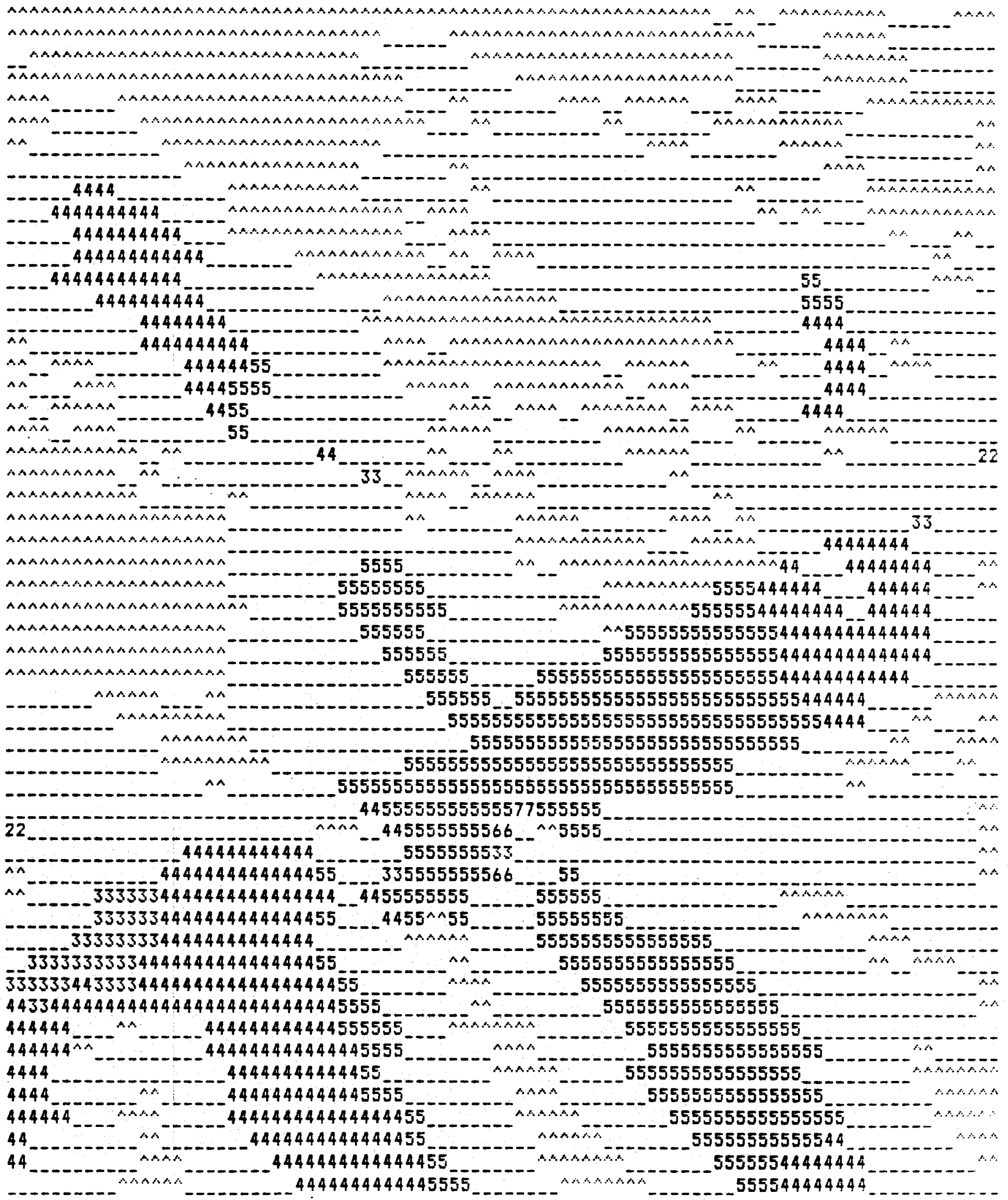


Digital Map $10(d)$

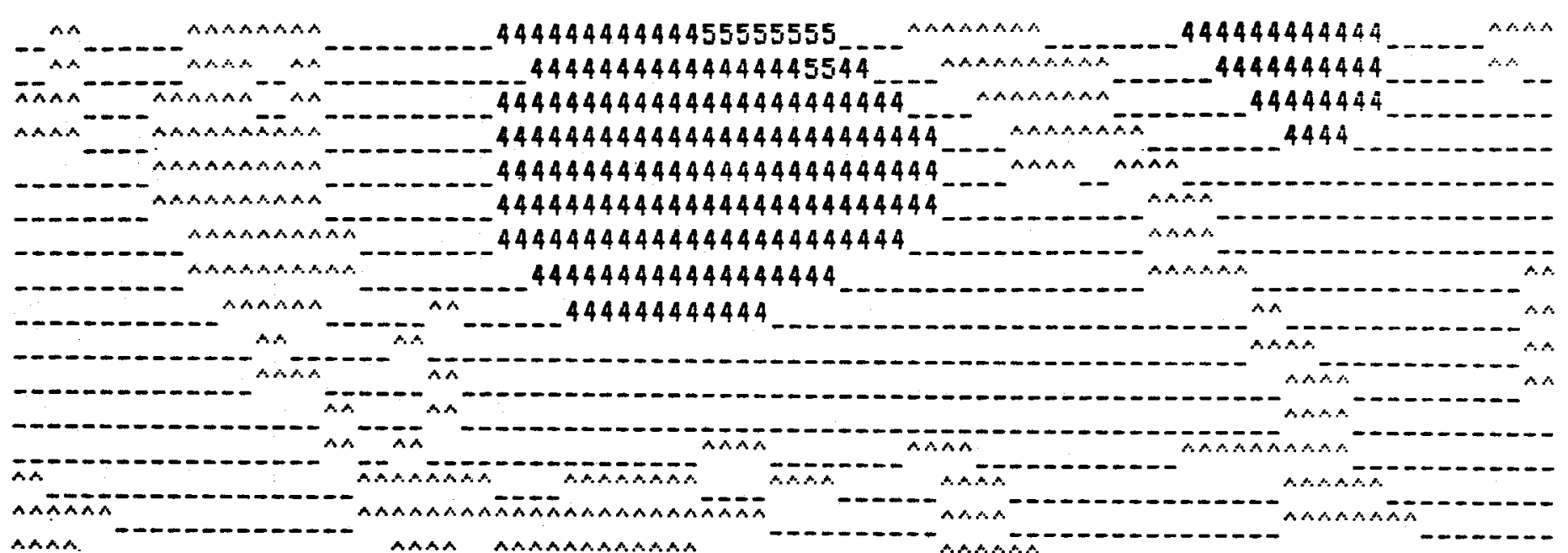

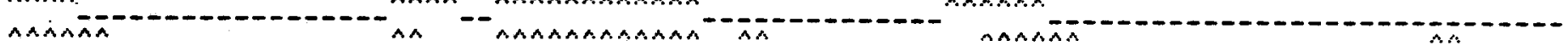
AАAAAA AAMAAA AMAMAM

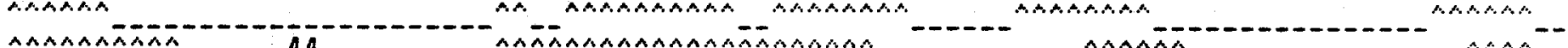
АААААААААА - $-44,-4444$

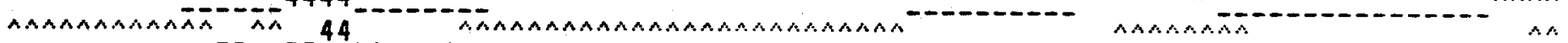
....... AA-TAAA $7 \overline{4}$

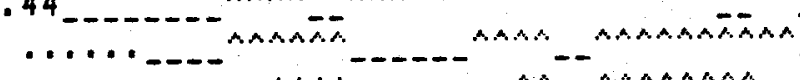


Digital Map 12 (a)

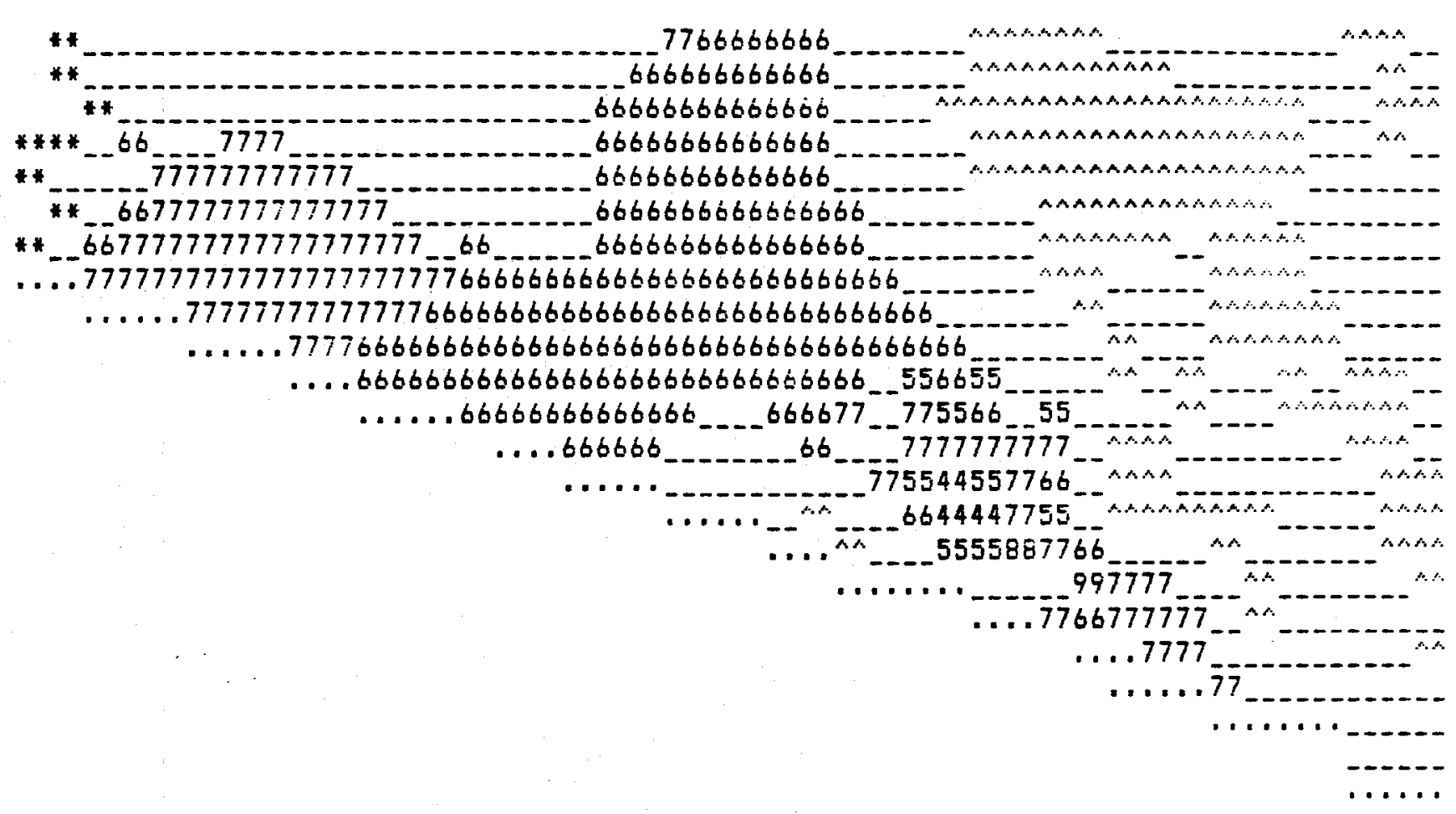

\section{DEGREE CELSIUS ISOTHERM LEVELS}

* Colorado River

$\therefore$ - Bedrock at Surface.

3 : 125 Degree Isotherm

4 1 125 Degree Isotherm from 1.5 ta $1.9 \mathrm{~km}$.

5 - 125 Degree Isotherm from 1.5 to $2.8 \mathrm{~km}$.

6 : 125 Degree Isotherm from 2.0 to $2.5 \mathrm{~km}$.

7 : 125 Degree Isotherm from 2.5 to $3.0 \mathrm{~km}$.

8 : 125 Degree Isotherm from 3.0 to $3.5 \mathrm{~km}$.
- Border with Mexico

: 125 Degree Isotherm Below Redrock Level

166 
Digital Map 12 (b)

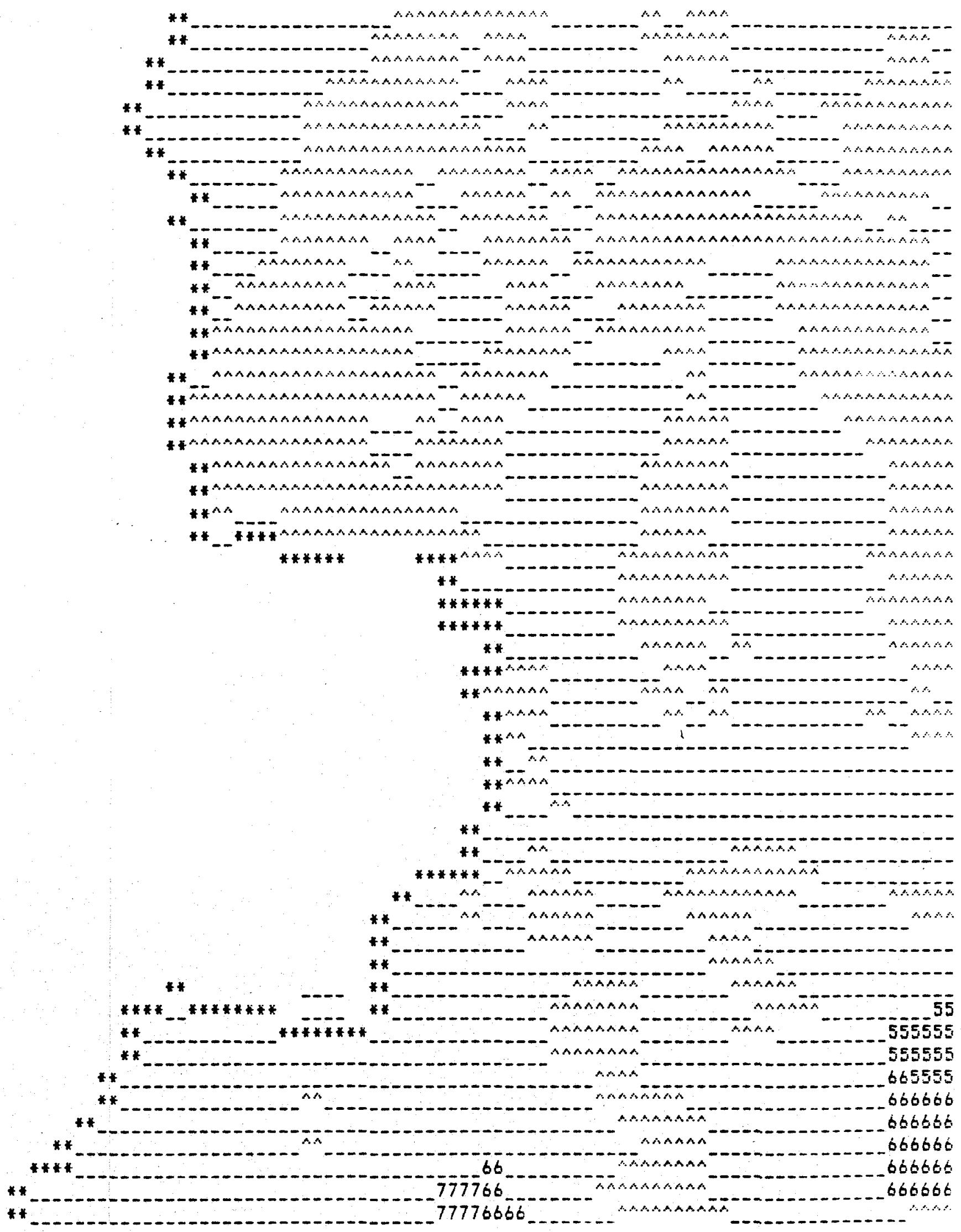




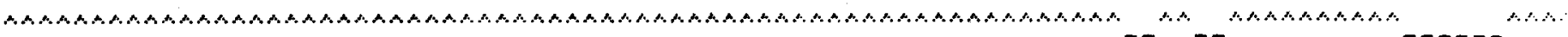

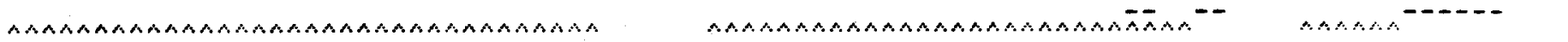

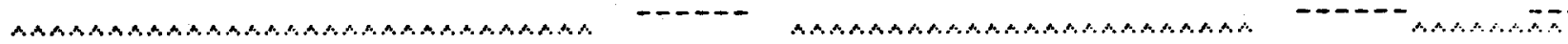

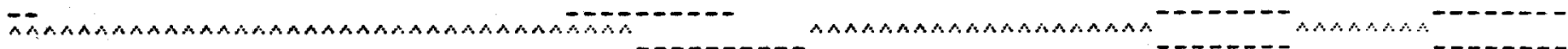

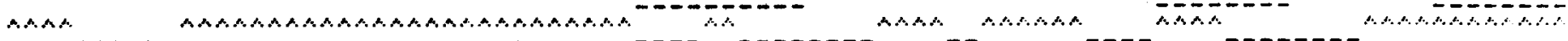

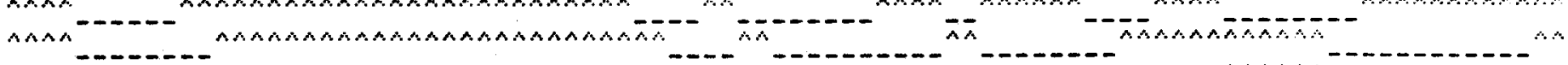
A - DAAAAAAAAAAAAAAAAAAA

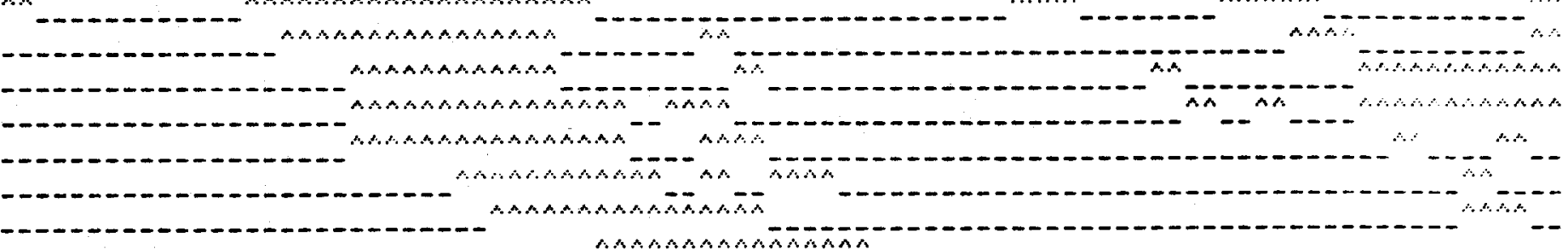

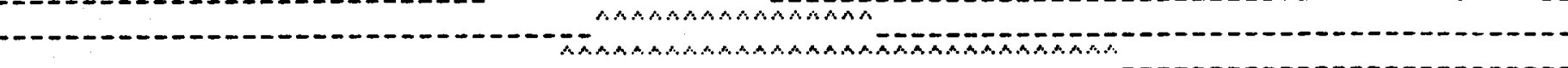

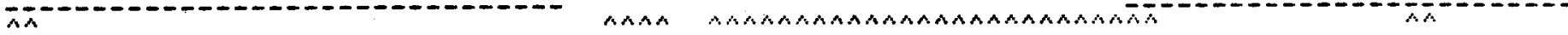

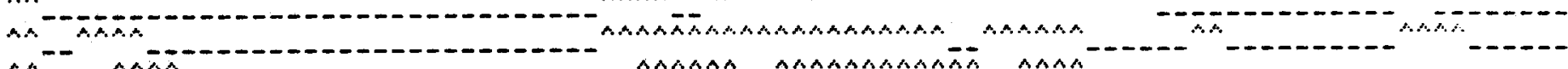

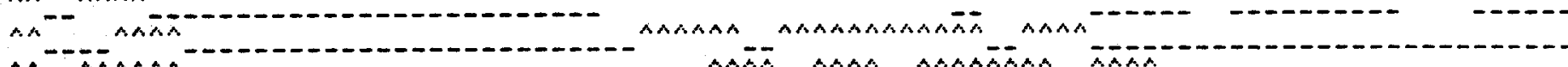
AAAA AAAA AMAMAAAAAAAA AA

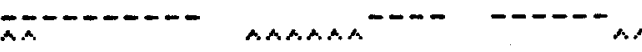

AMAMAAMAAA $\overline{\text { AM }}$

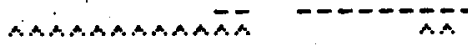

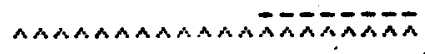
AAAAAAMAAAAAAAAAAAMA AAMAMAMAAARAAMAAMAAA AAAAAAMAMAMAAAAMAMAA ANAAAAAAMAAAAAAMANAANA MANAAAAAAAAAAAAACAMA AAAAAAAAAAAAANASAAAA AMAAAHAAAAAMAAMAAMAA

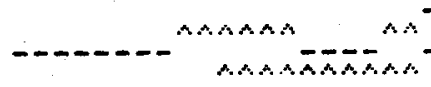
-O- -

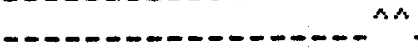

$-$ $\overline{x i n}$

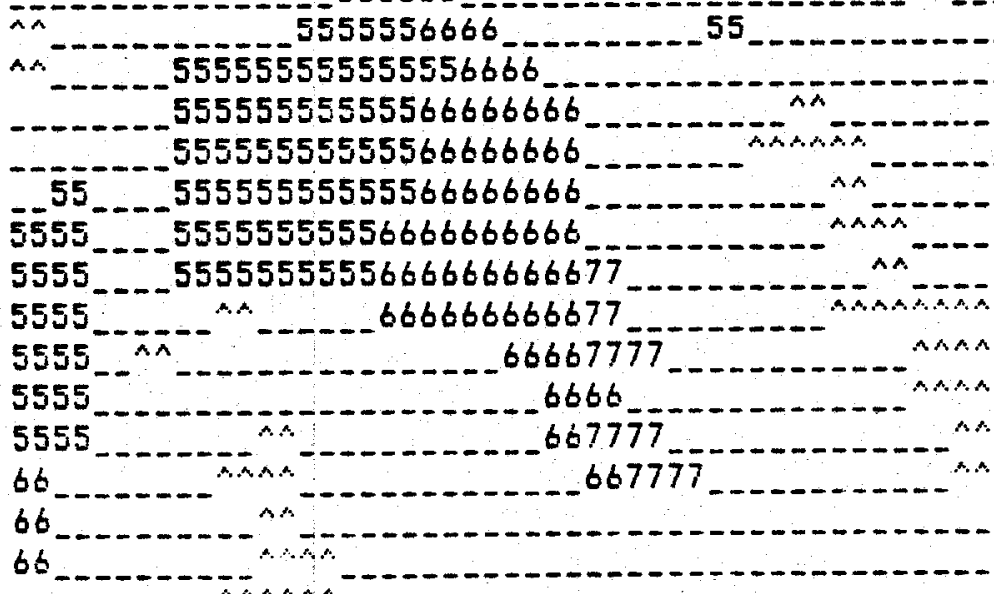
$55556 \overline{6}$ $\overline{7} \overline{8} \overline{8} \overline{8}$ $\overline{7} 888888 \overline{8}$ 777777888888888888 $77 \quad 888888888888$ $\operatorname{man} \pi x$ AAAAAAAAAAA AAAAAA- ANAS $A M$

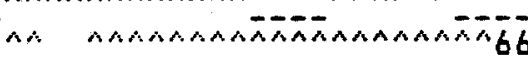
ANAANAMA7777_ 6666

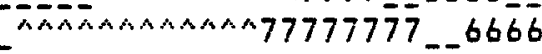
$07777777777777777766666 \overline{6}$ 777777777777777777666666

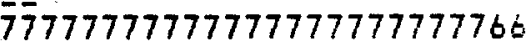
777777777777777766 7777777777777777

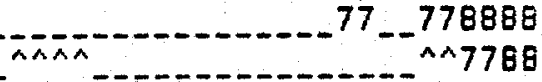
55 


\section{Digital Map 12(d)}

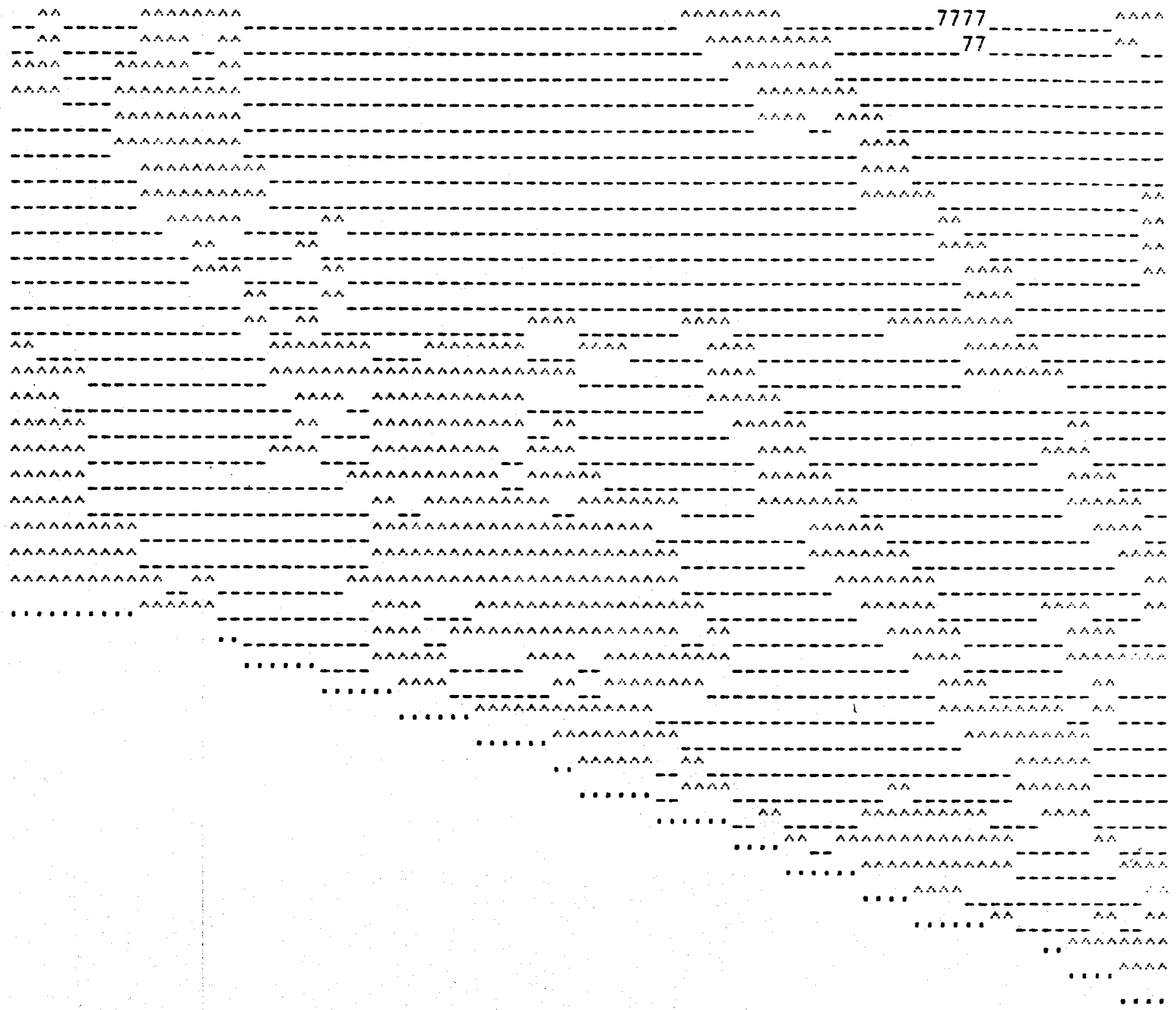


Digital Maf (7,k(a)

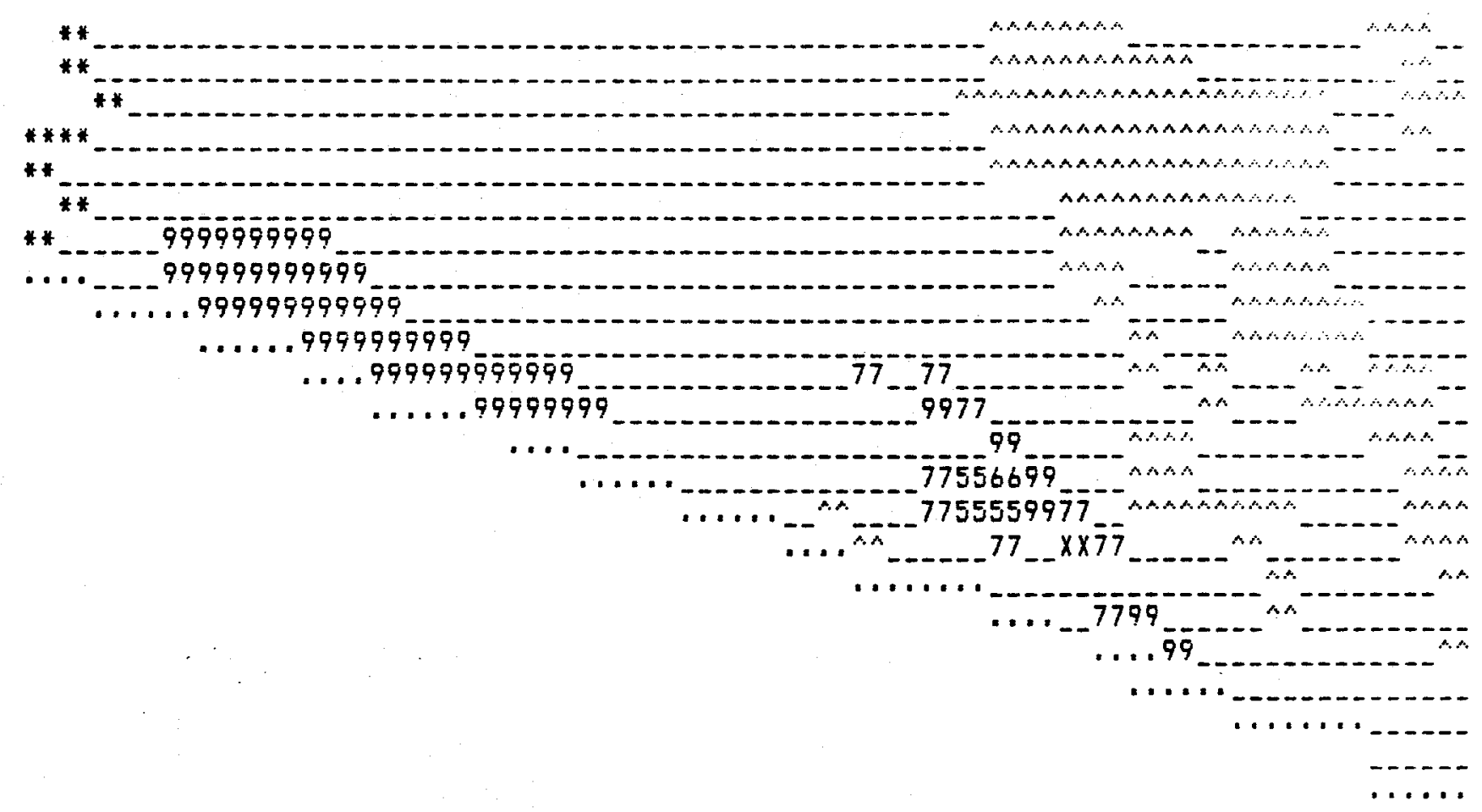

170 DEGREE CELSIUS ISOTHERM LEVELS

* Colorado River

- Eorder with Mexico

$\therefore$ : Eedrock at Surface. - 170 Degree Isotherm, Below Eedrock Leve!

$4: 170$ Degree Isotherm from $\$ .0$ to $1.5 \mathrm{~km}$.

5 : 170 Degree Isotherm from 1.5 to $2.0 \mathrm{~km}$.

6 : 170 Degree Isotherm from 2.0 to $2.5 \mathrm{~km}$.

7 : 170 Degree Isotherm from 2.5 to $3.0 \mathrm{~km}$.

8: 170 Degree Isotherm from 3.0 to $3.5 \mathrm{~km}$.

$9: 170$ Degree Isotherm from 3.5 to $4.0 \mathrm{~km}$.

$X: 170$ Degree Isotherm from $4.0 \mathrm{to} 5.0 \mathrm{~km}$. 
Digital Map (min)

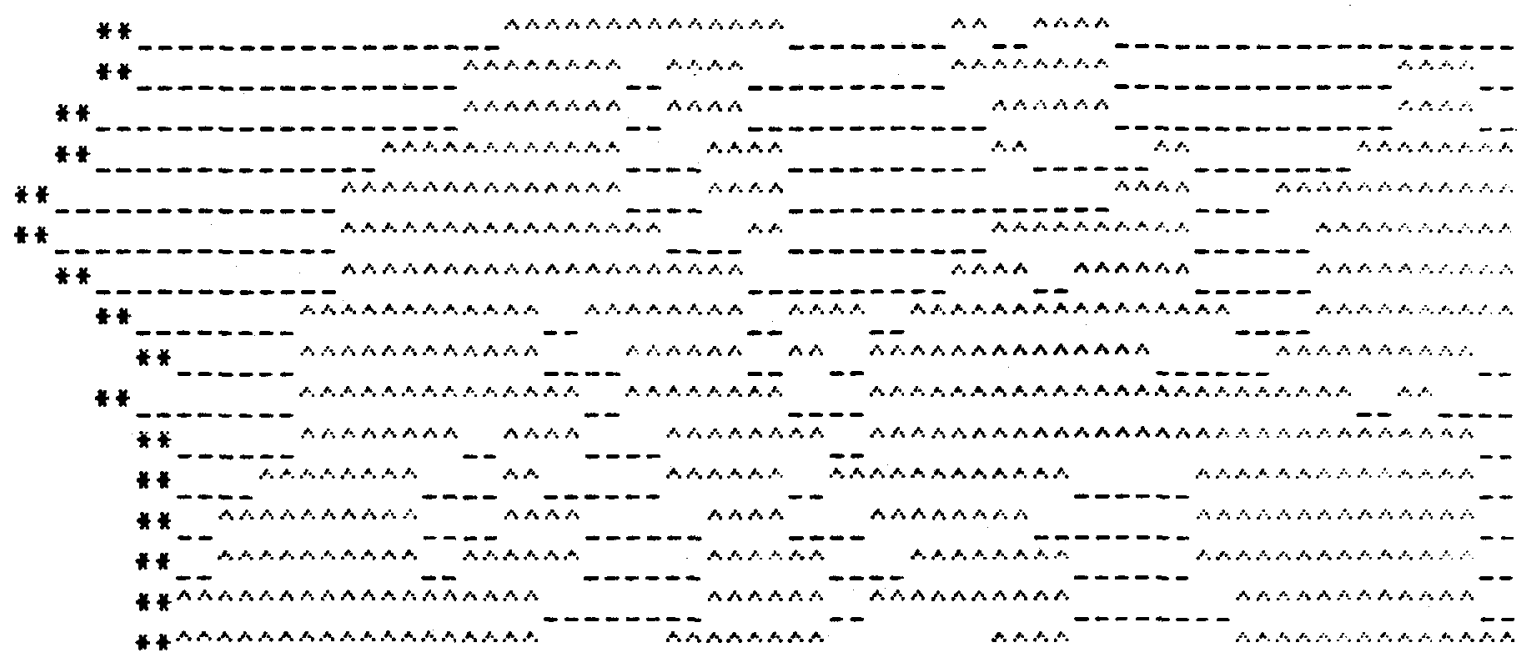

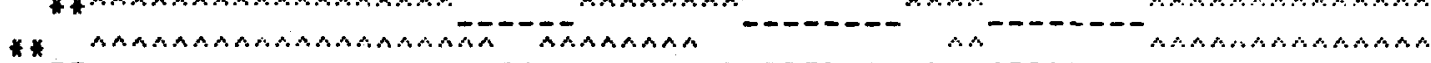

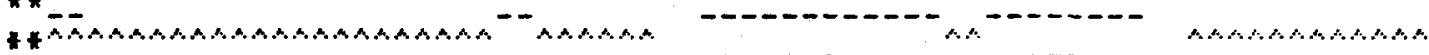
* *AAAAAAAAAAMAAAA AA- AAAN -

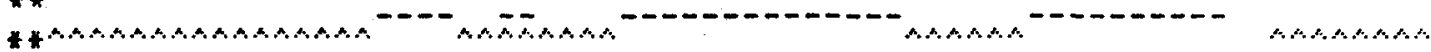

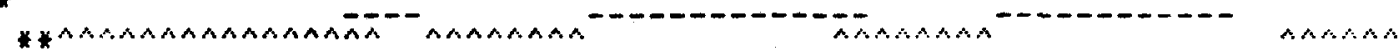

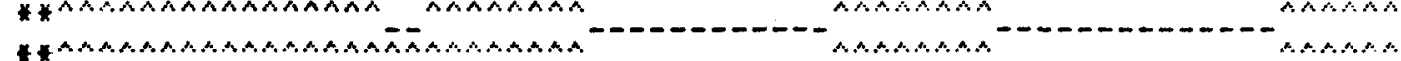
* *A ANANAAAAAAAAANAA

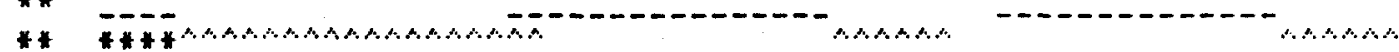

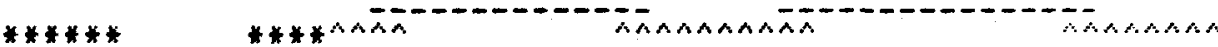
* *

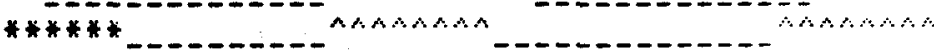

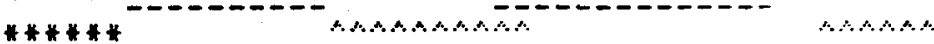

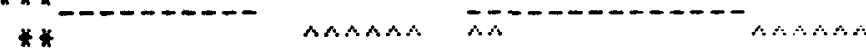

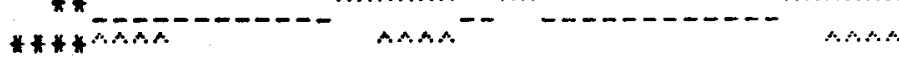

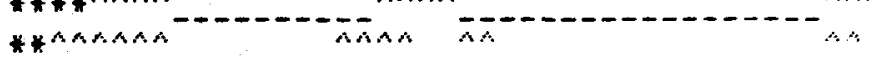

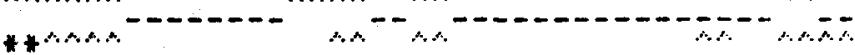

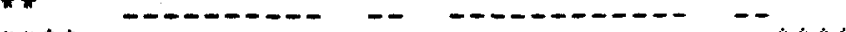
* AA $A$ * $\mathrm{Am}$

**AnA

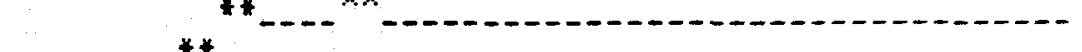

***** AA ANA

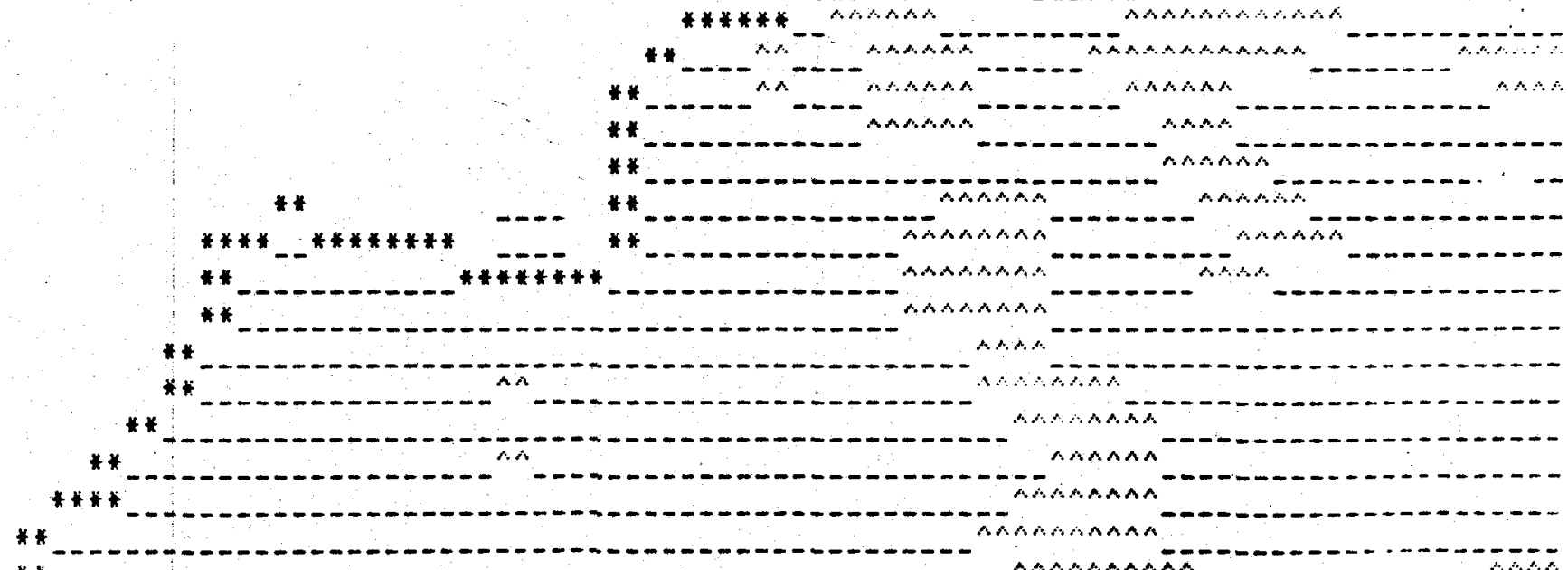

4

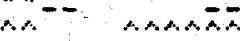

$*$ 


\section{Digital Map 13.fic)}

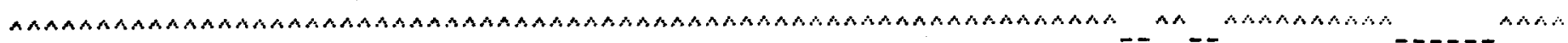

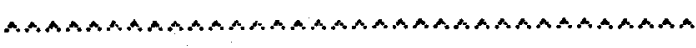

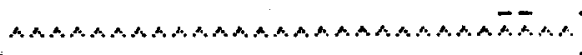
A.A.,A.A. $----$

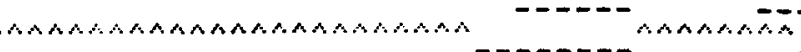

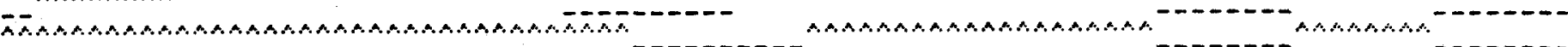

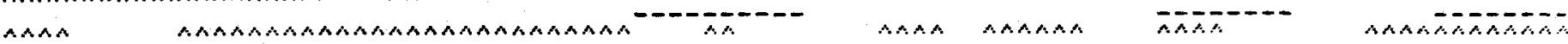

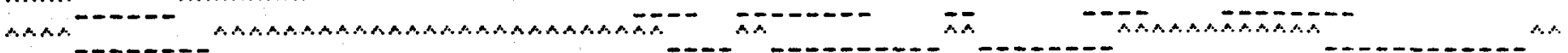

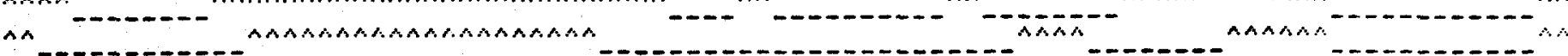
AAMAAAAAAAAAAAA -

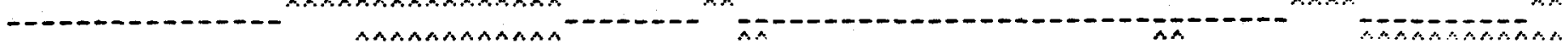

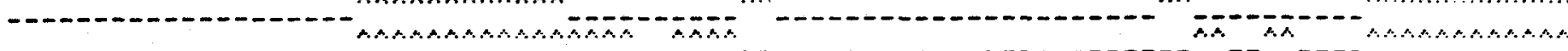
AAAAAAAAAAAAAAAA

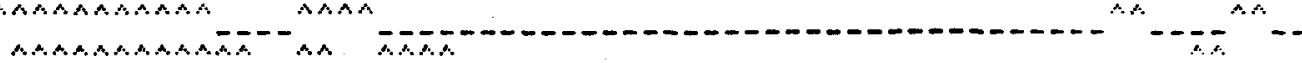

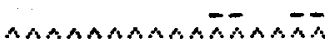

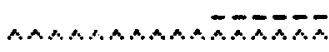

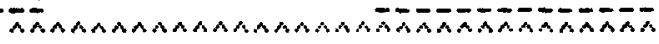

AA

A

$A^{-\infty} \rightarrow A A^{-}$

$A \cap-D A A A A A$

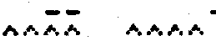

$A A A N A A M A M A A-D A$

MAAAAAMAAC. TA.

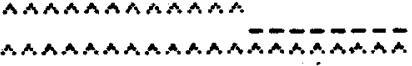

AAAAAAAAAAAAAAAAMAAA

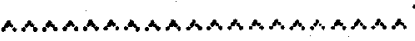

ANANANAMANAAAAAAAAAA

AAAAAAMAAAMAAAMAAAMAA

ANAAAAAMADAAAAAAMAMA

AAAANACAAAAAAAAAAAAA

AAAAAAAAAAAAAAAAAAAA

AAMAAA: AAD

- ANAAAAAAAA

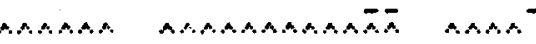
AAAA AAAA $A N A A A A M A$ AANA $_{-}$ AAMABA- - - AAAAMAÁ

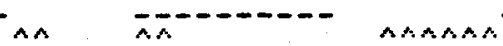

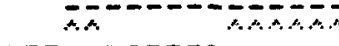

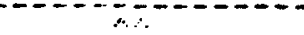

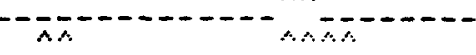
A $A$ AMAA ÄMAAA

等
(1)

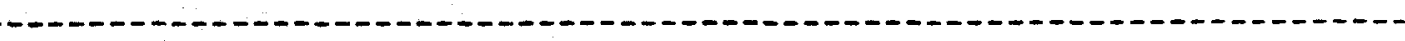

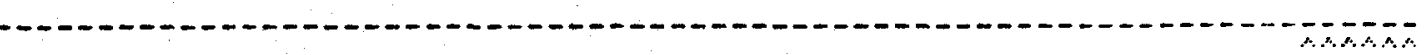
A.A.A.A.

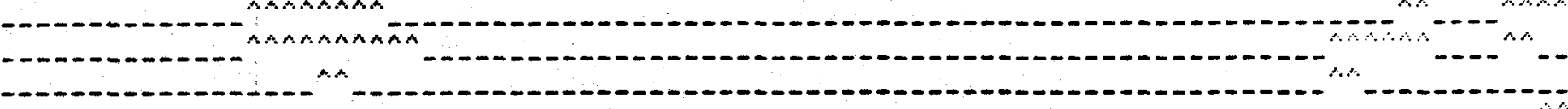

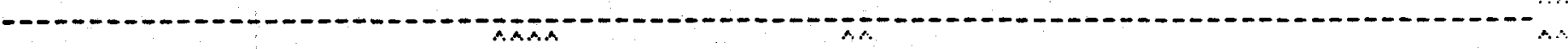

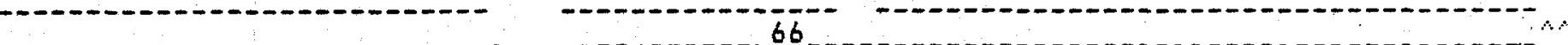
-

A

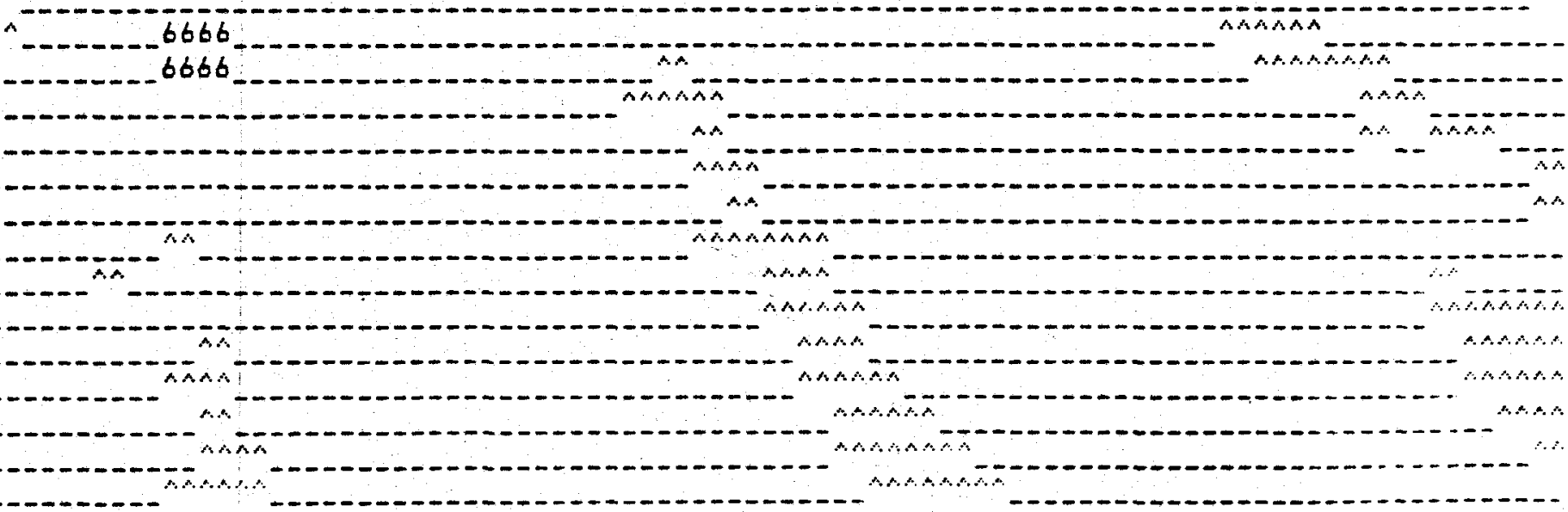




\section{Digital Map $13.1(d)$}

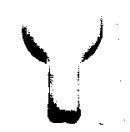

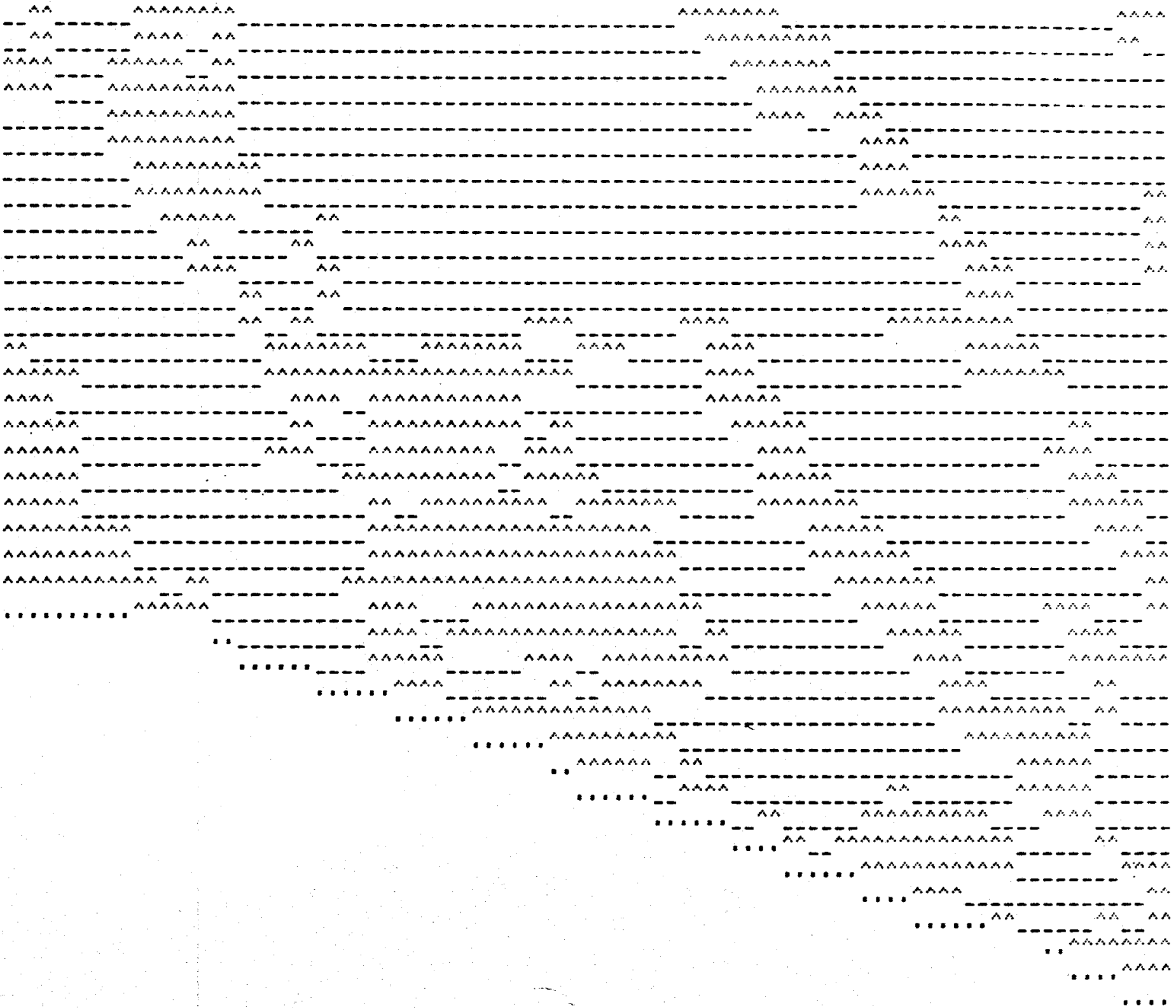




\section{Digital Map 13.2(a)}

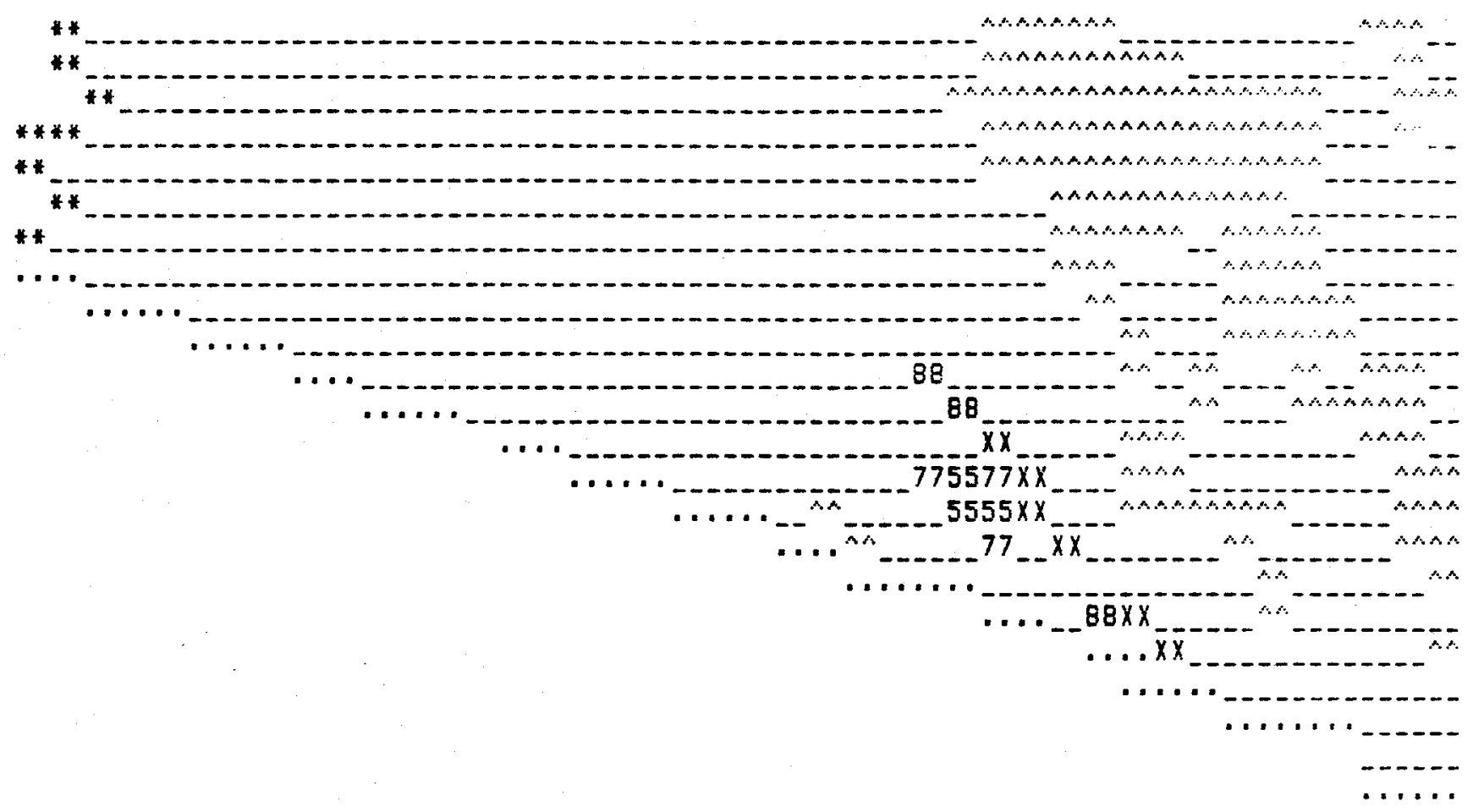

\section{DEGREE CELSIUS ISOTHERM LEVELS}

* Colorado River

- Border with Mexico

* Bedrock at Surface. - 190 Degree Isotherm Below Bedrock Level

4 : 190 Degree Isotherm from 1.0 to $1.5 \mathrm{~km}$.

5 : 190 Degree Isotherm from 1.5 to $2.0 \mathrm{~km}$.

6 : 190 Degree Isotherm from 2.0 to $2.5 \mathrm{~km}$.

7 : 190 Degree Isotherm from 2.5 to $3.0 \mathrm{~km}$.

8: 190 Degree Isotherm from 3.0 to $3.5 \mathrm{~km}$.

9 : 190 Degree Isotherm from 3.5 to $4.0 \mathrm{~km}$.

$x$ : 190 Degree Isotherm from 4.0 to $5.0 \mathrm{~km}$. 

AN AAMA

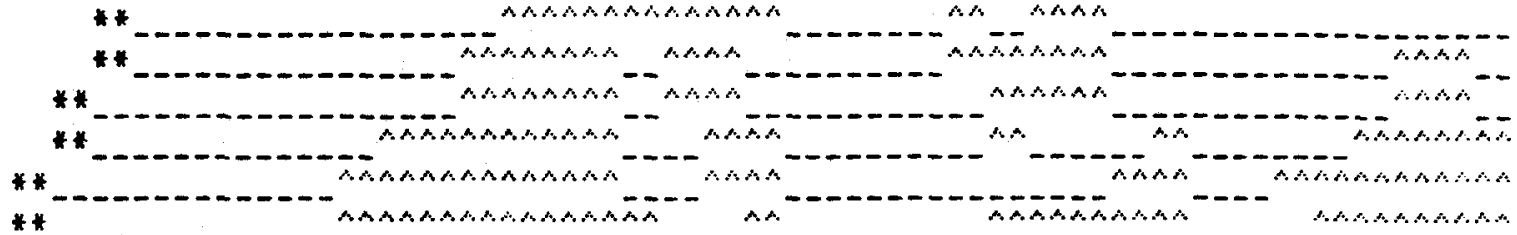

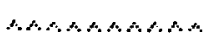
AMAA AMAMAA * *

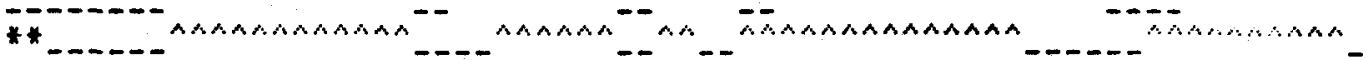

** *-0-0-

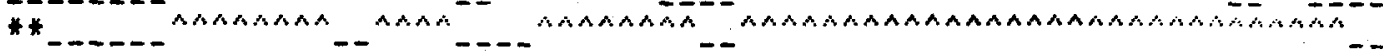

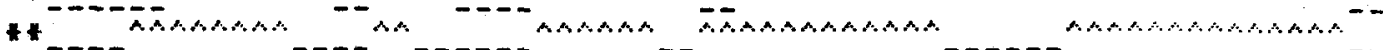

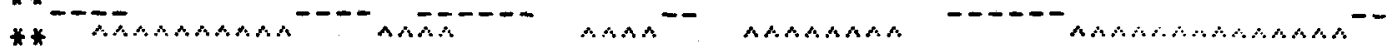

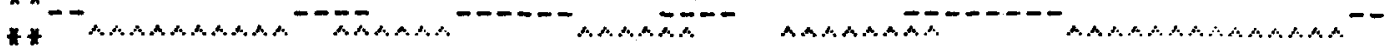

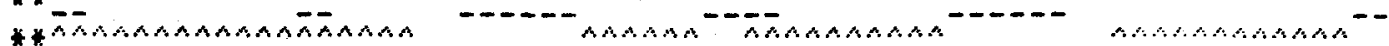

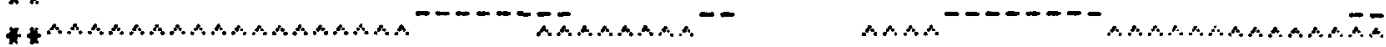

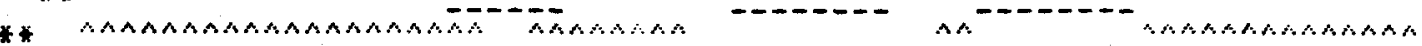

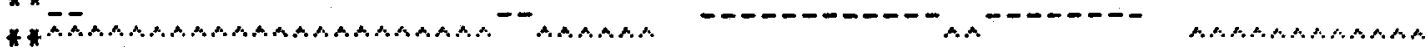

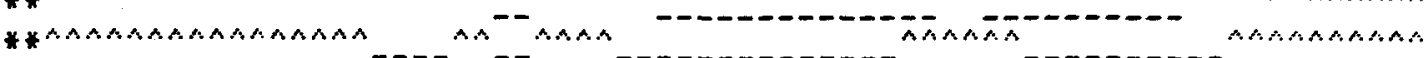

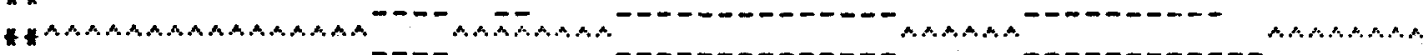

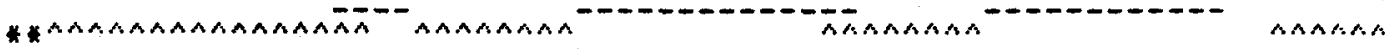

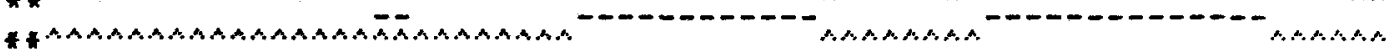

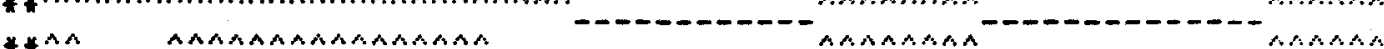

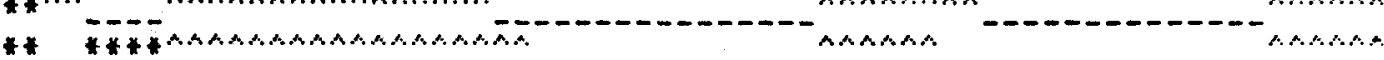

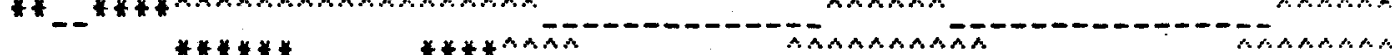
****** ****anan - * * and ******

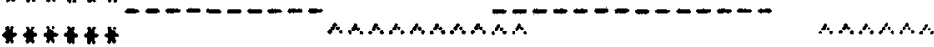
**

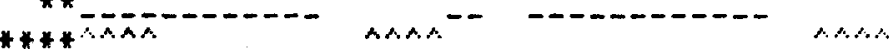

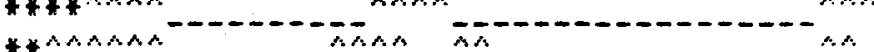
**АคАคА **A口 ** $*-\cdots$ n-

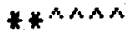

** $=-1$

$* *$

$*$ $----\frac{-10}{a-1}$ (n)
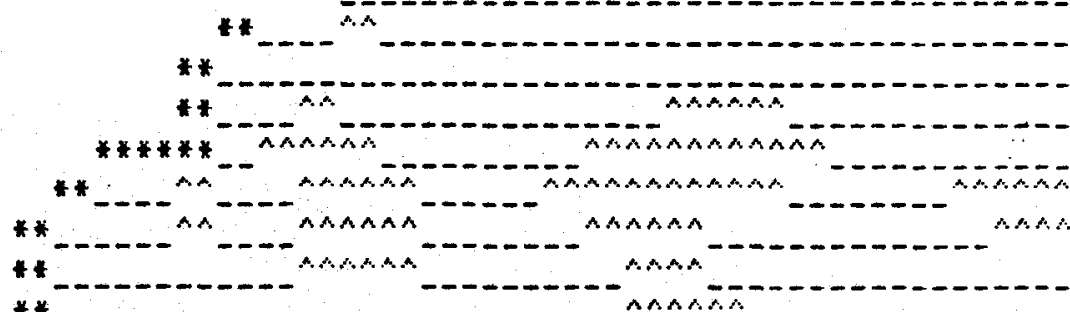

AAAAAA ANAS

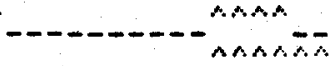

**

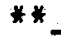
$\sin -\overline{x i n}$

$* *$ * $* * * * * * *$ ** **

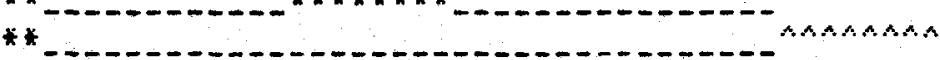$$
\text { A.ABABA. }
$$

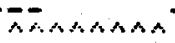
*
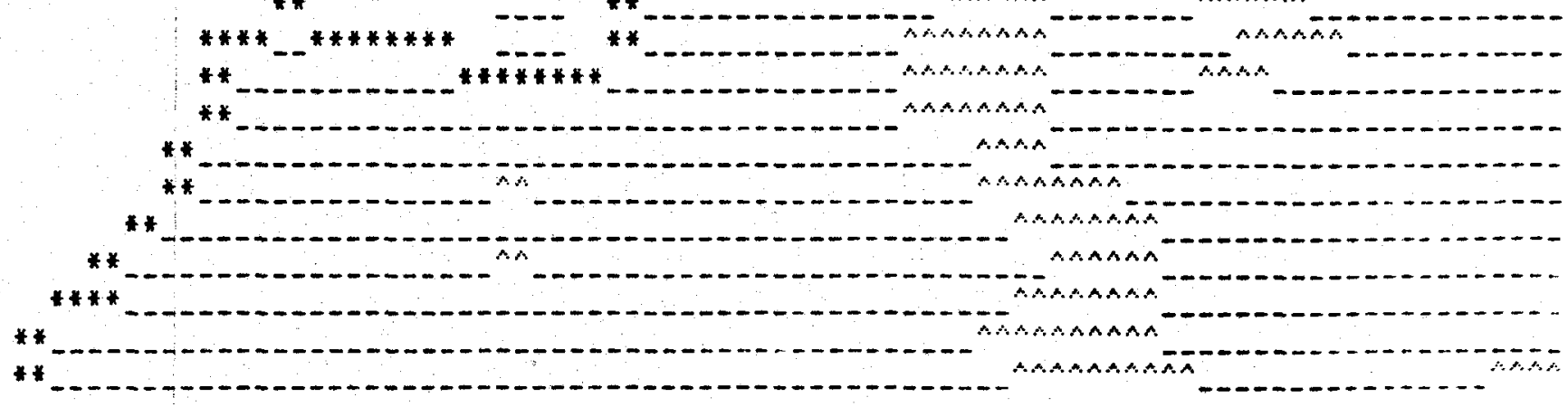


\section{Digital Map $13,2(\mathrm{z})$}

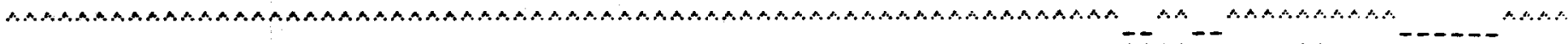
AAAAAAAMAAAAMAAAMANAMAAMAMAAMAAAAA

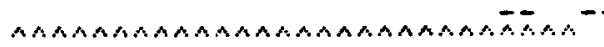
ANAAAS

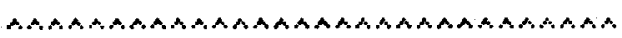

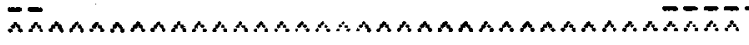

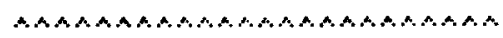
AAAAAAAAMAAMAAAAAAAA $-1--2$ A.A.A.A,A,

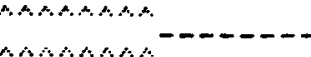
A DAAA

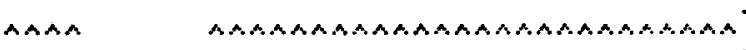

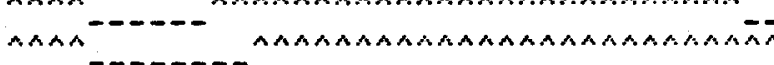

$\therefore \therefore$ AAMANABAAMAMAMAAMAAA

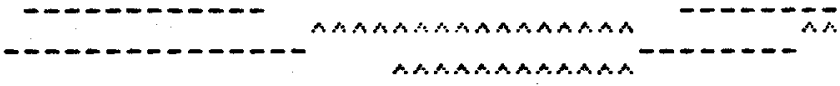
$-----\frac{-1}{4}$

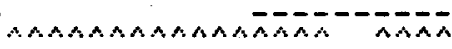

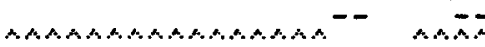

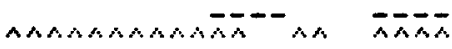

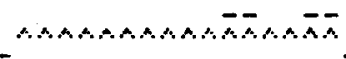
ANAMAAMAAA

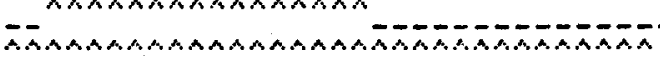

АА

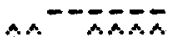

$A A^{--} A^{-1}{ }^{-1}-{ }^{-}$ $A A^{-1-\operatorname{ABAMAAA}}$

AMĀA AMAA

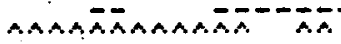
AMABABAaAaA Ë

AAAAASAAAA

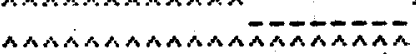
AAAAAAAMAAAAMARAABAA AAAAACAAAMAAAAAMANAN AAAMAAMAAAANAAAAMAAA AAAAAAMAAMANAMAAAAAAAA AAANAAAAARAAAANAAARA. AANAAAAAAAMAAAMAAAAN AAAAAAAMAMAAAAAAAAAA - aAAAAa Aa

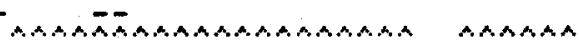
AลAAMA AAAAAAAAAAAA AAAA

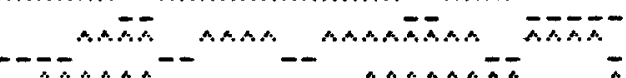

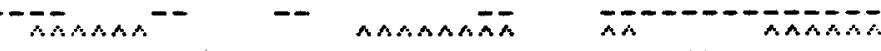
AA AA-OAAAA AAAAAA- AAAD

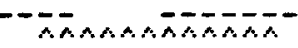

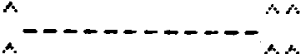
A.AA

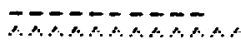
WAAAAAAAAAAA $A A-A B$ 


\section{Digital Map $(3.2$ 'd}

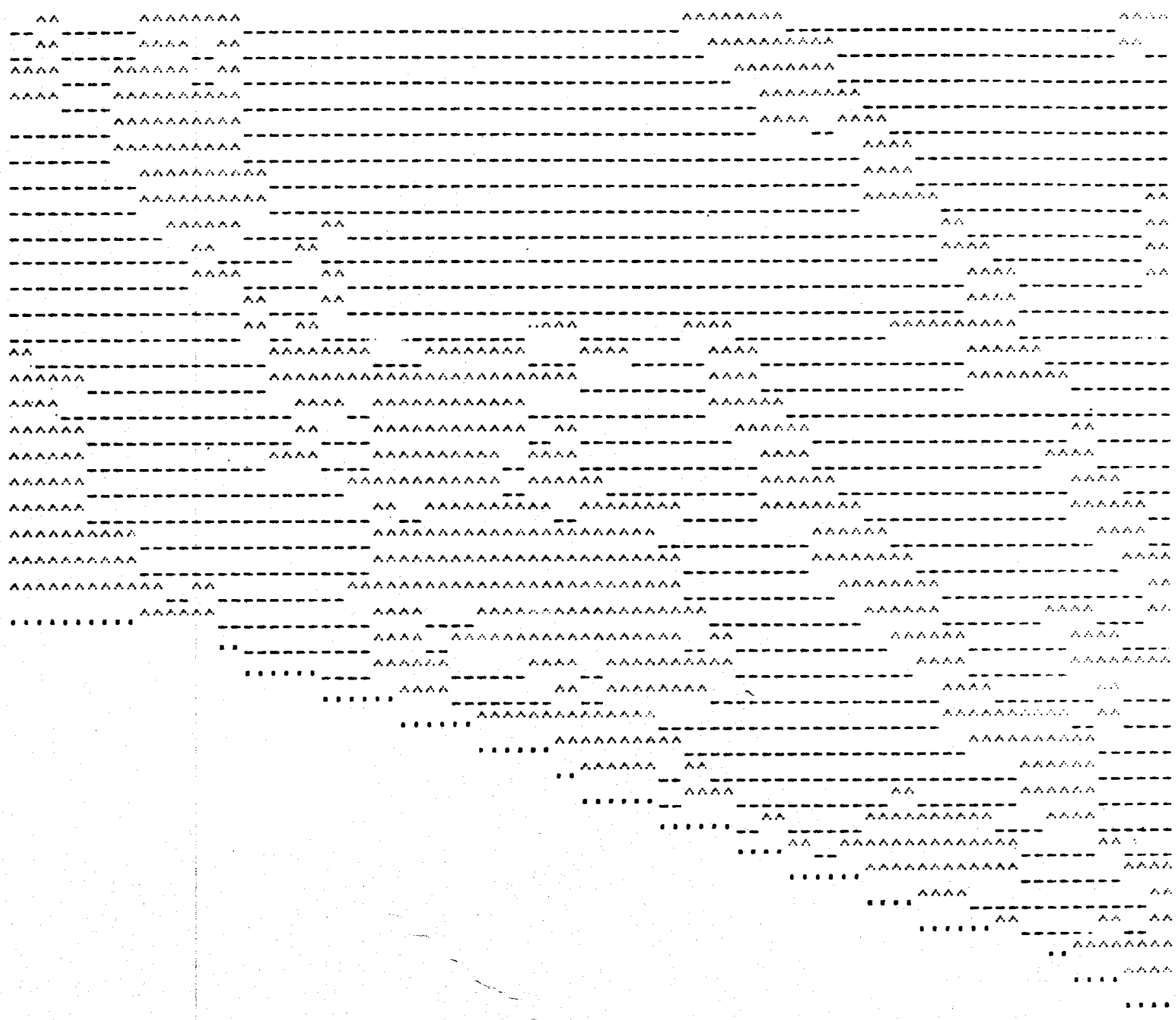




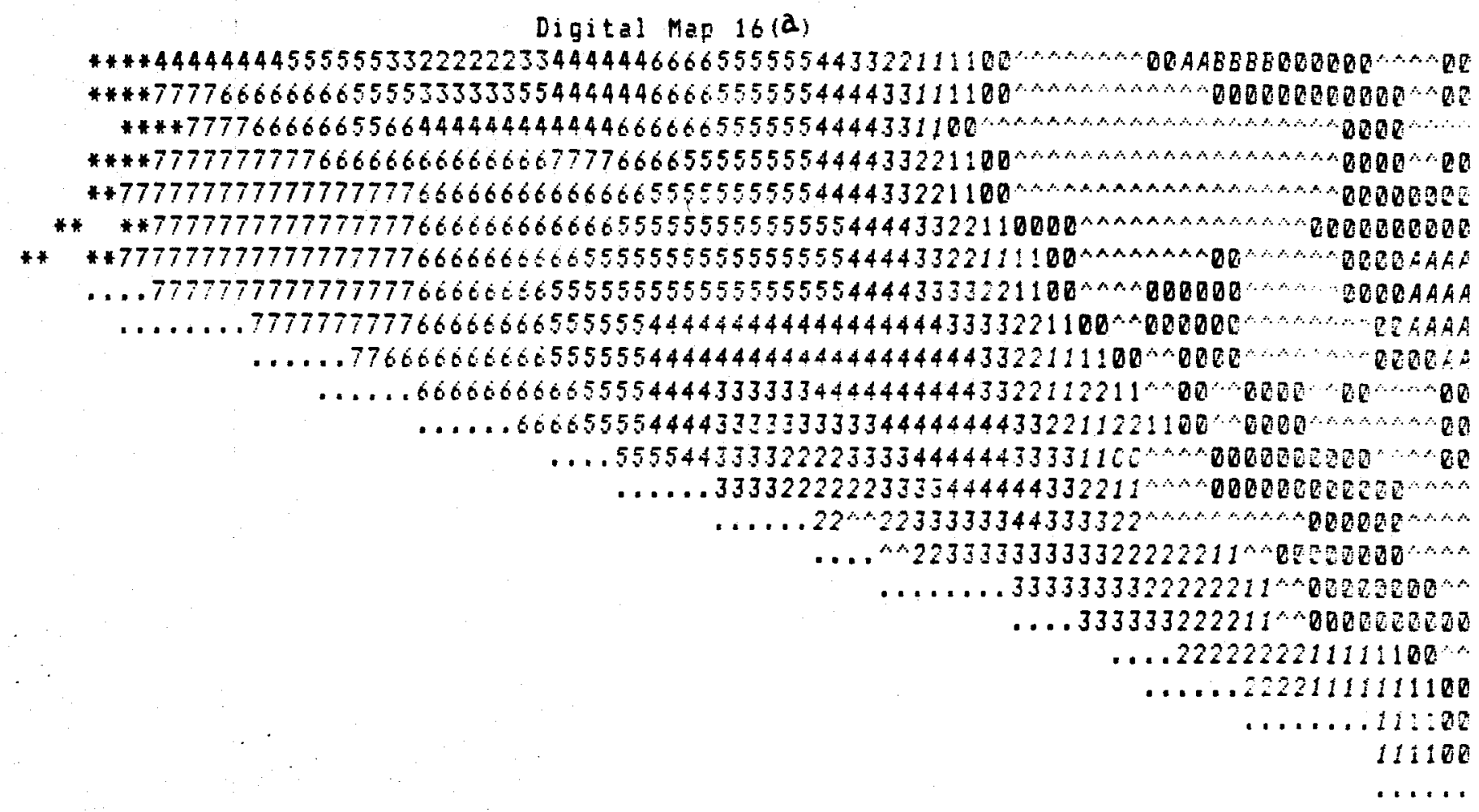

DEFTH OF UN:T 2 IN THE ETUDY AREA

* Colorado Fiver

A Bedrock at Surface
- Eorder with Mexico

: Unit I at Surface

$x=0,1$ : Unit I not Present: Bedrock at $40 \overline{0} 0 *(x+1) \mathrm{ft}$.

$x=2$ to 9: Unit I not Fresent: Bedrock at $1600 *(x-1) \mathrm{ft}$.

$x=1$ to $T$; Unit I at $x * 980+t$.

$A$ : Unit I at $-400 \& t$.

$B$ : Unit 1 at $400-1300 \mathrm{ft}$.

C: Unit! at $1300-2300 \mathrm{ft}$.

$D$ : Unit I at $2300-3600 \mathrm{ft}$. 


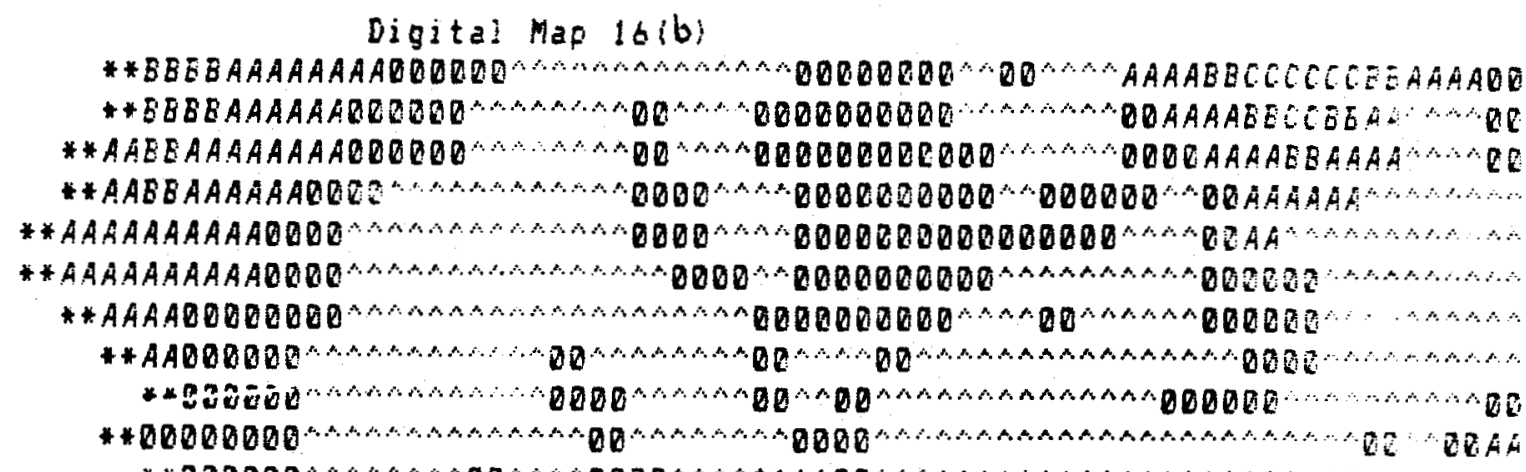

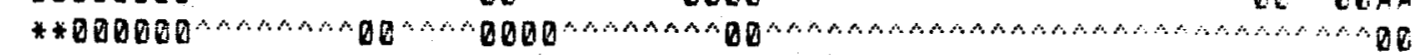

* *DOQE

* *Q0

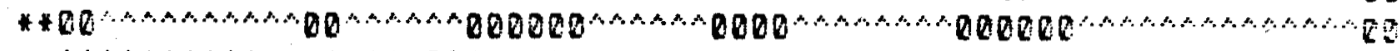

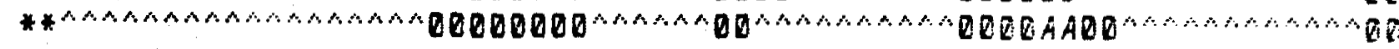

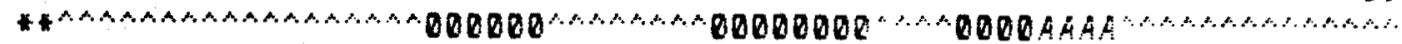

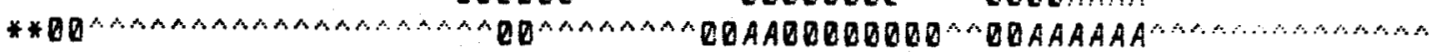

* HAM

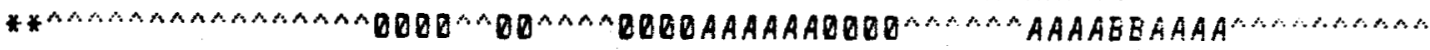

* * AnA

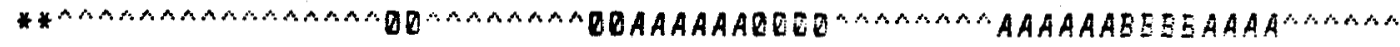

* * NAOA

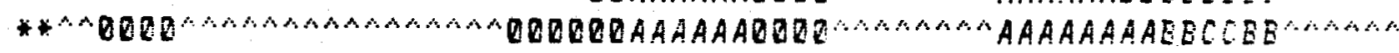

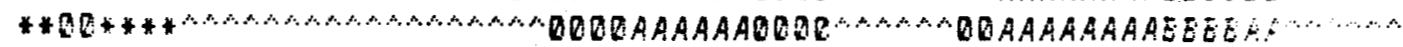

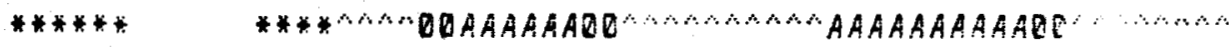

* QDOBAAAAAAQBOQ

***** AAAAAAQDQQ

**\#\#\#AAAAAAQ000

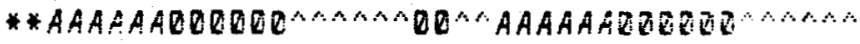

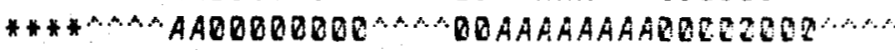

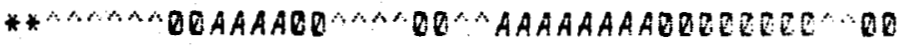

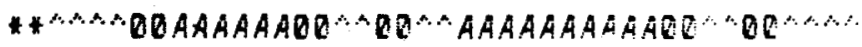

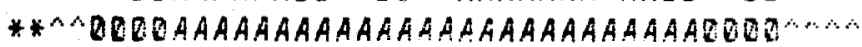

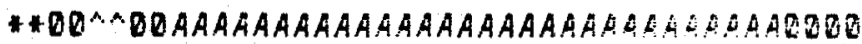

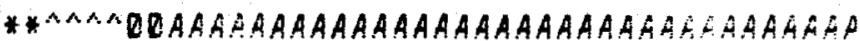

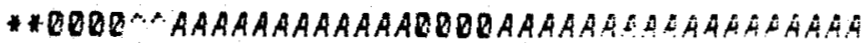

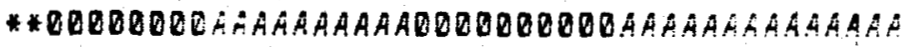

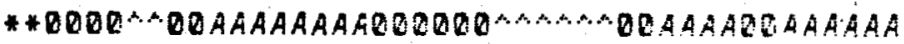
*****QDQAAAMAAAAAADQDQQ

+ Q0000 * *000000

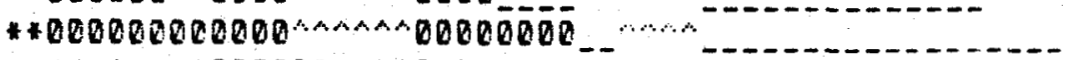
* 11111111000000000000000000 -

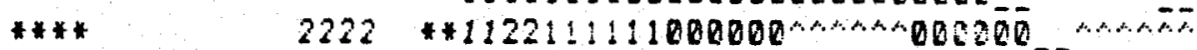

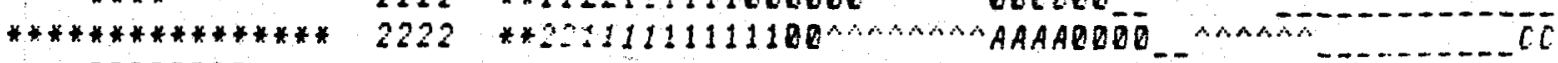

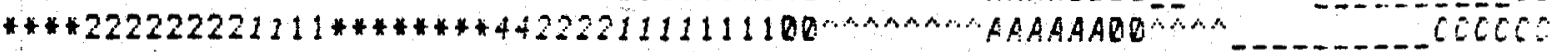

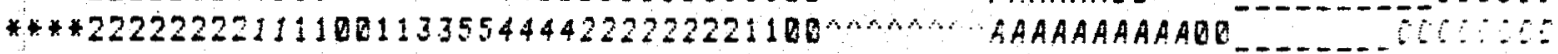

***222222222221110R11223355444422222211110000 NAAAAAAAAAABEEEG

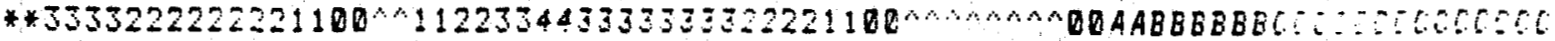

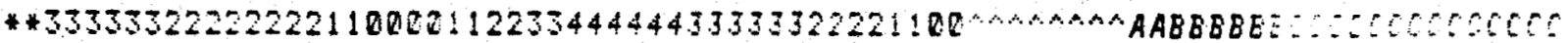

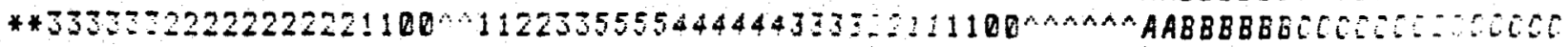

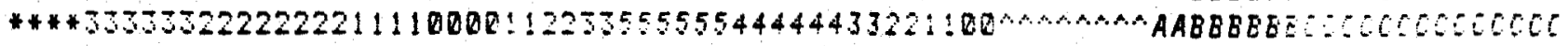

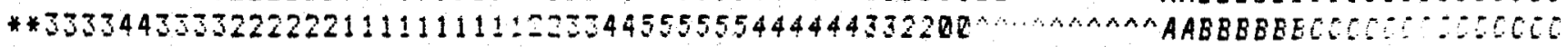

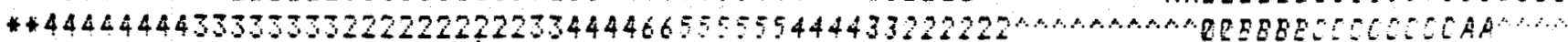


Digitel Map $16(C)$

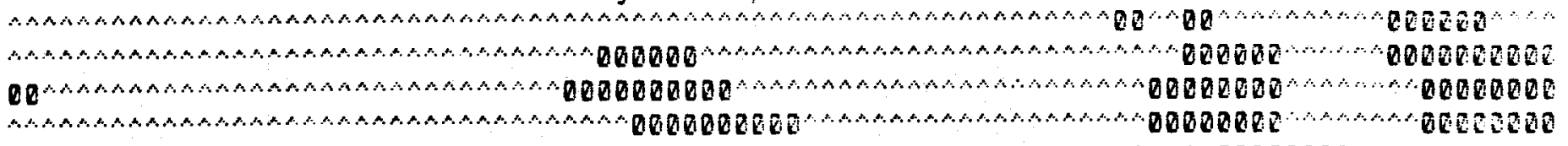
ANAOQOOODO

ANADQAAAAQE

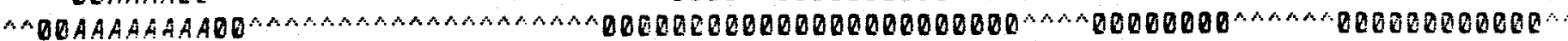

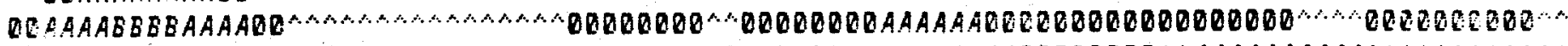

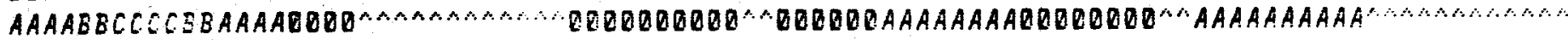
AABBCCCCCCCCCCEEAAOD AAAAA ANA

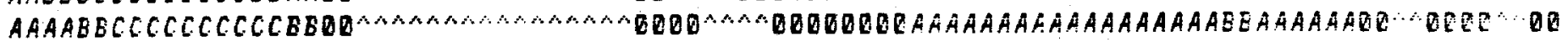
AAAABECCCCCCCCCCCCAAODOQDO

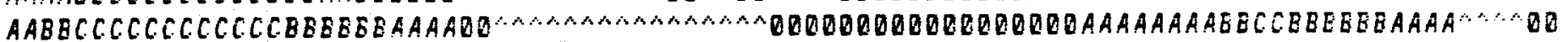

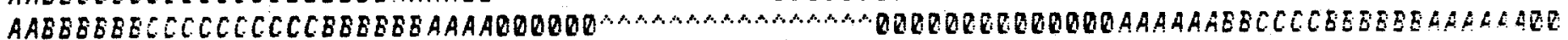
QOAAAAEBBBBECCCCCCCCBEBEBBAAAAQD A

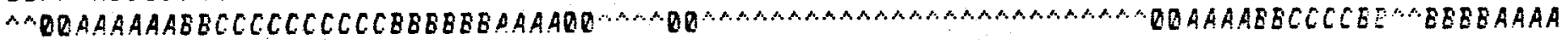

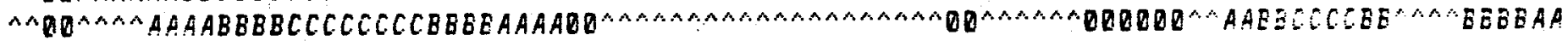

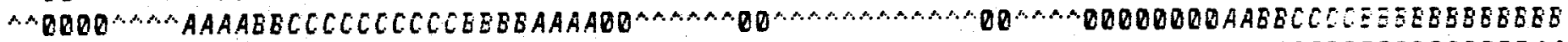

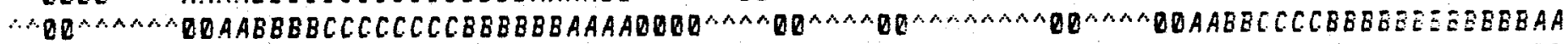

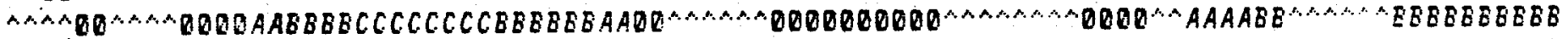

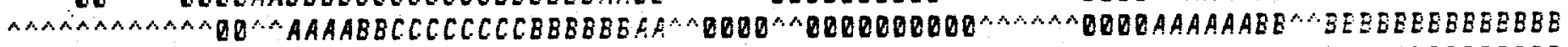

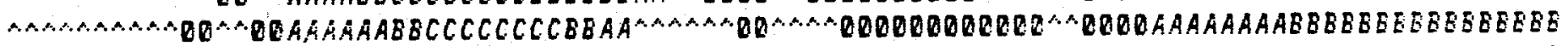

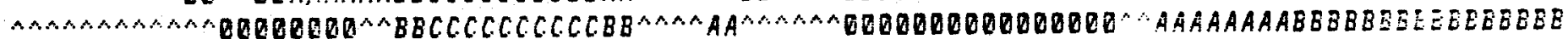
AAAMAMA

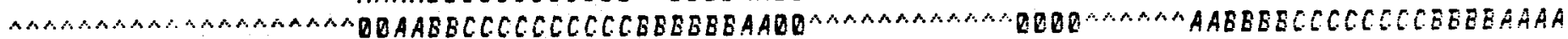

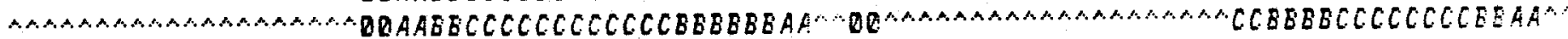

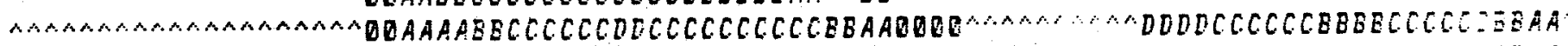

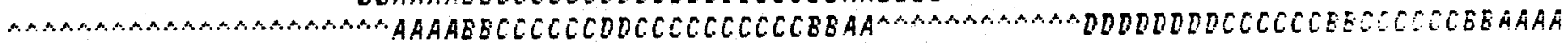

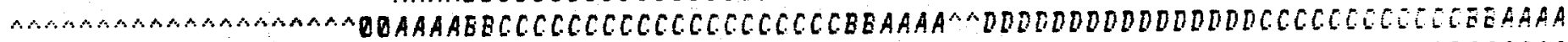

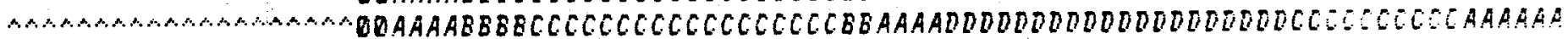

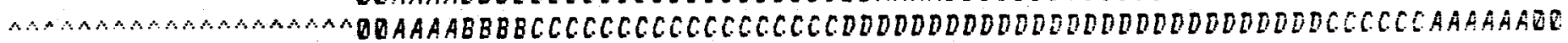

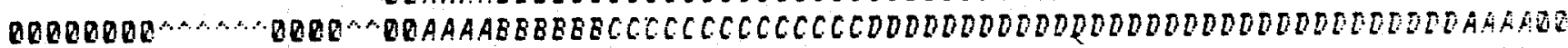

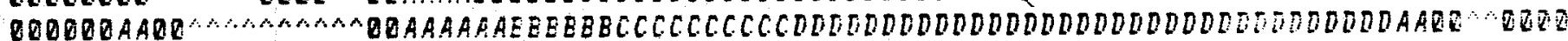

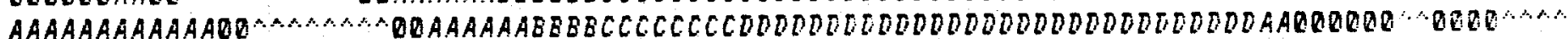

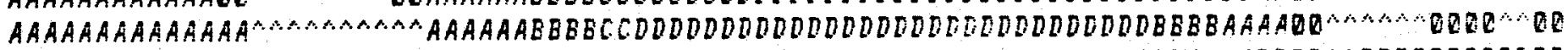

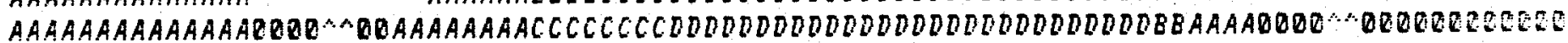

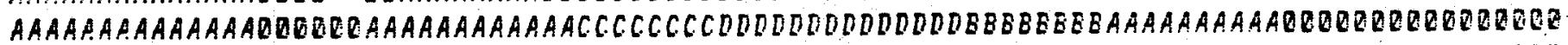

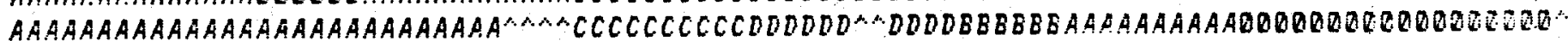

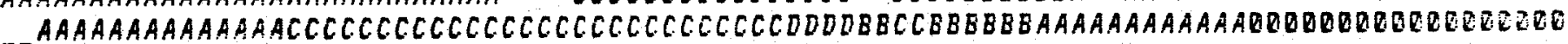
- $A$ AAAAAAAAACCCCCCCCCCCCCCCCCCCCCCCCCCCCCCDOEBCCCCCCEBBEAAAAAAAAAAAADOQ000000000000000

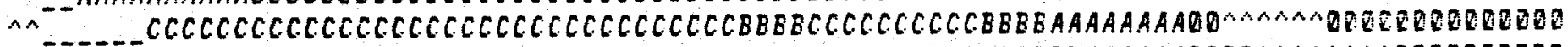

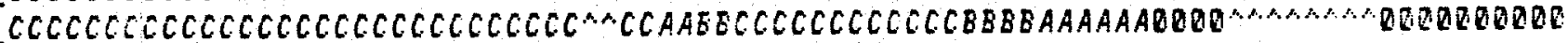
CCCCCCCCCCCCCCCCCCCCCCCCCCCCAA MAAAAABBCCCCCCCCCCCCCSOCBBAAAAAADEQDOO

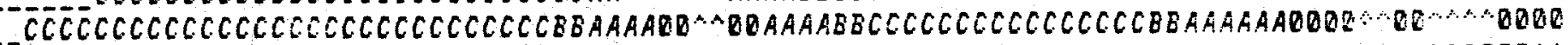

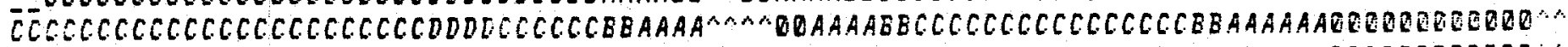

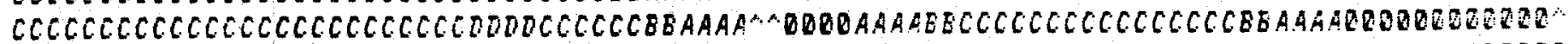

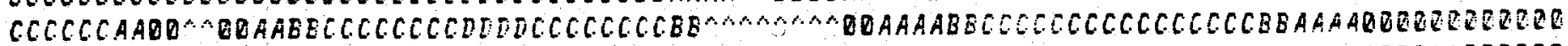

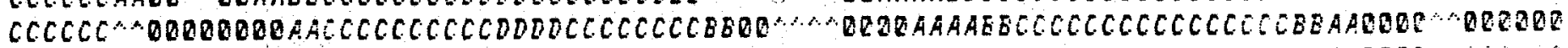

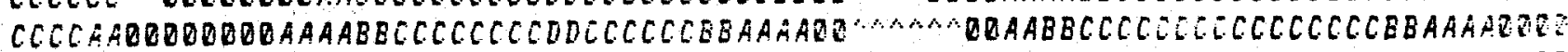

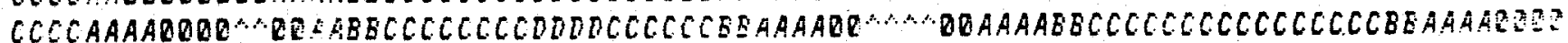

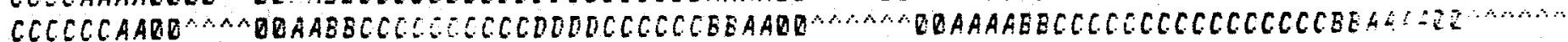

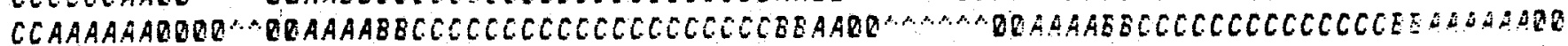

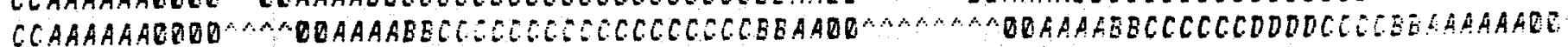

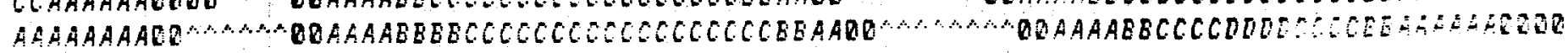


Digital Map 16 (d)

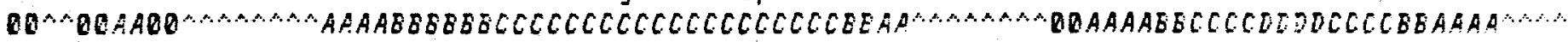

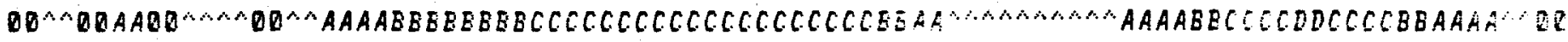

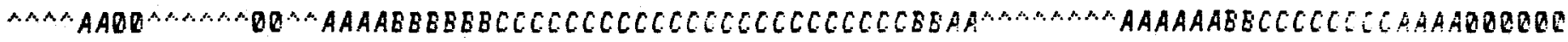

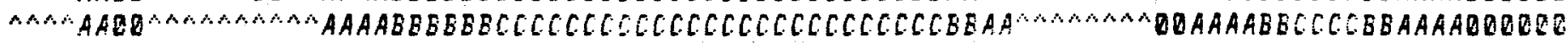

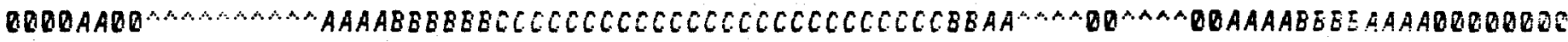

AAAAAAQO

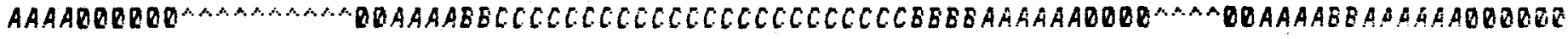

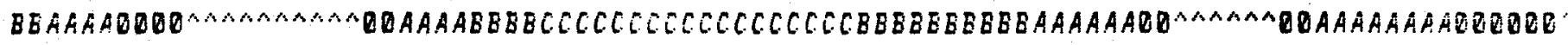

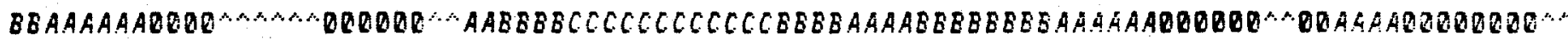

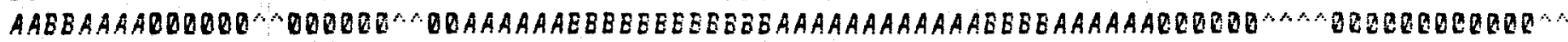

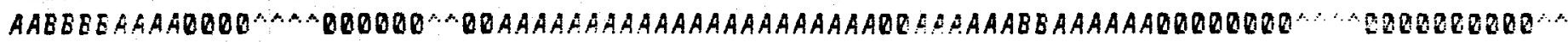

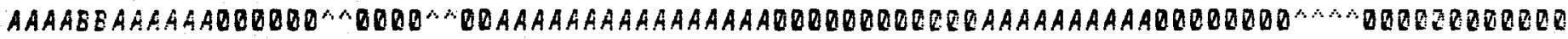

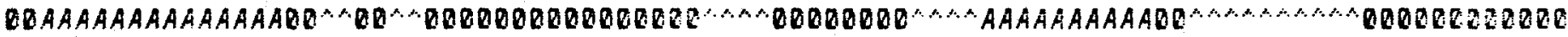

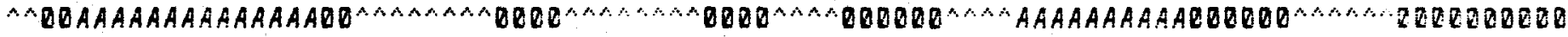

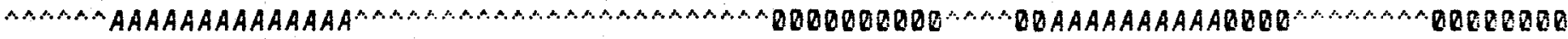

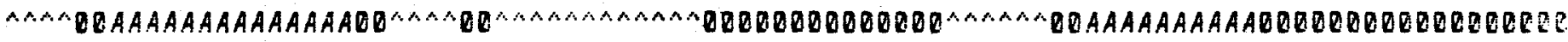

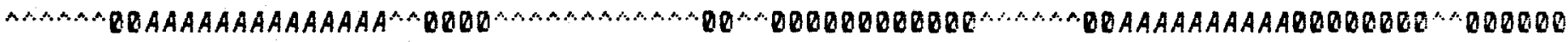

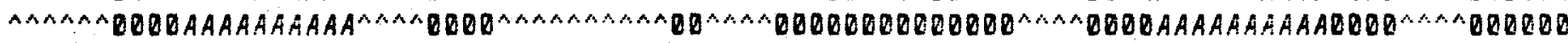

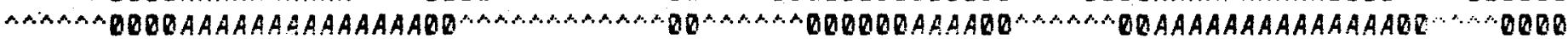

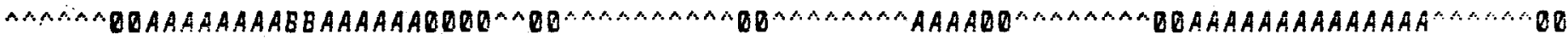

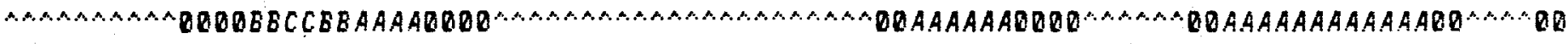

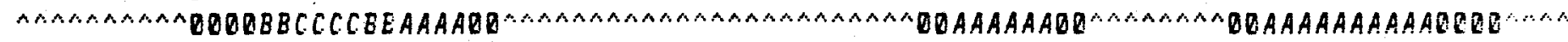

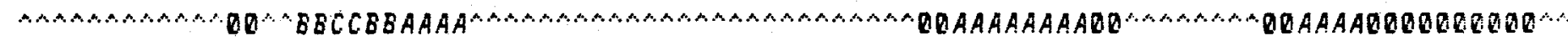

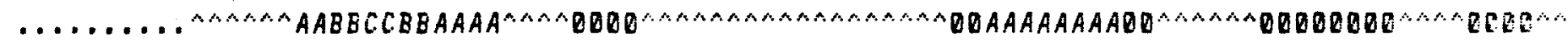

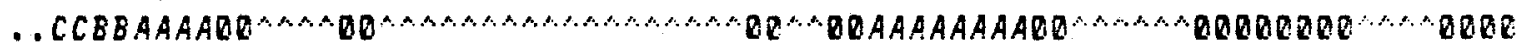

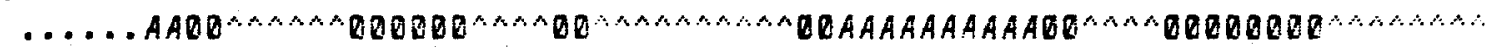
...... ..... .

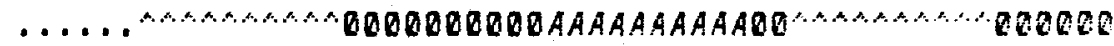
. AMAMAOQ

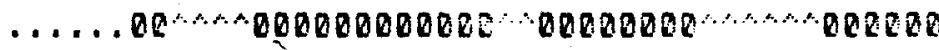

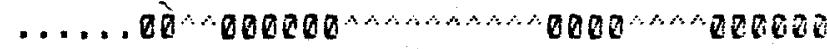
..... ..... $\ldots \ldots$. A $00000000000282^{\circ}$ .....

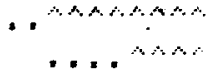
$\ldots$ 


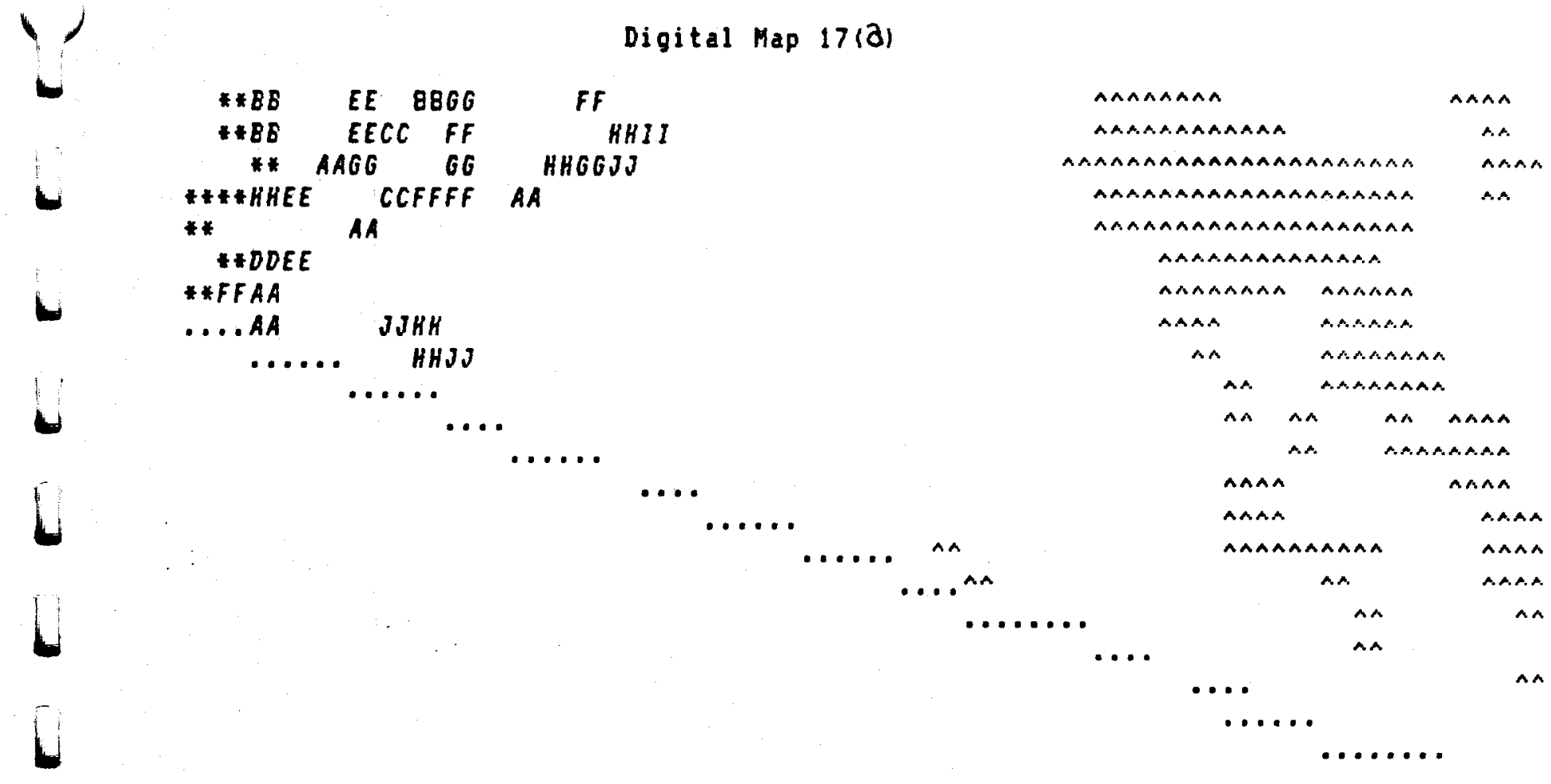

8

USGS GROUND HATER TEMPERATURE DATA

* Colorado River . Border with Mexico

TEMPERATURES, DEGREES C, AND CODES.

TEMP CODE TEMF

16

17

18

19

20

21

22

23

24

6
7
8
9
$A$
$B$
$C$
$D$
$E$

6

7

$\boldsymbol{E}$
25

26

27

28

30

31

32

33

34

CODE
$F$
$G$
$H$
$I$
$J$
$K$
$L$
$H$
$H$

$\wedge$ : Bedrock at Surface

$\begin{array}{ll}\text { TEMP } & \text { CODE } \\ 34 & 0 \\ 35 & P \\ 36 & Q \\ 37 & R \\ 40 & S \\ 41 & T \\ 42 & U \\ 43 & V \\ 44 & V\end{array}$


Digital Map $17(b)$

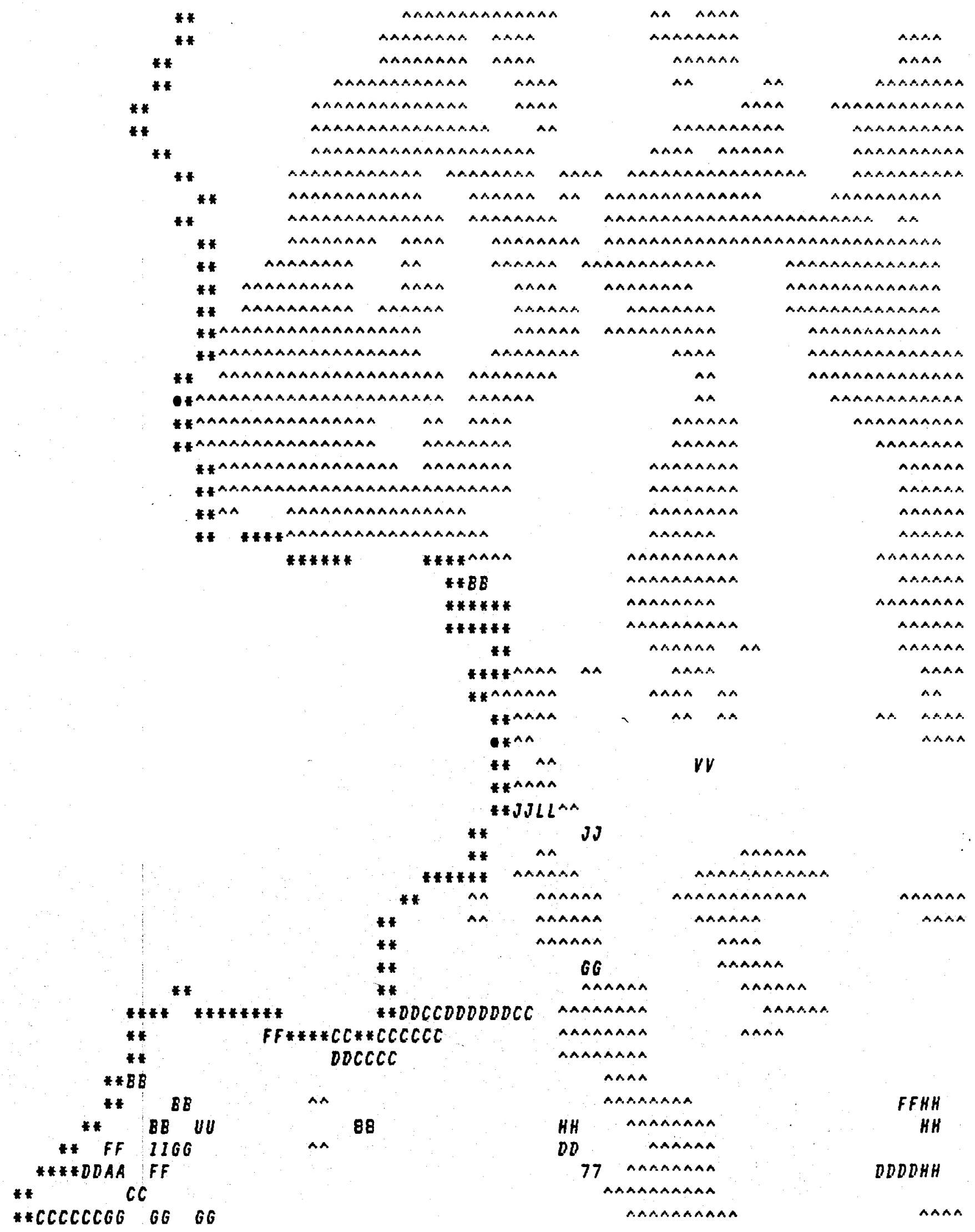


Digital Map $17(C)$

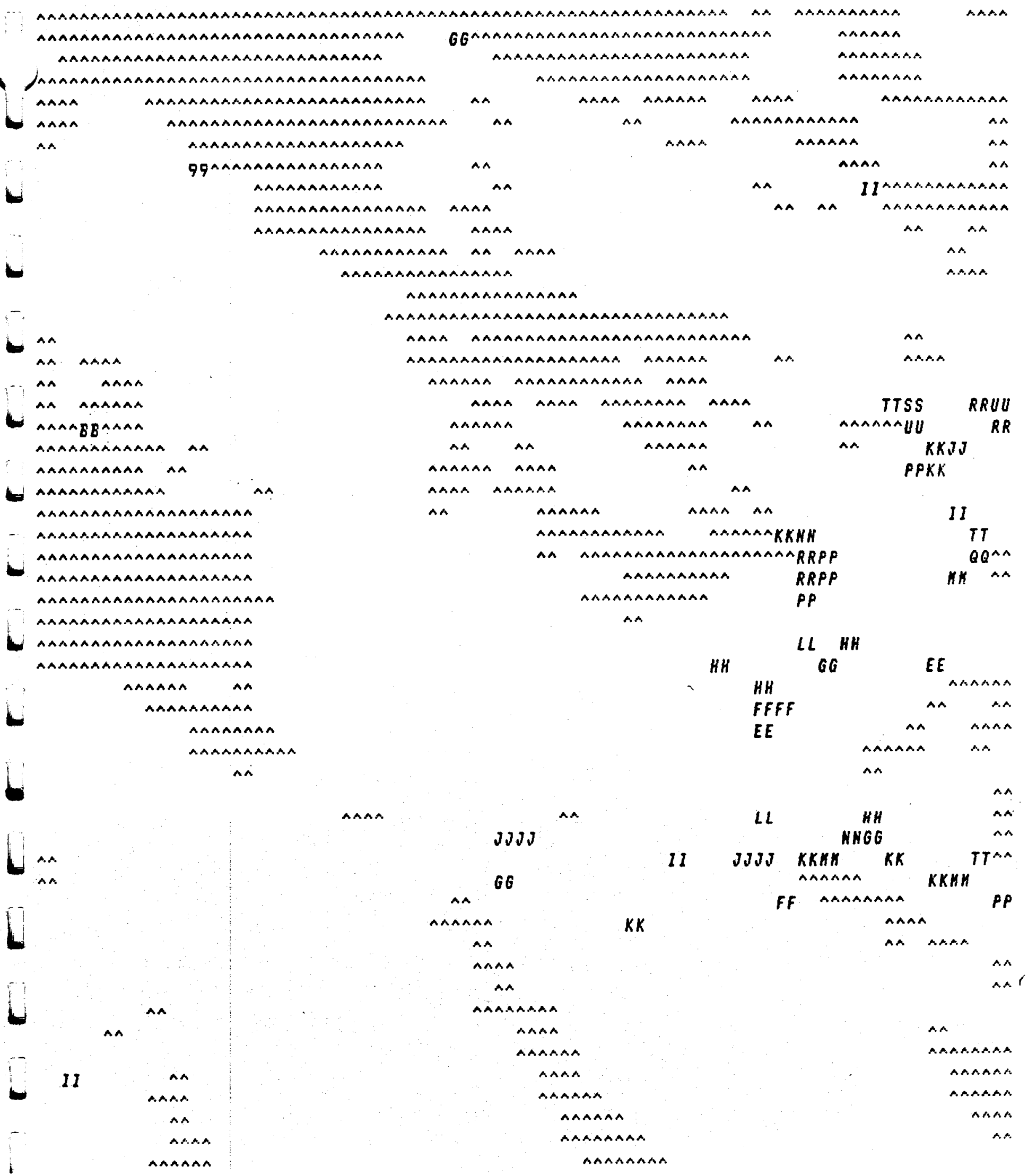

184 

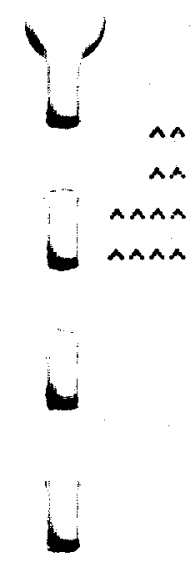

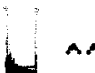

AMAAAA AAAA AAAAAA

AARAAA AAMAAA A.AAAA.A aAMAaAaAaAa anacanamaáa AAMAAAMAAMAA AA is: ....... a aAasian
Digital Map 17 (d)

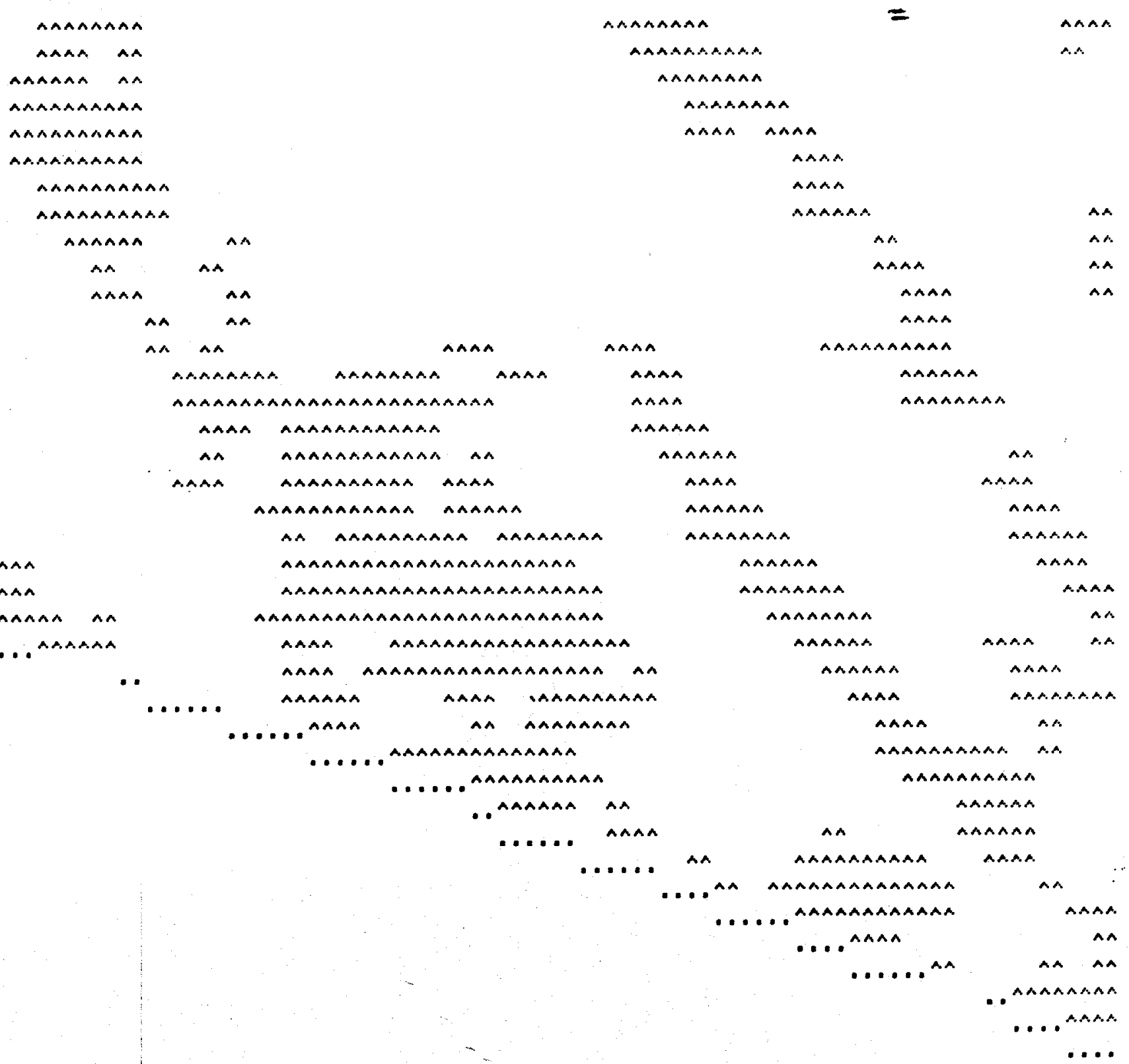




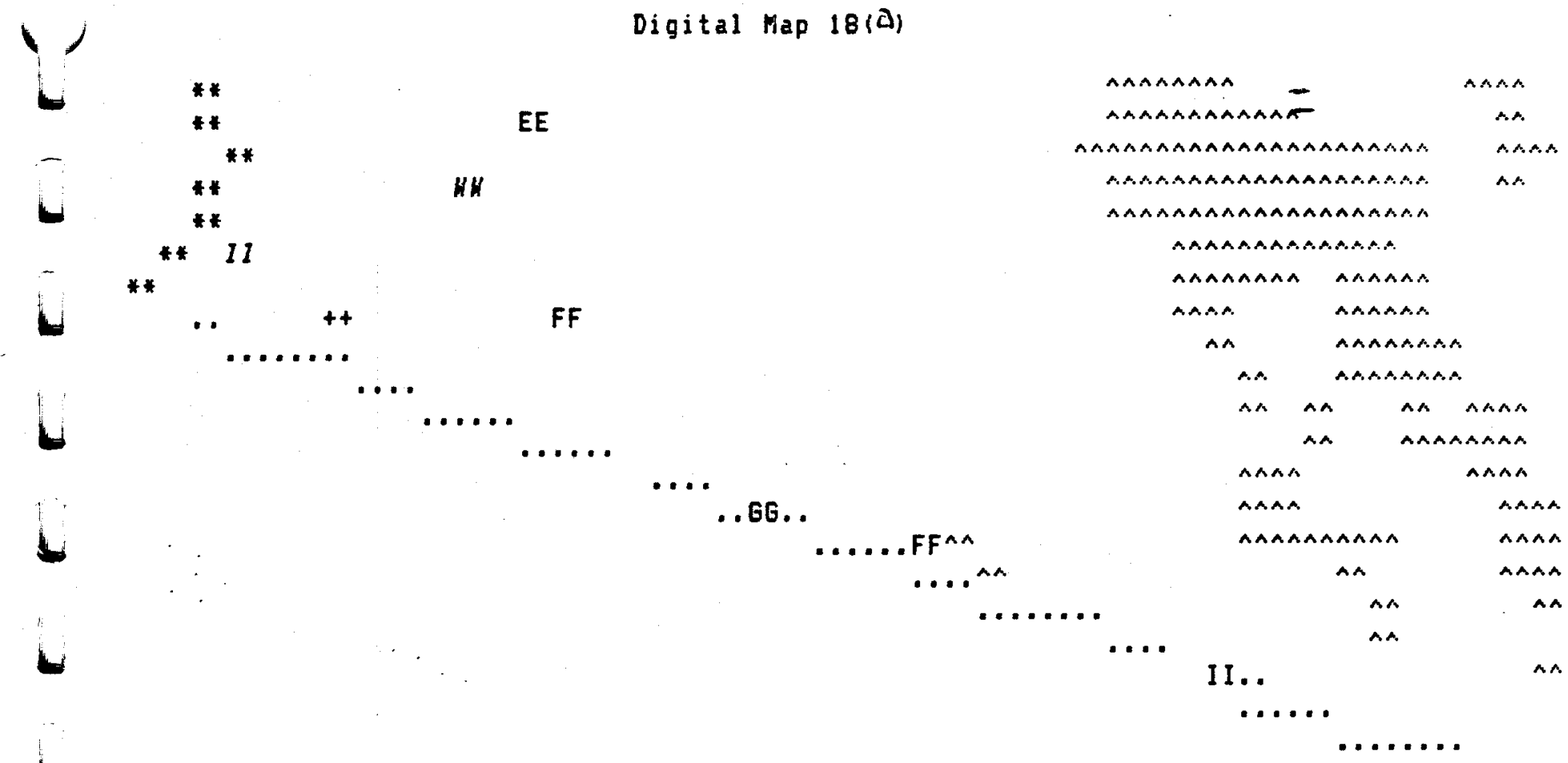

THERMAL HELL TEMPERATURE DATA

BORDER FEATURES: * : Colorado River

- Eorder with Mexico

A : Bedrock at Surface

WELLS PENTRATING UNIT I OR BOUSE

WELLS NOT PENETRATING UNIT I DR BOUSE

$A$ to 2: 30 to 56 C

A to 2: 30 to 56 C

a to z: 57 to $92 \mathrm{C}$

a to 2: 57 to $92 \mathrm{C}$

Deep Well near San Luis: + 
Digital Map $18(b)$

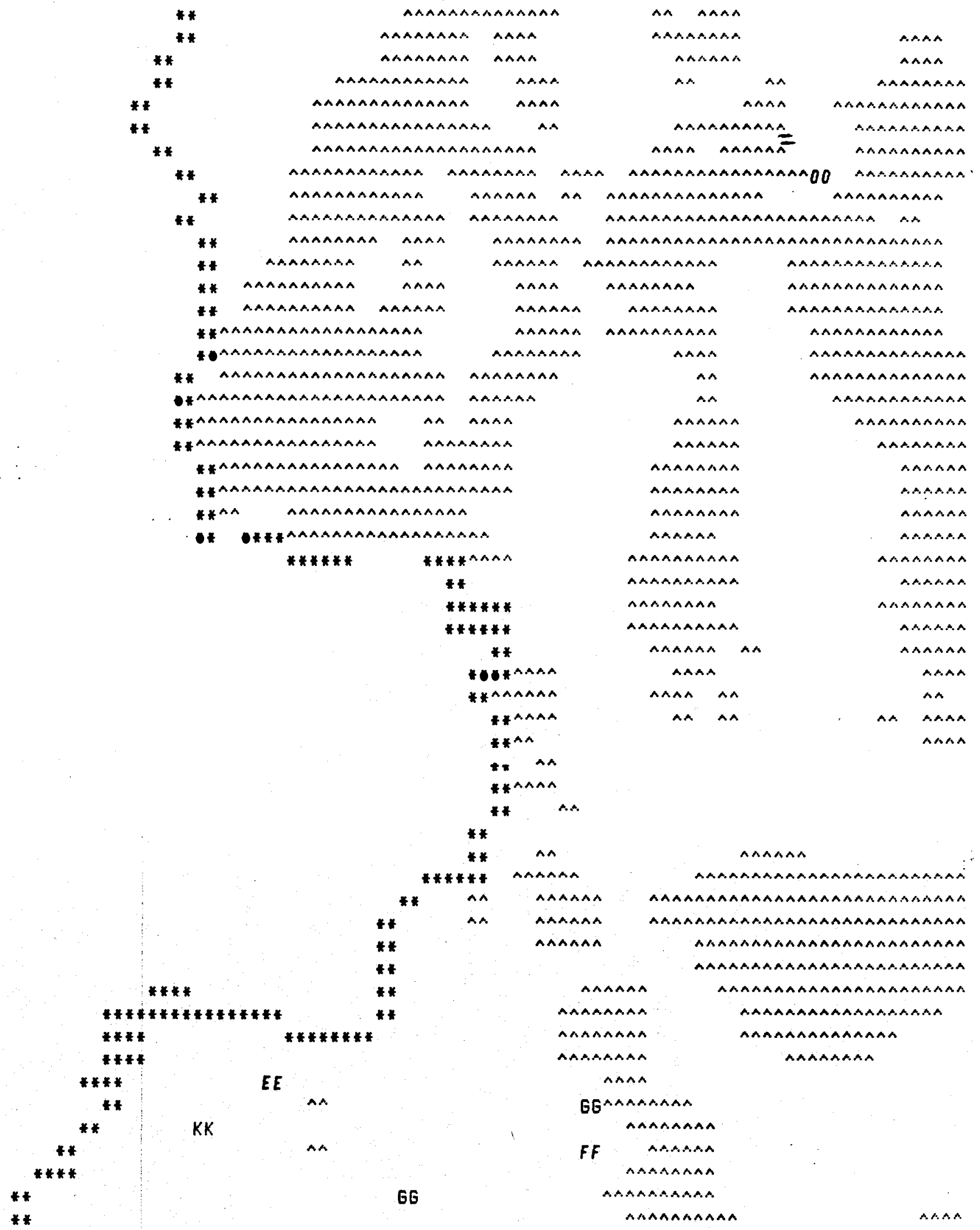


Digital Map 18(C)

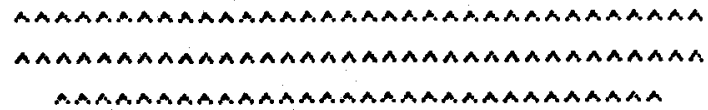

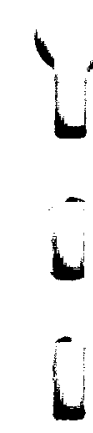

AAAAAAAAAAAAMAMAAAAMAAAAMAAAAAAAAMAA

AAAA

ANAN

A.A.

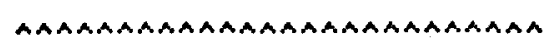

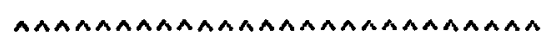

AMAAAAAAAAAAAAAAAMA.A.

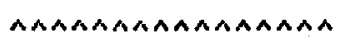

AAAAAAAMAMAAA

MAAAAAAMAAMAAAAN ANAM

MAAAAAAAMAMAAMAA MAMA

AMAMAMAMANAN AA MAAN

MAAAMAAAAAAMARAA

AヘAAANANANAヘANAN

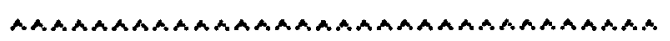

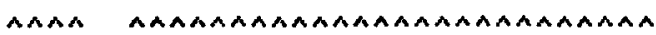

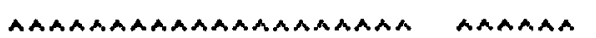

MAMAAA AMAMAAAAAMAA MAAA

amar anaA amaAmana aAma.

AคAヘA^

AA. AA

AANAAA AAAA

A.A.A. MAMAA.A

An

AnAAAA

AAMAAAMAAAAA AAAAAACCFFCC

AA AANAMAAAAMANANAAAAMANN

AAMAAAAAAA

AAAAAAAAAMAA

A.A.

AAMAAAMAMMAAAAMAAMAA

anananamamananamamá

AMAAAAAAAAAAAMAAAAMA.

$$
\begin{array}{r}
\text { ANAAAA AAN } \\
\text { AAAAAAAAMA } \\
\text { AMAAAAAA } \\
\text { AMAAMAMAAA }
\end{array}
$$

An

1

1

An

AAAA.

AAMANAAA

- amaAaAaA

AAAAAA

An eE

$\wedge \wedge$

An

AAAA

$\wedge \wedge$

$A A, A$

AคคAヘA
A.AA.

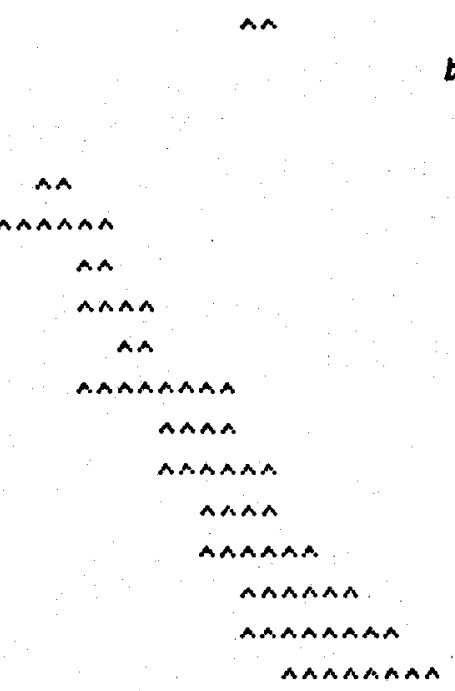

IIEE

EEEE

$b$

A.A.A.

AMANAA

AAAAAAAA

AMAMAAMAM

AAAA. MAMAAAMAAAAAAA AAAAAAAMAAAM NA

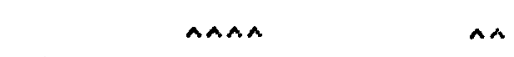

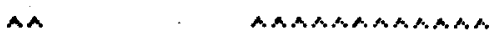

AN AA MAAAAMAAAANA

A. A. AN

AN

A.A.A.A.

$n \wedge$

AANA.

IILL JJDD ^^^^^^KK IIII AS AAGG

CC

$A A$

AA JJCC GGAA

GG AA

BB BB

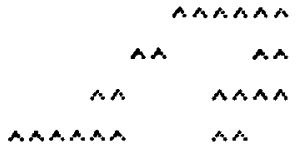

$\wedge \wedge$

$\wedge$ ค

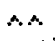

$\lambda s$

AA

AAAAAA

ANAAA.A.A.

GG

AAAA

AA MAAM

คᄉ

AA

MA

nematapam

AAMAAR

AAMACA.

ANAA

A. 


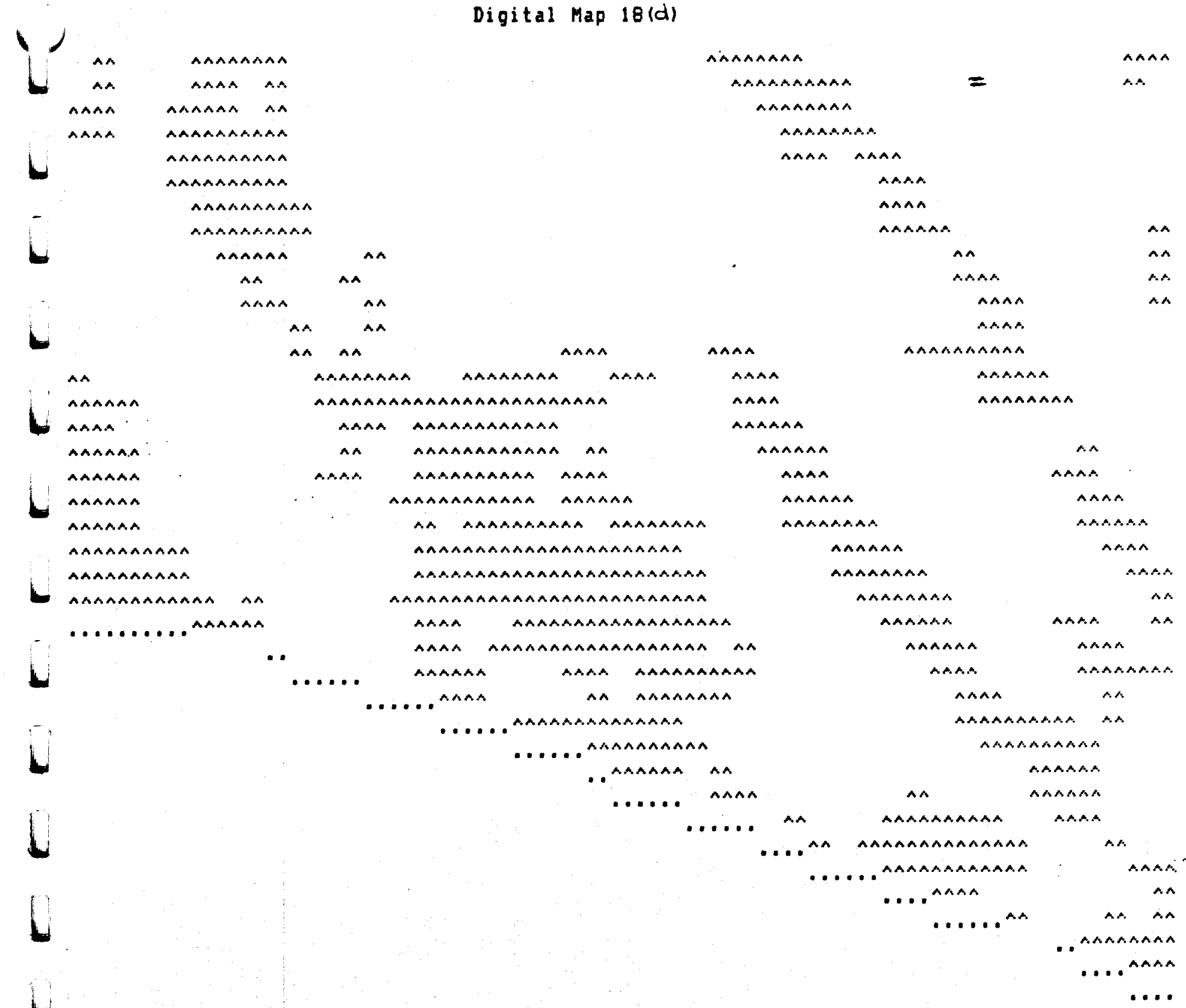

THERMAL WELL TEMPERATURE DATA

BDRDER FEATURES:

* Colorado River

- Border with Mexico

$\wedge$ : Bedrock at Surface

WELLS PENTRATING UNIT I OR BOUSE

$A$ to 2130 to $56 \mathrm{C}$

WELLS NOT PENETRATING UNIT I OR BOUSE

a to 2: 57 to $92 \mathrm{C}$

A to 2: 30 to $56 \mathrm{C}$

Deep Well near San Luis: +

a to 2: 57 to $92 \mathrm{C}$ 


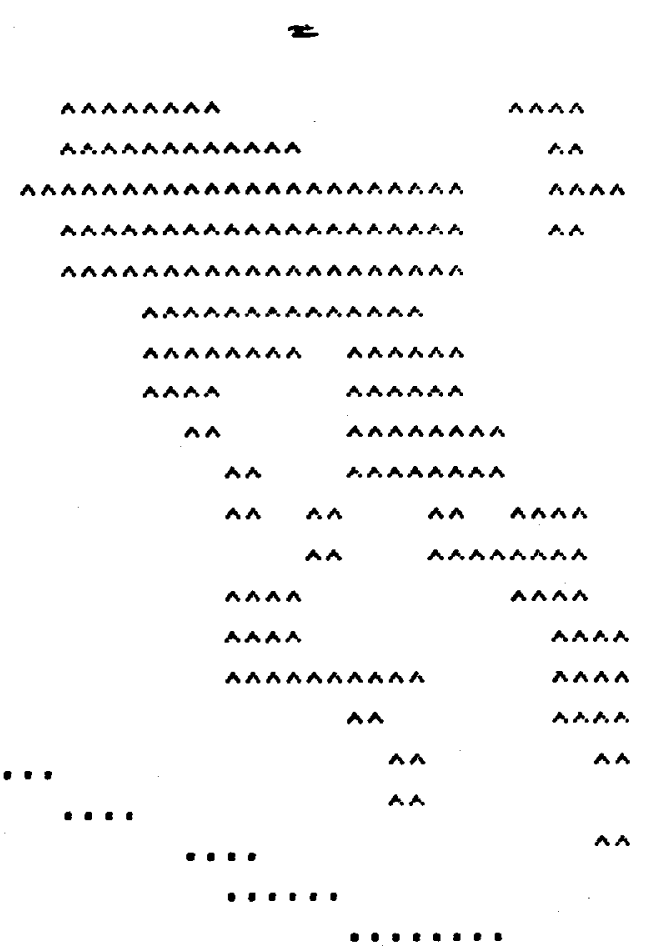

DIFFERENCES: ESTIMATED UNI II INTERIOR - ACTUAL GROUND WATER TEMPERATURES

\section{CODES:}

8: D DIFFERENCE

+ DIFFERENCE $>+26$ C

-: DIFFERENCE < $-26 C$

A - I: DIFFERENCE $=+1$ TO +26 C

- 2 : DIFFERENCE $=-1$ TO -26 C 
Digital Map 20(b)

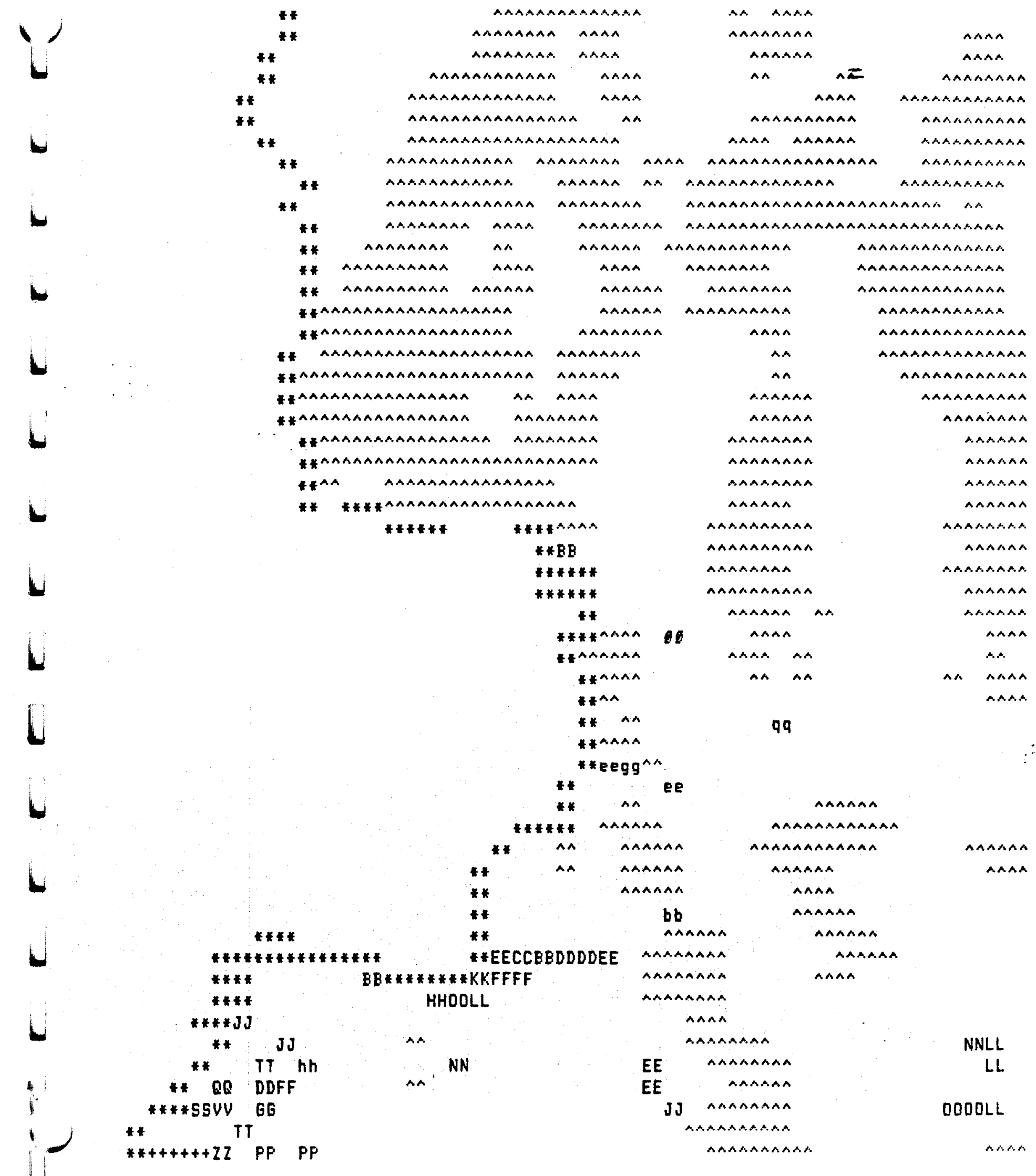




\section{Digital Map $20(c)$}

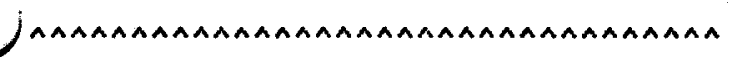

AAAAAMAAMAAAAAAAAAMAAAAAAAAAAA

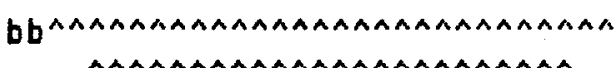

A.A.A.A.A.A.A.AA.A

$\operatorname{sinA}$

AAANAAAAAAAAAAAAAAAMAAAAAMAAAAAAAAAA

AAAMAAMAAAAAAMAAAMAM

ヘヘヘヘヘヘ

AAAA

MAMAAAAAAAAMAAAMAAAAAAMAMA

AAAM AAAAAA

$\wedge$

AAAAAAAA

AAnA

AMAMAMAAAMAMAMAMAMAMAAMMAA AA

MAAAAAAMAAMAAAAAAAAA

EEAAMAAAAMAMAAAAAN

$\wedge \wedge$

AAAAAARAAMAA. AA

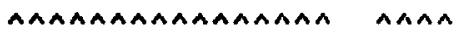

AAAAAAAAAMAAMAAA AAAA

AAAAAAAAAMAM AM ANAA

AAAAAAMAMAAMAAAA

FnnAnana

1

A A

AA AAคA

A^ คAAn

AA AMÁAAA

AMAABBANAA

AAMAAAAAAAAA AA

AAMAMAAAAA AM

AAAMAAAAMAAA Aa

AAAAAAANANAAAAANAAAA

AAAAMAAAARAAAAAAAMAA

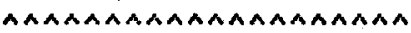

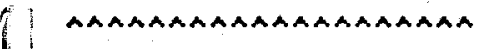

nAMAMAAAAAMAAAMAMAAMAA

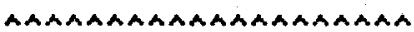

AAAAAAAAAAAAAAAAAMAA

AAAAAAAANANAAANAAAN.

ANAAAN AA

AAAAMAAAAA

AAAAAAAA

AAAAAAAAAA

Aᄉ

An

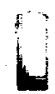

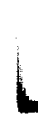

AN

$\wedge \wedge$

LL

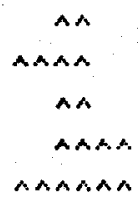

AMAAAAAAMAAMAAAA

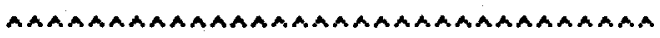

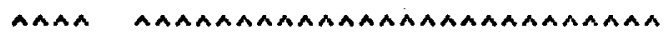

AAAMAAAMAMAAAAAAAMAA MAAMAA AA

^^

AAAA

ANAAAA AAAAMAMAAMAA MAAA

AAAA AAAA AAMAAAAA AAAA

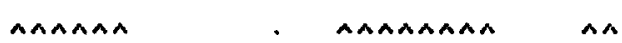

AA AA.

AAAAAA ANAA

AAAA AAAAAA

AAAAAA

An

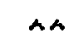

AN

AAAAAA

AAAAAAAAAAAA MAAAAAFfEE

AA MAAAAAAAANAAANAAAAAAZZEE

AAAAAMAAAA $\quad$ aAA

AAAAAMAAAAAA

An

00

MM II

iigg ffoo

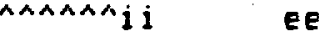

$A$ AADD

F CCC

BE

กn

$k k^{\wedge \wedge}$

BO AA

$A$

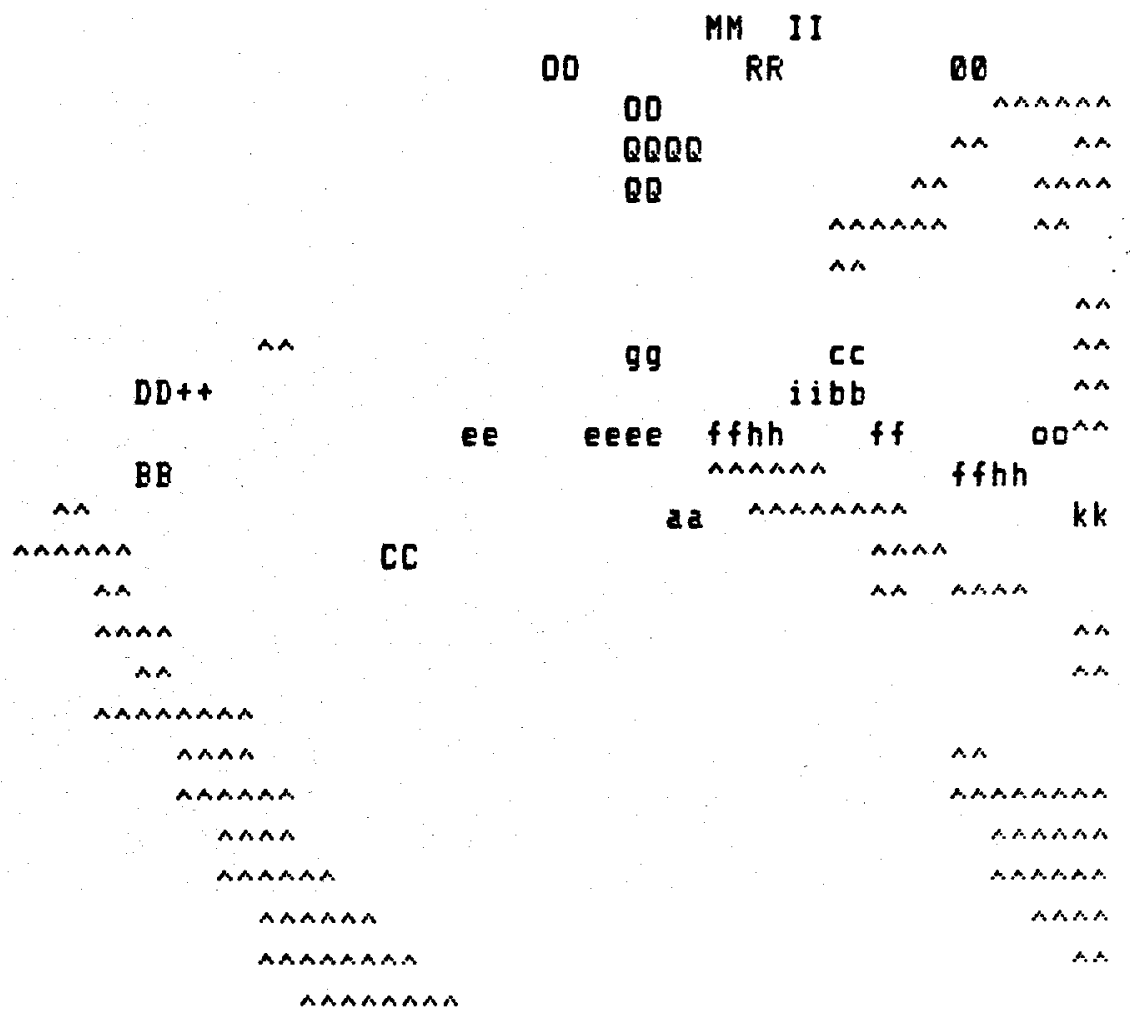




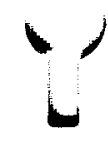

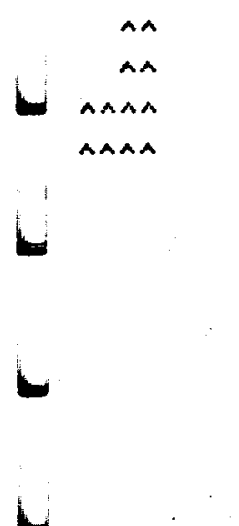

An

AAAAAA

MAMA

คคヘヘヘヘ

AAAAAA.

AAAAAA

maAaAa

AAMAAAAAAA

AAAAAAARAA

ANAAANANANAA AA

....... Aarana

Digital Map $20(d)$

$=$

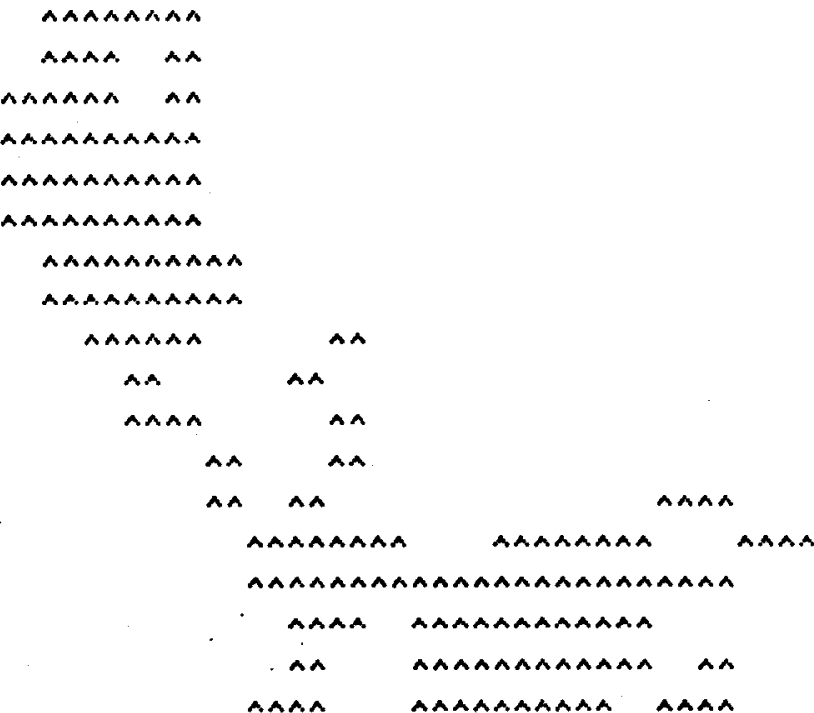

ANAAMAAA

$\wedge ハ \wedge$

AANAAAAAAA

AA

ヘヘヘヘANAN

AMAAAAAA.

AAA^ AヘAA

AヘA

AAAA

AAAMAA.

An

A.AA...

AヘAム

AAAA.

AnAA

AAAA

คヘAA

AAAAAA

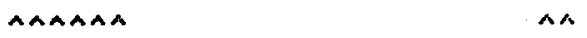

AAAA

AヘAAAN

AAAMANAAMAAN AAAMAN

AAAAAAMA

AAANAA

AAAAAMAAAAAAAAAMAMAAAA

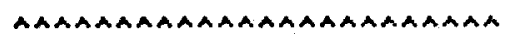

MAAAAAAAAAAANANAMAANAAAAAA.

AAAAAAAA

AAAAAAAA

AAAAAR

AAAA AAMAAAAMAMAAAMAAAA.

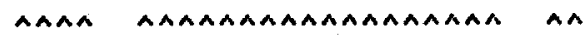

- -

AAMAAA

AAAA MAAMAAAAMA

AA ANAAAAAN

AAAAAA

AMAAMAAA

$$
\begin{aligned}
& \text {..... }
\end{aligned}
$$

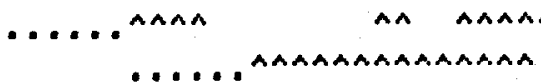$$
\text { -... ananananara }
$$$$
\text { - ananar aa }
$$$$
\text { . ma... akan }
$$$$
\text { . ... An }
$$

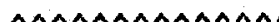

AAMAAAAAAA

- . Anararanarara

... An^a

.... Aa

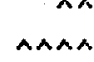

AAnA

AAAAAA

A^A^

AMAA

AN

A.AAA AA

AAAA

AAAAMAAA

An

AAAAAAAAAA AA

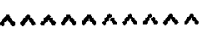

AAANAA

AAคAAA

A.AnA

$\wedge \wedge$

A.A.A.A.

Aᄉ

AA A.A

- anananar

... mana

$\ldots$ 
Digital Map $21(d)$

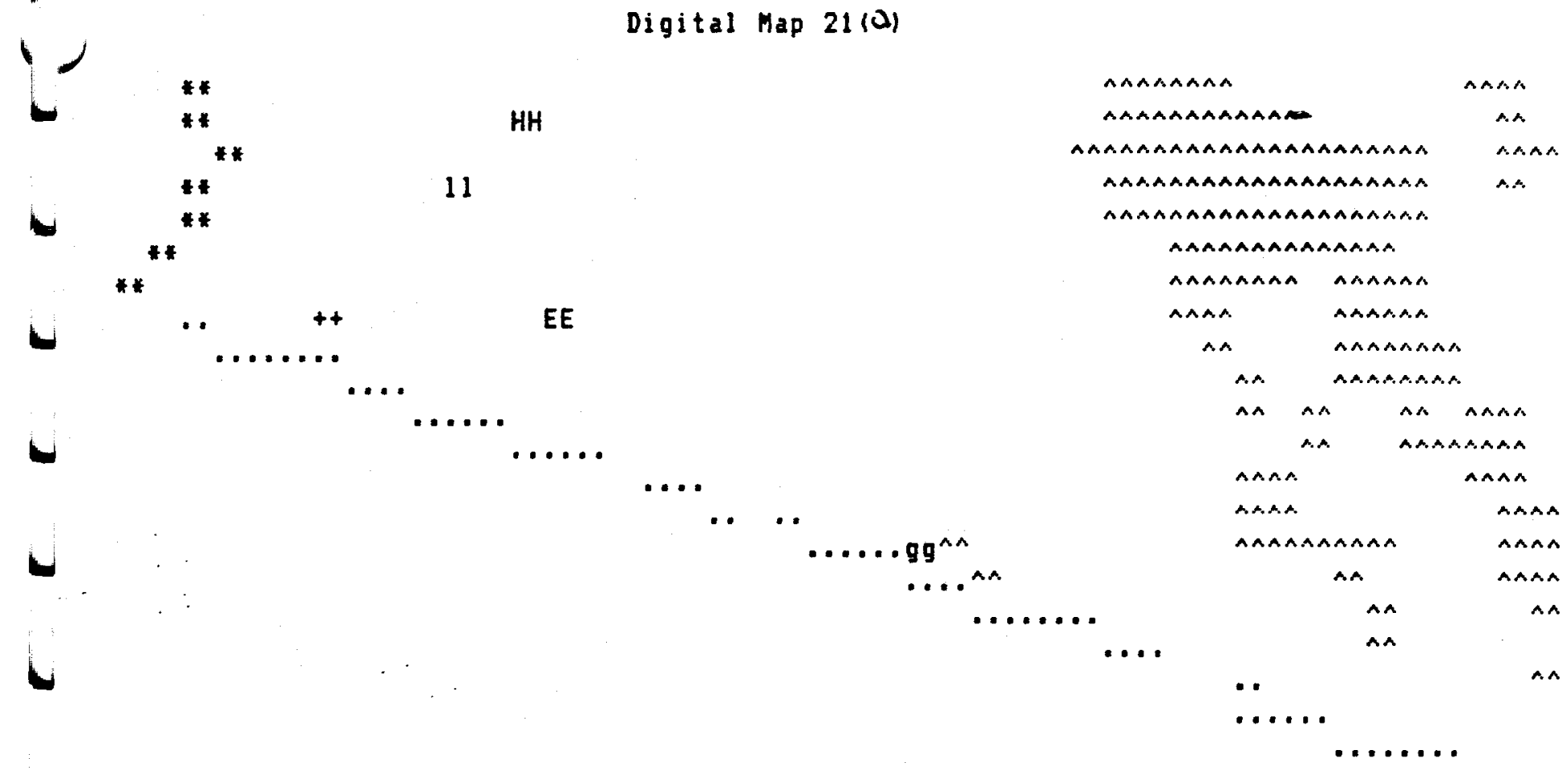

DIFFERENCES BETWEEN MEDIAN UNIT II PREDICTIONS AND THERMAL WELL TEMPERATURES

- Colorado River - Border with Mexico

$\wedge$ : Bedrock at Surface

THEORETIC NORMAL MINUS THERMAL WELL DATA

D: Difference $=0$

A to $2:$ Difference $=1$ to 26 degrees Celsius

a to 2: Difference $=-1$ to -26 degrees Celsius

+ Bifference $>26$ degrees Celsius.

- Difference < -26 degrees Celsius. 
Digital Map 21 (b)

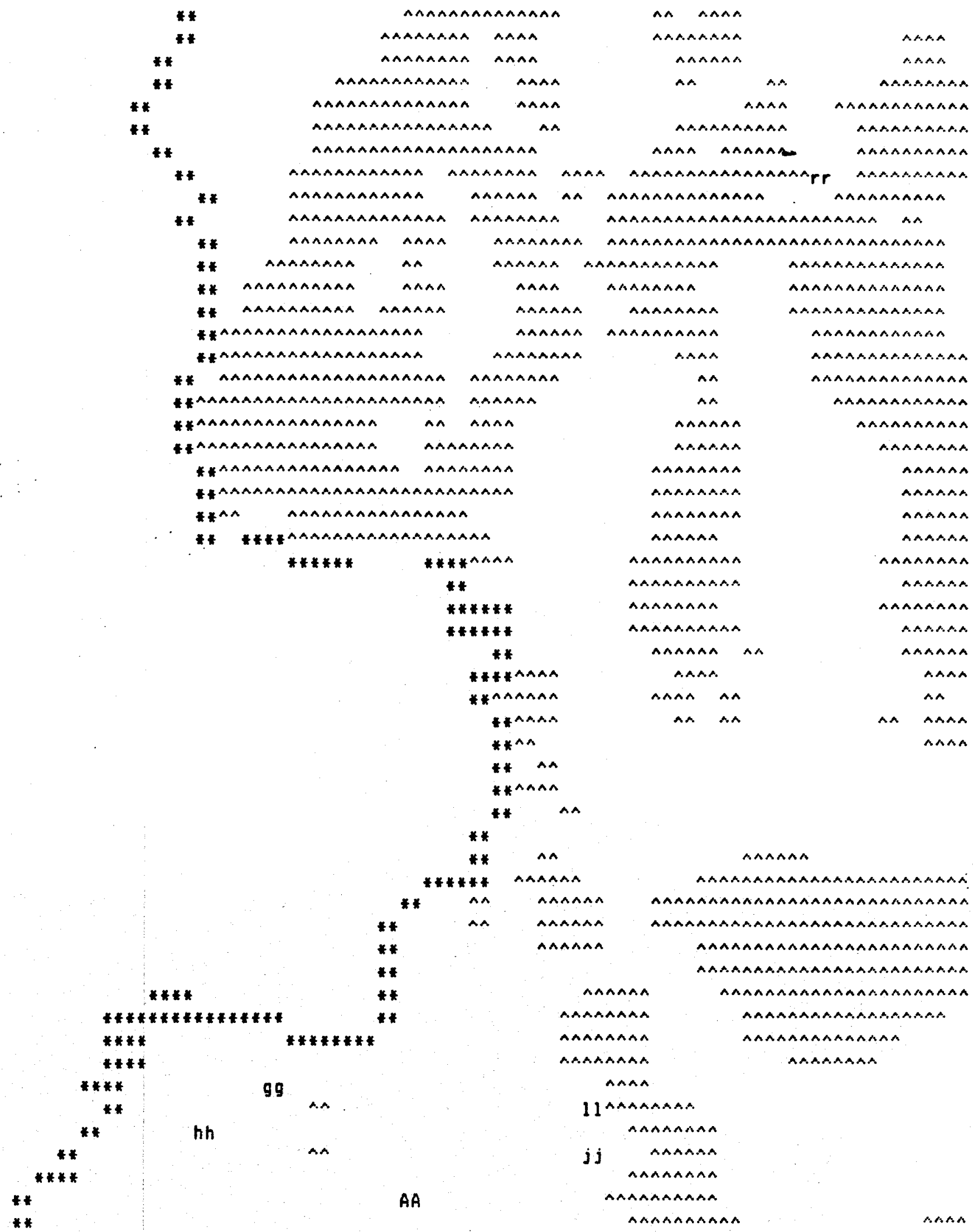


Digital Map $21(C)$

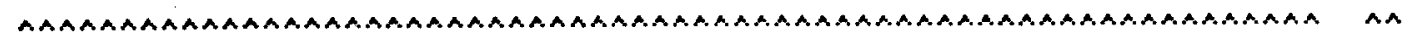

A.A.A.A.A.A.A.A.A.

AMA.A

AAMAAAAAAMAAAAAAMAAAAAMAAAAMAAMAMA

AAAAAAAAAAAMAAMAAMAMAMAAMAAAAA

AMAMAAAMAAAAAAAMAMAAAAAAAAAAAAAAAAAA

$\int_{\operatorname{lnana}}$

An

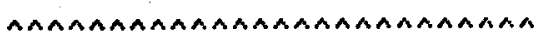

MAAAAA.A.A.AAAMAAAMAAAA.

MAAAAAAAAAAAAAAA

A.AAAAAA.A.A.AAA

AAヘAMAAMANAAANAN AAAN

A.A.MAAAAAAAAAAAA. AAAA

AAAAAAAANAAA AA AAAN

A.AAAAAAAAAAAAAAMAAA.

AMAMAMAAAAAANAAA

AAAAMAMAAAAAAAAAA.AAAAAAAAAAAAAAAA.

An

A.A A.A.A.

AヘヘA

AA MAAAAA

AAAA ANAA

AAMAAAMAAAAA AA

AnAMAAKAAA AA

AaAnamanamaA Aa

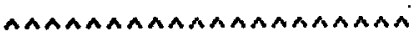

AAMAAAAAAAAAAAAAAAAR

AAANAAAMAAAAAAAMAAAAMA

MAAAAAAMAAMAAAAAMAAM

AAAAAAAAAAMAAAAAAAAB

AAMAAARAAAAAAARAMAAA

MAAAAA AN

AAAMANAMAA

AMAAAAAA

MAAAAAAAAA

$\wedge$

A.A.A.A.

A A

AsA.s

ANAAAAAA

AAAAAAAA

AnAMAN

AA Fr

$\mathbf{r}$

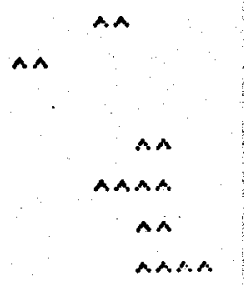

$\operatorname{AAMAAA~}$

AヘAAヘA

A.A AN

AAAAAA

An

ANAAAA ANAA

AAAA AARAAA

An

AヘAヘヘA

AAAAAAAAAAAA

AAAAMAAAAA

AAAAAMAMAAAA

An
An

AnAmAa

AA

AAAAAAAA

AAAA

AAAAMA

ANAA

AAAAAS.

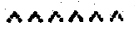

A.A.A.A.A.A.A.A.

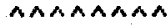

$b b$
AAAAAA.AMAAAAAAAAAAMAAAAAAAA.

MAAAAAAMAAAAAAAAAABA

AAAAAAAMAAAAAANAAAAA

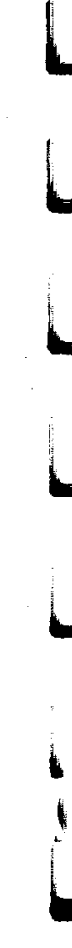

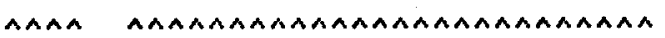

AAAAMAAAAAAAAAAMAAAA AAAMAA. A.

AMAMAA AAAAAMAMAAMA AAAA

AAAA AAMA MAMAAAAA AMMA

AAAANAAA AA

Aヘヘค คค

AAAAAAhheebb

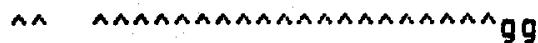

GbBB

BEBB

KK

MM EE
AヘAАA人

AAAMAAAA.

AAAAAAAAAAAAA

$\wedge \wedge$

A.A

$\wedge \wedge$

- AnAn

A.AAAAAAAAMAAA

ANAAAAMAAAMA

A.A. AN

As

A.A.A.
AAAMAAAA s

AAPA. yy
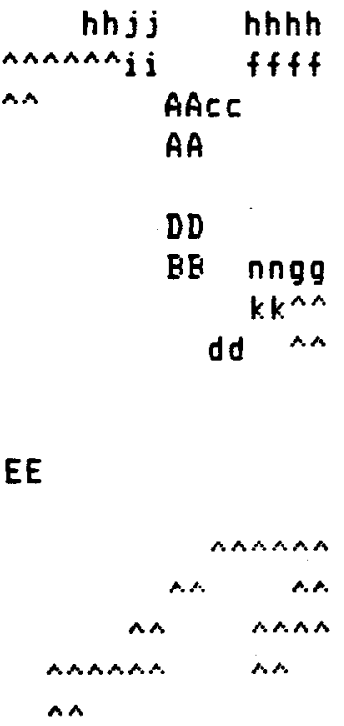

a AAEC

$A A$

DD

BE $n n g g$

$k k^{\wedge}$ dd

An

A.r.

$\therefore A$

A. A

คAคคAค

AAAAAAAA

A^^^

AA AAAA.

$\therefore x$

A.MAAAAAAA

AAAANA

AAcesen

ANAN

A. A. 
Digital Map $21(d)$

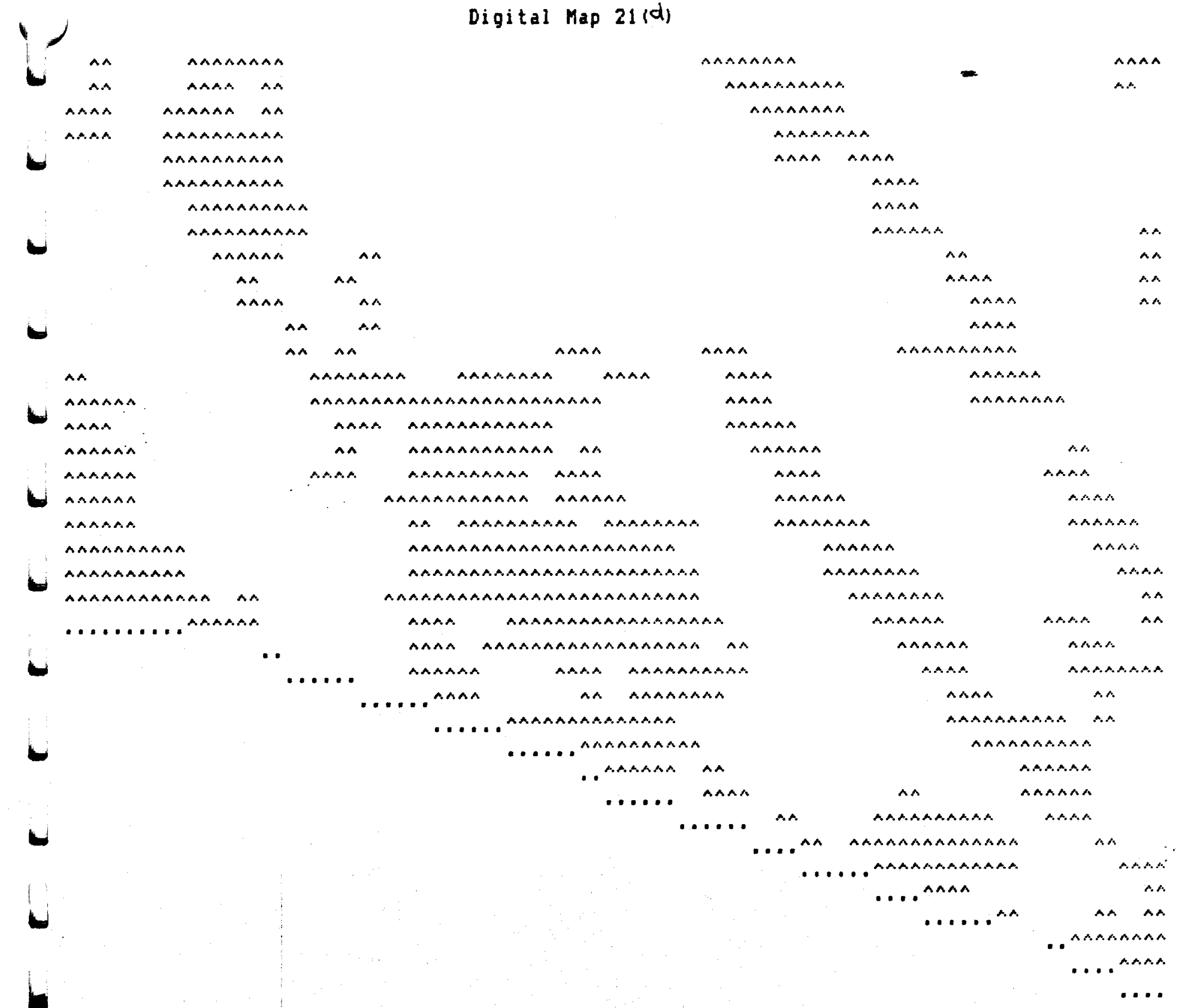

DIFFERENCES BETWEEN MEDIAN UNIT 11 PREDICTIONS AND THERMAL WELL TEMFERATURES

* : Colorado River : Border with Mexico

$\wedge$ : Bedrock at Surface

THEORETIC NORMAL MINUS THERMAL WELL DATA

O Difference $=0$

A to 2 : Difference $=1$ to 26 degrees Celsius

a to 2 : Difference $=-1$ to -26 degrees Celsius

: Difference $>26$ degrees Celsius.

1 - : Difference -26 degrees Celsius. 
Digital Map $23(a)$

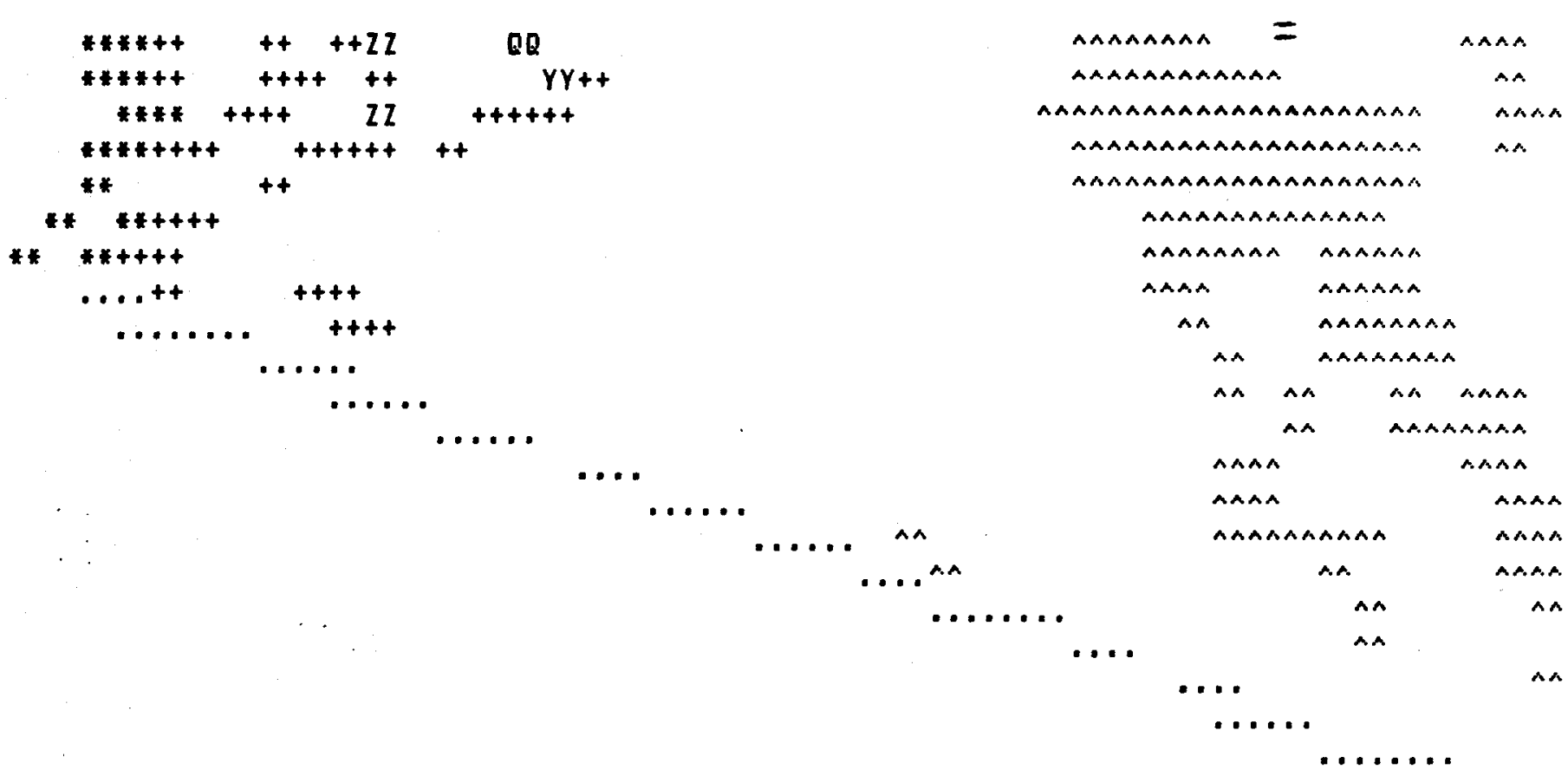

DIFFERENCES: ESTIMATED U2/UI INTERFACE - ACTUAL GROUND WATER TEMPERATURES

CODES:

D: DIFFERENCE

+ DIFFERENCE $>+26$ C

-: DIFFERENCE $<-26$ C

A - 2: DIFFERENCE $=+1$ TO $+26 \mathrm{C}$

a $-2:$ DIFFERENCE $=-1$ TO $-26 \mathrm{C}$ 
Digital Map 23 (b)

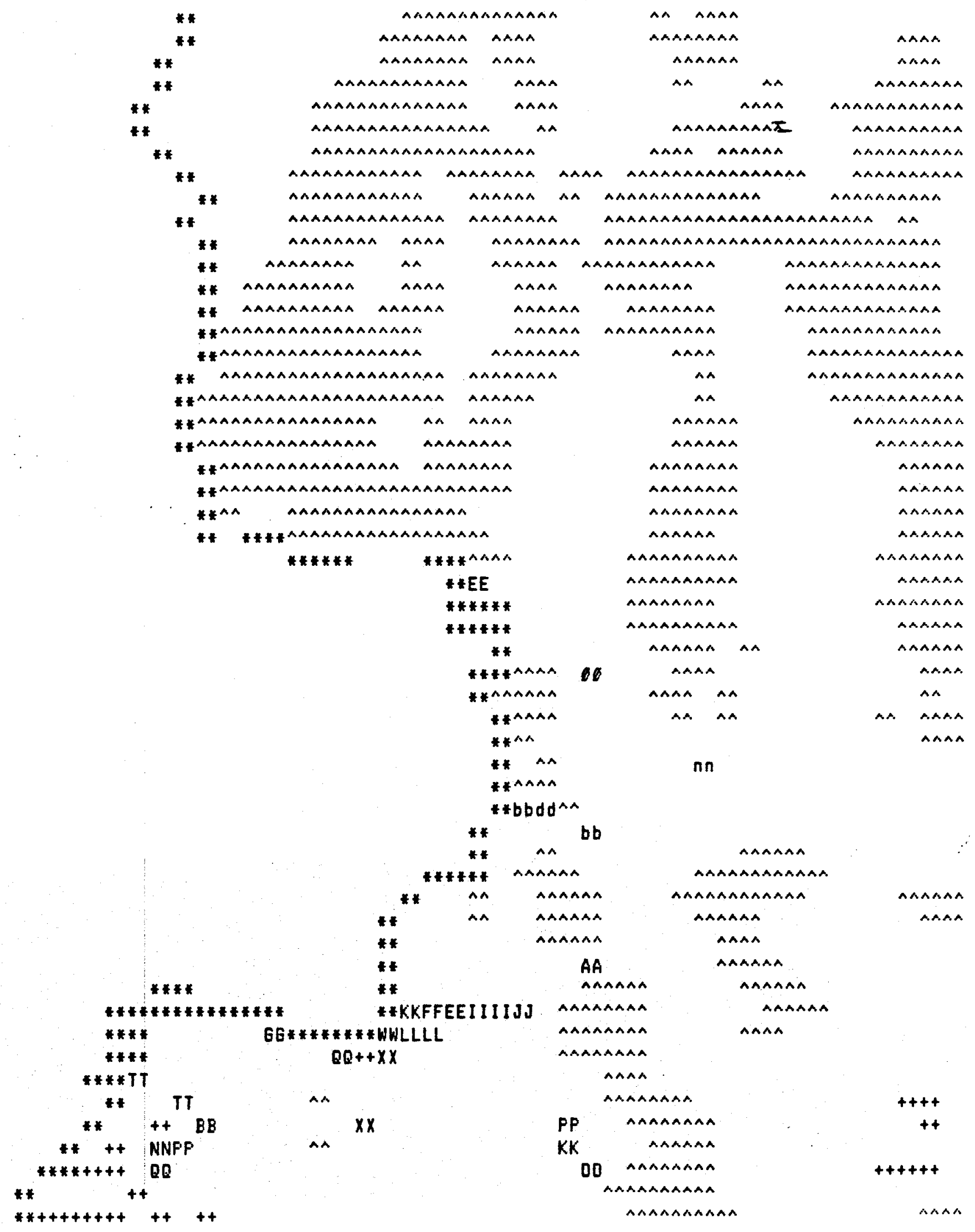


Digital Map 23(C)

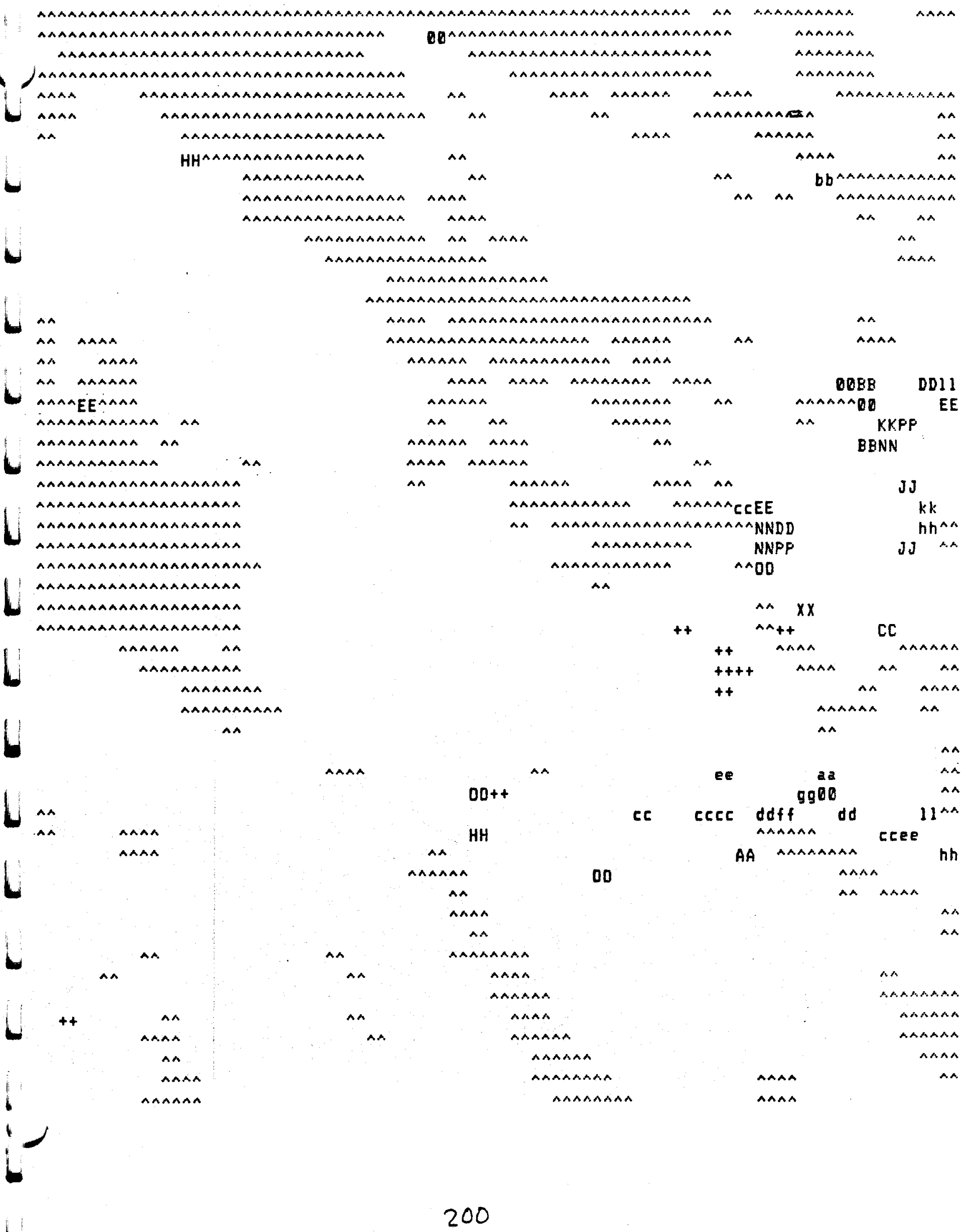




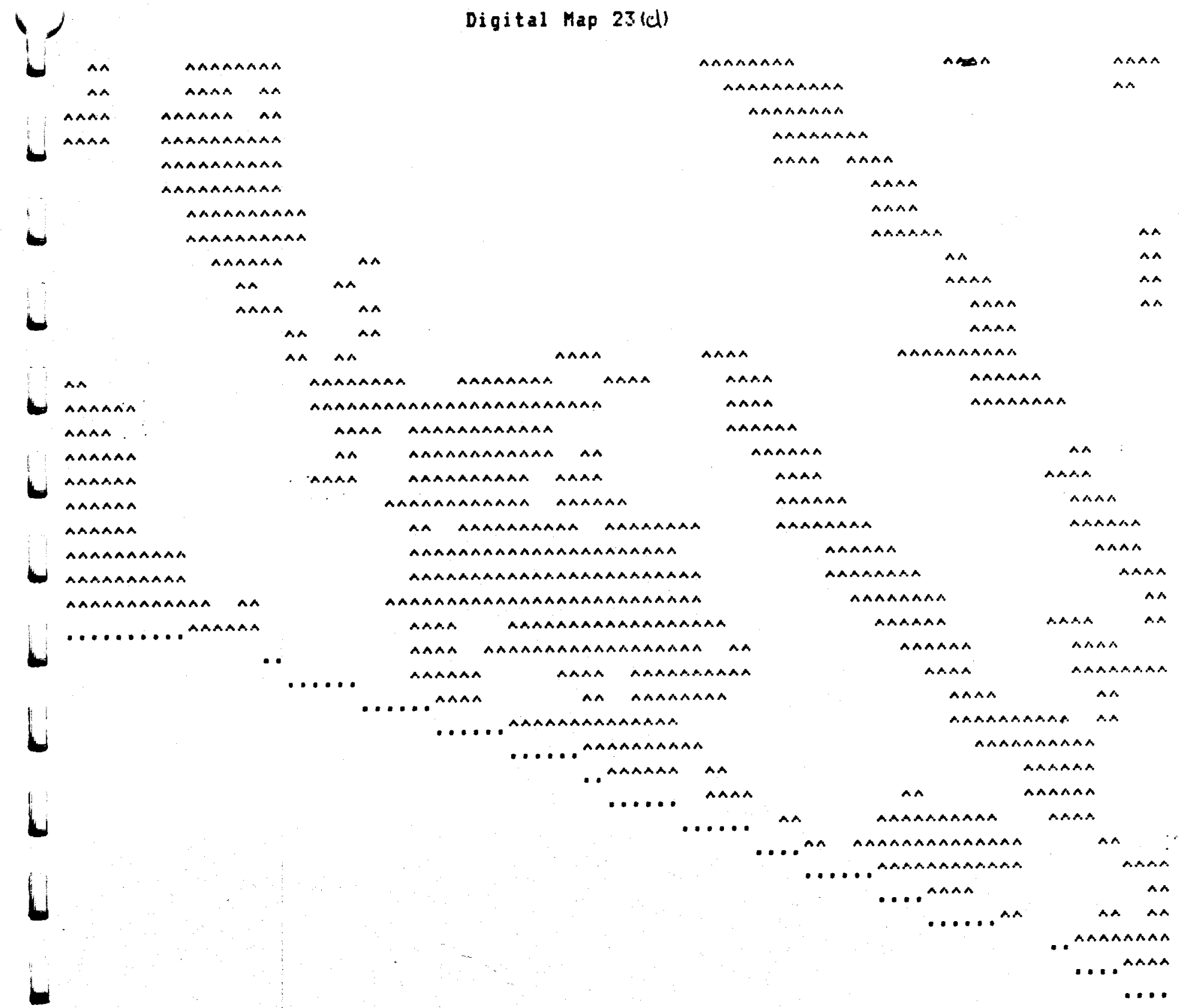




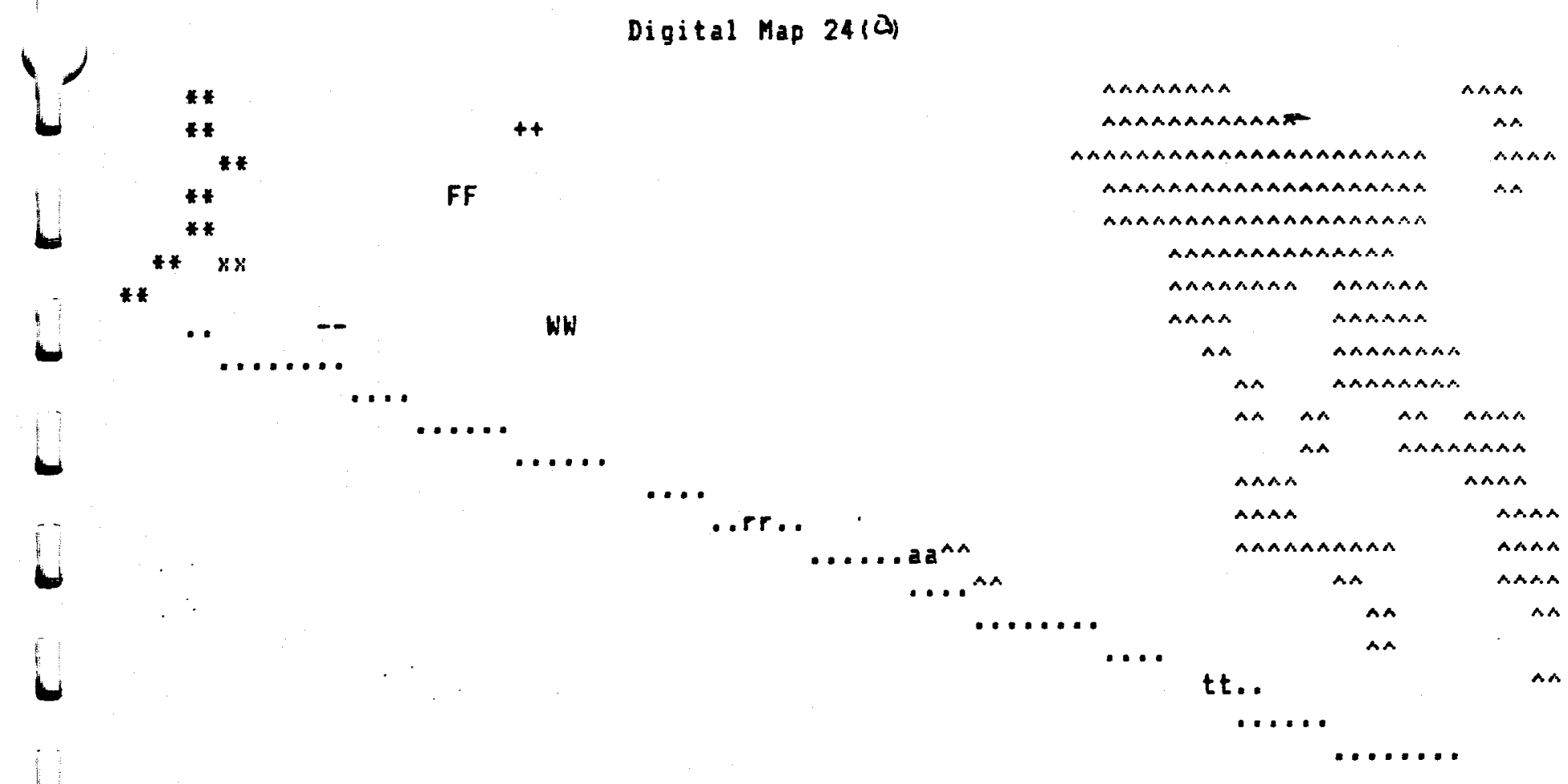

DIFFERENCES BETWEEN U2/UI INTERFACE PREDICTIONS AND THERMAL WELL TEMPERATURES

* : Colorado River $\quad$ - : Border with Mexico

THEORETIC NORMAL MINUS THERMAL WELL DATA

D: Difference $=0$

A to 2: Difference $=1$ to 26 degrees Celsius

a to 2: Difference $=-1$ to -26 degrees Celsius

+ Difference $>26$ degrees Celsius.

- Difference < -26 degrees Celsius. 
Digital Map 24(b)

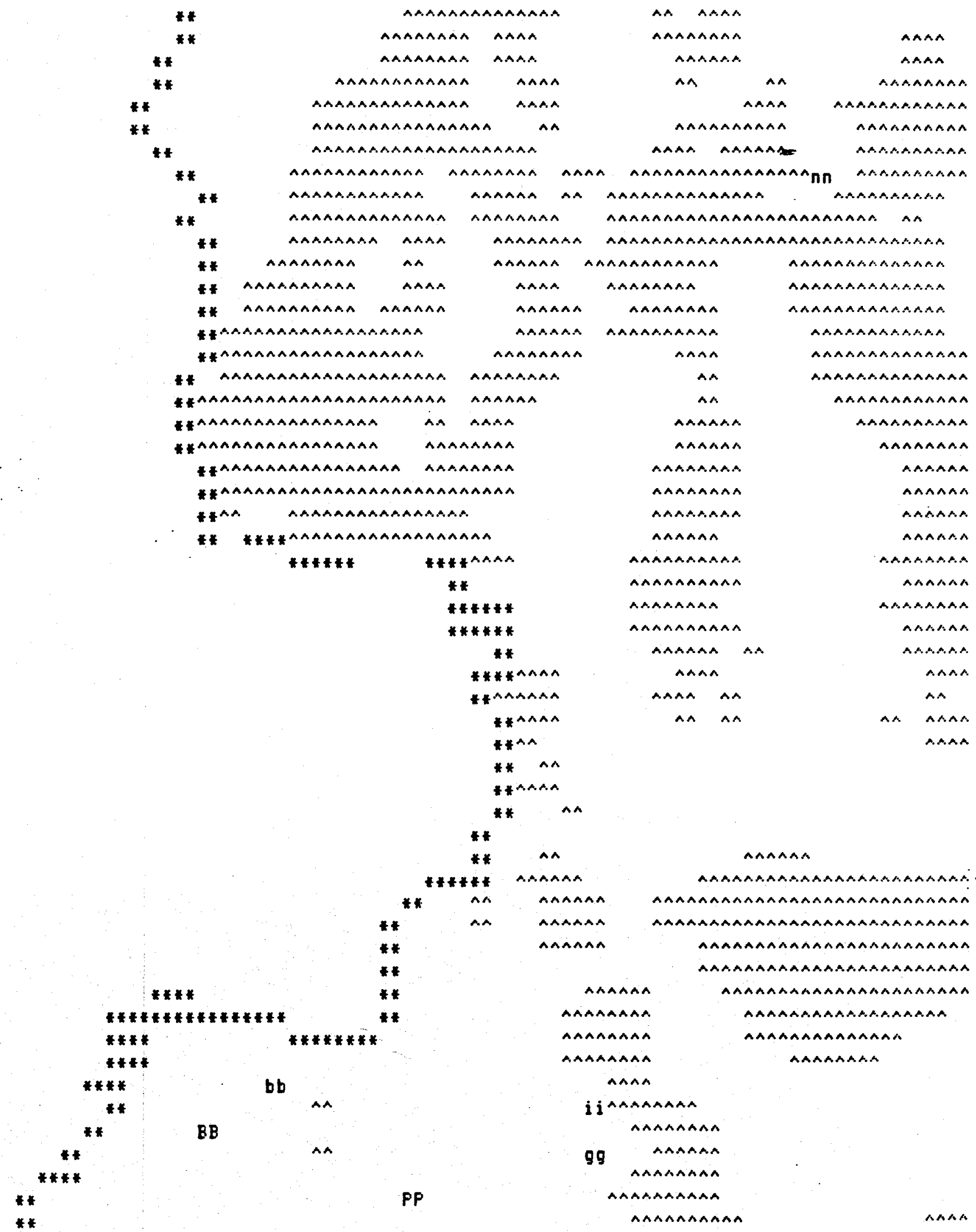


Digital Map $24(C)$

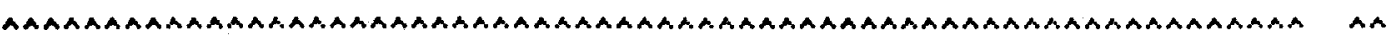

AAMAMAAMAAAAAMAAAAAAAAAMAAAMAMAMAA

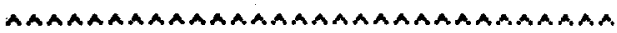

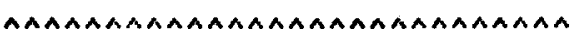

ARAAMAMAAM

AAA.

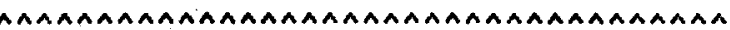

AAAAAAAAAAAAAAAMAAMAAAAA

AAMAAS

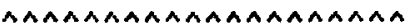

AMARAAAA.

lanan

AAAAAAAMAAMAARAAAAAAAAAAAA

An

AAAA AARAAA AARA

MANAAMAA

คヘヘヘ

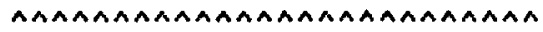

$\wedge$

AMAAAAAAAAAAA

MAAAAMAAAAAAAAAMAAAA

ヘヘヘヘAヘAヘAAトA

$\wedge \wedge$

$\operatorname{manh}$

AAARXA

$A \wedge$

AMAMAMAMAAMMAMAA AA

aAaAaAAaAaAa AA

AAMAAMAMANAMANAA AAAA

AA

AARARAARAMAAAAAA MAAR

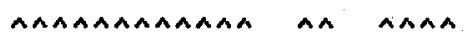

AAAAAAAAAAAAAAAA

^^

AA AMAA

AA AAAA

AA AANAAA.

AAAA AAAA

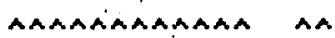

AヘANANAAAA AN

AAAAAAAAAMAA AA

AAMAAAAAAAAAAAAMAAAA

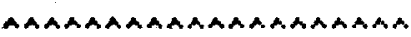

AAANAAAヘANAヘANAAAAAA

AAARAAMAAMAAAAAAAARA

AMAMAAMAMAMAAAMAAAMAAa

AAARAAAAAAAAAAARAAAA.

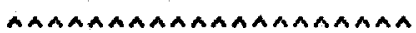

AAAAAAAAAAAAAAAAMARA

MAnAAA AA

AAAAAMARAM

AAAAAAAN

AAAAAAMAAA

AA

AAAN

An

AAAA

ananaAá

AMAAAAAA

AAANAA

An

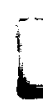

An.

An

คn

AAAA

An

anar

AANANA
AAAMAAAAAAMAMAAA

AAAAAAAAAAAMAMAAMAAAAAAAAAAAAAAA

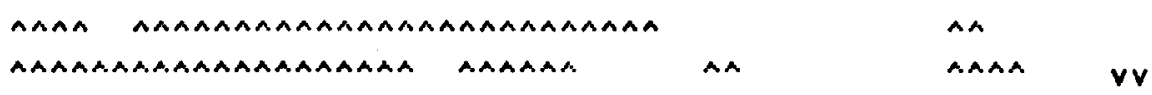

AMAMAM AMAAAMAMAAAA MAMA

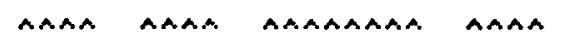

AMAAAA AAAAAMAA AN

AA AA

AAヘAヘA AヘAヘ

AAA.A. AAAAAA

An

MAヘヘヘA

AAAAAA

An

A.A

An คn

AAAAAAAAAAAAR

AAAAAヘAAANAA

Aᄉ A.A

$\wedge \wedge$

AAA.A.

\section{AAAAAAAAAAAA mAMAAAEECCGG}

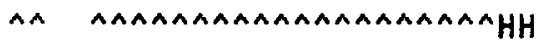

AAAARAAARA

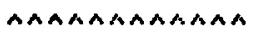

AA.

An

ヘヘヘAヘA

AA

AnAN

An.

AAAAAAAA

nAMA

AMANAA.

AAAA

A.AAAAA

AAAAAA

aAmAAAAA

AヘAAAAAA

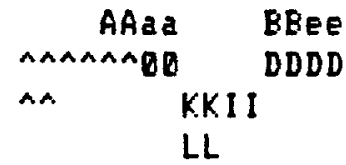

PP

LL KKEC

$h h^{\wedge \mu}$

FF
MMQQ

PPQQ

$+t$

$+t T T$

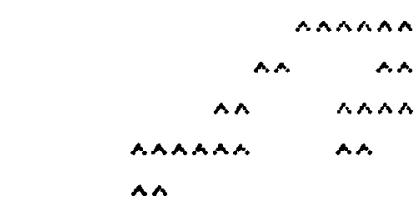

A

A.

$A$

A.A.

ค^^^^^

aAaAaAan

AAAN

AA AAAA

i i

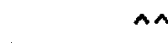

$\wedge$

Whathend.

ANAAAA

AAAAAR

ANAA

A. A. 

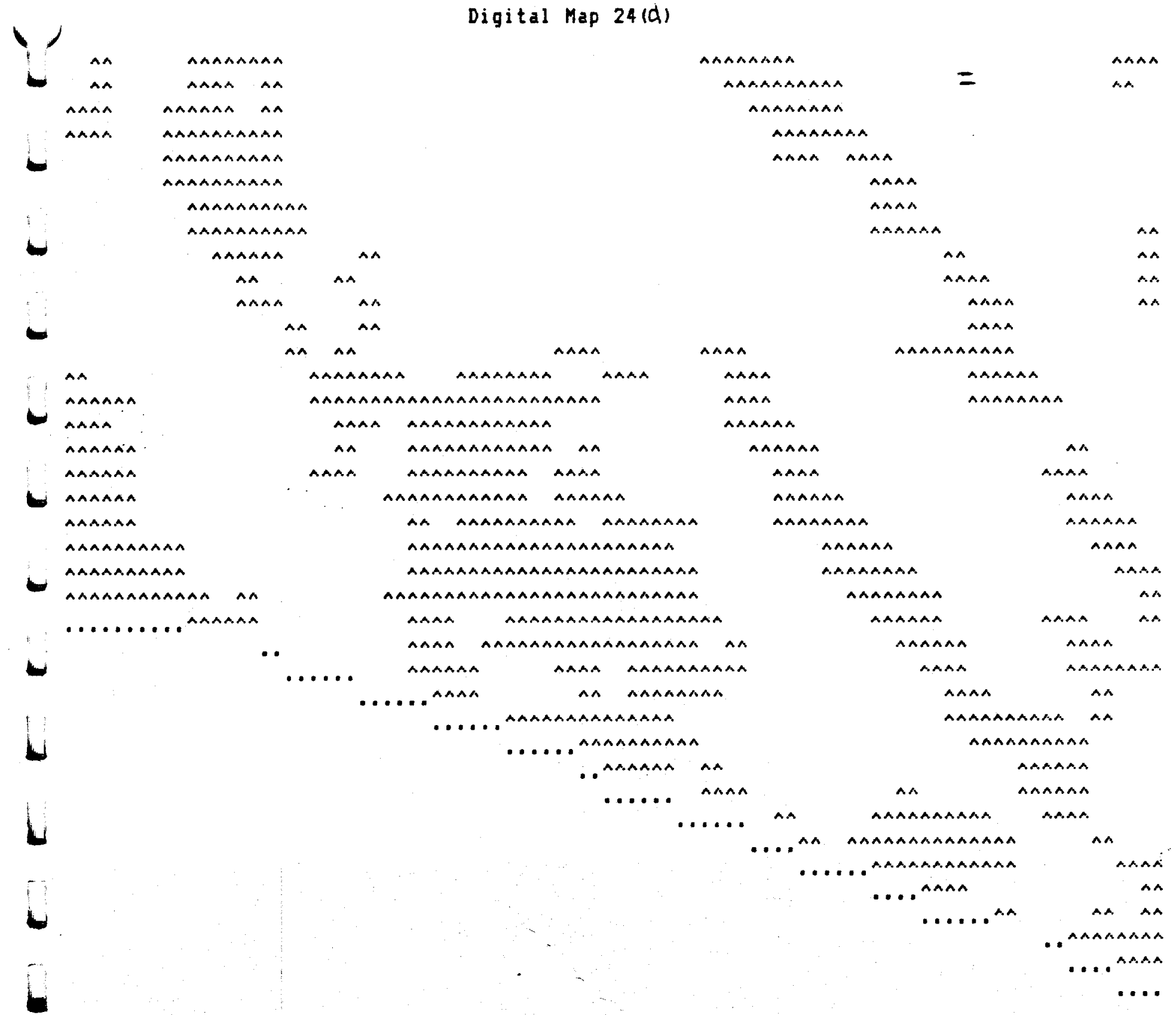
GEDTHERMAL EVALUATION OF THE YUMA AREA

GEQTHERMAL RESOURCE EVALUATION OF THE YUMA AREA

BIBLIOGRAPHICAL REFERENCES

VOLUMES

\begin{abstract}
SECOND UNITED NATIONS SYMFOSIUM ON THE DEVELOFMENT AND USE OF GEOTHERMAL RESOURCES, San Francisco, CA, USA, 20 - 29 MaY, $1975 ;$ volumes. Frepared by the Lawrence Berteley Laboratories, University of California for USERDA, USNSF and USGS, 1976.
\end{abstract}

VOLUME 1: Volume 1. Fiapporteurs Summaries; Present status of Resources Development; Geology, Hydrology and Geothermal Systems; Geochemical Techniques in Exploration.

VOLUME 2: Volume 2. Geophysical Techniques in Exploration: Environmental Factors and Waste Disposal; Drilling Technology.

VOLUME 3: Volume 3. Production Technology, Fieservoir Engineering and Field Management: Electricity Production; Space and Frocess Heating: Other Single and Multipurpose Developments: Economic and Financial Aspects; Legal and Institutional Aspects.

FROCEEDINGS, SECOND, THIRD AND FOURTH SYMFOSIA ON THE CERFO FFIETO GEDTHEFMAL FIELD, BAJA CALIFOFNIA, MEXICO. Sponsored by Comision Federal de Electricidad in cooperation with the United States Department of Energy, Division of Geothermal Energy. Frepared by Coordinadora Ejecutiva de Cerro Frieto, Mexicali, BC, MEX and Earth Sciences Division, Lawrence Berlely Laboratory, University of California, CA, USA.

VOLUME 4: Secand Symposium, October 17-19, 1979, Mexicali, EC, MEX.

VDLUME 5: Third Symposium, March 24-26, San Francisco, CA, USA.

VOLUME 6: Fourth Symposium, August 10-12, 1982, Guadalajara, JAL, MEX. 


\section{GEOTHERMAL RESOURCE EVALUATION OF THE YUMA AREA \\ BOOKS CONSISTING OF COLLECTED PAPERS}

Erobst, D.A. and Fratt, W.F.: United States Mineral Fesources. USGS Frofessional Faper 820, 1973.

Frost, E.G. and Martin, D.L., eds.: Mesozoic-Cenozoic Tectonic Evolution of the Colorado River Region, California, Arizona and Nevada. Cordilleran Fublishers, San Diego CA, 1982.

Hallam, A.: Encyclopedia of the Flanet Earth, Exeter Eoots: , Simon \& Schuster. 1983.

Johnson, C.E., Rojahn, C. and Sharp, R.V., eds.: The Imperial Valley, California, earthquake of Detober 15, 1979, USGs Frofessional Faper No. 1254, 1982.

Kruger, F. and Otte, C., eds.: Geothermal Energy. Stanford University Press, Stanford, CA, 1982.

Smith, F.E., and Eaton, G.F., eds.: Cenozoic Tectonics and Fegional Geophysics of the Western Cordillera. Geol. Soc. of America, Mem. 152, 1978. 


\section{GEOTHERMAL EVALUATION OF THE YUMA AREA}

\section{BOOKS, PAPERS, REPQRTS and MAPS =}

Aiken, C.L.V. : The Analysis of the Gravity Anomalies of Arizona. Fh. D. Dissertation, University of Arizona, Tucson, AZ, 1976.

Aiken, C.L.V.: Wetterauer, R.H. and de la Fuente, M.F.: A Merging of Aeromagnetic Data Sets in Southwest Arizona and Northwest Mexico and Analysis of the Results, Arizona Geological Soc. Digest, vol. 12, pp. 31-43, 1980.

Earr, R.C.: Geothermal Energy: Strategy and Eudgeting, pp. 22692272 in VOLUME 3 .

Eird, D.K. and Elders, W.A.: Hydrothermal Alteration and Mass Transfer in the Discharge Fortion of the Dunes Geothermal System, Imperial Valley of California, USA., Pp $285-296$ in VDLUME 1.

Elair, F.D., Cassel, T.A.V. and Edelstein, F.H.: Geothermal Energy: Investment Decisions and Commercial Development. John Wiley and Sons, New York, NY, 1982.

ELM Surface Responsibility Map, 1980. U.5. Department of the Interior, Eureau of Land Management Surface Responsibility, State of Arizona. Scale 1:500,000, 1980.

de Eoer, J.: Faleomagnetism of the Quaternary Cerro Prieto, Crater Elegante, and Salton Euttes Volcanic Domes in the Northern Fart of the Gulf of California Fhombochasm. PP. 91-102, in VOLUME 4.

Eulk, H.O.: Useful Climatic Statistics for Thirty-eith Arizona Locations. Arizona State University, Tempe, AZ. 1985.

Calvo, S.S.: Geothermal Resources in Arizona, a Bibliography. Arizona Eureau of Geology and Mineral Technology Circular 23 , Tucson, $A Z, 1982$.

Chronic, H.: Roadside Geology of Arizona. Mountain Press Fublishing Company, Missoula, MA, 1983.

Coney, F.J.: Plate Tectonics and the Laramide Orogeny. New Mexico Geologic Society Special Publication No. 6,pp 5-10.

Crowe, E.M.: Cenonozoic Volcanic Geology and Frobable Age of Inception of Easin-Range Faulting in the southeasternmost Chocolate Mountains, California. Geological Society of America Eulletin, vol 89, P. 251-264, Feb. 1978.

Davis, J.C.: Statistical Analysis in Geology. John Wiley and Sons. New Yort:, N.Y., 1973. 


\section{GEOTHERMAL EVALUATION OF THE YUMA AREA}

\section{BOOKS, PAPERS, REPQRTS and MAPS -}

Denton, J.C. and Dunlop, D.D.: Geothermal Resources Research. pp. 335-348 in [Kruger \& Otte, 1973 ].

Diaz C.,S., Fuente C., I., and de la Fena L. ,A.: Proposed Geologic Model Based on Geophysical Well Logs. pp. 46-61 in VOLUME 5.

Eberly, L.D., and Stanley, T.E.,Jr.: Cenozoic Stratigraphy and Geologic History of Southwestern Arizona. Geological society of America Bulletin, vol. 89, Pp. 921-940, June, 1978.

Elders,W.A., Meidav,T., Fobinson, F.T. and Eiehler, S. : Crustal Spreading in Southern California. Science, vol. 178, no. 4056, PP. $15-24,1972$.

Elders,W.A., Eird, D.A., Williams, A.E. and Schifman,F.: Model for a Heat Source of the Cerro Frieto Magma-Hydrothermal System, Baja California, Mexico. PP. 265-284 in VoLUME 6.

Frant, H.J., Sloat, E.F. and Gerety, V.: Final Report: Arizona Energy Consumption for State and Counties by Fuel-Type and Energy Consumption Estimates by End Use. Energy Division, Office of Economic Flanning and Development, 1984.

Fonseca L., H.L., The Cerro Frieto Geothermal Field. Geophysical Studies. pp. $3-34$ in VOLUME 6.

Fuis, G.S., Mooney, W.D., Healey, J.H., McMechan, G.A. and Lutter, W.J.: Crustal Structure of the Imperial Valley Region. Pp. $25-50$ in [Johnson, et,al, 1982].

Galbraith, F.W.: Craters of the Finacates. Arizona Geological Society Digest, vol 2 , PP. $161-164,1959$.

Garner, W.E., Frost, E.G., Tanges, S.E. and Germanario, M.F.: MidTertiary Detachment Faulting in the Trigo Mountains, Yuma County, Arizona. Pp. 159-171, in [Frost \& Martin, 1982].

Gertsch, W.D., Keller, J.G., Hahman, W.R.,Sr., ad Ruschman, D.: The Fotential for Using Geothermal Energy for Space Cooling at Williams Air. Force Ease, Arizona. U.S. Department of Energy, 1979.

Giardina, S.,Jr, and Conley, J.N.: Thermal Gradient Anomalies in Southern Arizona. Arizona $0 i l$ and Gas Conservation Commission Report of Investigation 6., Fhoenix, 1978.

Goldstein,N.E., Wilt,M.J. and Corrigan,D.J.: Analysis of the Nuevo Leon Magnetic Anomaly and its Fossible Relation to the Cerro Frieto Magmatic Hydrothermal System. pP. $35-42$ in VoLUME $t$. 


\section{GEDTHERMAL EVALUATION OF THE YUMA AREA}

BOOKS, PAPERS, REPORTS and MAPS =

Grant, M.A., and O'Sullivan, M.J.,: The old Field at Cerro Prieto Considered as a Lealy Aquifer. pp. $123-132$ in volume 6.

Gutmann, J.T.: Geologic Framework and Hot Dry Fock Geothermal Fotential of the Castle Dome Area, Yuma County, Arizona. Los Alamos Scientific Laboratory publication A-8723-HDF, Los Alamos, NM, 1981.

Gutmann, J.T.: Geology and Regional Setting of the Castle Dome Mountains, Southwestern Yuma County, Arizona. pp. 117-122 in [Frost \& Martin, 1982$].$

Haar, S.V. and Howard, J.H.: Intersecting Faults and Sandstone Stratigraphy at the Cerro Frieto Geothermal Field. PP. $118-134$ in VOLUME 4.

Hahman, F., Sr., Mancini, F., White, D., Chebab, M., Goldstone, L., and Weibel, E.: Evaluation of Geothermal Energy in Arizona. U.5. Department of Energy, 1979.

Helms, C.L.: The Sonoran Desert, kc Publications, Las Vegas, NV, 1983 .

Higgins,C.T. and Martin,R.C.,Geothermal Resource Map of California, Scale 1:750,000. California Department of Conservation, Division of Mines and Geology, 1980.

Howard, J.H., Halfman, S.E. and Haar, S.V.: Evaluation of the Geologic Characteristics at Cerro Frieto. Pp. 62-76 in VDLUME 5.

Jahns, Fi.H.: Collapse Depressions of the Finacate Volcanic Field, Sonora, Mexico. Arizona Geological Socjety Digest, vol 2 , pp. $165-$ $184,1959$.

Jakob, M.: Heat Transfer. John Wiley \& Sons, New York, NY, 1957.

Jones, N.O. and Campbel1, A.: Freliminary Geothermal Assessment of the Hyder Area. Bureau of Geology and Mineral Technology, Open File Report 79-13, Tucson, AZ, 1979

Kennedy,J.M. and Wolke,F.M.: From Here to There by Demonstration Drilling. Pp. $150 \Omega-1508$ in VOLUME 2 .

Koch, G.S., Jr., and Link, R.F.: Statistical Analysis of Geological Data. Dover Fublications, New Yort:, NY, 1970. 


\section{GEOTHERMAL EVALUATION OF THE YUMA AREA}

\section{BOOKS, PAPERS, REPORTS and MAPS =}

Lachenbruch, A.H.: Crustal Temperature and Heat Froduction: Implications of the Linear Heat-Flow Fielation. Journal of Geophysical Fesearch, vol 75, no. 17, pp. 5291-3300, June 10, 1970.

Lund,J.W., Culver, G.G. and Svanevit, L.S.: Utilization of Intermediate-Temperature Geothermal Water in rlamath Falls, Dregon, PP 2147-2152 in VOLUME 3.

Mancini,F., Hahman, W.F., White, D.H., and Wolfe, D.: Fotential of Geothermal Energy in Arizona. U.S. Department of Energy, AL0-3992, January 1979

Malysa, L.: Arizona Geothermal Institutional Handbook. DoE Publication DE-FCO7-79ID12015, May, 1980.

Mathur, P.: An Assessment of Solar Geothermal Hybrid System Concepts. U.S. Department of Energy, SAN-1101-14/1, March 15, 1979.

Mattick, F.E., olmsted, F.H. and Zohdy, A.A.F.: Geophysical Studies in the Yuma Area, Arizona and California. USGS Frofessional Faper 726D, 1973.

Morrison, R.B., Menges, C.M. and Lepley, L.K.: Neotectonic Maps of Arizona. Arizona Geological Society Digest vol 1S, PP. 179-18J, 1981.

Muffler, J.F. : Geothermal Fesources, FF. 251-261 in [Erobst \& Fratt, 1973$]$.

Olmsted, F.H., Loeltz, 0.J. and Irelan, E., Geohydrology of the Yuma Area. USGS Professional Faper 486H, 1973.

Dppentieimer, J.M. and Sumner, J.S.: Gravity Modeling of the Basins in the Easin and Range Frovince, Arizona. Arizona Geological Digest, vol. 13, pp. 111-115, 1981 .

Oppentieimer, J.M. and Sumner, J.S.: Depth to Bedrock Map of the Basin and Fange Frovince of Arizona. Scale 1:1,000, D00, 1980.

Fatten, E.F.,Jr.: Analog Simulation of the Ground Water System, Yuma, Arizona. USgS Frofessional Faper, 486I, 1977.

de 1 a Fena L.,A., Fuente C.,J., and Diaz C.,E.: Geologic Model of the Cerro frieto Geothermal Field. pp. 29-56 in VoLUME 4. 


\section{GEOTHERMAL EVALUATION OF THE YUMA AREA}

BOOKS, PAPERS, REPORTS and MAPS =

Fratt, F. and Kassoy, D.F.: Heat and Mass Transfer in a Fault Zone-Controlled Geothermal Feservoir: Numerical Fesults. Journal of Geophysical Fiesearch, Vol 88, no. E4, PP. 3458-3466, Apr. 10, 1981 .

Fridmore, C.L. and Craig, C.: Upper-plate Structure of and Sedimentation of the Eaker Feaks Area, Yuma County, Arizona. PP. 356-375 in [Frost \& Martin, 1982],

Fugsley, M. Geothermal Fiesource Area 3 , Elto County, Area Development Flan. Ello County, Nevada. Nevada Department of Energy, Carson City, NV, 1981.

Roy, R.F., Decker, E.R., El ackwel1, D.D. and Birch, F.: Heat Flow in the United States.Journal of Geophysical Research, vol. 73, no. 16, pp. 5207-5221,1968.

Saaty, T.L.: A Scaling Method for Priorities in Hierarchical Structures, Journal of Mathematical Psychology, vol. 15, no. 3, PP. 234-281, June, 1977.

Saaty, T.L.: Decision Making for Leaders. Lifetime Learning Publications, Eelmont, CA, 1982.

Sauck, W.A.: Regional Aeromanetic Survey of the State of Arizona. Fh. D. Dissertation, University of Arizona, Tucson, AZ, 1972.

Sass, J.H., Lachenbruch, A.H. Munroe, F.J., Greene, G.W. and Moses, T.H.,Jr.: Heat Flow in the Western United States. Journal of Geophysical Fesearch, vol. 76, no. 26, pp. 6576-6413, Sept. 10, 1971 .

Shafiqullah, M., Damon, F.E., Lynch, D.J., Reynolds, S.J., Rehrig, W.A. and Raymond, R.H.: K-Ar Geochronology and Geologic History of Southwestern Arizona and Adjacent Areas. Arizona Geological Society Digest, vol. 12, pp 201-259, 1980.

Shakel, D.W. and Harris, K.M.: Revised Minimum Age of Cerro Colorado Crater, Finacates Volcanic Field, Northwestern Sonora, Mexico. Arizona Geological Society Digest, vol 9, pp. 259-265, Dec: 1971.

Shearer, C. and Feiter, M.: Terrestrial Heat Flow in Arizona. Journal of Geophysical Fesearch, vol. 86, no. E7, Pp. 6249-6260. July $10,1981$. 


\section{GEOTHERMAL EVALUATION OF THE YUMA AREA}

\section{BOOKS, PAPERS, REPQRTS and MAPS =}

Smith, D.L., Nuckels, E., III, Jones, R.L. and Cook, G.A., Distribution of Heat Flow and Radioactive Heat Generationin Northern Mexico. Journal of Geophysical Research, vol. 84, no. E5, pp. 2371-2379, May 10, 1979.

Smith, S.A.: Geothermal Fesources: Their Characterization, Ownerstip, and Felationship as Compared to Water in Arizona Law. University of Arizona, Tucson, AZ, 1981.

Stacy, F.D., Fhysics of the Earth. John Wiley and Sons, New Yort, NY, 1977.

Stone, C.A.: Preliminary Assessment of the Geothermal Resource Potential of the Yuma Area. Bureau of Geology and Mineral Technology Open File Report 81-4,1981.

Struhsacker, E.M., Smith, C., Capuano, F.M.: An evaluation of Exploration Methods for Low-temperature Geothermal Systems inthe Artesian Cita Area, Idaho. Geological Society of America Bulletin, vol. 94, pp. 58-79, 1985.

Fivera,F., Eermejo, F.J., Castillo,F., Ferez,H., Abrajan,A., Study Update of Temperature Behavior and Distribution in Cerro Frieto II and III. $P p$ 81-92 in VOL.UME 6.

Telford, W.M., Geldert, L.F., Sheriff, R.E. and Keys, D.A., Applied Geophysics. Cambridge University Fress, Cambridge, 1976.

Tucker, W.C.,Jr.: Tectonic Geomorphology of the Lute Air Force Fange, Arizona, Arizona Geological Society Digest, vol 3, , PP: $63-86,1980$.

Turcotte,D.L. and Schubert, G. : Geodynamics. John Wiley and Sons, New York, NY, 1982.

US..GS Topographical Map of Arizona, 1981. U.S. Department of the Interior, Geological Survey, Topographical Map of the State of Arizona, Scale 1:500,000, 1981.

USGS Topographical Map of Southern California, 1991. U.S. Department of the Interior, Geological Survey, Topographical. Map of California, South Half, Scale 1:500,000, 1981.

Valette-Silver, J.N., Esquier F.,I., Elders, W.A., Collier, F.C., and Hoagland, J.F.: Hydrothermal Alteration of Sediments Associated with Surface Emissions from the Cerro Frieto Geothermal Field. pp. 140-148 in VOLUME 5 . 


\section{GEOTHERMAL EVALUATION OF THE YUMA AREA}

\section{BOOKS, PAPERS, REPORTS and MAPS}

Wahl, E.F.: Geothermal Energy Utilization. John Wiley and Sons, New Yort:, NY, 1977.

Waring, G.A., Blankenship, F.R. and Eentall, F.: Thermal Springs of the United States and Other Countries of the World - a Summary. USGS Frofessional Faper 492, 1965.

Wilson, E.D.: Geology and Mineral Resources of Southern Yuma County, Arizona. Arizona Bureau of Mines Eulletin 134, 1933.

Wilson, E.D., Moore, R.T., and Cooper, J.R.: Geologic Map of Arizona. Scale: 1:500,000, 1969

Witcher,J.C., Stone, C., and Hahman, W.F.,Sr.: Geothermal Resources Map of the State of Arizona. Arizon Eureau of Geology and Mineral Technology, 1982

White, D.H. and Goldstone, L.A.: Executive Summary: The Potential of Utilization of Geothermal Energy in Arizona. U.S. Department of Energy, August 1982.

White, D.H., and Goldstone, L.A.: Geothermal Development Flan: Yuma County. U.S. Department of Energy, August, 1982. 